\title{
Development, implementation and evaluation of surgical patient education
}

Citation for published version (APA):

Breemhaar, B. (1996). Development, implementation and evaluation of surgical patient education.

[Doctoral Thesis, Maastricht University]. Rijksuniversiteit Limburg.

https://doi.org/10.26481/dis.19961031bb

Document status and date:

Published: 01/01/1996

DOI:

10.26481/dis.19961031bb

Document Version:

Publisher's PDF, also known as Version of record

\section{Please check the document version of this publication:}

- A submitted manuscript is the version of the article upon submission and before peer-review. There can be important differences between the submitted version and the official published version of record.

People interested in the research are advised to contact the author for the final version of the publication, or visit the DOI to the publisher's website.

- The final author version and the galley proof are versions of the publication after peer review.

- The final published version features the final layout of the paper including the volume, issue and page numbers.

Link to publication

\footnotetext{
General rights rights.

- You may freely distribute the URL identifying the publication in the public portal. please follow below link for the End User Agreement:

www.umlib.nl/taverne-license

Take down policy

If you believe that this document breaches copyright please contact us at:

repository@maastrichtuniversity.nl

providing details and we will investigate your claim.
}

Copyright and moral rights for the publications made accessible in the public portal are retained by the authors and/or other copyright owners and it is a condition of accessing publications that users recognise and abide by the legal requirements associated with these

- Users may download and print one copy of any publication from the public portal for the purpose of private study or research.

- You may not further distribute the material or use it for any profit-making activity or commercial gain

If the publication is distributed under the terms of Article $25 \mathrm{fa}$ of the Dutch Copyright Act, indicated by the "Taverne" license above, 
DEVELOPMENT, IMPLEMENTATION AND EVALUATION OF SURGICAL PATIENT EDUCATION 
(C) B. Breemhaar, Goirle 1996

ISBN: 90-9009875-5

Foto omslag: Klaas Koppe, Hollandse Hocge, 1989

Productie en omslagontwerp: Tekstverwerking:

Datawyse Maastricht, Ruud Leliveld Monique Seebregs-Dielen

Bea van Wijk

Druk:

Datawyse Maastricht / Krips Repro, Meppel 


\section{DEVELOPMENT, IMPLEMENTATION AND EVALUATION OF SURGICAL PATIENT EDUCATION}

\section{PROEFSCHRIFT}

ter verkrijging van de graad van doctor aan de Rijksuniversiteit Limburg te Maastricht. op gezag van de Rector Magnificus, Prof. Mr. M.J. Cohen, volgens het besluit van het College van Dekanen, in het openbaar te verdedigen op donderdag

31 oktober 1996 om 16.00 uur

door

BEREND BREEMHAAR

geboren op 12 augustus 1957 te Hoogezand-Sappemeer 


\section{PROMOTORES:}

Prof. dr. H.W. van den Borne

Prof. dr. G.J. Kok

Prof. dr. P.D. Mullen (University of Texas, Houston)

\section{BEOORDELINGSCOMMISSIE:}

Prof. dr. A. Appels (voorzitter)

Prof. dr. E. Devine (University of Wisconsin, Milwaukee)

Dr. J. Diederiks

Prof. dr. G. van Heck (Katholieke Universiteit Brabant, Tilburg)

Prof. dr. G. Kootstra

The study presented in this thesis was performed at the Maastricht Health Research Institute for Prevention and Care (HEALTH), which participates in The Netherlands School of Primary Care Research (CARE), acknowledged in 1995 by the Royal Dutch Acadenly of Science (KNAW).

Financial support of this thesis by the Dutch Praeventiefonds, grant number 26-20, is gratefully acknowledged. 
Motto:

De werkelijkheid zwijgt. Zij toont alleen wat wij zien, en spreken doet zij helemaal niet. Zij geeft op onze vragen alleen antwoorden die wij zelf onder woorden brengen - en ook die grotendeels niet overeenkomstig de waarheid.

W.F. Hermans (uit: "Au pair", p. 278, De Bezige Bij, 1989)

Opgedragen aan mijn ouders en aan Renske 


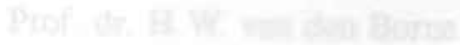

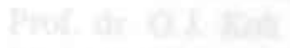

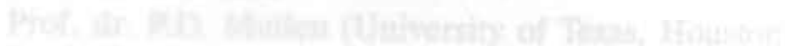

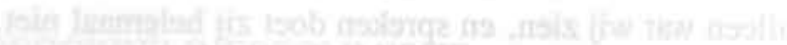

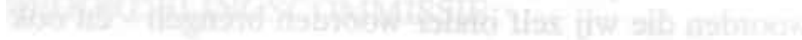

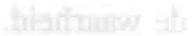

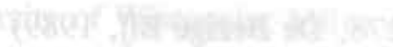




\section{Dankwoord}

Aan dit proefschrift en het onderzoek dat eraan ten grondslag ligt, hebben velen hun bijdrage geleverd die ik op deze plaats graag wil bedanken. In de eerste plaats is dit Nelleke Maris die als coördinator patiëntenvoorlichting mij in de beginfase van het onderzoek wegwijs maakte in het St. Joseph Ziekenhuis in Eindhoven (later Veldhoven) en mij ondersteunde bij het in samenwerking met stafleden van het ziekenhuis ontwikkelen van voorlichtingsmaatregelen voor operatiepatiënten. Om dezelfde reden dank ik Jos Kimenai, die als coördinator kwaliteitszorg deze rol in het St. Elisabeth Ziekenhuis in Tilburg vervulde. Hun diplomatieke kwaliteiten waren hierbij van onschatbare waarde. In de tweede plaats hebben vele leden van de medische en verpleegkundige staf van beide ziekenhuizen hun medewerking verleend door mij een ruimhartige blik te gunnen in de dagelijkse praktijk van de werkzaamheden binnen de (poli)kliniek chirurgie en door hun (vaak geduldige) ondersteuning te geven bij het ontwikkelen en invoeren van de voorlichtingsmaatregelen. Hoewel het binnen dit bestek nauwelijks mogelijk is iedereen te noemen, gaat wat betreft het St. Joseph Ziekenhuis mijn dank uit naar de chirurgen $\mathrm{H}$. Kluck, J. Charbon, C. Bruyninckx, F. Croiset van Ughelen en Th. van Straaten, de anesthesisten J. Beerens, J. Bitter en A. Bostelaar, de fysiotherapeuten C. van de Wetering en J. Vleut, de verpleegkundigen J. Marrees, J. Boonen en J. Vlemmix en het hoofd van het Patiënten Servicebureau M. Middelkoop. Hetzelfde geldt wat betreft het St. Elisabeth Ziekenhuis voor de chirurgen Chr. van der Werken, D. van Berge Henegouwen, H. Oostvogel en I. van Bebber, de anesthesist T. van der Hurk, de fysiotherapeut J. Poets, de verpleegkundigen R. Keijzers, A. van de Weegberg, M. van der Staak, W. Janssen en G. Kolmers, de medewerksters van het Patiëntenvoorlichtingscentrum R. Franken en M. de Wolff. Tevens ben ik hen en vele andere medewerkers van beide ziekenhuizen dankbaar voor hun medewerking bij het benaderen van patiënten met het verzoek om medewerking aan het onderzoek te verlenen. Uiteraard ben ik ook veel dank verschuldigd aan de galblaas- en liesbreukoperatiepatiënten die uiteindelijk bereid waren om aan de interviews ten behoeve van het onderzoek deel te nemen. G. Peters, $M$. Blom, M. Bachus, T. van der Molen, A. van de Nieuwenhof, M. Wilmer, J. van Eyck, I. Boeykens, C. de Ruyter en I. van Loon wil ik dank zeggen voor het vele interview- 
werk dat zij verrichtten om de informatie aan patiënten te ontlokken die het basismateriaal vormde waarop een groot deel van dit proefschrift is gebaseerd.

Ook van buiten beide ziekenhuizen heb ik van velen hulp ondervonden. Zonder de deskundige en enthousiaste ondersteuning van $\mathrm{H}$. Dubbelboer, verbonden aan het destijds nog zo aangeduide Nationaal Ziekenhuis Instituut. Zonder zijn hulp bij het verkennen van de bestaande voorlichtingspraktijk in beide ziekenhuizen en het ontwikkelen van verbeteringen waar die gewenst bleken, met alle bijbehorende voetangels en klemmen, was dit project waarschijnlijk in de kiem gesmoord. Hem wil ik voor de plezierige samenwerking hartelijk bedanken. Ook wil ik Eline Bruggemans bedanken als lid van de begeleidingscommissie. Voor hun hulp bij het ontwikkelen van materialen die onderdeel vormden van de nieuwe voorlichtingsmaatregelen gaat mijn dank uit naar B. Smit, destijds werkzaam bij het Audiovisueel Centrum van de KUB en L. van Koppen, indertijd verbonden als tekstschrijver aan het St. Joseph Ziekenhuis. Voor advies over statistische problemen kon ik terecht bij J. Scheirs, verbonden aan de vakgroep Sociologie van de KUB, waarvoor ik hem zeer erkentelijk ben. Bart van den Borne ben ik bijzonder dankbaar voor zijn deskundige hulp en bruikbare suggesties zonder welke dit project niet mogelijk was geweest. Zijn sympathieke ondersteuning en vast vertrouwen vormden een onmisbare steun bij het voltooien van dit proefschrift. Om dezelfde redenen gaat mijn dank uit naar Patricia Mullen en, zij het dikwijls wat meer op afstand, Gerjo Kok. Pat, thank you very much for your considerate support and your inspiring ideas. Bea van Wijk en Monique Seebregs, verbonden aan het IVA, ben ik veel dank verschuldigd voor de accurate en steeds voortvarende wijze waarop zij het manuscript van dit proefschrift persklaar hebben gemaakt. Ook gaat mijn dank uit naar het IVA voor de tijd die mij ter beschikking is gesteld om aan dit proefschrift te kunnen werken. Tenslotte: voor de hulp die Renske mij bood en het vertrouwen dat ze mij heeft geschonken, schieten woorden tekort. Dank daarvoor. 


\section{Contents}

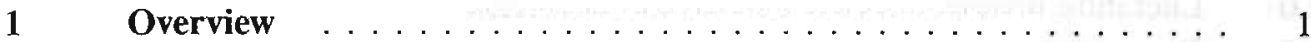

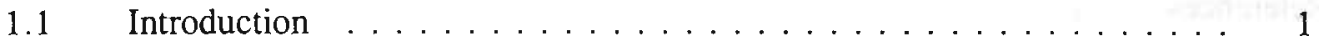

1.2 Effectiveness of psychoeducational interventions among abdominal surgical patients: a review . . . . . . . . . . . 2

1.2.1 Effectiveness of preparation methods .............. 3

1.2.2 Individual differences in the effects of psychoeducational interventions ....................... 4

1.3 Benefits of presurgical preparation and the role of perceived control . . . . . . . . . . . . . . 6

1.3.1 Relationship of perceived control to stress and coping . . . . . . . 6

1.3.2 Patient education as a means to enhance patients' level of

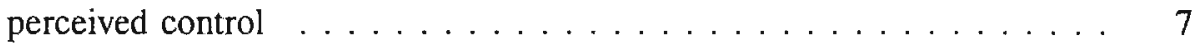

1.3.3 Individual differences in the benefits of perceived control . . . . . 8

1.4 Examination of existing practices of surgical patient education in two hospitals $\ldots \ldots \ldots \ldots \ldots$

1.4 .1 Method ......................... 9

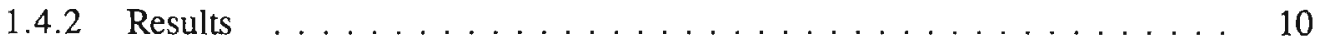

1.4 .3 Conclusions . . . . . . . . . . . . . . . . 11

1.5 Development and implementation of a program of preoperative surgical patient education $\ldots \ldots \ldots \ldots \ldots \ldots \ldots$

1.5.1 Program of surgical patient education $\ldots \ldots \ldots \ldots \ldots \ldots \ldots$

1.5.2 Elements of successful adoption of innovations . . . . . . . . . 13

1.5.3 The process of development and implementation of the program of surgical patient eduction in two hospitals . . . . . . . . . 13

1.6 Evaluation of the new program of surgical patient education . . . . . 15

1.6.1 Study 1: Test of the new program's implementation .......... 15

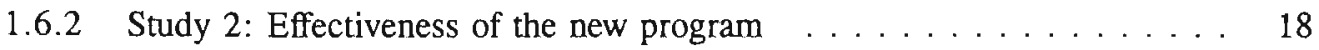

1.7 Conclusions . . . . . . . . . . . . . . . . . 22

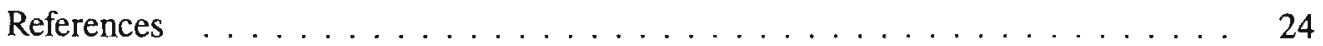


2 Effects of psychoeducational interventions in relation to abdominal surgical patients' preoperative fear, coping strategies and perceived control

B. Breemhaar, H.W. van den Borne, P.D. Mullen

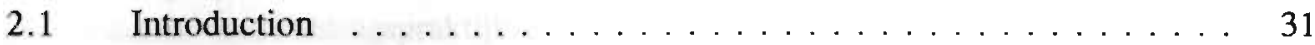

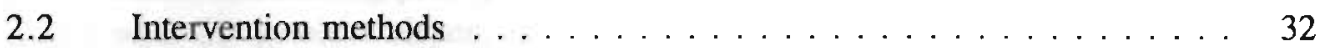

2.3 Effectiveness of different interventions . . . . . . . . . . . 33

2.4 Limitations of current knowledge ... . . . . . . . . . . . . 34

2.5 Interaction with patient characteristics $\ldots \ldots \ldots \ldots \ldots \ldots$

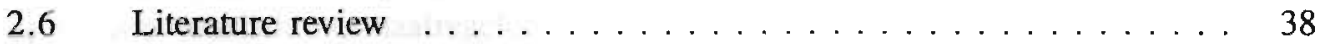

2.7 Discussion . . . . . . . . . . . . . . . . 40

References .......................... . . 43

3 Effects of education and support for surgical patients:

the role of perceived control $\ldots \ldots$. . . . . . . . . . . . . . . . . . . . 49

B. Breemhaar, H.W. van den Borne

4 Inadequacies of Surgical Patient Education

B. Breemhaar, H.W. van den Borne, P.D. Mullen

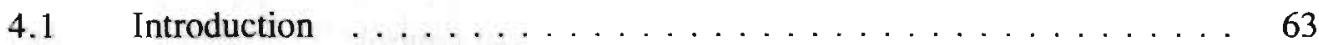

4.2 Method .......................... 65

$4.3 \quad$ Results . . . . . . . . . . . . . . . . . . . . . 69

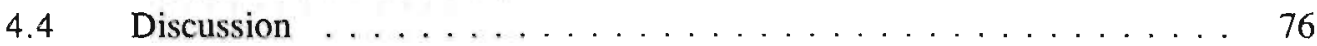

References . . . . . . . . . . . . . . . . . . 78 
A theory-based test of a method to install surgery patient education in everyday hospital practice

B. Breemhaar, H.W. van den Borne, P.D. Mullen

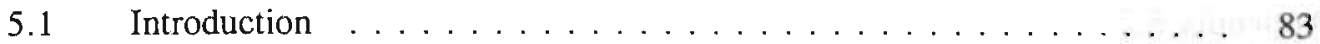

5.2 Content of effective surgical patient education $\ldots \ldots \ldots \ldots$. . . . 84

5.3 Factors in successful adoption of innovations . . . . . . . . . 87

5.4 Developing and implementing improvements in patient education . . . 87

5.5 Test of utilization of the measures . . . . . . . . . . . . . 92

$5.6 \quad$ Results . . . . . . . . . . . . . . . . . . 95

5.7 Discussion and conclusions . . . . . . . . . . . . . . . . . . 100

References . . . . . . . . . . . . . . . . . . . . . . . . 103

6 Effectiveness of surgical patient education delivered by hospital staff members . . . . . . . . . . . . . . . . . . . . 107

B. Breemhaar, H.W. van den Borne, P.D. Mullen, G. Kok

6.1 Introduction $\ldots \ldots \ldots \ldots \ldots \ldots \ldots \ldots \ldots \ldots \ldots \ldots$

6.2 Hypotheses . . . . . . . . . . . . . . . . . . . . . . . 109

6.3 Method .......................... . . 110

$6.4 \quad$ Results . . . . . . . . . . . . . . . . . . . . 118

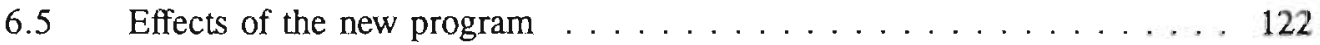

6.6 Discussion and conclusions . . . . . . . . . . . . . . . . 128

References . . . . . . . . . . . . . . . . . . . . . . . . 134

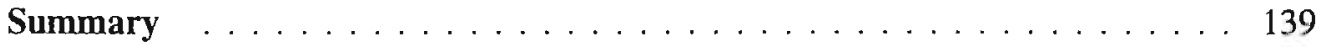

Samenvatting $\ldots \ldots \ldots \ldots \ldots \ldots \ldots \ldots \ldots \ldots \ldots \ldots \ldots \ldots$

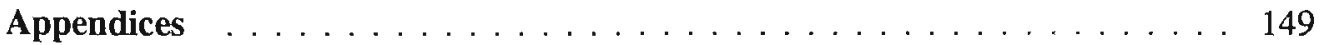

Appendix 2.1

Studies included in the review which examined the interaction between presurgical preparation and patients' preoperative fear, coping or locus of control 
Appendix 5.1

Surgical patient education before and after implementation of

the new program in both hospitals

\section{Appendix 5.2}

Leaflets with information about surgery and anesthesia

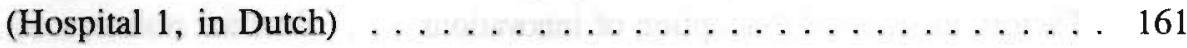

\section{Appendix 5.3}

Folder containing information about regulations and facilities in

the hospital and at the ward (Hospital 1, in Dutch) . . . . . . . 181

Appendix 5.4

Script for the slide-tape presentation about herniorrhaphy

(Hospital 2, in Dutch)

\section{Appendix 5.5}

Checklist of subjects to discuss with patients by nurses on admission (Hospital 1, in Dutch) . . . . . . . . . . . . 205

\section{Appendix 6.1}

Factor analysis of need for information (Pre surgical) . . . . . . . . 209

\section{Appendix 6.2}

Factor analysis of need for information (Post surgical) $\ldots \ldots \ldots 213$

\section{Appendix 6.3}

Measurement of perceived control 


\subsection{Introduction}

Patient education has developed considerably during the last 15 to 20 years in various areas of health care, both in the U.S. and in The Netherlands. Patients have become more demanding and require more complete information and support from their physicians. Also, health care professionals themselves have come to consider adequate information for and communication with patients as essential to good practice (Voorn, 1995). These changing standards are reflected in legislation in the field of health care. Both in the U.S. and in The Netherlands conditions for certification of hospitals include requirements for informing patients (Webber, 1990; Fahrenfort, 1990). In the beginning of the 1980's the Dutch parliament accepted a bill requiring the government to support the development of patient education in practice (Tweede Kamer, 1981-1982). Also, since April 1995 it is mandatory in The Netherlands that health care providers inform patients exhaustively about the risks and benefits of and alternatives to proposed treatments (Francissen, 1995, Leenen, 1995).

In addition to these developments, the need for cost containment in health care has led to greater emphasis on self-care among patients, resulting in shorter hospital stays and more out-clinic treatments (van Ballekom-van de Ven, 1994; Swinkels, 1990). This has required patients to fulfil a more substantial role in their treatment and care, which in turn, requires that they be adequately informed. Also, increased general educational levels and more pervasive tendencies towards democracy and egalitarism resulted in lower status of members in the health profession and stronger demands from patients for information (Ten Have, 1988). For economic reasons, competition among health care services to attract their "customers" has led to greater emphasis on quality of care, which is partially determined by provision of information and support to patients (Euverman, Fahrenfort \& Huising, 1991). Thus, patient education helps to enhance hospitals' public relations as well. Finally, among various patient categories, it has been increasingly recognised that adequate provision of information and psychological support enhances patients' psychological well-being and physical recovery from illness and treatment (Wilson-Barnett, 1994). Despite the large amount of evidence, in particular among surgical patients (see for example Devine, 1992), of the effectiveness of patient education and alternative methods to prepare patients for stressful medical procedures, few hospitals provide these components of care routinely (Wilson-Barnett, 1994). 
The research described in this thesis was meant to contribute to the development of patient education for patients hospitalized for surgery. It aimed at establishing a program to prepare patients for surgery that:

a) is effective in enhancing patients" physical recovery from surgery and psychological well-being during the course of treatment and care, and

b) can be carried out in their day-to-day practice by regular hospital staff members who are responsible for treatment and care of surgical patients.

The results of the study are meant to provide an example of the development and implementation of patient education for surgical patients in general hospitals. The study focuses on patients undergoing cholecystectomy and patients undergoing herniorrhaphy, because both are performed frequently in The Netherlands. Of the total number of surgical treatments performed in Dutch hospitals in 1991, 6.3\% were cholecystectomies or other operations of the gallbladder or biliary ducts and $11.8 \%$ were herniorrhaphies (SIG, 1993). Therefore, we consider these types of surgery as exemplary of surgical procedures of intermediate seriousness.

The present chapter provides a brief overview of the study and its results. A more extensive account of the study is presented in subsequent chapters, which provide detailed information about the theory and the methods employed, and the study's results. The chapter starts with an overview of previous studies evaluating psychoeducational interventions to prepare patients for surgery, paying attention in particular to individual differences between patients. Next, an attempt is undertaken to theoretically explain the effectiveness of these interventions. Based on these insights, we describe the process of development and implementation of a program of surgical patient education in two Dutch hospitals. As the first step, a study was performed to examine existing practices in both hospitals of educating patients undergoing herniorrhaphy and cholecystectomy. Finally, the method and the results are outlined of a field experiment, performed to evaluate the implementation and the effectiveness of the program.

\subsection{Effectiveness of psychoeducational interventions among abdominal surgical patients: a review}

On admission to hospital, surgical patients are confronted with a variety of problems, including fear of anaesthesia, fear of the impending operation and pain, uncertainty as to the experiences which they are to undergo and damage to self-image resulting from having to fulfil the role of patient (Kincey \& Saltmore, 1990; Johnston, 1988; WilsonBarnett, 1984; Ray, 1982; Salo, 1982). Although not entirely consistent (Wallace, 1986; Johnston \& Carpenter, 1980), most studies revealed a reversed linear relationship between presurgical stress on the one hand and postoperative physical recovery and psychological well-being on the other (Auerbach, 1989; Mathews \& Ridgeway, 1981; Ray \& Fitzgibbon, 1981).

Interventions to limit stress among surgical patients and to promote psychological wellbeing and physical recovery after surgery, are divided generally into three categories (Devine, 1992; Kincey \& Saltmore, 1990; Mathews \& Ridgeway, 1984). First, patients 
may be supplied with procedural and/or sensory information. Second, they may be instructed and motivated to pertorm physical behaviors which facilitate physical recovery and psychological well-being or to perform "cognitive" behaviors aimed at restructuring patients' cognitions to promote adequate coping and reduce stress. Finally, psychotherapeutic approaches have been employed in which patients are encouraged to express feelings concerning surgery, in which they are given reassurance or in which they react to other patients' feelings and help one another. These approaches are not always mutually exclusive, while various combinations of these measures have been employed as well.

\subsubsection{Effectiveness of preparation methods}

Many studies evaluated the effectiveness of these interventions with respect to improvement of physical recovery from surgery and psychological well-being. Reviews of these studies generally show that psychoeducational preparation of surgical patients is effective to accomplish these goals (Horne, Vatmanides \& Careri, 1994; Lipsey \& Wilson, 1993; Johnston \& Vögele, 1993; Devine, 1992; Webber, 1990). Among patients undergoing stressful medical procedures other than surgery, this conclusion was found to be valid as well (Kendall \& Epps, 1990; Miller, Coombs \& Stoddard, 1989). Although some did not differentiate between interventions, other reviews described the effectiveness of separate interventions with respect to various outcome variables (Johnston \& Vögele, 1993; Kendall \& Epps, 1990; Schultheis, Peterson \& Selby, 1987; Hathaway, 1986; Rogers \& Reich, 1986; Mathews \& Ridgeway, 1984). However, the relative effectiveness of separate types of intervention remains unclear.

An examination of these review studies demonstrated that behavioral instructions including relaxation, are largely beneficial among surgical patients (Johnston \& Vögele, 1993; Salmon, 1992; Mathews \& Ridgeway, 1984). As a subset of behavioral instructions, cognitive interventions were found to be effective as well (Weinman \& Johnston, 1988; Cochran, 1984). Some authors have termed interventions as "cognitive" although they were actually attempts to alter patients' behaviors (Miller, et al., 1989; Schultheis, et al., 1987). Therefore, some of the benefits ascribed to cognitive interventions probably should be considered as benefits from behavioral instructions. With respect to provision of information, most authors found sensory information to be superior when compared with procedural information (Suls \& Wan, 1989; Taylor \& Clark, 1986). Finally, limited evidence was found supporting the effectiveness of psychotherapeutical approaches to presurgical preparation (Kendall \& Epps, 1990; Hathaway, 1986; Mathews \& Ridgeway, 1984).

Our examination of review studies leaves some questions unanswered, however. Reviews of evaluations of psychoeducational interventions have not systematically detailed which intervention is effective with respect to precisely which outcome variable. Also, the question which intervention is most successful to affect particular outconnes remains to be answered. Although some authors attempted to address this issue (Johnston \& Vögele, 1993), this was unsatisfactory. Indeed, with the results of evaluations conducted up till now it may be impossible to answer this question, because practically each study evaluat- 
ing a particular intervention assessed a set of outcome variables that differed from outcomes measured by other studies evaluating the same intervention. Further, few studies provided an accurate description of the exact content of the intervention used and of the statistical properties of their results, preventing calculation of effect sizes (Johnston \& Vögele, 1993; Schultheis, et al., 1987). Also, interventions that were considered as different from one another, have often been contaminated. For example, behavioral instructions inevitably contain procedural and sensory information as well, making it difficult to determine whether the effectiveness of the intervention is due to information, instructions or both. Some authors have claimed combined interventions to be more effective than single interventions (Devine, 1992; Kincey \& Saltmore, 1990). However, drawing reliable conclusions with respect the relative effectiveness of single and combined interventions is troubled by the problem of contamination as well.

To obtain more complete knowledge of the match between interventions and outcomes and of the relative effectiveness of interventions, studies are required that compare different interventions, alone and in combination, with an (attention) control group, against a complete set of valid indicators of outcome (Kincey \& Saltmore, 1990).

\subsubsection{Individual differences in the effects of psychoeducational interventions}

The benefits of psychoeducational interventions have been found to vary between patients who differ in preoperative fear, coping and perceived control (Salmon, 1992; Kincey \& Saltmore, 1990; Rogers \& Reich, 1986; Hathaway, 1986; Mathews \& Ridgeway, 1984; 1981). Increased knowledge and understanding of these differences may help to more specifically direct interventions at those patients who are likely to benefit most from them.

Preoperative fear appears to be related to postoperative recovery and well-being (Auerbach, 1989; Martelli, Auerbach, Alexander \& Mercuri, 1987; Wallace, 1986; Mathews \& Ridgeway, 1981). Patients with high preoperative fear were found to benefit more from pre surgical preparation than patients with low fear (Mathews \& Ridgeway, 1984), but others have shown the opposite effect (Kincey \& Saltmore, 1990). In a literature search of studies performed among patients undergoing abdominal surgery, we found five studies that examined the interaction between psychoeducational interventions and preoperative fear. Two of these studies suggested that patients with high preoperative fear benefit more from presurgical preparation than low fear patients (Klos, Cummings, Joyce, Graichen \& Quigly, 1980; Johnson, Rice. Fuller \& Endress, 1978). However, Wilson (1981) and Williams, Workhoven \& Williams, (1975) found low fear patients to benefit more from either information in combination with emotional support or with relaxation instructions, than high fear patients. Finally, Dumas \& Johnson (1972) found no differences hetween patients with high or low preoperative fear who received emotional support preoperatively.

Also, coping seems relevant. Most studies found more successful courses of recovery among patients that coped by means of avoidance or blunting than among patients who 
employed sensitizing or monitoring as coping strategies (Salmon, 1992; Mathews \& Ridgeway, 1981). Among patients undergoing stressful medical procedures, sensitizers were found to benefit more from preparation interventions than avoiders (Schultheis, et al., 1987; Miller \& Mangan, 1983). In our literature search, we found five studies that examined the interaction between psychoeducational interventions and coping among patients undergoing abdominal surgery. Two of them found no differences between sensitizers and avoiders, following relaxation instructions, either alone or in combination with information (Wilson, 1981), and following either behavioral instructions, cognitive reappraisal or reassurance (Cohen, 1975). Three additional studies however, found avoiders to benefit least, or even to be harmed by preparation, while positive effects were obtained among neutrals (Andrew, 1970) and among sensitizers (Scott \& Clum, 1984; DeLong, 1970).

Finally, perceived control can be of as conceived of as a relevant factor. Many studies demonstrated that feelings of control can keep stress within bounds and psychological and physical well-being at an acceptable level, both among ill and healthy individuals. Although not unequivocal, evidence exists that patients with strong feelings of control benefit more from preparation for surgery or other stressful medical procedures than patients with weak feelings of control (Auerbach, 1989; Schultheis, et al., 1987). In our literature search, we obtained two studies that examined the interaction between presurgical preparation and patients' locus of control among abdominal patients. One of them found no differences between patients with an internal or an external locus of control (Hartsfield \& Clopton, 1985). Picket \& Clum (1982) however, found internals to benefit more from relaxation instructions than externals.

Few studies have reported results concerning the interaction between preoperative fear, coping and perceived control and preparation for surgery, and the findings are not straightforward. Conclusions concerning this interaction therefore seem premature. However, Miller et al.'s (1989) attempt to explain differences between patients in reactions to presurgical preparation, may provide an explanation to the results of the literature search. They suggested that measures to support patients' efforts to cope with undesirable events, should fit their individual coping preferences. They hypothesized that given control options, people attempt to limit the maximum danger of an undesirable event. In this case, people "monitor" the negative aspects of the event and their arousal remains high and information is likely to be preferred. In the absence of control, efforts to minimize danger are fruitless and persons are more likely to employ emotion focused ways of coping to reduce arousal. In that case, they are likely to "blunt" information about the negative event. However, people differ in the extent that they stop monitoring and start blunting in situations that offer little control. Some people, like those predisposed to cope with stress by sensitizing and those with an internal locus of control, continue to prefer information about the aversive event, since it places them in the presence of "external" safety signals. Others, although the event may be controllable, prefer not to receive information and try to place themselves in the presence of "psychological safety signals". Considering this explanation, we tentatively conclude that paticnts with high preoperative fear, patients coping by means of sensitizing or monitoring, and 
patients with a high level of perceived control benefit most from preparation interventions.

Since individual differences in preoperative fear, coping and perceived control are likely to be correlated with the extent to which patients stop monitoring and start blunting in the face of aversive events, measures of presurgical preparation should take these differences into account (Kincey \& Saltmore, 1990; Auerbach, 1989; Schultheis et al., 1987; Martelli et al, 1987). Next, we will detail patients' perception of control as a particularly important variable to explain the benefits of presurgical preparation and its differential effects between patients and between situations.

\subsection{Benefits of presurgical preparation and the role of perceived control}

Syme (1989) suggested beneficial effects from a high level of perceived control among individuals confronted with stressful events such as hospitalization and surgery. Perceived control is a useful concept to explain why and when preparation of patients for surgery is likely to improve their psychological well-being and physical recovery (Salmon, 1992; Syme, 1989; Kok, 1988). Wallston, Wallston, Smith \& Dobbins (1987) defined perceived control as "... the belief that one can determine one's own internal states and behavior, influence one's environment, and bring about desired outcomes" (p. 5). Perceived control is thus a subjective concept; there may be a discrepancy between actual possibilities of exercising control and possibilities of control that one perceives oneself. Feelings of control can keep stress within bounds and psychological and physical well-being at an acceptable level. This was demonstrated among ill persons (Thompson et al., 1993; Bunzel \& Grundböck, 1990; Partridge \& Johnston, 1989), among people suffering from chronic pain (Arntz \& Schmidt, 1989) and among healthy persons (Kraus \& Stryker, 1984; Averill, 1973). The situation of surgical patients in hospital includes various factors which cause their perceived control to decrease (Taylor, 1991; 1979; Eisendraht, 1987). However, attempts to increase patients' levels of perceived control in stressful medical situations have been demonstrated to reduce stress and improve psychological and physical functioning (Morris \& Royle, 1988; Mills \& Krantz, 1979).

\subsubsection{Relationship of perceived control to stress and coping}

Lazarus' transactional theory of stress and coping (Lazarus, 1993; Lazarus \& Folkman, 1987; 1984; Lazarus \& Launier, 1978) explains the benefits of perceived control. This model describes that when a person is confronted with an aversive event, he or she appraises to what extent the event threatens his or her well-being. The amount of stress experienced following this confrontation depends on the value attributed by the person to the particular aspect of well-being that is threatened by the event (primary appraisal; "what is at stake"), and on the possibilities that he or she perceives to reduce the threat (secondary appraisal). Following this process of appraisal, the person will attempt to 
reduce the stress. The particular coping strategies employed depend on the outcome of the appraisal process. When the event is considered a serious threat to well-being (high level of stress), emotion focused coping is more likely (e.g. avoidance, seeking social support, cognitive distortion). When the event is not considered as a serious threat (low stress), problem focused coping is more likely (e.g. trying to change the circumstances, talking to someone to solve the problem).

Perceived control is supposed to mediate the relationship between the threatening event and the experience of stress (Folkman, 1984), because control implicates various behavioral and cognitive opportunities to alter the (meaning of the) threatening event, which serve to decrease the extent to which a person feels threatened by the event. For example, Anderson (1987) found patients undergoing cardiac surgery who received preoperative information, alone or in combination with a coping intervention, to experience increased feelings of control in comparison with control group patients. Further, increased feelings of control were associated with reduced levels of preoperative anxiety. Also, apart from medical settings, many examples of studies in other settings are available that demonstrate the beneficial effects on physical and psychological functioning of interventions to enhance perceived or actual control in the face of stress (Syme, 1989).

Perceived control determines a person's coping strategies to deal with the threatening event as well (Lazarus, 1993). People deal with events which they consider as susceptible to change (high level of perceived control) by means of problem focused coping (Folkman \& Lazarus, 1980; 1985; Folkman, Lazarus, Dunkel-Schetter, DeLongis \& Gruen, 1986; Folkman, Lazarus, Gruen, DeLongis, 1986). When events are thought of as not amenable to change (low level of perceived control), people are more likely to employ emotion focused coping. This relationship has also been found with respect to coping with threats to one's health (Wallston, 1989; Strickland, 1978) and among ill patients (Breemhaar, Visser \& Kleijnen, 1990; Van den Borne \& Pruyn, 1985).

\subsubsection{Patient education as a means to enhance patients' level of perceived control}

As demonstrated by Anderson's (1987) study, surgical patient education and support are likely to stimulate patients' perceived control (Taylor, 1991). For example, tcaching patients behavioral skills to reduce pain offers them behavioral responses to decrease unpleasant aspects of medical treatment (Johnson \& Leventhal, 1974). Also, teaching mental strategies that decrease the impact of unpleasant aspects of treatment (Langer, Janis and Wolfer, 1975) and offering patients a choice between options for various types of treatment or care protocols (Morris \& Royle, 1988), improve their physical condition and psychological well-being. Procedural and sensory information may also improve patients' ability to predict more accurately what he/she is to undergo and to prepare for it better (Taylor \& Clark, 1986). 


\subsubsection{Individual differences in the benefits of perceived control}

A high level of perceived control does not seem to benefit every patient, however (Thompson, Cheek \& Graham, 1987). Rotter (1966) distinguished persons with an external locus of control, who generally believe they can themselves exert little control, from persons with an internal locus of control. Folkman (1984) suggested that enhancing perceived control may increase stress when it requires demands which the person concerned does not wish to meet or which he or she can not (or thinks he or she can not) meet. Indeed, as mentioned in section 1.2.2, patients characterized as 'internals' generally have been found to benefit from information about a medical procedure which they must undergo or from some alternative preparation method (Auerbach, 1989; Miller et al., 1989; Schultheis, et al., 1987; Mathews \& Ridgeway, 1984). Among 'externals', the effects are neutral or even detrimental. Consequently, patient education interventions should take into account differences between patients to the extent that they desire control (Martelli, et al., 1987). Otherwise, increasing control may harm well-being and recovery (Kincey \& Saltmore, 1990; Rogers \& Reich, 1986).

Next, we will describe the development of a program of surgical patient education, based on theoretical notions concerning the effectiveness of presurgical preparations and on the practical opportunities and restrictions to improve patient education in two general hospitals. In advance, the method and the results will be described of an examination of the existing practices with respect to treatment, care and education and support of surgical patients in both hospitals.

\subsection{Examination of existing practices of surgical patient education in two hospitals}

Despite the potential benefits of presurgical information and support, in practice most patients do not receive sufficient psychoeducational preparation for surgery. Lack of information is a common complaint among patients hospitalized for surgery (Webber, 1990; Wallace, 1986), while Visser (1986) showed that many patients admitted into hospitals have little relevant knowledge of their illness and treatment. Most surgical patients however, were found to prefer extensive information preoperatively (Wallace, 1985). Various barriers keep health care providers from providing adequate patient eduction and support, like lack of time, lack of support, ambiguity concerning responsibilities for educational tasks, and finally, a medical-technological professional attitude combined with reluctance to offer information and overestimation of patients" medical knowledge (Wilson-Barnett, 1994; Webber, 1990, Krupat, 1986; Ruzicki, 1985).

As far as studies evaluating the effectiveness of surgical patient education interventions are concerned, these barriers often have led to provision of the intervention by someone who is not a member of the regular hospital staff, usually on a temporary basis, as indicated by O'Connor, Devine, Cook, Wenk \& Curtin (1990) and Devine, O'Connor, Cook, Wenk \& Curtin (1988). This may explain why the extent to which programmes of surgical patient education whose effectiveness has been evaluated favorably, have been 
implemented in hospitals has been rather limited. In every day practice, however, it is desirable that staff members themselves conduct patient education, because patients tend to value information highest when it is provided by their "own" doctors and nurses (Van den Borne, Pruyn \& de Mey, 1986). Also, patient education is most likely to become a regular element of patient care when it is carried out from the start by regular health care providers.

Successful implementation of patient education measures which are suitable for application by hospital staff members, requires their compatibility with everyday hospital practices and with skills and attitudes of hospital staff members (McCullough, Boggs \& Varner, 1980). Therefore, collaboration with hospital staff members seems essential to successfully develop and implement a program of surgical patient education (Orlandi, Landers, Weston \& Haley, 1990). As the first step in the process to improve surgical patient education, we examined the existing practices with regard to treatment, care and education in two hospitals for patients undergoing cholecystectomy or herniorrhaphy. The study examined the events happening to patients, the information given to them and their subjective experiences. It served to obtain a picture of the practice of treatment and care of these patients and of problems with regard to patient education, mutually shared by the investigators and the health care providers involved.

\subsubsection{Method}

The examination was carried out in two 600-bed general hospitals in The Netherlands. We observed various interactions between patients and health care providers. During each interaction, the observations focused on the health care professionals who met with the patients, the events taking place for medical examination and therapy, the information given to patients, verbal and non-verbal behavior and emotional reactions of patients, as well as the environment in which the event took place.

Interviews were held with relevant health care providers to collect information about the events happening to cholecystectomy and herniorrhaphy patients during the course of their stay in the hospital, including information provided to patients during these events. Also, general information was obtained concerning details about treatment and care.

Open-ended interviews were held with 14 cholecystectomy and 20 herniorrhaphy patients before, during, and after their stay in hospital. The interviews focused on 1) information received by patients, 2) their subjective experiences and 3) behavior of the patient and health care provider. In addition, in one of both hospitals, data were collected among 54 patients by means of structured questionnaires. Questions dealt with pre-operative fear (asked before surgery), need for information about facilities and regulations, health care providers and medical details (before and after surgery), and oral and written information received (before and after surgery and one week postdischarge). All patients admitted during a six month period in this hospital to undergo herniorrhaphy or cholecystectomy were asked to answer the questionnaires. The rate of participation was $83 \%$. 


\subsubsection{Results}

At least 17 different events were found to occur during the course of treatment and care of patients undergoing cholecystectomy or herniorrhaphy. Also, patients were found to meet many different health care providers. Patients undergoing herniorrhaphy met on average 19 different physicians, nurses, laboratory workers and administration employees, while patients undergoing cholecystectomy met on average 22 different professionals. Further, these events took place at many locations. Both patients undergoing herniorrhaphy and patients undergoing cholecystectomy visited at least nine different places in the hospital.

\section{Problems experienced by patients}

The results of the structured interviews showed that $50 \%$ of the patients feared anaesthesia and adverse physical postoperative reactions, while 30 to almost $50 \%$ desired additional information about these subjects. Many patients felt uncertain about the roles and responsibilities of various health care providers and their identities. Approximately $50 \%$ of the patients indicated a desire to receive additional information about the medical aspects of their condition, treatment and care. Finally, on discharge many patients had not received relevant information about discharge from a nurse $(50 \%)$ or from a ward physician $(70 \%)$. In addition, many patients expressed a desire to receive extensive information about these subjects. These results were confirmed by those of the open-ended interviews with patients and of the observations of interactions between patients and staff members.

\section{Organizational barriers to patient education}

Interviews with the anesthetists showed that in one of the two hospitals, all patients scheduled for surgery on a particular day, were visited by one and the same anesthetist on the day before surgery, who did all the visiting on a given day. This large caseload often caused him or her to visit patients hastily and sometimes not at all. Further, the large number of different health care providers caused confusion among patients concerning their roles, making it hard to obtain desired information from the most appropriate person. The patient interviews and the observations revealed several examples of lack of coordination among health care providers with respect to information giving, causing mistakes like lack of information to patients or contradictory information. Finally, patients often were embarrassed by unexpected visits from physicians, sometimes taking place at inconvenient locations. This ad hoc character of physician contacts troubled patients' processing of information and asking questions adequately.

\section{Inadequacies of the method of providing information}

Results of the structured interviews showed that patients did not systematically receive oral information about certain subjects at particular occasions. According to the openended interviews, variations between patients in information provision did not correspond closely with variations in their desires to receive information. Indeed, physicians in particular were found reluctant to offer information to patients. Contacts with physicians 
took place hastily, and often they provided incomplete information, which sometimes led patients to ask for additional information. In particular this was the case for information from anesthetists. Finally, the information provided to patients did not always match their particular interests at the time when it was given. On admission they received a lot of information, often more than they could cope with adequately. At discharge, however, they often received less information than desired.

\subsubsection{Conclusions}

These results suggested first that the information for patients about the following subjects should be improved: the roles and functions of health care providers and in particular their relationship to patients, medical aspects of the illness and preparations for and recovery from surgery and anaesthesia and about behavior facilitating recovery after discharge. Second, the consistency of information provision should be improved, and information should be distributed more evenly along the course of treatment. Finally, staff members' educational responsibilities and tasks should be more carefully delineated to avoid inconsistencies and gaps in information provision.

\subsection{Development and implementation of a program of preoperative surgical patient education}

Next, we will describe the content of a new program of surgical patient education, followed by the description of a theoretical approach to adoption of innovations. Finally, the process of developing and implementing the program in 2 hospitals will be detailed.

\subsubsection{Program of surgical patient education}

The program's content was founded primarily on the shortcomings of the existing practices with respect to patient education in both hospitals as revealed by the examination, but also on knowledge of effective means to prepare patients for surgery and on knowledge of the mediating role of patients' perceived control, determining the effectiveness of psychoeducational interventions. Figure 1.1 shows an overview of the new program of patient education in both hospitals, and of previously existing measures. 


\begin{tabular}{|c|c|c|c|c|}
\hline & & & Standard patient education & New patient education \\
\hline \multirow{2}{*}{\multicolumn{2}{|c|}{$\begin{array}{l}\text { 1. Written } \\
\text { information }\end{array}$}} & Hospital 1 & $\begin{array}{l}\text { Leaflet about anesthesia } \\
\text { Leaflet about cholecystectomy } \\
\text { Leaflet about the hospital } \\
\text { Leaflet about the ward }\end{array}$ & $\begin{array}{l}\text { Improved leaflet about anesthesia } \\
\text { New leaflet about herniorrhaphy } \\
\text { Improved leaflet about cholecystectomy } \\
\text { Folder at the ward containing improved } \\
\text { information about the hospital and the } \\
\text { ward }\end{array}$ \\
\hline & & Hospital 2 & $\begin{array}{l}\text { Leaflet about the hospital } \\
\text { Leaflet about 'who's who' }\end{array}$ & $\begin{array}{l}\text { New leaflet about anesthesia } \\
\text { New leaflet about herniorrhaphy } \\
\text { New leaflet about cholecystectomy } \\
\text { Folder at the ward containing improved } \\
\text { information about the ward } \\
\text { Leaflet about the hospital (uncharged) }\end{array}$ \\
\hline & $\begin{array}{l}\text { Audiovisual } \\
\text { information }\end{array}$ & $\begin{array}{l}\text { Hospital } \\
1 \& 2\end{array}$ & None & $\begin{array}{l}\text { Slide-tape presentation about } \\
\text { undergoing a herniorrhaply } \\
\text { Slide-tape presentation about } \\
\text { undergoing a cholecystectomy }\end{array}$ \\
\hline & $\begin{array}{l}\text { Oral infor- } \\
\text { mation }\end{array}$ & $\begin{array}{l}\text { Hospical } \\
1 \& 2\end{array}$ & $\begin{array}{l}\text { Unstructured information by } \\
\text { nurse on admittance } \\
\text { Unstructured information from } \\
\text { different health care providers } \\
\text { at several moments during } \\
\text { hospitalisation }\end{array}$ & $\begin{array}{l}\text { Systematic provision of information by } \\
\text { nurses on admittance, supported by a } \\
\text { checklist displaying relevant topics. } \\
\text { Unstructured information from } \\
\text { health care providers at several } \\
\text { moments during hospitalisation } \\
\text { (unchanged) }\end{array}$ \\
\hline
\end{tabular}

Figure 1.1: Standard and new surgical patient education program in both. hospitals.

Contrary to our earlier recommendation of systematic evaluation of various preparation methods, alone and in combination, we undertook a rather eclectic approach to the composition of the program. Because the study aimed at developing a model of surgical patient education, suitable to be carried out by health care providers themselves, it was considered necessary to cooperate closely with staff members in the everyday hospital setting, both with respect to development and implementation of the program. This requirement did not allow us to conduct a field experiment with systematic variation of various levels of treatment. Moreover, since the relative effectiveness of various approaches to surgical preparation methods has not yet been adequately established, a pragmatic approach to the design of surgical patient education seemed appropriate.

Written information concerning surgery and anaesthesia was contained in leaflets, which were provided to patients preoperatively by nurses at the ambulatory department. Information about regulations and facilities at the hospital and the ward was contained in folders at the wards. A slide-tape presentation showed procedures regarding admission, preparations for and recovery from surgery, locations of these procedures, and health care providers involved. Their tasks were explained, together with their responsibilities. The presentation could be viewed preoperatively at the ambulatory department, some days prior to admission. Assignments were made to nurses concerning topics to be discussed with patients on admission. Along with these modes of communication, instructions were conveyed concerning patient behavior facilitating presurgical preparation and postopera- 
tive recovery and psychological support. To promote even distribution of information over time and to structure the subjects the patients received information about, agreements were made with nurses and physicians regarding the timing when to provide written, oral and audiovisual information. Perceived control was enhanced by including information about behavioral opportunities to reduce discomfort and to improve physical well-being during recovery from surgery. E.g. the leaflets and the slide-tape presentation instructed patients to indicate pain in order to receive pain medication, to cough and breathe deeply in order to improve pulmonary functioning. To prevent undesirable consequences of increasing perceived control among patients with low needs for control, patients were encouraged to enact these opportunities for control only in as far as they themselves were willing to.

\subsubsection{Elements of successful adoption of innovations}

Successful adoption of an innovation depends on the extent to which its potential users perceive it as 1) relatively advantageous, in the sense of cost-effectiveness, time gained, social status, and so forth, 2) compatible with their existing values and needs, 3) comprehensible, 4) trialable and 5) visible (Rogers, 1962). In addition, according to Zaltman, Duncan \& Holbek (1973), an innovation is adopted more readily when it enhances social relationships between the users, when messages concerning the innovation are communicated easily between its users and when it is implemented by the time that its potential users are prepared to adopt it. Rogers (1962) considered a decentralized process of adoption of innovation, in which the initiator and the potential adopters cooperate to obtain mutual understanding, as most appropriate when the users are sufficiently educated and when the innovation has limited technical complexity. Advantages of decentralization are a better fit between the innovation and the users' needs and problems and a sense: of being able to control the process on the users' side (see also: Orlandi, et al., 1990).

Next, we will illustrate how these theoretical principles were brought into the practice of development and implementation of the program of surgical patient education in two hospitals.

\subsubsection{The process of development and implementation of the program of surgical patient education in two hospitals}

To obtain cooperation from relevant hospital staff members in the process of development and implementation of the new program of surgical patient education, the project's objectives and method were explained to the hospital management and staff surgeons. Following their willingness to cooperate, other relevant disciplines were approached, such as clinical and ambulatory nurses, anesthetists, and physiotherapists. Because they increased compatibility of the new program with their professional needs and values, the following conditions enhanced their willingness to cooperate: First, the existing practice of treatment, care and patient education would serve as a starting point. Second, they 
were in the position to contribute to and monitor the process of development and implementation.

To improve cooperation and communication about the innovation between the initiator of the project and the adopters of the program of patient education in the hospital and between the adopters themselves, a project group was installed. This group was to decide on the measures to be developed and to contribute to their actual development. It was composed of the project coordinator ${ }^{1}$ and a member of each discipline involved in treatment and care of patients undergoing cholecystectomy and herniorrhaphy. Based on the results of the examination described in section 4, the group decided which shortcomings of patient education were to be addressed and which activities were required to attain improvements. Group members provided feedback about the group's activities to their colleagues and reported in the group about their reactions, thus increasing the visibility of the development process.

Not all improvements proposed were considered feasible by all members. For example, limiting physician-patient contacts at the ward exclusively to ward physicians, was desirable to improve patients' recognition of the surgeon and the ward physician, as well as to limit the number of different health care providers that patients are confronted with during admittance. However, although ward physicians are formally responsible for clinical patients' treatment and care, the surgeons were not prepared to agree with this division, obviously because this was incompatible with their professional needs and values. Thus, not all improvements were attained which were desirable considering the shortcomings in patient education detected previously. Most measures for which agreement was attained (figure 1.1) concerned information provision during the preoperative period and most of these measures were designed to be carried out by nurses.

In hospital 1, no project group was established, since in particular surgeons and anesthetists in this hospital were reluctant to cooperate with other disciplines. They did not consider cooperation advantageous because, in their opinion, this meant loss of time and unnecessary involvement in other disciplines' affairs. In this hospital, development of improvements of patient education was carried out during separate meetings with representatives from separate disciplines, taking more meetings and time compared to hospital 2. It seems likely that this has limited communication among health care providers about the new program and it may have hampered interpersonal relationships between them.

The measures agreed upon were elaborated in 'task groups', consisting of a representative of each discipline involved in the project group. One task group was installed for each measure. After completion, agreements were made concerning implementation of the program. To ensure the perception of trialability of the new program, it was made clear that initially, it was to be implemented for a limited period of time only. Following this period, decisions were to be made about more definite application eventually after adjustments based on previous experiences.

Since nurses of the clinical wards and the ambulatory department were to play a relatively large role in execution of the program, before implementation they were informed about the purpose of the program and how to apply the measures in practice, in order to

The author served as project coordinator. 
enhance comprehensibility. To promote continuation following initial implementation, one nurse was appointed from each ward and the ambulatory department of each hospital to monitor application of the program and to keep the project coordinator informed about application. In both hospitals some adjustments were carried out. In hospital 1, it was necessary to appoint nurses from the ambulatory department to distribute leaflets about surgery and anaesthesia to patients, because surgeons refrained from providing them. In the second hospital, after several patients did not show up to watch the slide-tape presentation, it was decided to provide patients with the leaflet about anaesthesia during their visit to the ambulatory department, instead of during their visit to watch the tape-slide presentation.

\subsection{Evaluation of the new program of surgical patient education}

To evaluate the new program, two studies were performed. The first examined the program's implementation, while the second assessed the effectiveness of the program to improve herniorrhaphy and cholecystectomy patients' recovery from surgery and their psychological well-being.

\subsubsection{Study 1: Test of the new program's implementation}

It was hypothesized that:

1. Patients admitted after implementation of the program receive information from more preoperative sources than patients admitted before implementation of the program.

2. Patients admitted after implementation of the program receive more written information about cholecystectomy and about anaesthesia, than patients admitted before implementation.

3. Patients admitted after implementation of the program evaluate this information more positively than patients admitted before implementation.

4. Patients admitted after implementation of the program receive more oral information on admission from nurses than patients admitted before implementation.

5. Patients admitted after implementation of the program evaluate this information more positively than patients admitted before implementation.

\section{Method}

A non-equivalent control group design was employed with two cohorts of surgical patients. First, data were collected among patients admitted into the hospital before implementation of the new program of surgical patient education (group 1). After development and implementation of the new program, similar data were collected among patients who were admitted after implementation of the new program (group 2; see figure 1.2). 


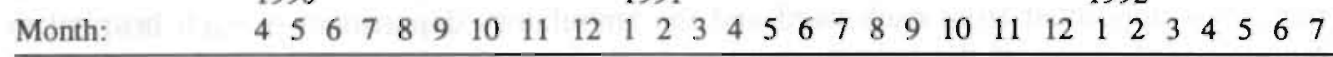

\begin{tabular}{llllll}
\hline Hospital 1: & $\mathrm{O}_{1}-$ (group 1) & $\mathrm{XO}_{2}$ & (group 2) & \\
Hospital 2: & & $\mathrm{O}_{1}$ & - (group 1) & $\mathrm{XO}_{2}-$ (group 2) $^{-}$ \\
\hline
\end{tabular}
$\mathrm{O}_{1}=$
Base line measurements among patients receiving existing information.
$\mathrm{X}=\quad$ Implementation of the new program of surgical patient education
$\mathrm{O}_{2}=\quad$ Measures among patients receiving information according to the new program.

\section{Figure 1.2: Design of the study.}

Participants The study was carried out in both hospitals where the new program of surgical patient education was developed and implemented. 195 Adult patients participated in the study, of which 124 underwent herniorrhaphy and 71 underwent cholecystectomy. Group 1 consisted of 95 patients (61 herniorraphy and 34 cholecystectomy) and group 2 of 100 patients (63 herniorraphy and 37 cholecystectomy). The response rate was $84 \%$.

Measures By means of structured interviews, individual patients were asked whether they had received and read each of the leaflets and folders, and how they judged its sufficiency and its comprehensibility. Second, patients in group 2 were asked whether they had watched the slide-tape presentation. All of these questions were asked on the day of admission. Third, on the day of admission, postoperatively and one week after discharge, questions were asked concerning receipt of oral information about particular subjects from the surgeon, the ward physician, the nurse, and, with respect to information about anaesthesia, from the anesthetist. When a patient answered affirmatively, his or her opinion concerning sufficiency and comprehensibility was asked. Finally, an index was calculated for each patient based on the number of leaflets and folders he or she had received, added to the number of subjects mentioned above about which oral information had been received on admission from nurses, and one more point when the patient watched the slide-tape presentation.

\section{Results}

Hypothesis 1 was confirmed. Comparison of the indices of total preoperative information received showed that this index was significantly higher among patients in group 2 than in group 1. No support was obtained in favor of hypothesis 2 . The two groups did not differ significantly with respect to the proportion of patients who received the leaflets about cholecystectomy and about anaesthesia. Hypothesis 3 was partially confirmed. The leaflet about anaesthesia was evaluated by patients in group 2 significantly more positive than in group 1. However, the evaluations of the written information about cholecystectomy did not differ between groups. Hypothesis 4 was not confirmed. In hospital 1 only, patients in group 2 received significantly less information from nurses about 'preparations for surgery' and 'regulations at the ward' than patients in group 1. Finally, hypothesis 5 was partially confirmed. Oral information from nurses on admission about the subject 
'recovery' was evaluated significantly more positive by patients in group 2 than in group 1.

\section{Discussion}

The findings suggest that the new program of surgical patient education was implemented to a limited extent only. Hypothesis 1, predicting that patients in group 2 would receive more information than patients in group 1 when all preoperative sources of information addressed by the new program were taken into account, was supported. However, disconfirming hypothesis 2 and 4 respectively, patients in group 2 did not receive more written information about cholecystectomy and about anaesthesia, nor did they receive. any more oral information from nurses on admission than patients in group 1. Hypothesis 3 and 5 were partially confirmed. Patients in group 2 evaluated written information about anaesthesia and oral information from nurses on admission about 'recovery' more positive than patients in group 1. Thus, considering all sources of preoperative information, the program's implementation was successful. However, limiting the comparison to sources available both before and after implementation of the program, implementation was only modest.

To explain these results, we offer three alternative explanations. First, to tailor the program to patients' needs for control, we intended to provide them with infonmation only to the extent that they themselves desired information. Consequently, patients in group 2 who may have desired little or no information and thus may not have undertaken action to be informed, received limited information.

Second, various barriers hindered providing information according to the programme. For example, in hospital 2 the slide-tape presentation was displayed only once each week. Initially in hospital 2, the leaflet about anaesthesia was provided only to those few patients who watched the slide-tape presentation.

Third, not all conditions that promote successful implementation of an innovation (Rogers, 1962; Zaltman et al. 1973) were met adequately. Promotion of surgical patient education appeared not to be fully compatible with some of the physicians' professional values and needs, since not all of them were prepared to improve patient education. For example in hospital 1, some physicians openly expressed reluctance to provide patients with adequate information and to undertake action to improve surgical patient education. Also, in hospital 1, the surgeons' refusal to participate in the project group may have harmed their relationship with members of other disciplines. Finally, especially in hospital 1, the long period of time that elapsed before the process of developing and implementing surgical patient education gained tangible results, may have made the process insufficiently rewarding to some staff members.

Although the results of this study do not clearly demonstrate that implementation of the program was succesful, this does not necessarily mean that the program failed to reach its objectives, namely improvement of surgical patients' physical recovery and psychological well-being. We only measured the amount of information received by patients in group 1 and 2 . However, the quality of the information received by patients in group 2 was supposed to be higher than the quality of the information received by patients in group 1 . 


\subsubsection{Study 2: Effectiveness of the new program}

A second study was performed to examine the effectiveness of the new program of surgical patient education, with respect to patients' physical recovery from surgery and their psychological well-being during the course of treatment and care. This study also investigated patients' level of perceived control as a variable that may explain the effectiveness of the intervention to reduce stress among surgical patients and to improve recovery from surgery. We hypothesized that:

1. Surgical patients admitted into the hospital after implementation of the new patient education program delivered by regular members of the surgical staff (group 2) will exhibit higher levels of psychological well-being and physical recovery, compared to patients admitted before implementation of the program (group 1).

2. Surgical patients in group 2 will exhibit higher levels of perceived control, compared to patients in group 1.

3. Patients with a high level of perceived control will demonstrate higher levels of psychological well-being and recovery from surgery, compared to patients with a low level of perceived control, whether or not they were exposed to the new program.

4. Increased levels of psychological well-being and physical recovery among patients in group 2 in comparison to patients in group 1, are mediated by increased levels of perceived control.

\section{Method}

Participants The study was carried out among the same groups of patients who participated in study 1. Similar to study 1, 195 adult patients participated (124 herniorrhaphy patients and 71 cholecystectomy patients). Group 1 consisted of 95 patients and group 2 of 100 patients. The response rate was $84 \%$.

Mi'usures Data were collected during four structured face to face interviews during patients' course of treatment and recovery (table 1.3).

Data analysis Hypotheses 1 and 2 were tested by performing multivariate analyses of covariance of the differences between groups in mean scores on dependent variables indicating physical recovery and psychological well-being, and the three variables indicating perceived control. Differences were tested multivariately, clustering dependent variables by time of measurement, followed by univariate testing. Type of surgery was included as the second factor, with three levels (herniorrhaphy, traditional cholecystectomy and laparoscopic cholecystectomy ${ }^{2}$ ). Because patients in group 2 received significantly more visits during hospitalization from their partner or someone else with whom they felt closely related, the number of such visits was employed as a covariate. Hypothesis

In the course of the study laparascopy, a new technique to perform cholecystectomy, was introduced. This caused the number of patients undergoing cholecystectomy by means of laparascopy among patients admitted into the hospital after implementation of the new patient education measures to be larger $(n=30)$, than among patients admitted before implementation of the new measures $(n=10)$. 
3 was tested by determining Pearson's correlation coefficients between patients' scores on perceived control and their scores on the variables of physical recovery and psychological well-being. For these analyses, patients in groups 1 and 2 were pooled. Hypothesis 4 was tested by multivariate analyses of covariance of the differences between groups in mean scores on clusters of dependent variables indicating physical recovery or psychological well-being measured at the same time. Included as covariates were, apart from number of visits, those measures of perceived control in which both groups were found to differ significantly.

Table 1.3: Variables and timing of measurement ${ }^{\mathrm{s}}$.

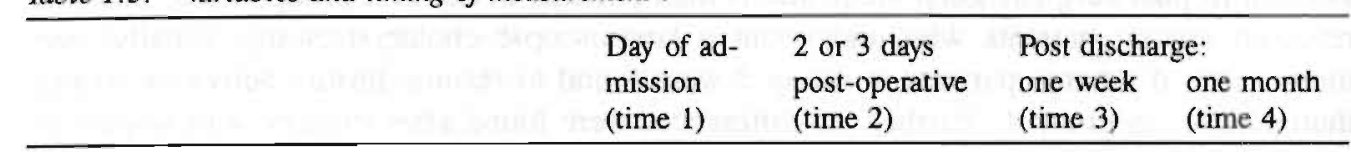

Effect variables:

$\begin{array}{ll}\text { a) Resumption physical activities } & \mathrm{x} \\ \text { b) No. phys. complaints after surgery } & \mathrm{x} \\ \text { c) No. phys. complaints at measurement } & \mathrm{x} \\ \text { d) Pain } & \mathrm{x} \\ \text { e) Bothered by pain } & \mathrm{x} \\ \text { f) Distressed by pain } & \mathrm{x}\end{array}$

g) IADL

h) Job resumption

i) Resumption of domestic work

j) Resumption of leisure

k) Preoperative fear

1) Preoperative anxiety

m) Need for information about:

- hospital stay, surgery, opportunities to obtain information $x$

- the illness

- surgery and hlth. care providers

n) Need for information about:

- surgery and its consequences

- the period after discharge

- discharge

n) Knowledge (2 different versions)

o) Subjective health

Mediating and moderating variables:
a) Quality of close relationship
b) Number of visits in hospital
c) Perceived control (3 different versions)

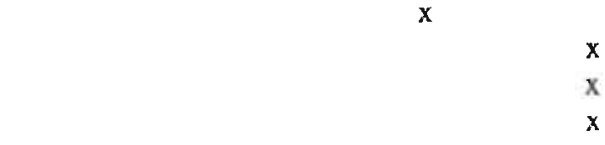

$\mathrm{x}$

x $x$

$x$

$x$

$x$

$X$

$\mathbf{X}$

$\mathrm{x}$

$x$

$\mathrm{x}$
$\mathrm{x}$
$\mathrm{x}$
$\mathrm{x}$

$\mathbf{X}$

Information concerning length of stay and medications is not included in the table. This information was obtained from the medical files. 


\section{Results}

We limit the description of the results to univariate main and interaction effects significant at $\mathrm{p} \leq .05$. Univariate analyses of differences between groups and of interactions between group and type of surgery with respect to any particular variable, were performed only to the extent in which the results of multivariate analyses including this variable were significant at $\mathrm{p} \leq .10$.

Physical recovery Patients in group 2 stayed in the hospital on average 1.28 days shorter than patients in group 1. Patients undergoing a traditional cholecystectomy in group 2 took more post surgical sleep medications than patients in the first group, while this was reversed among patients who underwent a laparoscopic cholecystectomy. Finally, one month after discharge patients in group 2 were found to resume leisure activities sooner than patients in group 1 . Further, no differences were found after surgery with respect to physical recovery.

Psychological well-being On the day of admission into the hospital, patients in group 2 had fewer needs for information about admission and the operation than patients in group 1. Further, no significant main or interaction effects were found with respect to psychological well-being.

Perceived control One week after discharge from the hospital, patients who underwent traditional cholecystectomy in group 2 showed significantly stronger feelings of control compared to group 1. Among patients undergoing herniorrhaphy this relationship was reversed, while among patients undergoing laparoscopic cholecystectomy no differences were detected. Pre- and post operatively, no significant main or interaction effects were found. Perceived control was significantly and positively related to all variables indicating successful psychological well-being and physical recovery, except for the number of sleep medications taken and the three variables concerning post-operative pain.

Controlling for group differences in perceived control Analyses of covariance of the differences between group 1 and 2 were repeated, employing the level of perceived control after discharge as a covariate, together with number of visits received in the hospital. These analyses were performed to examine whether the differences obtained between the two groups in length of stay, use of post surgical sleep medications, resumption of leisure and, at admission, need for information about admission and surgery were mediated by perceived control after discharge, as predicted by hypothesis 4 . Findings for sleep medication among traditional cholecystectomy and laparoscopic cholecystectomy patients and for resumption of leisure activities persisted. However, no differences were found with respect to length of stay and with respect to psychological well-being, either on the day of admission, or postoperatively.

\section{Discussion}

Evaluation of the program's effectiveness showed that patients in group 2 were discharged sooner, resumed leisure activities sooner, felt less need for information about admission and surgery on the day of admission, and took more sleep medications. The latter difference was limited to patients undergoing traditional cholecystectomy. No significant 
differences were found for the remaining variables indicating physical recovery or psychological well-being. Thus, as predicted by hypothesis 1 , to a small extent, the new program of surgical patient education improved patients' recovery and psychological wellbeing.

Hypothesis 2 predicts an increase in perceived control among patients following implementation of the new program. The only significant increase in perceived control was found one week after discharge among patients who underwent traditional cholecystectomy. Among herniorrhaphy patients, a decrease in perceived control was found at this time. In accordance with hypothesis 3 , perceived control was positively related to most variables of physical recovery after surgery and psychological well-being. Finally, supporting hypothesis 4 , when perceived control one week after discharge was kept constant between group 1 and 2, the difference between groups in length of stay was no longer significant. However, the faster resumption of leisure activities and, among traditional cholecystectomy patients, the larger number of sleep medications taken postoperatively among patients in group 2, remained significant. Below, these findings will be discussed briefly.

First, apart from partial implementation of the program discussed in section 1.6.1, the moderate effects of the program found in this study may be explained because the program's scope was limited. It did not offer a solution to all shortcomings of surgical patient education that were detected during the examination of existing practices of treatment, care and education of herniorrhaphy and cholecystectomy patients in both hospitals. Therefore, the program's potential to improve patients' psychological wellbeing and physical recovery may have been below optimum.

Also, efforts to increase patients' level of perceived control may have been to timid. Apart from standardized information, on request, patients were provided with additional information, and they were given behavioral recommendations to contribute themselves to their recovery and well-being during hospital stay. However, patients were left to decide for themselves whether they employed these behaviors or not. All together, these manipulations to enhance perceived control may have been without sufficient engagement. Some doubt was cast on the finding that patients' length of stay was shortened following implementation of the program, because in recent years length of stay in hospitals has decreased for medical, technological and financial reasons (Swinkels, 1990). Because in the present study patients in group 2 were admitted 6-8 months later than patients in group 1, one might argue that the obtained decrease in length of stay was the result of a history effect. However, comparison of the decrease in length of stay among the patients in groups 1 and 2 of the sample in our study with the decrease among all patients admitted into both hospitals for herniorrhaphy or cholecystectomy in the same periods in which we collected data among patients in group 1 and in group 2, showed this to be unlikely. The significant increase in perceived control following implementation of the new program, one week after discharge among traditional cholecystectomy patients, may be explained because traditional cholecystectomy is an operation of moderate seriousness with a mildly complicated course of recovery (Zwaveling \& De Boer, 1986). Therefore, instructions to ask for pain and sleep medications, how to relieve pain, etc., may have matched cholecystectomy patients' experiences and subjective need for help accurately. 
Thus, the perception of their ability to contribute to their well-being during the course of treatment and recovery may have increased. The decrease in perceived control one week after discharge among herniorrhaphy patients is difficult to explain, however. The absence of an increase in perceived control on the day of admission, may be explained by -at that moment- lack of experience among patients with their current hospital stay. At that particular time, they had relatively few opportunities to validate the information in practice. Since each patient experiences to a particular extent pain and bodily discomfort after surgery, and his/her behavior is controlled by situational factors, this may explain the absence of differences in perceived control postoperatively.

The difference between groups in length of stay was no longer significant when perceived control one week after discharge was kept constant. This suggests that traditional cholecystectomy patients' relatively strong perception of their own ability to contribute to their recovery -which may have began to rise slowly during the days after surgery and discharge- led them to perform preventive behaviors (e.g. adequate bodily movements) post surgically. In turn, this may have prevented complications in wound healing, resulting in earlier discharge. However, since differences between group 1 and 2 in amount of sleep medications taken and resumption of leisure activities persisted when differences between both groups in perceived control one week after discharge were kept constant, the increased level of perceived control after discharge among traditional cholecystectomy patients cannot explain these effects of the program.

\subsection{Conclusions}

We conclude that involvement of members of the regular hospital staff in the process of developing and implementing a new program of surgical patient education was only partly successful. The scope of the new program was limited because we did not succeed to establish each improvement of patient education which was desirable considering the shortcomings of existing methods of surgical patient education. During the development process, some of the improvements proposed were not perceived as feasible by some of the staff members. In particular physicians were reluctant to implement particular measures because of time constraints and insufficient motivation. Further, the extent to which the new program was implemented by staff members was limited. Indications were found that not all conditions for successful adoption of an innovation like the new program of surgical patient education were met adequately (e.g. incomplete compatibility between the new program and in particular physicians' professional needs and values, and participation in the process was insufficiently rewarding because of its long duration). Finally, our efforts to increase patients' level of perceived control may have been to timid. Since it was attempted to prevent undesirable consequences among patients predisposed with low needs of control, care was taken not to thrust information upon them that was meant to enhance control (e.g. asking questions, breathing deeply, etc.). However, this may have had the effect of putting barriers in the way of obtaining information for those who may have had higher control needs that might have been satisfied by this information.

These shortcomings of the new program in scope and in implementation were reflected by the results of the evaluation of its implementation. The amount of information received 
by patients from all preoperative sources which were addressed by the program, was increased after its implementation. Also, some of the information from written and oral sources was evaluated more positively after implementation. However, when comparisons were limited to information provided to patients from sources which were available both before and after implementation of the program, no increase was obtained in the amount of information received after implementation.

Although the program's effects on patients' physical recovery from surgery and psychological well-being were limited (reduced length of stay, earlier resumption of leisure activities, reduced need for information about admission and surgery, and among traditional cholecystactomy patients more adequate use of sleep medication), we conclude that surgical patient education provided by regular hospital staff members can be effective. That the effects were only slight, may have been caused by the shortcomings of the new program and by shortcomings of the circumstances in which it was developed and implemented, as we have mentioned above. Despite our suggestion that the manipulation of perceived control was weak, the results of study 2 revealed that to some extent perceived control served as a mediating variable that was responsible for these positive effects. This suggests that, according to this study, even a moderate increase of perceived control can have significant positive effects on recovery after surgery. However, irrespective of its effect on perceived control, the improved program of patient education was shown to play an independent role as well. Further research is required to assess more adequately the impact of perceived control on patients' recovery and psychological well-being and to improve understanding of the mechanisms involved.

With respect to the involvement of hospital staff members, we conclude that close cooperation with members of all disciplines involved in treatment and care of surgical patients is a prerequisite for developing and implementing a program of surgical patient education. However, it is important to have and to keep them sufficiently motivated to contribute to measures of patient education. This requires that the development process fulfills all conditions which enhance adoption and diffusion of an innovation like a new program of patient education. Thus, among other conditions described by Rogers (1962) and Zaltman, et al. (1973), the process should be compatible with their needs and values. This requires adequate exploration of staff members' expectations regarding the opportunities for conducting patient education, its benefits and their personal contribution to educational tasks, in order to identify both opportunities and limitations to improve patient education.

Since the study also demonstrated the difficulties to meet these requirements adequately, it seems likely that relatively much energy will be needed and much time will elapse before staff members are sufficiently motivated and equipped to provide ideal surgical patient education. However, since many experimental studies clearly demonstrated the beneficial effects of psychoeducational interventions on surgical patients' recovery and well-being, application of such interventions in everyday practice of hospitals should not be postponed much longer. Therefore, provisionally, we suggest to appoint 'special' staff members who lend an ear to patients and who provide them with appropriate information and behavioral and cognitive instructions. In the field of care for patients with chronic diseases, examples are available of staff members, usually nurses, with specialized tasks 
for treatment, care and education of patients with - for example - diabetes or CARA (Ballekom van de Ven, van Esveld-Plugge, Euverman, Fahrenfort, Houtsma, Huising, Koster, Maris \& Vahl, 1991). These staff members should be appropriately motivated and trained with respect to sensitiveness for surgical patients' needs for information.

\section{References}

Anderson, E.A. (1987),

Preoperative preparation for cardiac surgery facilitates recovery, reduces psychological distress and reduces the incidence of acute postoperative hypertension, Journal of Consulting and Clinical Psychology, 55, 513-520.

Andrew, J.M. (1970),

Recovery from surgery, with and without preparatory information for three coping styles, Journal of Personality and Social Psychology, 15, 223-226.

Arntz, A., Schmidt, A.J.M. (1989),

Perceived control and the experience of pain, in: Steptoe, A., Appels, A. (eds.), Stress, Personal Control and Health, New York, Wiley.

Auerbach, S.M. (1989),

Stress management and coping research in the health care setting: an overview and methodological commentary, Journal of Consulting and Clinical Psychology, 57, 388-395.

Ballekom-van de Ven, K.P. van (1994),

Patient education in hospitals, A review of the effectiveness of health education and health promotion, Utrecht, The Netherlands, Landelijk Centrum GVO.

Ballekom-van de Ven, K.P. van, Esveld van-Plugge, K., Euverman, D., Fahrenfort, M., Houtsma, M., Huising, A., Koster, S., Maris, G., Vahl, L. (1991),

Handboek Coördinator, Patiëntenvoorlichting, Utrecht, The Netherlands, Nationaal Ziekenhuisinstituut, Landelijk Centrum Gezondheidsvoorlichting en -opvoeding.

Breemhaar, B., Visser, A.Ph., Kleijnen, J. (1990),

Perceptions and behavior among elderly hospital patients: description and explanation of age differences in satisfaction, knowledge, emotions and behaviour, Social Science and Medicine, 31, 1377-1385.

Borne, H.W. van den, Pruyn, J.F.A. (1985),

Lotgenotencontact bij kankerpatiënten, Van Gorcum, Assen.

Borne, H.W. van den, Pruyn, J.F.A., Meij, K. de (1986),

Help given by fellow patients, in: Stoll, B.A. (ed.), Coping with Cancer Stress, Dordrecht, The Netherlands, Martinus Nijhoff.

Bunzel, B., Grundböck, A. (1990),

Die Kontrollüberzeugung und ihre Beziehung zum Operationserfolg bei Herztransplantationen, Prävention, 13, 41-44.

Cochran, T.M. (1984),

Psychological preparation of patients for surgical procedures, Pat. Ed. Couns., 5, 153-158. 
Cohen, F. (1975),

Psychological preparation, coping and recovery from surgery, Dissertation Abstracts International, 37, 454b, California.

DeLong, R.D. (1971),

Individual differences in patterns of anxiety, arousal, stress relevant information and recovery from surgery, Dissertation Abstracts International.

Devine, E.C. (1992),

Effects of psychoeducational care for adult surgical patients: a meta-analysis of 191 studies, Patient Education and Counseling, 19, 129-142.

Devine, E.C., O'Connor, F.W., Cook, T.D., Wenk, V.A., Curtin, T.R. (1988),

Clinical and financial effects of psychoeducational care provided by staff nurses to adult surgical patients in the post-DRG environment, American Journal of Public Health, 78, 1293-1297.

Dumas, T.G., Johnson, B.A. (1972),

Research in nursing practice: a review of five clinical experiments, International

Nursing Studies, 9, 137-149.

Eisendraht, S.J. (1987),

Issues of control in the general hospital setting, International Journal of Psychosomatics, 34, 3-5.

Euverman, M., Fahrenfort, M., Huising, S. (1991).,

Handboek coördinator patiëntenvoorlichting, Utrecht, The Netherlands, Nationaal

Ziekenhuis Instituut/Landelijk Centrum GVO.

Fahrenfort, M. (1990),

Patient education in Dutch hospitals: The fruits of a decade of endeavors, Patient

Education and Counseling, 15, 139-150.

Folkman, S. (1984),

Personal control and stress and coping processes: A theoretical analysis, Journal of

Personality and Social Psychology, 46, 839-852.

Folkman, S., Lazarus, R.S. (1980),

An analysis of coping in a middle-aged community sample, Journal of Health and

Social Behavior, 21, 219-239.

Folkman, S., Lazarus, R.S. (1985),

If it changes it must be a process: Study of emotion and coping during three stages of a college examination, Journal of Personality and Social Psychology, 48, 150-170.

Folkman, S., Lazarus, R.S., Dunkel-Schetter, C., DeLongis, A., Gruen, R.J. (1986),

Dynamics of a stressfull encounter: Cognitive appraisal, coping and encounter outcomes, Journal of Personality and Social Psychology, 50, 992-1003.

Folkman, S., Lazarus, R.S., Gruen, R.J., DeLongis, A. (1986),

Appraisal, coping, health status and psychological symptoms, Journal of Personality and Social Psychology, 50, 571-579.1.

Francissen, P. (1995),

Nieuwe wet stelt patiënt centraal, Tijdschrift voor Gezondheidsvoorlichting, 12, 4, $2-5$. 
Hartsfield, J., Clopton, J.R. (1985),

Reducing pre surgical anxiety: a possible visitor effect, Social Science and Medicine 20, 529-533.

Hathaway, D. (1986),

Effect of preoperative instruction on postoperative outcomes: a meta-analysis, Nursing Research, 35, 269-275.

Horne, D.J. de L., Vatmanidis, P., Careri, A. (1994),

Preparing patients for invasive medical procedured 1: Adding behavioral and cognitive interventions, Behavioral Medicine, 20, 5-13.

Johnson, J.E., Rice, V.E., Fuller, S.S., Endress, M.P. (1978),

Sensory information, instruction in a coping strategy and recovery from surgery, Research in Nursing and Health, 1, 4-17.

Johnson, J.E., Leventhal, H. (1974),

Effects of accurate expectations and behavioral instructions on reactions during a noxious medical examination, Journal of Personality and Social Psychology, 29, 710-718.

Johnston, M. (1988),

Impending surgery, in: Fisher, S., J. Reason, (eds.), Handbook of life stress, cognition and health, Wiley \& Sons.

Johnston, M., Vögele, C. (1993),

Benefits of psychological preparation for surgery: a meta-analysis, Annals of Behavioral Medicine, 15, 245-256.

Johnston, M., Carpenter, L. (1980),

Relationship between pre-operative anxiety and post-operative state, Psychological Medicine, 10, 361-367.

Kendall, P.C., Epps, J. (1990),

Medical treatments, in: M. Johnston and L. Wallace (eds), Stress and Medical

Procedures, Oxford Medical Publications, Oxford.

Kincey, J., Saltmore, S. (1990),

Surgical treatments, in: M. Johnston and L. Wallace (eds), Stress and Medical

Procedures, Oxford Medical Publications, Oxford.

Klos, D., Cummings, J., Joyce, J., Graichen, J., Quigly, A. (1980),

A comparison of two methods of delivering presurgical instructions, Patient Education and Counseling, 6-13.

Kok, G.J. (1988),

Health motivation: health education from a social psychological point of view, in:

Maes, S., C.D. Spielberger, P.B. Defares, I.G. Sarason (eds.), Topics in Health Psychology, John Wiley \& Sons, New York.

Krause, N., Stryker, S. (1984),

Stress and well-being: the buffering role of locus of control beliefs, Social Science and Medicine, 18, 783-790.

Krupat, E. (1986),

A delicate imbalance, Psychology Today, november, 22-26. 
Langer, E.J., Janis, I.L., Wolfer, J.A. (1975),

Reduction of psychological stress in surgical patients. J. o. Experimental Psychology, 155-165.

Lazarus, R.S. (1993),

Coping theory and research: past, present, and future, Psychosomatic Medicine, 55, 234-247.

Lazarus, R.S., Folkman, S. (1984),

Coping and adaptation, in: Doyle-Gentry, W. (ed.), Handbook of Behavioral Medicine, Guilford Press, New York.

Lazarus, R.S., Folkman, S. (1987),

Transactional theory and research on emotions and coping, European Journal of Personality, 1, 141-169.

Lazarus, R.S., Launier, R. (1978),

Stress-related transactions between person and environment, in: Pervin, L.A., M.

Lewis, (eds.), Perspectives in interactional psychology, Plenum, New York.

Leenen, H.J.J. (1995),

Invoering WGBO, Conceptie, groei en geboorte, Medisch Contact, 50, 413-414.

Lipsey, M.W., Wilson, D.B. (1992),

The efficacy of psychological, educational, and behavioral treatment: confirmation

from meta-analysis, American Psychologist, 48, 1181-1209.

Mathews, A., Ridgeway, V. (1981),

Personality and surgical recovery: a review, British Journal of Clinical Psychology, 20, 243-260.

Mathews, A., Ridgeway, V. (1984),

Psychological preparation for surgery, in: Steptoe A. Mathews A., Health Care and Human Behaviour, Academic Press, New York.

Martelli, M.F., Auerbach, S.M., Alexander, J., Mercuri, L.G. (1987),

Stress management in the health care setting, matching interventions with patient coping styles, J. Consulting and Clinical Psychology, 55, 201-207.

McCullough, C., Boggs, B.J., Varner, B.J., (1980),

Implementation of educational programs for patients, Nursing Administration

Quarterly, 4, 61-68.

Miller, S.M., Coombs, C., Stoddard, E. (1989),

Information. coping and control in patients undergoing surgery and stressful medical procedures, in: Steptoe, A., Appels, A., (eds.), Control and Health, New York, Wiley.

Miller, S.M., Mangan, C.E. (1983),

Interacting effects of information and coping style in adapting to gynaecologic stress: should the doctor tell all?, J. of Personality and Social Psychology, 45, 223-236.

Mills, T., Krantz, D.S. (1979),

Information, choice and reacting to stress, a field experiment in a blood bank with a laboratory analogue, $J$. of Personality and Social Psychology, 37, 608-620. 
Morris, J., Royle, G.T. (1988),

Offering patients a choice of surgery for early breast cancer; A reduction in anxiety and depression in patients and their husbands, Social Science and Medicine, 26, 583-585.

O'Connor, F.W., Devine, E.C., Cook, T.D., Wenk, V.A., Curtin, T.R. (1990),

Enhancing surgical nurse's patient education: development and evaluation of an intervention, Patient Education and Counseling, 16, 7-20.

Orlandi, M.A., Landers, C., Weston, R., Haley, N. (1990),

Diffusion of health promotion innovations, in: Glanz, Lewis, Rimer, (eds), Health behavior and health education theory, Jossey Bass.

Partridge, C., Johnston, M. (1989),

Perceived control of recovery from physical disability: Measurement and prediction,

British Journal of Clinical Psychology, 28, 53-59.

Picket, C., Clum, G.A. (1982),

Comparative treatment strategies and their interaction with locus of control in the reduction of postoperative pain and anxiety, J. o. Counseling and Clinical Psycholo$g y, 50,439-441$.

Ray, C. (1982),

The surgical patient: psychological stress and coping resources, in: Eiser, J.R. (ed.)

Social psychological and Behavioral Medicine, Wiley, New York.

Ray, C., Fitzgibbon, G. (1981),

Stress, Arousal and coping with surgery, Psychosomatic Medicine, 11, 741-746.

Redman. B.K. (1981),

Patient Fducation in Hospitals: Developmental Issues, Journal of Nursing Administration, September, 28-30.

Rogers, E. (1983),

Diffusion of innovations, third edition, New York, The Free Press.

Rogers, M., Reich, P. (1986),

Psychological intervention with surgical patients: evaluation outcome, Advances in

Psychosomatic Medicine, 15, 23-50.

Rotter, J.B. (1966),

Generalized expectancies for internal vs. external control of reinforcement, Psychological Monographs, 80, 1-28.

Ruzicki, D.A. (1985),

Motivating patient care staff to teach: a plan for action, in: American Hospital Association Media Center, Surgical patient education does make a difference, Live Interactive Satellite Video Teleconference.

Sälmon, P. (1992),

Psychological factors in surgical stress: implications for management, Clinical Psychology Review, 12, 681-704.

Salo, M. (1982),

Endocrine responses in anesthesia and surgery, in: Watkins, J., M. Salo (eds.) Trauma, stress and immunity in anesthesia and surgery, Butterworth, London. 
Schultheis, K., Peterson, L., Selby, V. (1987),

Preparation for stressful medical procedures and person $\mathrm{x}$ treatment interactions, Clinical Psychology Review, 7, 329-352.

Scott, L.E., Clum, G.A. (1984),

Examining the interaction effects of coping style and brief interventions in the treatment of post surgical pain, Pain, 20, 279-291.

Syme, S.L. (1989),

Control and health: a personal perspective, in: A. Steptoe, A. Appels (eds.), Stress, Personal Control and Health, Wiley, New York.

SIG (1993),

Jaarboek Ziekenhuizen, Kliniek, Dagverpleging en Polikliniek, Utrecht, The Netherlands.

Strickland, B.R. (1978),

Internal-external expectancies and health related behavior, Journal of Consulting and Clinical Psychology, 46, 1192-1211.

Suls, J., Wan, C.K. (1989),

Effects of sensory and procedural information on coping with stressful medical procedures and pain: a meta-analysis, J. o. Consulting and Clinical Psychology, 57, 372-379.

Swinkels, M.A.A. (1990),

Eerder thuis, beter af? Proefschrift, Rijksuniversiteit Leiden, The Netherlands.

Taylor, S.E. (1991),

Health Psychology, New York, Random House.

Taylor, S.E. (1979),

Hospital patient behavior: reactance, helplessness or control?, J.o. Soc.Iss. 35 . 156-184.

Taylor, S.E., Clark, L.F. (1986),

Does information improve adjustment to noxious medical procedures?, in: M.J.

Saks and L. Saxe, Advances in Applied Social Psychology, vol 3, Lawrence Erlbaum Associates, New Jersey.

Thompson, S.C., Cheek, P.R., Graham, M.A. (1987),

The other side of perceived control: disadvantages and negative effects, in:

Spacapan, S., Oskamp, S, (eds.), The Social Psychology of Health, The Claremont Symposium of Applied Social Psychology, Sage, Beverly Hills.

Tweede Kamer (1981-1982),

Motie Wessels-Tuinstra, 16771.

Ten Have, H. (1988),

Patiëntenvoorlichting in een ethisch kader, in : Damoiseaux, V., Visser, A.Ph., (eds.), Patiëntenvoorlichting, Een interdisciplinaire benadering, Assen, The Netherlands, Van Gorcum.

Visser, A.Ph. (1986),

Patiënt in het ziekenhuis, Van Gorcum, Maastricht.

Voorn, Th. (1995),

De WGBO in de praktijk, Medisch Contact, 50, 13, 415-416. 
Wallace, L.M. (1986),

Informed consent to elective surgery: the 'therapeutic' value?, Social Science and Medicine, 22, 29-33.

Wallace, L.M. (1985),

Surgical patients' preferences for pre-operative information, Patient Education and Counseling, 7, 377-387.

Wallston, K.A., Wallston, B.S., Smith, S., Dobbins, C.J. (1987),

Perceived control and health, Current Psychological Research and Review, 6, 5-25. Wallston, K.A. (1989),

Assessment of control in health-care settings, in: Steptoe, A., Appels, A., Stress, Personal Control and Health, New York, John Wiley and Sons.

Webber, G.C. (1990),

Patient education, a review of the issues, Medical Care, 28, 1089-1103.

Weinman, J., Johnston, M. (1988),

Stressful medical procedures: an analysis of the effects of psychological interventions and the stressfulness of the procedure, in: Maes S. et. al. (red.), Topics in Health Psychology, Wiley, New York.

Williams, J., Workhoven, J., Williams, B. (1975),

The psychological control of preoperative anxiety, Psychofysiology., 12, 50-54.

Wilson-Barnett, J. (1984),

Alleviating stress for hospitalized patients, International Review of Applied Psychology, 33, 493-503.

Wilson-Barnctt, J. (1994),

Preparing patients for invasive medical ans surgical procedures 3: Policy implications for implementing specific psychological interventions, Behavioral Medicine, $20,23-26$.

Wilson, J.F. (1981),

Behavioral preparation for surgery: benefit or harm?. J.o. Behavioral Medicine 4, 79-102.

Zaltman, G., Duncan, R., Holbek, J. (1973), Innovations and Organizations, London, John Wiley \& Sons. 
 \\ Effects of psychoeducational interventions in relation to abdominal surgical patients' preoperative fear, coping strategies and perceived control'}

B. Breemhaar ${ }^{2}$, H.W. van den Borne ${ }^{3}$, P.D. Mullen $^{4} 5$

\section{$2.1 \quad$ Introduction}

High levels of preoperative stress among patients before and after admission into hospital and during presurgical preparation, have been shown to be positively associated with debilitated psychological adjustment, medical complications and slow speed of physical recovery after surgery (Taylor, 1991; Auerbach, 1989). To reduce stress and to promote psychological well-being and physical recovery, several interventions have been developed to prepare patients for surgery. Most evaluations of these interventions generally show positive results. However, the effectiveness of different psychoeducational interventions is not always equal and appears to vary across outcome variables and individual patients.

In this article, we provide a brief overview of the effectiveness of various interventions that have been employed to prepare patients for surgery, together with a discussion of limitations of current knowledge. The issue of differential effects of presurgical preparation among patients who differ in preoperative fear, coping and perceived control is

1 This study was made possible by a grant from the Dutch Pracventic Fonds, projectnumber: 26-20.

2 Drs. B. Breemhaar is researcher at IVA, Institute for Social Research, Tilburg, The Netherlands.

3 Dr. H.W. van den Borne is professor of Patient Education at the Dept. of Health Promotion of the University of Limburg, Maastricht, The Netherlands.

4 Dr. P.D. Mullen is Professor of Behavional Science and Health Education and Deputy Director, Center for Health Promotion Research and Development, University of Texas, School of Public Health, Houston, Texas, USA.

5 The authors gratefully acknowledge the assistance from Mr. Joop van Poppel and Mrs. Trijnie Horlings in searching the literature. 
addressed by presenting the results from a review of studies that investigated this interaction.

\subsection{Intervention methods}

Interventions to limit stress among surgical patients and to promote psychological wellbeing and physical recovery after surgery, can be divided into three categories (Devine, 1992; Kincey \& Saltmore, 1990; Devine \& Cook, 1986; Williams \& Kendall, 1985; Mathews \& Ridgeway, 1984; Cochran, 1984). First, patients may be supplied with information about events that will take place before and after surgery (procedural information) and about physical sensations and emotions likely to be caused by these procedures (sensory information; Suls \& Wan, 1989; Taylor \& Clark, 1986). Second, patients may be instructed and motivated to perform behaviors which facilitate physical recovery and psychological well-being. Examples are preoperatively refraining from smoking, postoperative coughing and deep breathing to enhance restoration of pulmonary functioning, relaxation instructions to relieve postoperative pain, bodily exercises to prevent postoperative thrombosis and asking questions to staff members. Instructions aimed at restructuring patients' cognitions in order to promote adequate coping and reduce stress, have been subsumed into this category as well, like systematic desensitization (Huber, 1986), pleasant imagery (Quinn, 1986) and stress inoculation (Wells, Howard, Nowlin \& Vargas, 1986). These particular interventions also have been termed "cognitive coping" or "cognitive restructuring". Third, psychotherapeutic approaches have been employed in which patients are encouraged to express feelings concerning surgery, are given reassurance or, in group sessions, react to other patients' feelings and help one another. These three approaches are not always mutually exclusive, while various combinations of these measures have been employed as well. Usually, the interventions are provided to individual patients prior to surgery, before or shortly after admission into the hospital.

Several review studies which summarized the results of investigations evaluating the effects of methods to prepare patients for surgery, employed meta-analysis (Lipsey \& Wilson, 1993; Johnston \& Vögele, 1993; Devine, 1992; Devine \& Cook, 1986; Hathaway, 1986; Mumford, Schlesinger \& Glass, 1982). Others offered more descriptive reviews (Horne, Vatmanidis \& Careri, 1994; Webber, 1990; Weinman \& Johnston, 1988; Rogers \& Reich, 1986; Mathews \& Ridgeway, 1984; Cochran, 1984). Overall, these studies conclude that presurgical psychoeducational preparation of patients is an effective means to reduce patients' psychological distress, pain and to improve recovery from surgery. In the next section, we will explore these studies more closely, in order to find out the effectiveness of different types of preparation methods. 


\subsection{Effectiveness of different interventions}

Johnston \& Vögele (1993) conducted a meta-analysis of 38 studies employing a control group with random assignment. They included studies that evaluated the following interventions, separately or in combinations: procedural information, sensory information, behavioral instruction, cognitive restructuring, relaxation, hypnosis and emotion focussed interventions. They concluded that all outcomes studied (negative affect, pain, pain medication, length of stay, behavioral and clinical recovery, physiological indices, and patient satisfaction) were beneficially and significantly affected by presurgical preparation. They found the most straightforward results with respect to procedural information and behavioral instructions, including relaxation. The effects of cognitive restructuring were restricted to negative affect, pain, pain medication, and clinical recovery. Finally, small effects were obtained by sensory information, hypnosis and emotion focussed interventions.

Behavioral instructions and cognitive restructuring With respect to the effectiveness of behavioral instructions, the conclusions drawn by earlier reviews do not consistently correspond with those of Johnston \& Vögele (1993). Mathews \& Ridgeway (1984) discussed the results of a limited number of evaluation studies that met rigorous methodological criteria (random assignment and attention control groups). They concluded that behavioral instructions are relatively successful to promote psychological well-being and recovery from surgery (see also Weinman \& Johnston, 1988). However, contrary to Johnston \& Vögele's conclusions, they considered cognitive restructuring or "coping" methods as most effective. Also, Cochran (1984), following a discussion of early preparation studies, claimed cognitive coping strategies to be most effective. More recently, Salmon (1992) mentioned six studies evaluating the effectiveness of various techniques of cognitive restructuring among surgical patients that found reduction in psychological distress and pain and an improvement of recovery.

Reviews of studies conducted among the wider population of patients undergoing stressful medical procedures found evidence for the effectiveness of both behavioral instructions and restructuring cognitions as well (Kendall \& Epps, 1990; Miller, Coombs \& Stoddard, 1989; Schultheis, Peterson \& Selby, 1987; Kendall \& Watson, 1981). Most of them however, did not distinguish consequently between cognitive restructuring and behavioral instructions and often subsumed both under the heading of "coping" or "cognitivebehavioral" interventions. Therefore, often it is not clear which part of the effectiveness of these interventions should be attributed to behavioral instructions or to cognitive restructuring.

Information Hathaway (1986) subjected studies evaluating preoperative preparation methods to meta-analysis and, like Johnston \& Vögele (1993), found procedural information to be superior to sensory information. It should be noted however that only two studies were included in Hathaway's study evaluating sensory information only. On the other hand, Salmon (1992) found procedural information to be of little value among surgical patients, while he regarded sensory information more effective, with or without 
the combination with procedural information. Mathews \& Ridgeway (1984) also concluded that sensory information seemed more effective among surgical patients than procedural information. Reviews of studies among patients undergoing stressful medical procedures found sensory information to be superior to procedural information (Kendall \& Epps, 1990; Miller, et al., 1989; Schultheis, et al., 1987). Some concluded that a combination of both types appeared to be most effective (Suls \& Wan, 1989; Taylor \& Clark, 1986).

Psychotherapeutic interventions Cochran (1984) examined studies evaluating interventions in which patients were visited preoperatively by hospital staff members and were given reassurance, with or without providing procedural and/or sensory information. She considered its effects primarily to be caused by the information conveyed, and concluded that a general caring and reassuring attitude seems insufficient. Mathews \& Ridgeway (1984) reviewed the findings from five studies evaluating provision of emotional support and non-directive discussion of patients' worries. Although a few benefits were found in some of them, according to Mathews and Ridgeway it was often unclear whether they were the consequence of the psychotherapeutic modality of the interviews, rather than of factual information or behavioral instructions conveyed during the interviews as well (see also Rogers \& Reich, 1986). Rogers \& Reich (1986) mentioned several studies that demonstrated the effectiveness of hypnosis to relieve postoperative pain, although negative results have been obtained with hypnosis as well (Kendall \& Epps, 1990). Also, among patients undergoing stressful medical procedures, little evidence has been found for the beneficial effects of psychotherapeutical interventions (Kendall \& Epps, 1990; Anderson \& Masur, 1983; Kendall \& Watson, 1981).

\subsection{Limitations of current knowledge}

It remains unclear which interventions are, and which are not effective with regard to particular outcomes and which of them is most effective (Weinman \& Johnston, 1988). Although some authors claimed that the combination of particular interventions from different modalities is more effective than single interventions (Kincey \& Saltmore, 1990), the evidence supporting this claim is not unequivocal. Finally, it has been found repeatedly that the effectiveness of interventions interacts with patient characteristics. However, explanations of the interaction effects are inconclusive. In the following we will elaborate on each of these issues.

\section{Specific and relative effectiveness of interventions}

Most reviews of studies evaluating presurgical preparation were dedicated primarily to the question whether recovery from surgery could be improved by psycho-educational interventions, without paying attention to the question of differential effectiveness. For example, Devine's (1992) and Devine \& Cook's (1986) meta-analyses were restricted to overall effects obtained on various outcome variables and did not differentiate among interventions. Rogers \& Reich (1986) described results of psychological interventions 
(information provision, hypnosis, relaxation, and psychotherapy) among surgical patients with respect to various physical, physiological, and psychological measures, but they did not show systematically which interventions affected particular outcomes, and which did not. Also, Hathaway (1986), computed effect sizes for types of presurgical interventions and types of outcome measures, but offered no information about the: interaction between these two. Thus, the questions which outcome variables are most likely to be affected by a particular intervention, and which intervention is relatively successful to affect a particular outcome variable remain to be answered.

Johnston \& Vögele (1993) attempted to provide a solution to this issue. In their metaanalysis described above, they examined if, and to what extent particular outcome variables were differentially affected by presurgical interventions. In addition, based on binomial tests, they indicated the particular interventions that contributed significantly to the effects found for each variable. Although the results offer a general picture of the relative success of various interventions (see above), the authors consider firm conclusions unwarranted about the relative success of the interventions in improving particular outcomes. Their reluctance was based on the sometimes arbitrary grouping of the interventions that were employed in the selected studies, and because effect sizes could only be calculated in a minority of cases. Further, studies included in their analysis that shared a common intervention approach tended to assess divergent outcome measures, preventing a systematic comparison of the interventions' effects on similar outcomes.

Kincey \& Saltmore (1990) also observed this lack of knowledge about the match between interventions and outcomes and about the relative effectiveness of interventions. Admitting its difficulty, they recommended study designs that compare different interventions, alone and in combination, with an (attention) control group, against a complete set of valid indicators of outcome. Interpretation of the results of such studies should take into consideration the independence of various indicators of recovery, causing an intervention to be effective with respect to some indicators, while it is not to others (Johnston \& Vogele, 1993; Salmon, 1992; Johnston, 1984). Current data do not allow such an analysis, since the interventions evaluated and the outcomes measured vary strongly, in a non-systematic pattern (O'Halloran \& Altmaier, 1995; Johnston \& Vögele, 1993). Moreover, the interventions employed have not always been described in adequate detail that would permit proper classification (Johnston \& Vögele, 1993; Schultheis, et al., 1987).

\section{Combined interventions}

A large number of studies have evaluated combinations of two or more types of interventions. Most of these studies combined information provision with an alternative preparation method. For example, Wilson (1981) evaluated information, both procedural and sensory, and relaxation instructions, both separately and in combination. Langer, Janis \& Wolfer (1975) evaluated information provision and a cognitive reappraisal intervention, also both separately and in combination. A final example is a study by Schmitt \& Wooldridge (1973) that evaluated an intervention consisting of a group meeting of surgical patients prior to their operation, supervised by a nurse, in which patients received information and behavioral instructions and exchanged personal concerns about surgery. 
Meta-analyses have repeatedly reported larger effect sizes among studies combining two or more interventions than among studies evaluating single interventions (Devine, 1992; Kincey \& Saltmore, 1990; Hathaway, 1986; Mumford et al., 1982). However, interpretation of this finding is not straightforward, since often it is not clear whether an intervention should be classified as "single" or as "combined". In particular, single interventions often incorporate elements from different intervention types (Rogers \& Reich, 1986). For example, sensory information inevitably contains some procedural information as well. Also, provision of behavioral instructions is almost impossible without providing some procedural and sensory information. This impossibility of conducting an intervention to prepare patients for surgery without provision of information, may explain why combined interventions have always incorporated information. As a consequence, conclusions about the relative effectiveness of single and combined interventions seem premature.

This ambiguity concerning the exact content of interventions also complicates drawing conclusions about the relative effectiveness of single interventions. Among the studies reviewed by Johnston \& Vögele (1993), some evaluated a combined intervention while the elements constituting the combination could not be separated (for example: HoldenLund, 1988; Boore, 1978; Hayward, 1975; Lindeman \& Stetzer, 1973; Schmitt \& Wooldridge, 1973), casting doubt on their conclusions about the effectiveness of particular interventions.

\subsection{Interaction with patient characteristics}

It is as yet unclear whether certain interventions have detrimental effects on the attempts of particular individuals to cope with the stresses of surgery (Kincey \& Saltmore, 1990). However, increased knowledge of patient characteristics that interact with specific preparation methods may help to improve the effectiveness of these methods (O'Halloran \& Altmaier, 1995; Salmon, 1992; Hathaway, 1986) or to enhance a more self-determined choice by surgical patients of interventions potentially available (Rogers \& Reich, 1986). For example, patients differ to the extent in which they experience preoperative fear. A reversed linear relationship has repeatedly been demonstrated between on the one hand preoperative fear and state anxiety and on the other postoperative physical recovery and psychological well-being (Auerbach, 1989; Martelli, Auerbach, Alexander \& Mercury, 1987; Jamison, Parris \& Maxson, 1987; Mathews \& Ridgeway, 1981; Ray \& Fitzgibbon, 1981; Reading, 1979; Sime, 1976; Auerbach, 1973; Johnson, Leventhal \& Dabbs, 1971;), although these findings have not been consistent (Wallace, 1986; Johnston \& Carpenter, 1980; Bruegel, 1971). The effects of presurgical preparation have been found to vary with level of preoperative fear. Some studies provide evidence that surgical patients with high preoperative fear benefit more from presurgical preparation than patients low on preoperative fear (Hathaway, 1986; Mathews \& Ridgeway, 1984), while others have shown the opposite effect (Kincey \& Saltmore, 1990).

Patients also differ in their strategies to cope with the stress caused by hospitalization and surgery. Typical classifications are "avoiders" or "blunters" of information concerning illness and surgery and "sensitizers" or "monitors", who desire to receive detailed 
information (Auerbach, 1989; Miller et al., 1989; Mathews \& Ridgeway, 1981). Most studies have found more successful courses of recovery from surgery among avoiders than among sensitizers (Salmon, 1992; Kaloupek \& Stoupakis, 1985; Mathews \& Ridgeway, 1981; George, Scott, Turner \& Gregg, 1980; Cohen \& Lazarus, 1973). Andrew (1970) on the other hand, found that sensitizers recovered faster than avoiders, while Sime (1976) found no differences. Some studies among patients undergoing various medical procedures demonstrated that sensitizers benefit more from preparation than avoiders (Miller \& Mangan, 1983; Auerbach, Martelli \& Mercury, 1983; Shipley, Butt \& Hortwitz, 1979; Shipley, Butt, Horwitz \& Farbry, 1978; Andrew, 1970).

A final factor of relevance here is perceived control, the belief that one can determine one's own internal states and behavior, influence one's environment, and bring about desired outcomes (Wallston, Walston, Smith \& Dobbins, 1987). Perceived control varies among individuals and within a person from situation to situation and can be considered as a state variable (Wallston, 1989). Although various attempts have been undertaken to assess perceived control (Wallston, 1989; Partridge \& Johnston, 1989), many studies among patients undergoing surgery or alternative stressful medical procedures employed Rotter's I-E Scale of locus of control. According to Rotter (1966) locus of control is a person's generalized expectancy that important outcomes occur as a function of what they do or what they are (internal locus of control) or that these outcomes depend on powerful others or occur randomly (external locus of control). Thus, locus of control is considered a relatively stable personality trait.

Feelings of control can keep stress within bounds and psychological and physical wellbeing at an acceptable level among ill persons (Bunzel \& Grundböck, 1990; Partridge \& Johnston, 1989; Pruyn, van den Borne, de Reuver, de Boer, Bosman, ter Pelkwijk \& de Jong, 1988; Marks, Richardson, Graham \& Levine, 1986), among chronic pain patients (Arntz \& Schmidt, 1989) and among healthy persons (Krause \& Stryker, 1984; Mills \& Krantz. 1979). Taylor (1991) concluded that enhancing surgical patients' level of perceived control by providing them preoperatively with information or cognitive reappraisal training, improves adjustment to surgery. A high level of perceived control does not always seem beneficial, however (Thompson, Cheek \& Graham, 1987). Johnson, Leventhal \& Dabbs (1971) demonstrated that surgical patients with an internal locus of control used more analgesics after surgery and stayed in the hospital longer than external patients, although these are not necessarily negative outcomes. Further, Clum, Scott \& Burnside (1979) found no differences between surgical patients with an internal and patients with an external locus of control in pain, use of analgesics, postoperative complaints and length of stay. However, 'internals' who sought out much information preoperatively exhibited a significantly stronger relationship between postoperative pain and analgesic use than 'internals' who had sought out little information. Among 'externals' the relationship between pain and use of analgesics was not affected by preoperative information. According to Clum et al. (1979) their findings reflect the internal patients' attempts to employ their knowledge to improve their situation, albeit rather unsuccessfully, since increased use of analgesics was not accompanied by less pain. Perceived control has been shown to affect the effectiveness of presurgical preparation (Rice, 1982; Padilla, et al. 1981; Auerbach, Kendall, Cuttler \& Levitt, 1976). In general, patients with an 
internal locus of control appear to benefit more from preparation than patients with an external locus of conmol (Auerhach, 1989; Schultheis, et al., 1987).

\subsection{Literature review}

To obtain a more conclusive picture of the effectiveness of presurgical preparation among patients differing in preoperative fear, coping and perceived control, we performed an additional review of the literature. Since this review was carried out to prepare an empirical investigation of the effectiveness of psychoeducational interventions among patients undergoing herniorrhaphy or cholecystectomy, it was restricted to studies conducted among patients of whom the majority underwent abdominal surgery.

\section{Method}

Relevant studies were identified by a computer search performed in October 1993, on the stocks of Embase, Medline, Psychinfo, Socscisearch and Nursing and Allied Health. Word entries were "patient education", "patient communication", "patient information", "health education", "psychological preparation", "psychological intervention", "psychoeducational intervention". "surgery", "operation", "abdominal surgery" and combinations of these. No exclusion was made on year of publication. In addition to this procedure, bibliographies of reviews and other relevant articles were scanned for references on evaluation of presurgical preparation and related studies. To be included in our sample, a study had to meet the following criteria: a) inclusion of a control group, b) more than $50 \%$ of the subjects studied underwent abdominal surgery, c) adequate description of treatments, mediating and dependent variables and results, measurement of preoperative fear, coping or locus of control, and e) publication in a journal in English, Dutch or German language.

\section{Results}

Preoperative fear Five studies were found that measured preoperative fear (see appendix 2.1). One of them (Wilson, 1981) measured preoperative fear by means of a three item scale. Klos \& Cummings (1980) and Johnson, Rice, Fuller \& Endress (1978) employed a sub scale of the Multiple Adjective Checklist (Radloff \& Helmreich, 1968). One study (Dumas \& Johnson, 1972) employed a retrospective measure of presurgical distress, asking patients post operatively to describe how they had felt before surgery. Finally, Williams, Workhoven \& Williams (1975) employed the IPAT Anxiety Scale Questionnaire (Cattell \& Scheier, 1963) to assess preoperative anxiety.

Dumas \& Johnson (1972) compared patients in a control group to patients receiving emotional support preoperatively from a nurse to reduce stress. They obtained a negative relationship between preoperative distress and various indicators of postoperative recovery (e.g. vomiting, use of anti-emetics and infections), and no interaction was found between preoperative distress and receipt of emotional support. Williams et al. (1975), found low fear patients to benefit more from an intervention consisting of extended procedural and sensory information and emotional support. Among patients with low fear on the day 
before surgery, those in the intervention condition scored lower on anxiety measured immediately before surgery, compared to those receiving cursory information. Among patients with high fear on the day before surgery, the difference was reversed. Wilson (1981) found comparable results among patients receiving relaxation instructions. Among patients with low preoperative fear, those receiving relaxation instructions had shorter lengths of stay than those in the control group, while high fear patients who received relaxation instructions had longer lengths of stay.

Johnson et al. (1978) studied the effectiveness of procedural information, sensory information and behavioral instructions. Contrary to the previous studies, their results largely indicate that patients with high preoperative fear benefit most from any type of preparation. After surgery, they found among high fear patients that those receiving behavioral instructions showed less negative and more positive moods than those in a control group. Among patients with low preoperative fear it was reversed. Further, among high fear patients, those receiving procedural information showed more positive postoperative moods and less anger and helplessness than those in a control condition. Also, after discharge they left their house sooner. Among patients with low preoperative fear, both groups did not differ or, in the case of leaving their house, those receiving procedural information scored less favorably. Also, among high fear patients, those receiving sensory information demonstrated less negative and more positive moods after surgery than those in the control group. Among patients with low fear, those receiving sensory information did not differ or scored less favorably than the controls. However, diverging from this pattern was the finding that high fear patients receiving procedural information scored similarly on postoperative negative moods and worse on postoperative fear, when compared to those in a control group. Also, low fear patients receiving procedural information showed less postoperative negative moods and similar postoperative fear than those in a control group.

Support for the relatively strong benefits of presurgical preparation among patients with high preoperative fear also was found by Klos et al. (1980). They evaluated the effectiveness of procedural information and behavioral instructions, either written, oral or both. High preoperative fear patients receiving written information and instructions stayed shorter in the hospital, drank sooner after surgery and scored higher on energy-movement and appetite than those in the control condition. Also, high fear patients in any of the experimental conditions took oral medications sooner after surgery than those in the control condition. With respect to all of these outcomes, the results among low fear patients were exactly reversed.

Coping Five studies measured coping (see appendix 2.1). Two of them (Scott \& Clum, 1984; Cohen, 1975) assessed coping by means of a structured interview prior to surgery, and two (Andrew, 1970; DeLong, 1970) by a sentence completion test. One study measured the degree to which patients were disposed to avoid active coping, termed "denial", by means of a three item scale developed by the author (Wilson, 1981).

Wilson (1981) also evaluated relaxation instructions, either alone or in combination with provision of procedural and sensory information, among patients with high or low scores on 'denial'. However, no differences were found between both groups on various indica- 
tors of physical and psychological recovery from surgery. Also, among surgical patients receiving either behavioral instructions, cognitive reappraisal or reassurance, Cohen (1975) found no differences in anxiety, negative psychological symptoms, postsurgical complications, use of analgesics and length of stay between patients classified as "sensitizers", "avoiders" or "neutrals". Andrew (1970) on the other hand, found neutrals to benefit most from preparation. Neutrals receiving procedural information used less post surgical medication and had shorter lengths of stay than neutrals in a control condition. Avoiders on the other hand who received procedural information, used significantly more medications and did not differ in length of stay from those in the control condition. Sensitizers were not affected by procedural information at all. Sensitizers were found to benefit most from preparation in a study by Scott \& Clum (1984). Sensitizers who were offered relaxation instructions prior to surgery experienced less post surgical pain and anxiety than sensitizers in the control group. Avoiders in both conditions did not differ from each other. Finally, DeLong (1970) evaluated detailed procedural information among sensitizers, avoiders and neutrals. Of these three groups, neutrals had the most favorable course of recovery from surgery, irrespective of type of information. Avoiders had the worst course of recovery, also irrespective of information. However, avoiders who received detailed information demonstrated more postoperative complaints than those receiving general information. Among sensitizers, recovery was also dependent on type of information received; those receiving detailed information recovered faster than those who received general information. With respect to sensitizers, these results resemble those of Scott \& Clum (1984).

Locus of control Only two studies were found that assessed locus of control, as an indicator of perceived control (appendix 2.1). Both Pickett \& Clum (1982) and Hartsfield \& Clopton (1985) measured patients' locus of control by means of Rotter's (1966) LOC measure.

Hartsfield \& Clopton (1985) failed to find an interaction between the intervention and locus of control. Pre and post intervention anxiety levels among patients undergoing cholecystectomy with different loci of control were affected similarly by behavioral instructions and reassurance. However, Picket \& Clum (1982) found, also among cholecystectomy patients, that internals benefitted more from preparation than externals. Patients in a cognitive distraction condition demonstrated lower levels of post surgical pain and anxiety, than patients in both a relaxation and a control condition. This effect was stronger among internals than among externals.

\subsection{Discussion}

Several overvicws of studies examining the effects of various interventions to prepare patients for surgery did not differentiate among types of interventions. This omission has made it difficult to draw conclusions about the effectiveness of particular interventions. Others that did discuss the effectiveness of particular interventions, have demonstrated that behavioral instructions, including relaxation, are largely beneficial. Cognitive 
interventions were found to be effective as well. However, some reviewers termed interventions "cognitive" which were attempts to alter patients' behaviors. Therefore, some of the benefits ascribed to cognitive interventions probably should be ascribed to behavioral instructions. With respect to provision of information, most authors found sensory information, alone or in combination with procedural information, to be superior when compared with procedural information alone. Finally, only limited evidence was found supporting the effectiveness of psychotherapeutic approaches to presurgical preparation.

Although relevant from a clinical point of view, the overviews of evaluation studies did not detail systematically the match between interventions and affected outcomes. This is not surprising, since a complete and systematic picture of the effects of each intervention with respect to all relevant outcome variables cannot be constructed from studies currently available. First, outcome measures assessed by studies evaluating a particular intervention vary greatly, preventing systematic comparison of the interventions' effects on similar outcomes. Second, the interventions in many of these studies have been grouped arbitrarily. Finally, the exact content of the intervention evaluated in many studies is not clear. In particular, interventions considered as consisting of only one type of preparation, often incorporate elements from other types. This also hampers examination of the validity of the claim that combined interventions are more effective than single interventions. Assessing the relative effectiveness of different (combinations of) interventions with respect to particular outcomes requires studies that compare different interventions, with an (attention) control group, against a complete set of valid indicators of outcome (Kincey \& Saltmore, 1990).

Results from studies of the interaction of the effectiveness of presurgical preparation with patient characteristics suggest that patients with high preoperative fear, patients coping by means of sensitizing or monitoring, and patients with a high level of perceived control benefit most from preparation interventions. However, since the number of studies that reported results concerning these interactions is low, and because the findings are not straightforward, these conclusions should be treated with caution.

Although not unequivocally, these findings are in line with Miller et al.'s (1989) suggestion that measures to support patients' efforts to cope with undesirable events, should fit their individual coping preferences. They hypothesized that given control options, people are motivated to spend effort to limit the maximum danger of an undesirable event. In the absence of control, efforts to minimize danger are fruitless and persons are likely to stop their efforts and will employ more emotion focused ways of coping. Second, Miller hypothesized that arousal remains high in aversive situations when persons "monitor" the negative aspects of the event, while arousal decreases when they "blunt" these negative aspects. When an aversive event is controllable, monitoring is the main response and receipt of information is preferred, in order to attempt to minimize the danger of the event. When the event is not (longer) perceived as controllable, people usually blunt information about the event, to reduce arousal. In this case individuals reduce stress by engaging in coping techniques that place them, as Miller et al. $(1989$, p. 109) call it, in the presence of "psychological safety signals". However, people differ with respect to the extent that they stop monitoring and start blunting in situations that offer little control. 
Some continue to prefer information about the aversive event, since it places them in the presence of "external" safety signals.

According to Miller et al. (1989), measures to support coping with an undesirable event like surgery should take these individual differences into consideration (see also O'Halloran \& Altmaier, 1995; Kincey \& Saltmore, 1990; Auerbach, 1989; Schultheis et al., 1987; Martelli et al, 1987). For example, avoiders are more likely to blunt information about a threatening event and may be harmed when provided with this type of information, like the patients in Andrew's (1970) study. Similarly, providing behavioral instructions to sensitizers, who are likely to keep monitoring information about the threatening event, may support them to adjust to surgery, as was suggested by Scott \& Clum's (1984) results. On the other hand, Picket \& Clum (1982) found patients with an internal locus of control to benefit more from cognitive distraction than patients with an external locus of control. This would be contrary to Miller et al.'s (1989) predictions, since internals, who are more likely to keep monitoring information about an aversive event, would be expected to prefer information instead of cognitively being "pulled away" from the situation. An alternative interpretation of Picket \& Clum's results, consistent with Miller et al.'s explanation, would be as follows: cognitive distraction was superior to internals' natural, but, in their particular circumstances that afforded little opportunity for active coping, sub optimal coping strategy.

To obtain a more conclusive picture of the effects of psychoeducative interventions to prepare patients for surgery among patients differing in preoperative fear, coping and perceived control, additional research is required. From a clinical point of view, it is important to find out which patients are likely and which are less likely to benefit from particular interventions. This may enlarge the potential benefits of presurgical preparation, in terms of patients' physical recovery, psychological well-being and cost reduction (Wilson-Barnett, 1994). In particular, patients' perceived control seems a crucial explanatory variable, since it has been demonstrated that it may determine patients' preoperative fear and their ways of coping (Breemhaar \& Van den Borne, 1991 (chapter 3)). For the time being, it seems important not to expect presurgical preparation to have similar beneficial effects for all patients. Instead, we believe that sufficient indications are available to recommend employment of preparation interventions that are tailored to individual differences between surgical patients in preoperative fear, coping and perceived control. Apart from the question of differential effects of presurgical preparation among different patients therefore, there is the issue how to select patients suited for particular interventions. This issue should receive proper attention in future studies and field trials, in which cooperation with members from the medical profession seems essential to put current knowledge into practice. 


\section{References}

Anderson, K.O., Masur, F.T. (1983),

Psychological preparation for invasive medical and dental procedures, Journal of

Behavioral Medicine, 6, 1-36.

Andrew, J.M. (1970),

Recovery from surgery, with and without preparatory information for three coping

styles, Journal of Personality and Social Psychology, 15, 223-226.

Arntz, A., Schmidt, A.J.M. (1989),

Perceived control and the experience of pain, in: Steptoe, A., Appels, A. (eds.),

Stress, Personal Control and Health, New York, Wiley. Auerbach, S.M. (1989),

Stress management and coping research in the health care setting: an overview and methodological commentary, Journal of Consulting and Clinical Psychology, 57, 388-395.

Auerbach, S.M., Martelli, M.F., Mercury, L.G. (1983),

Anxiety, information, interpersonal impacts, adjustments to a stressful health care

situation, Personality and Social Psychology, 44, 1284-1296.

Auerbach, S.M. (1973),

Trait-state anxiety and adjustment to surgery, Journal of Consulting and Clinical

Psychology, 40, 264-271.

Auerbach, S.M., Kendall, P.C., Cuttler, H.F., Levitt, N.R. (1976),

Anxiety, Locus of control, Type of preparatory information and adjustment to dental

surgery, J.o. Consulting and Clinical Psychology, 44, 809-818.

Boore, J. (1978),

Prescription for recovery, London, Royal College of Nursing.

Breemhaar, B., Borne, H.W. van den (1991),

Effects of education and support for surgical patients: The role of perceived control,

Patient Education and Counseling, 18, 199-210. Bruegel, M.A. (1971),

Relationship of preoperative anxiety to perception of postoperative pain, Nursing

Research, 20, 26-31.

Bunzel, B., Grundböck, A. (1990),

Die Kontrollüberzeugung und ihre Beziehung zum Operationserfolg bei Herztransplantationen, Prävention, 13, 41-44.

Cattell, R.B., Scheier, I.H. (1963),

Handbook for the IPAT Anxiety Scale Questionnaire, 2nd ed., Institute for Personality and Ability Testing, Champaign, Illinois.

Cochran, T.M. (1984),

Psychological preparation of patients for surgical procedures, Pat. Ed. Couns., 5, 153-158.

Cohen, F. (1975),

Psychological preparation, coping and recovery from surgery, Dissertation Abstracts International, 37, 454b, California. 
Cohen, F., Lazarus, R.S. (1973),

Active coping processes, coping dispositions and recovery from surgery, Psychosomatic Medicine, 35, 375-389.

Clum, G.A., Scott, L., Burnside, J. (1979),

Information and locus of control as factors in the outcome of surgery, Psychological Reports, 45, 867-873.

DeLong, R.D. (1970),

Individual differences in patterns of anxiety, arousal, stress relevant information and recovery from surgery, Dissertation Abstracts International.

Devine, E.C. (1992),

Effects of psychoeducational care for adult surgical patients: a meta-analysis of 191 studies, Patient Education and Counseling, 19, 129-142.

Devine, E., Cook, T. (1986),

Clinical and cost saving effects of psychoeducational interventions with surgical patients: a meta-analysis, Research in Nursing and Health, 9, 89-105.

Dumas, T.G., Johnson, B.A. (1972),

Research in nursing practice: a review of five clinical experiments, International Nursing Studies, 9, 137-149.

George, J.M., Scott, D.S., Turner, S.P., Gregg, J. (1980),

The effects of psychological factors and physical trauma on recovery from oral surgery, Journal of Behavioral Medicine, 3, 291-310.

Hartsfield, J., Clopton, J.R. (1985),

Reducing presurgical anxiety: a possible visitor effect, Social Science and Medicine 20, 529-533.

Hathaway, D. (1986),

Effect of preoperative instruction on postoperative outcomes: a meta-analysis,

Nursing Research, 35, 269-275.

Hayward, J. (1975),

Information - a prescription against pain, The study of Nursing Care Reports (Serie

2,5), London, Royal College of Nursing.

Holden-Lund, C. (1988),

Effects of relaxation with guided imagery on surgical stress and wound healing, $R e$ search in Nursing and Health, 11, 235-244.

Horne, D.J. de L., Vatmanidis, P., Careri, A. (1994),

Preparing patients for invasive medical procedured 1: Adding behavioral and cognitive interventions, Behavioral Medicine, 20, 5-13.

Huber, H.P. (1986),

Möglichkeiten der psychologischen Operationsvorbereitung bei Kindern und

Erwachsenen, Wiener Klinische Wochenschrift, 98, 667-670.

Jamison, R.N., Parris, W.C.V., Maxson, W.S. (1987),

Psychological factors influencing recovery from outpatient surgery, Behavioral Research and Therapy, 25, 31-37, 1987. 
Johnson, J.E., Rice, V.E., Fuller, S.S., Endress, M.P. (1978),

Sensory information, instruction in a coping strategy and recovery from surgery,

Research in Nursing and Health, 1, 4-17.

Johnson, J.E., Leventhal, H., Dabbs, J.M. (1971),

Contributions of emotional and instrumental respons processes in adaptation to surgery, J. o. Personality and Social Psychology, 20, 55-64.

Johnston, M. (1984),

Dimensions of recovery from surgery, International Review of Applied Psychology, 33, 505-520.

Johnston, M., Carpenter, L. (1980),

Relationship between pre-operative anxiety and post-operative state, Psychological

Medicine, 10, 361-367.

Johnston, M., Vogele, C. (1993),

Benefits of psychological preparation for surgery: a meta-analysis, Annals of Behavioral Medicine, 15, 245-256.

Kaloupek, D.G., Stoupakis, T. (1985),

Coping with a stressful medical procedure: Further investigation with volunteer

blood donors, Journal of Behavioral Medicine, 8, 131-148.

Kendall, P.C., Epps, J. (1990),

Medical treatments, in: M. Johnston and L. Wallace (eds), Stress and Medical

Procedures, Oxford Medical Publications, Oxford.

Kendall, P.C., Watson, D. (1981),

Psychological preparation for stressful medical procedures, in: Medical Psychology,

Contributions to Behavioral Medicine, New York, Academic Press.

Kincey, J. and S. Saltmore (1990),

Surgical treatments, in: M. Johnston and L. Wallace (eds), Stress and Medical

Procedures, Oxford Medical Publications, Oxford.

Klos, D., Cummings, J. et al. (1980),

A comparison of two methods of delivering pre surgical instructions, Patient

Education and Counseling, 6-13.

Krause, N., Stryker, S. (1984),

Stress and well-being: the buffering role of locus of control beliefs, Social Science and Medicine, 18, 783-790.

Langer, E.J., Janis, I.L., Wolfer, J.A. (1975),

Reduction of psychological stress in surgical patients. J. o. Experimental Psychology, 155-165.

Lindeman, C.A., Stetzer, S.L. (1973),

Effects of preoperative visits by operating room nurses, Nursing Research, 22, 416.

Lipsey, M.W., Wilson, D.B. (1993),

The efficacy of psychological, educational, and behavioral treatment: confirmation from meta-analysis, American Psychologist, 48, 1181-1209. 
Mathews, A., Ridgeway V. (1984),

Psychological preparation for surgery, in: Steptoe A. Mathews A., Health Care and Human Behavior, Academic Press, New York.

Mathews, A., Ridgeway, V. (1981),

Personality and surgical recovery: a review, British Journal of Clinical Psychology, 20, 243-260.

Marks, G., Richardson, J.L., Graham, J.W., Levine, A. (1986),

Role of health locus of control beliefs and expectations of treatment efficacy in adjustment to cancer, Journal of Personality and Social Psychology, 51, 443-450.

Martelli, M.F., Auerbach, S.M., Alexander, J., Mercuri, L.G. (1987),

Stress management in the health care setting, matching interventions with patient coping styles, J. Consulting and Clinical Psychology, 55, 201-207.

Miller, S.M., Coombs, C., Stoddard, E. (1989),

Information, coping and control in patients undergoing surgery and stressful medical procedures, in: Steptoe, A., Appels, A., (eds.), Control and Health, New York, Wiley.

Miller, S.M., Mangan, C.E. (1983),

Interacting effects of information and coping style in adapting to gynaecologic stress: should the doctor tell all?, J. of Personality and Social Psychology, 45, 223 236.

Mills, T., Krantz, D.S. (1979),

Information, choice and reacting to stress, a field experiment in a blood bank with

a laboratory analogue, J. of Personality and Social Psychology, 37, 608-620.

Mumford, E., Schlesinger, H.J, Glass, G.V. (1982),

The effects of psychological intervention on recovery from surgery and heart attack:

an analysis of the literature, Am. J. of Public Health, 72, 141-151.

O'Halloran, C.M., Altmaier, E.M. (1995),

The efficacy of preparation for surgery and invasive medical procedures, Patient

Education and Counseling, 25, 9-16.

Padilla, G.V., Grant, M.M., Rains, B.L., Hansen, B.C., Bergstione, N., Wong, H.L., Hanson, R., Kubo, W. (1981),

Distress reduction and the effects of preparatory teaching films and patient control,

Research in Nursing and Health, 4, 375-387.

Partridge, C., Johnston, M. (1989),

Perceived control of recovery from physical disability: Measurement and prediction,

British Journal of Clinical Psychology, 28, 53-59.

Picket, C., Clum, G.A. (1982),

Comparative treatment strategies and their interaction with locus of control in the reduction of postoperative pain and anxiety, J. o. Counseling and Clinical Psychology, 50, 439-441.

Pruyn, J.F.A., Borne, H.W. van den, Reuver, R.S.M. de, Boer, M.F. de, Bosman, L.L.J., Pelkwijk, M.A. ter, Jong, P.C. de (1988),

De Locus of Control-schaal voor kankerpatiënten, Tijdschrift voor Sociale Gezondheidszorg, 66, 404-408. 
Quinn, J.C. (1986),

Another dimension in postanesthesia nursing. $J$. of Postanesthesia Nursing, 1, 2630.

Radloff, R., Helmreich, R. (1968),

Groups under stress, New York, Appleton-Centry-Crofts.

Ray, C., Fitzgibbon, G. (1981),

Stress, Arousal and coping with surgery, Psychosomatic Medicint. 11, 741-746.

Reading, A.E. (1979),

The short term effects of psychological preparation for surgery, Social Scienci and

Medicine, 13A, 641-654.

Rice, V.F.H. (1982),

Effects of need for personal control and information on strains associated with a threatening event, Dissertation Abstracts International, 43, 02.

Rogers, M., Reich, P. (1986),

Psychological intervention with surgical patients: evaluation outcome, Advances in

Psychosomatic Medicine, 15, 23-50.

Rotter, J.B. (1966),

Generalized expectancies for internal vs. external control of reinforcement, Psychological Monographs, 80, 1-28.

Salmon, P. (1992),

Psychological factors in surgical stress: implications for management, Clinical Psychology Review, 12, 681-704.

Schmitt, F.E., Wooldridge, P.J. (1975),

Psychological preparation of surgical patients, Nursing Research, 22, 108-116.

Schultheis, K., Peterson, L., Selby, V. (1987),

Preparation for stressful medical procedures and person $\mathrm{x}$ treatment interactions, Clinical Psychology Review, 7, 329-352.

Scott, L.E., Clum, G.A. (1984),

Examining the interaction effects of coping style and brief interventions in the treatment of post surgical pain, Pain, 20, 279-291.

Shipley, R.H, Butt, J.H., Horwitz, E.A. (1979),

Preparation to reexperience a stressful medical examination: effects of repetitious videotape exposure and coping style, $J$. of Consulting and Clinical Psychology, 47, 485-492.

Shipley, R.H, Butt, J.H., Horwitz, E.A., Farbry, J.E. (1978),

Preparation for a stressful medical procedure: effect of amount of stimulus preexposure and coping style, $J$. of Consulting and Clinical Psychology, 46, 499-507.

Sime, A.M. (1976),

Relationship of preoperative fear, type of coping and information about surgery to recovery of surgery, J. o. Personality and Social Psychology, 34, 716-724.

Suls, J., Wan, C.K. (1989),

Effects of sensory and procedural information on coping with stressful medical procedures and pain: a meta-analysis, J. o. Consulting and Clinical Psycholngy, 57, 372-379. 
Taylor, S.E. (1991),

Health Psychology, New York, Random House.

Taylor, S.E., Clark, L.F. (1986),

Does information improve adjustment to noxious medical procedures?, in: M.J. Saks and L. Saxe, Advances in Applied Social Psychology, vol 3, Lawrence Erlbaum Associates, New Jersey.

Thompson, S.C., Cheek, P.R., Graham, M.A. (1987),

The other side of perceived control: disadvantages and negative effects, in:

Spacapan, S., Oskamp, S, (eds.), The Social Psychology of Health, The Claremont

Symposium of Applied Social Psychology, Sage, Beverly Hills.

Wallace, L.M. (1986),

Informed consent to elective surgery: the 'therapeutic' value?, Social Science and Medicine, 22, 29-33.

Wallston, K.A. (1989),

Assessment of control in health-care settings, in: Steptoe, A., Appels, A., Stress,

Personal Control and Health, New York, John Wiley and Sons.

Wallston, K.A., Wallston, B.S., Smith, S., Dobbins, C.J. (1987),

Perceived control and health, Current Psychological Research and Review, 6, 5-25.

Webber, G.C. (1990),

Patient education, a review of the issues, Medical Care, 28, 1089-1103.

Weinman, J., Johnston M. (1988),

Stressful medical procedures: an analysis of the effects of psychological interventions and the stressfulness of the procedure, in: Maes S. et. al. (red.), Topics in Health Psychology, Wiley, New York.

Wells, J.K., Howard, G.S., Nowlin, W.F., Vargas, M.J. (1986),

Presurgical anxiety and postsurgical pain and adjustment: Effects of a stress inoculation procedure, J. o. Consulting and Clinical Psychology, 54, 831-835.

Williams, C.L., Kendall, P.C. (1985),

Psychological aspects of patient education for stressful medical procedures, Health

Education Quarterly, 12, 135-150.

Williams, J., Workhoven, J., Williams, B. (1975),

The psychological control of preoperative anxiety, Psychophysiology., 12, 50-54.

Wilson, J.F. (1981),

Behavioral preparation for surgery: benefit or harm?. J.o. Behavioral Medicine 4, 79-102. 


\section{$3 \quad$ Effects of education and support for surgical patients: the role of perceived control ${ }^{1}$}

B. Breemhaar ${ }^{2}$, H.W. van den Borne ${ }^{2}$

Reprinted with permission from the editor of Patient Education and Counseling.

Drs. B. Breemhaar and Dr. H.W. van den Borne are respectively researcher at IVA, the Institute for Social Research in Tilburg. The Netherlands and professor of Patient Education at the department of Health Promotion at the University of Limburg in Maastricht, The Netherlands. 


\title{
Effects of Education and Support for Surgical Patients: The Role of Perceived Control ${ }^{*}$
}

\author{
B. Breemhar and H.W. van den Borne

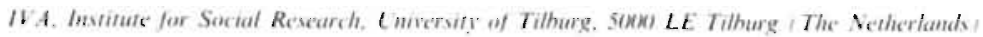

(Received March 4th. 1991)

(Accepled August 2131, 1991)

\section{Abstract}

It has been shoun that the provision of echacation and support to surgical patients has a positive effeet on their physical and psichological well-being before and after surgery. This article argues that this effert can be explained by the fact that educatoon and support increase or maintain the patients feelings of control. Perceived control has been shown to be able to reduce the stress experienced in connection with surgery and to determine the manner in which stress is dealt with. The artick investigates the conditions under which increasing the extent of perceived control is advantageous. The positive effect of measures to increase perceived control appears to be dependent on the indiridual rendency of the patient to ascribe influence to him/herself and the extent to which a given simation offers opportunities to actually exercise control. The aricle concludes with a discussion of the significance of this analysis for the pracrice of pationt education and support.

Keywords: Surgical patients: Control: Stress: Coping.

\footnotetext{
"The present urticle is adapted from the atuthors' contribution to the symposium on Applied Social Psychology organized by the Association of Researchers in Social Psychology, which look place on $29 / 30$ November 1990 in Nijmegen (The Neherlands).
}

\section{Introduction}

On admission to hospital, surgical patients find themselves confronted with a variety of problems. These include fear of anesthesia, fear of the impending operation and of pain, uncertainty as to the experiences which they are to undergo and damage to self-image resulting from having to fullil the role of patient $[1-4]$. Hospital staff are aware of these factors and attempt to keep them within bounds by means of patient education and support. That they do not always succeed in doing so has been shown by studies of patients' level of satisfaction with the information provided, their emotional state and their knowledge [5-7].

A large number of experimental studies have shown that the systematic provision of education and support to surgical patients can indeed be successful, if this is applied consistently and meets the patients' actual needs [8-10]. The majority of the measures evaluated in these studies belong to one of the following three categories or a combination of them [11-13]. Firstly, the provision of information about the procedures and/or the perceptions and experiences to be expected in connection with the operation. Secondly. the acquisition of behavior which can contribute 
to a smoother course of events and better recovery from the operation (for example relaxation and breathing exercises). Thirdly, the provision of mental strategies to reduce threatening cognitions with respect to the operation (restructuring of cognitions), for example by diverting one's attention.

There is as yet little certainty as to the reasons for the effectiveness of these measures. The present article investigates whether the explanation for the positive effects is that the measures increase or maintain the patient's perceived control. Taking the relevant scientific literature as the starting point. the article examines the role of perceived control in the experience of stress by surgical patients and the manner in which stress is dealt with. The question of when increasing perceived control is effective and when it is not is also dealt with. This exploration of the literature was carried out in preparation for a study of the effect of patient education and support in surgical wards [14].

\section{Perceived control over events}

An important theoretical concept which seems to be applicable to explaining the effectiveness of education and support for surgical patients is the patients' perceived control $[15,16]$. Rodin defines perceived control as "...the expectancy to have the power to participate in decisions to obtain desirable consequences." [17, p. 154]. More specifically. Gatchel describes perceived control as "...the subject's perception of a contingency between the performance of some behaviour and the ability to avoid or escape a stressful, unpleasant event." [18, p. 1]. A significant characteristic of perceived control is the assumption made by people that they are themselves responsible. through their own efforts in a given situation, for the results which accrue to them in that situation [19]. Perceived control is thus a subjective concept: there may be a difference between the actual possibilities of exercising control and the possibilities of control which one experiences oneself.

From a practical point of view it is important to distinguish between two aspects of perceived control. With respect to personal mastery expectations, the theory of social learning distinguishes between (a) outcome expectations and (b) expectations as to selfefficacy [20]. Outcome expectations means someone's expectations that certain efforts in a particular situation will lead to the desired results. Self-eflicacy means a person's expectation as to his/her abilities to actually implement these efforts. This distinction is of practical importance for the provision of education and support to surgical patients. The accent can be placed on increasing the patient's insight into behavior which can contribute to his her well-being or on increasing individual abilities to actually implement this behavior.

There are various reasons for attributing a role to perceived control in explaining the effects of measures taken to prepare patients for surgery. In the first place, numerous studies have shown that feelings of control can keep stress within bounds and increase psychological and physical well-being [21-27]. Secondly, the situation of surgical patients in hospital includes various factors which cause their perceived control to decrease [28.29]. According to Tagliacozzo and Mauksch [30], the treatment of hospital patients and the organization of care are aimed primarily at their being passive and cooperative, while minimizing their own active contribution.

Explanation of the positive role of perceived control in adaptation to surgery: a model of stress and coping

The ideas developed by Lazarus with respect to stress and coping offer a good basis for providing theoretical support for the positive role of perceived control in measures directed at improving recovery after surgery. 
After giving a brief description of Lazarus's model, we will examine the relation between perceived control and the central variables of this model.

Lazarus's theory of stress and coping [31-33] is based on the view that stress is determined by the relation between a person and his/her environment. The significance attached by the person to the situation at a given moment determines the extent of the stress which he/she experiences and the way in which he/she deals with it. Figure I gives a sketch of the model developed by Lazarus et al.

When confronted with an unpleasant event in a given situation, the person concerned attempts to appraise whether it forms or can form a danger to his/her well-being (primary appraisal). He/she also appraises the extent to which he/she has means at his/her disposal to deal with this danger (secondary appraisal). These two processes of appraisal can lead to the event being viewed as a threat to wellbeing. A result of this threat is the experiencing of a certain amount of stress, which can manifest itself as fear, anxiety, uncertainty. threat or damage to self-image, frustration etc.

An attempt will then be made to deal with the stress caused by this unpleasant event (coping). Coping is defined as "...efforts, both action-oriented and intrapsychic, to manage (i.e. master, tolerate, reduce, minimize) environmental and internal demands, and conflicts among them, which tax or exceed a personis resources" [31. p. 311]. Coping can lake a large number of different forms and fulfils a number of functions. Essentially. however. coping has (wo main functions [33]. The furst of these is that of exerting a concrete influence on the relation between the person and his/her environment in a stressful siluat. tion (problem-focused coping). This includes coping strategies such as planned problem solving and confrontation. Secondly. coping regulates emotions (emotion-focused coping): this includes such strategies as escape/avoidance and positive reevaluation.

The manner of coping with stress in a given situation is dependent, amongst other factors. on the outcome of the process of appraisal described above. The greater the perceived threat of an unpleasant event to one's wellbeing. the more negative emotions will be experienced which require a greater measure of regulation. This allows less opportunity for problem-focused coping. Conversely, the less stress is experienced, the more one will concentrate on problem-oriented coping [34]. In most situations, however, both forms are present simultaneously: a certain regulation of emotions can be considered a necessary precondition for dealing effectively with a problem by means of behavior $[34,35]$. The form of coping which is accentuated can vary greatly.

Fig. 1. L.azarus' transactional model of stress and coping.

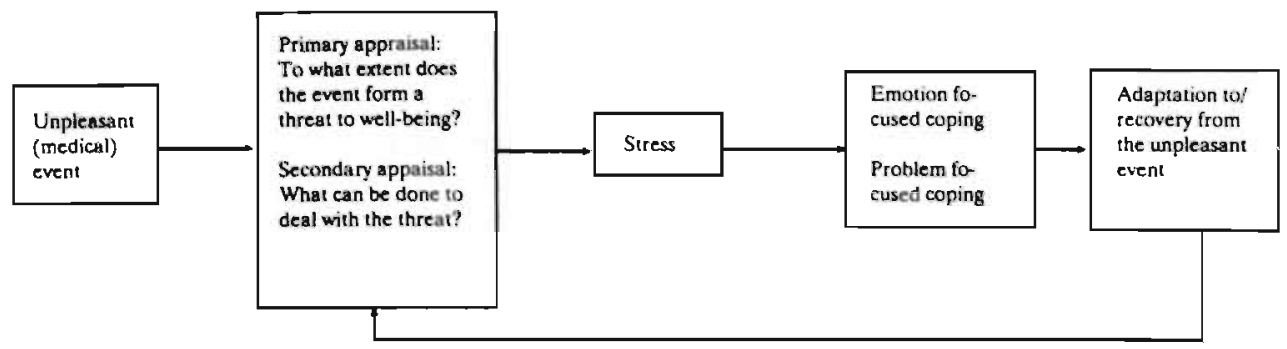


Repeated attempts have been made to determine which coping strategies are successful in given situations [36-39]. Although there is a certain measure of agreement between the results of these studies, a satisfactory explanation for the relation between coping strategies and result has not been provided [33]. It is unclear what the relation is between the level of success of specific coping strategies and the type of unpleasant experience and the specific circumstances under which that experience takes place. It is also unclear whether coping strategies are stable enough in time that they can influence wellbeing in the long term.

Both the extent to which stress is experienced and the manner of coping are determined in part by the extent to which one assumes that one is able to control the situation in which an unpleasant event takes place. We will deal with this point in greater detail below.

\section{The influence of perceived control on stress}

The perception of control influences to an important extent the process of appraisal that results in stress being experienced [34]. The more possibilities of exerting influence that one assumes, the less strongly feelings of stress are experienced. A large number of experimental studies support this relation [18,40]. These studies compare, for example. the reactions of test subjects who were able to influence aversive stimuli with the reactions of others who were not able to do so (e.g. were or were not able to influence the intensity of bursts of noise or electric shocks). These experiments show among other things that greater perceived control is accompanied by a greater tolerance of the event [4I] and fewer somatic complaints during it [42]. The results of an aversive stimulus also appear to be less serious when the person concerned assumes that he/she can exercise control. It has been shown, for example [43]. that test subjects who considered that they were able to terminate bursts of noise performed better in a mental task after a series of such aversive stimuli and showed less frustration than subjects who considered that they were not able to terminate the noise.

\section{The influence of perceived control on coping}

According to Lazarus et al.. the control which a person considers he/she has in a given situation determines the manner in which stress is dealt with in that situation [3.3.34]. This assumption is based on research into the relation between secondary appraisal ("What can I do in this situation to influence the event?") and coping strategies [44]. For the purposes of this study, a sample group of adults (45-64 years of age) from the normal population were asked each month for the course of a year how they had coped with unpleasant events during the previous month. The results showed that events which were viewed as susceptible to being changed (high level of perceived control) were dealt with primarily by using forms of problem-focused coping. Events which were considered not to be susceptible to being changed (low level of control) were dealt with primarily with emotion-focused coping strategies.

These results have been reproduced in a more recent study of similar design with a similar sample group [36]. A study of students during an examination period has also shown [35] that the use of forms of problem-focused coping decreased greatly in the period shortly after the examination in comparison to the pe. riod before it. After the examination. stress was dealt with primarily by means of distancing. a form of emotion-focused coping. According to the authors of the study. this can be explained by the fact that during preparation for an examination. students experience the stressful situation as being capable of being influenced; studying for the examination can increase the chance of a good result. After the examination one cannot do much more than wait for the result, and it is no longer worth applying problem-focused coping.

Research on the relation between locus of 
control and coping with illness and threats to health also supports Lazarus's suggestion that perceived control influences coping. A few of these studies [45] dealt with the differences in physical and psychological health and healthpromoting behavior between persons with an internal and an external locus of control [46]. In a survey of these studies. Strickland [47] shows that internals collect more information in connection with health and display more behavior conducive to health than externals. Internally oriented persons also appear to collect more information about their illness and to have more knowledge about it than externals. Chronically ill persons with an internal locus of control, finally, appear to make more attempts to influence their medical care in a direction they desire than externally oriented chronically sick people. Strickland concludes that "...the bulk of research is consistent in implying that when faced with health problems, internal individuals do appear to engage in more generally adaptive responses than do externals." [47, p. 1205]. More recent studies of hospital patients [48] and cancer patients [49] also demonstrate the importance of generalized expectations of control for behavior which determines adaptation to illness.

\section{The influence of patient education and support on perceived control}

Many education and support measures for surgical patients are able to stimulate perceived control [29]. For example, behavior control is increased [50] by teaching patients behavior which decreases unpleasant aspects or results of medical treatment (for example, breathing deeply after an operation, swallowing exercises in connection with endoscopy). Cognitive control can be increased by teaching patients mental strategies to decrease the unpleasant aspects of an operation [5I]. These include, for example, seeking distraction by thinking of other (more pleasant) things or emphasizing the positive aspects of the treatment. The availability of options, for example with respect to various treatments or the location where an injection is to be given. increases the control the patient has over decisions with respect to medical examinations and treatment [26]. Finally, information about the procedure to be followed during treatment and about the physical sensations to be expected can increase perceived control [52]. The patient can thus predict more accurately what he/she is 10 undergo and can prepare for it better.

\section{When is control advantageous?}

We have suggested above that a high level of perceived control often restricts the experience of stress and influences the way in which it is dealt with. It has also been stated that education and support measures to accompany medical procedures can increase the control exercised by patients. The question is: under what circumstances does control reduce stress and stimulate coping strategies which facilitate effective adaptation to stressful events? Finding an answer to this question is important in order to successfully apply psychoeducative interventions to reduce emotional problems and to facilitate the recovery of patients who must undergo medical treatment. We shall first examine the consequences of measures to increase control in the case of persons who differ in the extent to which they tend to ascribe control to themselves in a given situation. Secondly, we shall discuss the consequences of measures to increase control in situations which differ in the extent to which they allow the exercise of control.

\section{Individual differences in optimum level of perceived control}

Increasing the level of perceived control can lead to an increase in stress if this control brings with it demands which the person concerned does not wish to meet or which he/she cannot (or thinks he/she cannot) meet [34]. Placing responsibilities on people with which they are unfamiliar or which their capacities do not allow them to bear will increase rather 
than reduce stress. Giving dietary rules to at patient with stomach trouble, for example. will probably not lead to a reduction in fear of the complaints recurring if he/she does not expect a diet to be of use or does not consider the diet to be practicable.

In a study by Auerbach et al. [53]. there are indications of the necessity that measures to increase control should fit in with the level of control that someone tends to ascribe to him/herself in a given situation. The study examined the interaction between locus of control and the provision of information to patients who were to undergo dental treatment. Patients were distributed at random into two groups. One group received specific. detailed information about the treatment to be carried out while the second group was given more general information. The internally and externally oriented patients in each group were then distinguished from one another. Internals in the group which received detailed information scored higher when evaluated by the dentist with regard to their level of adaptation during treatment than internals in the group which received more general information. In the case of the externals the results were precisely the opposite. This indicates that the detailed information for the externally oriented patients included more information than they wished to have. making them nervous and anxious and less well able to undergo treatment than the externals who received general information which concealed more facts from them.

Studies of the interaction between coping and the provision of information in the case of surgical patients also shows the negative effects of increasing the level of perceived control above a level desired by the patient. In such a study of patients who underwent an operation for slipped disc [54], the subjects were divided into avoidant copers (using denial, avoidance and trivializing the seriousness of unpleasant events), vigilant copers (actively dealing with the event by seeking information. talking to others etc.) and neutrals. On the ba- sis of the relationship discussed above between perceived control and coping, it is suggested that avoiders have a lower expectation of control than vigilant copers [55]. Halt of the subjects received oral information about the complaint and the operation and the other half did not receive information. Neutrals who received the information turned out after the operation to require significantly less medication and to have a shorter stay in hospital than neutrals who had not been provided with information. Avoiders who received information, on the other hand, required significantly more medication after the operation than avoiders who had not received information. In the case of the vigilant copers no differences were discerned.

These results suggest that information about the complaint and the operation which increases control can improve adaptation to an operation for slipped disc. If, however. the intended control reaches a level above that wished for by the patient, as in the case of the avoiders, adaptation can be reduced. The fact that no difference was discerned in the case of the vigilant copers can be explained by the fact that these patients probably collected the desired information themselves, even if they did not receive it within the context of the experiment. Similar results have been found in the case of patients undergoing abdominal operations [56] and in the case of chagnostic procedures [57,58].

It can be concluded that increasing the perceived control of patients who tend to attribute little control to themselves in general or in the specific situation of surgery is not ac. companied by an improvement in adaptation to medical treatment and by improved recovery. In the case of patients who attribute more control to themselves. measures to increase control do have a positive effect. Measures to increase perceived control appear above all to affer these patients support in developing expectations with regard to surgery. This con. clusion is justified in the case of medical treatment characterized by restricted duration 
and by not having major consequences for the patient's further life. This may possibly be dif ferent in the case of more drastic medical procedures such as hemodialysis or heart transplantation. in which major long-term adjustments in lifestyle are unavoidable. A certain caution with respect to this conclusion is also desirable in the case of the medical procedures discussed here. A small number of studies suggest that patients with an (extremely) low !evel of anxiety before an operation display less effective postoperative physical and psychological adaptation than patients with greater preoperative anxiety [59.60]. It is possible that extensive avoidance or denial and little or no information about the operation are accompanied by insufficient preparation for the pain and restricted function experienced after the operation. a factor which slows down recovery and adaptation.

\section{Perceived and acrual control in a given situation}

With a view to successful coping with stressful events it is important that a situation also allows for the exercise of control [34]. Someone who thinks that he/she has considerable control and chooses to deal with an unpleasant event by taking direct intervening action will probably not succeed in dealing with the event successfully if the situation. seen objectively, allows for little or no control. A lower expectation of control is then more realistic, with the regulation of emotions offering more chance of success. An example may serve to make this clear. A person with a heart complaint who is told that heart catheterization or a heart operation is necessary will in general do better to accept this and concentrate on the positive sides instead of making attempts to overcome the complaint by means of physical exercise or a healthy diet. Folkman and Lazarus state that .... a key factor in coping effectiveness is whether or not the choice of coping strategy fits the possibilities for coping in an encounter. The major criterion has to do with the extent to which an outcome is within a person's control" [37, pp. 314-315].

Support for this view is provided by, among others, Cohen and Lazarus [61]. They compared recovery after a slipped disc. gallbladder or thyroid operation in patients who made use of various coping strategies. Avoidant copers recovered more successfully than vigilant copers. The latter had significantly more postoperative complications and remained in hospital significantly longer. Cohen and Lazarus explain this by pointing out the possibility that vigilant copers actively attempt to influence the situation before and after the operation themselves by increasing their knowledge of various aspects of the operation. After the operation, however, the situation offers virtually no opportunity for exercising influence; pain and impairment of function enforce a passive, wait-and-see attitude, which conflicts with the behavior wished for by vigilant copers. Avoidant copers, in contrast, assume a wait-and-see attitude from the very beginning. which fits more with the opportunities allowed for by the situation.

The results of a study of patients who underwent a diagnostic gynecological examination (colposcopy) can be explained in the same way [58]. Patients who tended to avoid information about the procedure (referred to as blunters) showed less arousal before, during and after the examination than patients who tended to actively collect information about the examination (monitors). According to the authors of the study, the examination and the situation in which it was carried out offered the patients no opportunity to exercise control. The information which monitors collected provided them with more knowledge of the unpleasant aspects of the examination. Because of the absence of opportunities to reduce these unpleasant aspects, this knowledge may well have served merely to increase the anxiety and arousal of these patients.

Studies of the effect of measures intended 
Fig. 2. Dagrammatic summary of the relations between perceived control and stress, coping and adaptation to aversive stimuli (the sign + and - refer to an increase or reduction in the variable concerned).

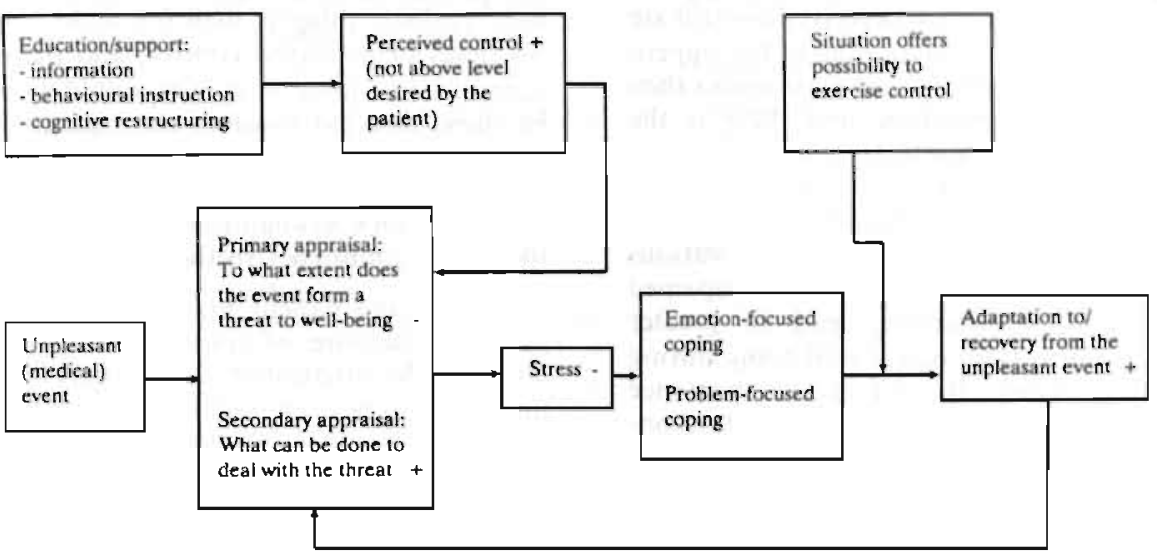

to increase the expectation of control also support the view that the positive effect of perceived control occurs only on condition that a situation makes possible the exercise of control [58.62.63].

It can be concluded that increasing the expectation ef control is accompanied by improved adaptation to medical treatment and improved recovery if the situation in which the treatment takes place also offers actual opportunities for control [29]. If the situation in fact does not allow for control, measures aimed at increasing control tend in fact to have an adverse effect. Figure 2 gives a diagrammatic summary of the relations between perceived control and stress. coping and adaptation to aversive stimuli, as well as the situation in which control is conducive to effective adaptation.

Figure 3, finally, gives a diagrammatic summary of the effects of increasing the perception of control under the various circumstances described in this section.

\section{Conclusions and implications for practice}

What is the significance of the relation discussed above between control expectation and stress/coping for the provision of education and support to surgical patients? Under what circumstances can one expect that patient education and support contribute to an improvement in postoperative physical and psychological adaptation? In order to answer these questions, we distinguish between the four situations which arise when the two conditions which determine the effect of measures to increase control are combined. These situations and implications for practice are summarized in Fig. 4.

Firstly, there is the situation in which the patient tends generally, or in the situation in which surgery takes place, to attribute a considerable measure of control to him/herselif

Fig. 3. Effects of measures to increase perception of control.

\begin{tabular}{lll} 
& $\begin{array}{l}\text { Extent to which } \\
\text { patient tends to } \\
\text { ascribe control } \\
\text { to him/herself } \\
\text { Greal Littic }\end{array}$ & $\begin{array}{l}\text { Extent to which } \\
\text { situation makes } \\
\text { control, possible }\end{array}$ \\
\hline $\begin{array}{l}\text { Effect of } \\
\text { increasing } \\
\text { control }\end{array}$ & + & \\
\hline
\end{tabular}


and in which the situation also actually allows control to be exercised. In this case it can be expected that the positive effects of measures to increase and maintain perceived control are at a maximum. Information as to the impending events, perceptions and experiences then aids effective preparation. and there is the maximum level of benefit from behavioral instruction aimed at ensuring that the procedure is a success and that recovery is good. Offering choices with respect to various treatments for example will, if accompanied by effective information, lead to greater physical and psychological well-being during and after surgery. It is of great importance that staff ensure that the possibilities for control which are presented by means of providing information, behavioral instruction and choices can also actually be put into practice.

Secondly, there is the case in which the patient tends to attribute little control to him/herself and the medical situation with which he/she is confronted allows little or no control to be exercised. Measures to increase perceived control are then undesirable. Information about unpleasant aspects of a medical procedure which the patient cannot influence can better not be provided, particularly when the patient does not desire them [64]. The most realistic thing is then for there to be a low level of perceived control, and the most appropriate coping strategies would seem to be those directed towards the regulation of emotions. In such cases, support can best take the form of assistance with such coping strategies, such as cognitive restructuring and increasing confidence in the staff.

Thirdly, the patient may attribute a considerable measure of control to him/herself although the situation in fact permits little or no control to be exercised. Here too, measures to increase perceived control are undesirable. It is important to assist the patient in accepting that he/she can (temporarily) not influence events with which hu'she will be confronted in the situation concerned. The patient must be prevented from altempting to deal with stress by actively intervening in the situation and thus necessarily becoming frustrated. These patients also benefit most from the provision of coping strategies directed towards the regulation of emotions.

Fig. 4. Erfects of inereasing perception of control dependent on circumstances with respect to patient/situation, and implications for practice.

\begin{tabular}{|c|c|c|c|}
\hline & \multicolumn{3}{|c|}{ Extent to which patient tends to ascribe control to him/herself } \\
\hline & & Great & Little \\
\hline \multirow[t]{3}{*}{$\begin{array}{l}\text { Extent to which } \\
\text { situation makes } \\
\text { eontrol possible }\end{array}$} & High & $\begin{array}{l}\text { Effect: + } \\
\text { Recommended: } \\
\text { Enhancing percerved } \\
\text { control by giving } \\
\text { information, } \\
\text { offering choices, } \\
\text { instructing } \\
\text { behaviour, etc. }\end{array}$ & $\begin{array}{l}\text { Effect: } \pm \\
\text { Recommended: } \\
\text { Enhancing perceived } \\
\text { control only if required } \\
\text { by the situation. } \\
\text { If not required, } \\
\text { supporing regulation } \\
\text { of emotions is } \\
\text { preferable }\end{array}$ \\
\hline & Low & Effect: - & Effect: - \\
\hline & & $\begin{array}{l}\text { Recommended: } \\
\text { Providing information } \\
\text { only it strongly desired } \\
\text { discourage problem } \\
\text { focused coping, suppor- } \\
\text { ting regulation of } \\
\text { emotions }\end{array}$ & $\begin{array}{l}\text { Recommended: } \\
\text { Providing no threatening } \\
\text { information, supporting } \\
\text { regulation of emotions } \\
\text { by cognitive restructuring, } \\
\text { increasing confidence } \\
\text { in staff, etc. }\end{array}$ \\
\hline
\end{tabular}


In so far as the patient clearly desires it. the necessary information can be mude available. provided it is made clear that he/she can do little in the way of influencing the situation positively by means of his/her behavior.

Finally, the patient may ascribe little control to him/herself even though the situation actually does allow for control. If the situation does not require it, and if the patient does not desire it. it is better in such cases not to provide (detailed) information and behaviora! instruction. This also applies to offering choices. As in the two previous situations, it is more important to provide assistance in regulating emotions. If the situation does in fact demand that the patient should contribute actively to the success of the procedure and/or recovery after it, it is important that he/she should be convinced of the value of the desired behavior and of his/her own abilities to carry out that behavior. For example, a patient who must breathe deeply or cough vigorously after an operation in order to restore lung function needs to have properly explained to him/her why this is important. This behavior must also be practised with him/her both before and after the operation so that he/she realizes that he/she is capable of producing the required behavior. In general, providing essential information means that the patient must have made clear to him/her what the importance of that information is and how he/she can make good use of it. Finally, the patient must be convinced that he/she is capable of making effective use of the information.

In conclusion. we can state that the results of patient education and support measures for perceived control can explain many of the positive and also negative effects of these measures in surgical patient. Measures to educate patients should be directed more towards increasing the opportunities of the patient him/herself for playing a role in his/her treatment and recovery [65]. It is however of the greatest importance that the application of these measures is restricted by the specific circumstances, which are determined by the individual patient and the situation in which treatment (or a part of it) takes place.

\section{Acknowledgments}

The authors are most grateful to Prof. Dr. G I. Kok for hes commenis on an carlier version of this article. This study was made possible by a gaast from the Dutch Pracientic fonds i Nr. 26-20).

\section{References}

1 Boeke S: Psychologische aspecten van het ondergaan van een operatie (diss.). Erasmus Universitet. Rotterdam. 1988.

2 Ray $C$ : The surgical paticnt psychological siress and cop. ing resoures. in: Eiser JR ed. Social Psychohegical and Behavioral Medicine. New York: Wiley, 1982.

3 Salo $\mathbf{M}$ : Endocrine responses in anesthesia and surgery. in: Watkins 3. Salo M eds. Traama. Siress and Immunuty in Anesthesia and Surgery. London: Bulterworth. 1982

4 Johnston M: Impending surgery. In: Fisher S. Reuson J eds. Handbook of Life Stress. Cognition and health. New York: Wilcy. 1988.

5 Dekkers F. Patien nenvoorlichting. de Onmacht en de Pijn. Baarn: Ambo. 1981

6 Visser APh: Patient in het. Ziekenhuis Maasirnch. Van Gorcum. 1946

7. Visser: APh ed: Onderzoek naar de Jevredenheid san Ziekenhuispatiènten. Lochem: De Tijưstroom, 1988

8 Hathaway D Effect of preoperatuve instruction on postoperative ourcomes: a meta-analysis. Nurs Res 1986 : 35: $269-275$

9 Devine E. Cook T. Clincal and cost saving effects of psychoeducational interventrons, with surgical patients at mets-analysis, Res Nurs Heshih 1985: 9 - 89-105

10 Webber GC Patremt education: a review of the isvues Med Care 1990, 28. 1089-1103

11 Kendall PC. Watson D. Psychological preparauon for stressfut medical procedures, in: Medical Psychology. Contributions to Behwioral Medicine. New York. Academic Press, 1981.

12 Mathews A. Ridgeway V: Psychological preparation for surgery. in. Sicptoe A. Mathews A eds. Health Care and Human Behaviour. New York: Academic Press. 1984.

13 Weinman J, Johnston $M$. Siressful medical procedures an asalysis of the efiects of psychological intervencions and the stressfulness of the procedure, in: Maes $\mathrm{S}$ et al eds. Topics in Health Psychology. New York: Wiley. 1988

14 Breemhar B. Borne HW var den: Case study: Develop. ment and evaluation of a model of putient education in surgical wards. Patient: Educ Couns 1990: 16 $39-42$

15 Kok GS: Health motivation health education from a social psychological poim of view. in Maes S. Spiclberger CD. Defares PB, Sarason 16 eds. Topics in Health Psy. chology. New York. Wiley, 1988 
16 Syme SL: Controt and health: a personal perspective. in: Steptoe A. Appels A eds. Stress. Personal Control and Health. New York: Wiley, 1989

17. Rodin. J: Behaviora! medicine: beneficial effects of self control training in aging. Int Rev Appl Psychol 1983: 32 $153-181$

18 Gatchel RJ: Perceived control: a review and evaluastion of therapeutic implications, in: Baum A. Siñger J eds. Advances in Environmental Psychology. New Jersey: Lawrence Erlbaum. 1980

19 Rodin J. Timko C. Harris S: The construct of control: biological and psychosocial correlates. Annu Rev Gerontol Geriatries 1985: 5: 3-55.

20 Bandura A. Self-eficacy: toward a unifying theory of behavior change. Psychol Rev 1977; 84: 191-215.

21 Thompson SC: Will it hurt less if I can control it? A complex answer to a simple question. Psychol Buth 1981: 90: 89-101.

22 Marks G. Richardson JL., Giraham JW. Levine A: Role of health locus of control beliefs, and expectations of trealment efficacy in adjustment to cancer. J Pers Soc Psychol 1986: $51: 43-450$

23. Krause N. Stryker S: Siress and well-being the buffering role of locus of control beliefs. Soc Sci Med 1984: 18: 783-790.

24 Pruyn JFA, van den Borne HW, de Reuver RSM, de Boer MF. Bosman L. ter Pelkwijk. MA. de Jong. PC: De Locus of Control-schaal soor kankerpatienten. Tijdschr Soc Gezondheidszorg 1988: 66: 404-408

25 Klein RF. Kliner VA, Zipes DP. Troyer WG. Wallace AG: Transfer from a coronary unit. Arch Intern Med 1968: 122: $104-108$

26 Mills RT, Krantz DS: Information. choice and reactions to stress: a field experiment in a bloodbank with a laboratory analogue, J Pers Soc Psychol 1979, 37. 608-620.

27 Morris J. Royle GT: Offering patients a choice of surgery for early breast cancer. a reduction in anxiety and depression in patients and their husbands. Soc Sei Med 1988: 26 $583-585$.

28 Taylor SE: Hospital patient behavior reactance. helplessness or control? J Soc l\$s 1979: 35: 156-184.

29 Taylor SE: Health Psychology. New York: Random House, 1986

30 Tagliacozzo DL. Mauksch HO. The patien's view of the patient's role, in Jaco EG ed Patients. Physicians and IIIness. New York: Free Press. 1972.

3 Lazarus RS. Launier Rt: Stress-relaied Iransactions between person and environment. in: Pervin LA, Lewis M eds. Perspectives in Interactional Fsychology. New York: Plenum. 1978

32 Lazarus RS. Folkman S: Coping and adaptation, in Doyle-Gentry $W$ ed Handbook of Behavioral Medicine New York Guifford Press. 1984

33 Lazarus RS. Folkman S: Transactional theory and research on emotions and coping. Eur I Per; 1987; I: $141-169$

14 Folkman S: Personal control and stress and coping pro- cesses: a theoretical analysis. $J$ Pers Soc Psychol 1984. 46. $839-852$

35 Folkman S, Lazarus RS: If it ehanges it must be a process study of emotion and coping during three stages of a col. lege examination. J Pers Soc Psychol 1985; 48: 150-170.

36 Folkman S. Lazarus RS. Dunkel-Scherter C. DeLongis A. Gruen RJ. Dynamies of a stressfull encounter. cogniuse appraisal, coping and encounter outcomes I Per Soc Psychat 1986: 50: 992-1003

37 Folkman S. Lazarus RS. The relationship belween coping and emotion: implications for theory and research. Soc Sci Med 1988: 26: 309-317.

38 Folkman S. Lazarus RS. Gruen RJ. DeLongis A: Apprasal. coping, health status and psychological symp. toms I Pers Soc Psychol 1986: 50: 571-579

39 Feif JA. Kampen D. van Doom DC. Resing WCM. van den Berg PT: De relatie tussen ingrijpende gebeurtenissen. coping-stijlen en klachten. Gedrag Gezondheid 1990: 18 $182-196$.

40 Averill JR: Personal control over aversive stimuli and its relationship to stress. Psychol Bull 1973. 80: 286-303.

41 Suub E. Turski B. Schwartz GE: Self-contral and predictability: their effects on reactions to aversive timulation. J Pers. Soc: Psychol 1971: 18: 157-162

42 Penebaker JV. Burnam MA. Schaeffer MA. Harper DC. Lack of control as a determinant of physical symptoms. J Pers Soc Psychol 1977: 35: 167-174

43 Glass DC. Singer JE: Urban Stress: Experiments on Noise and Soctal Stressors. New York: Academie Press. 1972.

44 Folkman S. Lazarus RS. An analysis of coping in a middle-aged community sumple. I Health Soc Behat 1980: $21 \cdot 219-239$

45 Wallston KA. Wallsion BS: Who is responsible for your health, the construct of health locus of control. in Sanders GS. Suls J eds. Social Psychology of Health and IIness. New Serscy: Lawrence Erlbaum. 1982.

to Rotter JB: Generalized expectancies for internal versus external control of reinforcemeist. Psychol Monogr 1966. 80 ino 609 )

47 Stricklend BR: Internalexternal expectancies and health related behavior. I Consule Cin Psuchol 1978: 46 $1192-1211$.

48 Breemhaar B. Visser APh. Kleijnen J: Perceptions and behaviour among elderly hospital pattents: description and explanation of age differences in satisfaction. knowledge. emotions and behaviour. Soc Sci Med 1990: $3 !: 1377-1385$.

49 Borne HW. van den Pruyn JFA. Lotgenotenconuct bij Kankerpatienten. Assen: Van Gorcum. 1985.

50 Johnson JE. Leventhal H: Elfects of accurate expectations and behavioral instructions on reactions during a noxious medical examination. I Pers Soc Psychol 1974: 29: $710-718$

51 Langer EJ, Janis IL. Wolfer JA: Reduction of psychological stress in surgical patients. I Exp Psychol 1975: 155-165

52 Taylor SE. Clark LF: Does information improve adjust- 
ment to noxious medical procedures? in: Saks MJ. Saxe L. eds. Advances in Applied Social Psychology. Vol 3. New Jersey: Lawrence Erlbaum, 1986.

53 Auerbach SM. Kendall PC. Cuttler HF. Levitt NR: Anxiety. locus of control, type of preparatory information, and adjusiment to dental surgery, J Consult Clin Psycho! 1976: 44: 809-818.

54 Andrew M: Recovery from surgery, with and without preparatory information for three coping styles. J Pers Soc Psychol 1970: 15: 223-226.

55 Hitton BA: The relationship of uncertainty, control. commitment and threat of recurrence to coping strategies used by women diagnosed with breast cancer. I Behav Med 1989: 12: 39-54.

56 DeLong RD: Individual differences in patterns of anxiety. arousal. stess-relevant information and recovery from surgery. Diss Abstr Int 1971: 32: 554b.

57 Shipley RH. Butt JH. Horwitz B. Farbry JE: Preparation for a stressful medical procedure: effect and amount of stimulus preexposure and coping style. J Pers Soc Psychol 1978: 46: 499-507.

58 Miller SM, Mangan CE: Interacting effects of information and coping style in adapting to gynaccologic stress: should the doctor tell all? J Pers Soc Psychol 1983: 45: 223-236.

59 Janis IL: Psychological Stress: Psychoanalytic and Behavioral Studies of Surgical Patients. New York: Wiley. 1958
60 Boeke S. Duivenvoorde HJ. Verhage F. Zwaveling A. Verband tussen peri-operatieve angst en postoperatief herstef. Nederlands Tijdschr Geneesk 1990: 134: 483-486.

61 Cohen F, Lazarus RS: Active coping processes, coping dispositions and recovery from surgery. Psychosom Med 1975: 35: 375-389.

62 Schulz R. Hanusa BH: Long term effects of control and predictability enhancing interventions: findings and ethical issues. J Pers Soc; Psychol 1978: 36: 1194-1201

63 Averill JR, O'Brien L. DeWitt GW: The influence of response effectiveness on the preference for warning and on psychophysiological stress reactions. J Pers 1977; 45: 395

64 Miller SM: When is a litule information a dangerous thing? Coping with stressfull events by monitoring versus blunting in: Levine S, Ursin $\mathrm{H}$ eds Coping and Health. New York: Plenum Press. 1980.

65 Bartlett EE: Putting patient education back into control. Patienı Educ Couns 1990: 16: 185-186

\section{Correspondence to:}

B. Breemhas

IVA, Institute for Social Research

University of Tilburg

PO BOX 90153

5000 L.E Tilburg

The Netherlands 


\title{
4 Inadequacies of Surgical Patient Education $^{12}$
}

\author{
B. Breemhaar ${ }^{3}$, H.W. van den Borne ${ }^{4}$, P.D. Mullen ${ }^{5}$
}

\subsection{Introduction}

Fear, anxiety, uncertainty, loss of control, and decrease of self esteem are emotional problems likely to be experienced by patients when confronted with the need for surgery and admission into hospital (1-7). Despite numerous evaluation trials demonstrating the success of preparation for surgery programs in decreasing aversive reactions (8-12), in every day practice most hospital patients do not receive such education and counseling $(13,14)$.

Previous studies of information provided by health care providers to surgical patients and patients' informational needs, found that lack of information is a common complaint of hospitalized (surgical) patients (13-16). Most surgical patients (80-90\%) prefer to receive extensive information preoperatively (17). Subjects about which surgical patients were found to desire more information concern the reason for surgery, the (sexual) consequences of surgery, specific medical details concerning surgical procedures, the functions of different health care providers, discharge from the hospital, and behavioral instructions during the post operative period and recovery at home (18-20). In addition, Visser (14) showed that many hospital patients have little relevant knowledge of their illness and treatment and, to a lesser extent, of facilities and regulations of the hospital (see also 13).

1 This study was made possible by a grant from the Dutch Praeventiefonds, projectnumber 26-20. The authors are grateful to Prof. dr. G.J. Kok (University of Limburg. Maastricht, The Netherlands) for his comments on an earlier version of this article.

2 Published in: Patient Education and Counseling, (1996), 28, 31-34. Reprinted with permission from the editor of Patient Education and Counseling.

3 Drs. B. Breemhaar is researcher at IVA, Institute for Social Research of the University of Brabant, Tilburg, The Netherlands.

4 Dr. H.W. van den Borne is professor of Patient Education at the Dept. of Health Promotion of the University of Limburg, Maastricht, The Netherlands.

5 Dr. P.D. Mullen is Professor of Behavioral Science and Health Education and Deputy Director, Center for Health Promotion Research and Development, University of Texas, School of Public Health, Houston, Texas, USA. 
Many factors keep health care providers from implementing patient education which, according to patients' standards, is adequate $(15,21)$. Temporal, spatial and personnel barriers have been mentioned as causes of inadequate patient education. Lack of time among staff members was observed as an important barrier by Wallace (13; see also: $16,22)$. Also, lack of support for nurses doing patient education and the widespread belief among professionals that they are already engaged in comprehensive patient education have also been observed as contributing to insufficient information provision (23). Lindeman \& Van Aernam (24) mentioned ambiguity among hospital nurses concerning responsibilities for particular educational tasks and concerning the content of surgical patient education, as barriers to adequate information transmission. Finally, on the part of health care providers, causes of insufficient provision of information include a professional attitude among physicians which is predominantly medical-technological, reluctance to offer information, and misconceptions of patients' medical knowledge and their ability to remember information $(13,25)$.

Nevertheless, it is desirable that health care professionals themselves conduct patient education, because they have regular and extensive contacts with patients while carrying out treatment and care tasks (40). Indeed, patients wish to receive information from "their own" doctors and nurses $(26,17)$. Second, patient education is officially considered an essential element of complete patient care in hospitals, both in The Netherlands (27) and in the U.S. $(28,29)$. Third, patient education is more likely to be continued when it is carried out by health care providers themselves; patient education performed on a temporary basis by someone from outside the hospital is likely to be terminated when the project is finished, or when priorities shift. Finally, when primary health care providers successfully supply patient education, instead of some other employee, this may help to decrease hospital costs (30).

Successful implementation of patient education measures which are suited for application by hospital staff members, requires their compatibility with everyday hospital practices and with skills and attitudes of hospital staff members (31). This is required first, because regular treatment and care tasks should not be disrupted by patient education measures. Second, because it has been demonstrated that innovations, like patient education, are more likely to be implemented successfully when they are compatible with the existing values and needs of the potential users (32). Therefore, Orlandi et al. (33) consider collaboration between developers and potential providers of a health education program as an essential prerequisite to its adoption and diffusion.

Consequently, measures to improve patient education should be based on an explicit and complete picture of the existing practices with regard to treatment, care and education of patients undergoing surgery in a given hospital. This requires close examination of the practices taking place during the period from the patient's first visit to the surgeon at the ambulatory department of the hospital and his or her last visit to the surgeon after discharge from the hospital where he or she underwent surgery. Questions that should be answered include: Which problems exist with regard to patient education for patients undergoing a particular type of surgery in a specific hospital? What opportunities are available to resolve these problems? What constraints jeopardize application of solutions? 
In this article we describe a study of the course followed by patients undergoing cholecystectomy or herniorrhaphy while hospitalized for surgery. The study examined the events happening to patients, information given to them and their subjective experiences. It aimed at answering the following questions: 1) Which events happen to patients undergoing cholecystectomy or herniorrhaphy in the hospital during the course of their treatment? 2) In what order do these events take place? 3) Whom are patients interacting with during these events? 4) What information and support do they receive? 5) What are the subjective experiences of patients during the events and upon receiving this information and support? The study is meant to provide the necessary foundation for development and implementation of patient education procedures which are suitable for application by members of the hospital staff.

We selected cholecystectomy and herniorrhaphy because both are performed frequently in The Netherlands ${ }^{6}$, and because they are considered exemplary of surgical procedures of intermediate seriousness (41). Herniorrhaphy is a fairly uncomplicated type of surgery, with respect to the seriousness of the underlying physical defect, the operation itself, and post-operative recovery. Patients undergoing cholecystectomy usually have a longer and more complicated history of illness, the operation is more complex, and recovery requires more time.

\subsection{Method}

The examination was carried out in two 600-bed general hospitals in The Netherlands. The method of data collection was based on previous investigations of patient education in Dutch hospitals $(19,35,36)$, and will be explained below. Before the start of the examination, we approached the management and the surgical staff of each hospital to explain the objectives of the project. An important condition facilitating their support was that they considered improvement of patient education advantageous, because it might lead to improved relationships with patients. Next, we discussed the method of the examination with all of the other relevant disciplines (clinical and ambulatory nursing staff, anesthetists, physiotherapists). They were asked for advice on the method of the examination, to increase its perceived validity.

\section{Observations}

In both hospitals observations were performed of interactions between patients and health care providers (see Table 4.1). In the first hospital, relevant events and locations to be observed were chosen in cooperation with the medical staff. In the second hospital, fewer events and locations were observed compared to the first hospital. Based on the experiences with observations in the first hospital, it was decided to limit the observations in the second hospital to occasions that were considered most relevant to patient education. During each event, the observations focussed on 1) the health care professionals who met operations of the gallbladder or biliary ducts and $11.8 \%$ were herniorrhaphies (34). 
with the patients, 2) events taking place for medical examination and therapy, 3) the information given by the health care provider to the patient, 4) his or her non-verbal behavior, 5) emotional reactions of patients, 6) the questions they asked and other (non-)verbal reactions to the health care provider, and 7) the environment in which the event took place. An observation of an event lasted approximately one morning or one afternoon.

Table 4.1: Number of half-day observations performed in both hospitals.

\begin{tabular}{lcc}
\hline & Hospital 1 & Hospital 2 \\
\hline Ambulatory department & 4 & 2 \\
Patient Information Desk & 1 & - \\
Blood department & 1 & - \\
Electro cardiography department & 1 & - \\
Department of radiology & 1 & - \\
Admission administration & 1 & 4 \\
Clinical surgical wards & 8 & 1 \\
Physiotherapy & 1 & 1 \\
Patient visit by surgeons & 4 & 1 \\
Patient visit by anesthetist & 1 & 1 \\
Introductory room and recovery room (operating theatre) & 2 & - \\
Anesthetist (operating theatre) & 2 & - \\
Dietician & 1 & \\
\hline
\end{tabular}

\section{Interviews with health care providers}

Open-ended interviews with relevant health care providers in both hospitals provided information about the following subjects: events occurring to cholecystectomy and herniorrhaphy patients during the course of their stay in the hospital, the sequence of these events, what is being done during the events, with whom the patient is interacting during the events, which information is provided to patients during the events, and common reactions of patients like asking questions, emotional and physical reactions. Further, general information was obtained concerning medical details, length of stay, administrative procedures, diet and exercise prescriptions after surgery, pre- and postoperative treatment, and behavioral recommendations for patients after discharge. The interviews were guided by a list of relevant subjects, which differed between interviews depending on the interviewee's discipline. Thus, the number of subjects discussed and, consequently, the length of the interviews varied between cases. During each interview notes were made of the answers given, which were subsequently extended to a complete report of the interview.

In both hospitals, interviews were held with one member of each of the following disciplines: general surgery, ambulatory nursing, clinical nursing (two interviews in hospital 1), admission administration, anesthesiology (two interviews in hospital 1), and physiotherapy. In addition, in the first hospital interviews were held each with one of the following staff members: head of the patient education desk, dietician, and head of the operating theatre. The first interviews were held with members of disciplines whose relevance for the treatment and care of surgical patients in the hospital was obvious (e.g. 
surgeons, clinical nurses of the surgical ward). Additional interviewers were selected according to their relevance as this became clear in previous interviews. Relevant informers were asked to participate by letter or orally, after announcement in a news bulletin for hospital personnel of the hospital management's and the surgical staff's approval of the project. All staff members approached for participation agreed to cooperate.

\section{Patient interviews}

Open-ended interviews were held with cholecystectomy and herniorrhaphy patients and recorded on audio tape. Patients were interviewed at various stages before, during, and after their stay in hospital. In the first hospital eight stages were identified. Because this appeared to be unnecessarily detailed, in the second hospital the number of stages was reduced to three (see Table 4.2). In each stage, interviews were held with cross-sectional samples of patients. During the interviews the events were discussed in chronological order. For each stage we focussed on the following subjects for every event of interest: 1) information received, 2) subjective experiences, and 3) behavior of the patient and health care provider. Also, although less detailed, information was collected about events that occurred before the stage covered by the interview. We attempted to distribute the interviews evenly across the stages. To participate in the open-ended interviews, patients had to meet with the following criteria: 1) 18 years or older, 2) no urgency involved, 3) command of the Dutch language, and 4) no other reason for admission besides surgery for gall stones or inguinal hernia. Patients were randomly recruited by consecutive enrollment, after they were scheduled for surgery. When they agreed to participate, the interviewer made an appointment for the interview. Table 4.2 shows the number of patients interviewed in each stage. Each interview lasted approximately one hour to one hour and a half. The interviews were recorded on tape and subsequently a transcription was made.

Table 4.2: Number of open-ended interviews with patients in each stage.

\begin{tabular}{lcc}
\hline & Cholecystectomy & Herniorrhaphy \\
\hline Hospital 1 & 0 & 0 \\
1. After first visit to the ambulatory department & 0 & 1 \\
2. Shortly before admission & 2 & 2 \\
3. Shortly after admission & 0 & 2 \\
4. On the evening before surgery & 7 & 2 \\
5. Shortly after surgery & 0 & 4 \\
6. Shortly before discharge & 1 & 1 \\
7. Before the first follow up visit & 2 & 1 \\
8. After the first follow up visit & & \\
Hospital 2 & & 2 \\
1. Before admission & 1 & 3 \\
2. Shortly after surgery & 1 & 2 \\
3. After discharge & 0 & \\
\hline
\end{tabular}


In the first hospital, 12 patients undergoing cholecystectomy and 13 patients undergoing herniorrhaphy were interviewed. In the second hospital 2 patients undergoing cholecystectomy and 7 patients undergoing herniorrhaphy were interviewed. Unfortunately, in this hospital a relative large proportion of the patients undergoing cholecystectomy who were approached for participation $(n=7)$ did not participate. One of them refused participation, while four others, although they were scheduled for admission, were not actually admitted into the hospital during the period in which the interviews were held. We undertook a smaller number of open-ended interviews in the second hospital compared to the first, because in addition to the open-ended interviews, in this hospital structured interviews were held as well (see below). In both hospitals fewer patients were interviewed in the early and the last stages of their hospital stay, compared to interviews held at intermediate stages. This was because sometimes patients were admitted into the hospital sooner than expected, leaving insufficient time to approach them properly for participation in an interview before admission. Also, some patients could not be contacted after discharge at their home address because they temporarily lived elsewhere or because address information was incorrect. Consequently, the information collected about the last stages may be incomplete. In contrast, we expect the information about the early stages to be complete, since every patient was asked retrospectively about events that happened before the stage in which he or she was interviewed. However, the information about the early stages may be colored by subsequent experiences for many patients. In both hospitals, more men than women were interviewed. This is the result of the fact that more patients undergoing herniorrhaphy were interviewed than cholecystectomy, while herniorrhaphy is performed more often in men. The patients who were interviewed were distributed evenly across three age categories (18-30, 31-50 and 50 years and older).

\section{Structured interviews with patients}

In hospital 2, data were collected by means of structured questionnaires about the following topics: 1) need for information with respect to hospital facilities, ward regulations, name and function of relevant health care providers, and medical details (four-point scale; measured two times: 18 items pre-operatively, 16 items after surgery), 2) pre-operative fear (measured pre-operatively: six items with four-point scale), and 3) amount of written information and amount of oral information received from physicians, nurses, anesthetist, and in case of cholecystectomy patients only, physiotherapist, and dietician (two-point scales; measured three times: 16 items pre-operatively, 11 items post-operatively, and 9 items one week after discharge). More detailed information concerning the measurement of the variables is described elsewhere (37).

All patients admitted to this hospital for cholecystectomy or herniorrhaphy during November 1990 through April 1991 were approached for participation in the interviews. They met the same criteria as patients participating in the open-ended interviews. Of 91 patients asked to participate, 64 patients met our eligibility criteria (83\%). Ten eligible patients refused participation (16\%). Six patients were not interested in participation, while one patient was treated as a day surgery case and another had not understood the purpose of participation. Finally, from two patients the reason for refusal is unknown. Table 4.3 shows the distribution of gender and age of patients who were interviewed. 


\begin{tabular}{llcc}
\hline & & \multicolumn{2}{c}{ No. of patients } \\
\cline { 3 - 4 } Sex: & Male & Cholecystectomy & Herniorrhaphy \\
\cline { 3 - 4 } & Female & 17 & 31 \\
& & & 2 \\
Age: & $18-30$ & 2 & 4 \\
& $31-50$ & 9 & 15 \\
& 51 and older & 10 & 14 \\
\hline
\end{tabular}

\section{Data analysis}

Each open-ended interview and each observation was processed separately for each separate phase in the routing. Within each phase, we distinguished between health care providers whom the patients met for diagnostic, treatment, care, or administrative reasons. Separately for each meeting, the data from the interviews and the observations were arranged with respect to: a) what was done (actions) during the meeting by the health care provider, b) what oral or written information was provided to the patient, c) how the patient (re)acted (e.g. asking questions, showing emotions), and d) how he or she felt during the event (e.g. (dis)satisfied, afraid, uncertain). Each time when a health care provider's action, particular type of information, a patient's (re)action, or feeling was mentioned in an interview or observed for the first time, it was written down under the particular phase and meeting at hand. Each time when it was mentioned in a next interview or observation, it was tallied to the previous one. This provided a qualitative picture with strong face validity of the events taking place before, during, and after hospitalization for surgery, with particular attention to patients' informational nceds, the information they received and their reactions. The frequencies of patients' answers to the structured interviews were recorded and provided additional information.

\subsection{Results}

\section{Routing through the hospital}

Figure 4.4 shows the routing through the hospital of patients undergoing herniurrhaphy and cholecystectomy, divided into four stages: 1) the period before admission into the hospital, 2) the period from the admission to the operation, 3) the period from the operation to discharge from the hospital, and 4) the period after discharge. Displayed are the events that took place in each stage, the location where the events took place and the persons patients met during these events. 


\begin{tabular}{|c|c|c|c|c|c|}
\hline Phase: & Event: & Aspects of the event: & Location: & Involved: & \\
\hline \multirow[t]{3}{*}{1.} & $\begin{array}{l}\text { Before } \\
\text { admission }\end{array}$ & $\begin{array}{l}\text { Visit of general } \\
\text { practitioner }\end{array}$ & $\begin{array}{l}\text { - Questioning and physical } \\
\text { examination } \\
\text { - Information, explanation } \\
\text { - Referral to surgeon }\end{array}$ & $\begin{array}{l}\text { General practitioners } \\
\text { office }\end{array}$ & $\begin{array}{l}\text { - General practitioner } \\
\text { - Secretary }\end{array}$ \\
\hline & & $\begin{array}{l}\text { Echography } \\
\text { (cholecystectomy } \\
\text { patients) }\end{array}$ & $\begin{array}{l}\text { - Asking questions } \\
\text { - Examination } \\
\text { - Explanation }\end{array}$ & $\begin{array}{l}\text { Radiology department } \\
\text { of the hospital }\end{array}$ & $\begin{array}{l}\text { - Receptionist } \\
\text { - X-ray technician } \\
\text { - Radiologist }\end{array}$ \\
\hline & & $\begin{array}{l}\text { Registration for } \\
\text { admission }\end{array}$ & & $\begin{array}{l}\text { Admission registration } \\
\text { desk }\end{array}$ & $\begin{array}{l}\text { Admission } \\
\text { desk clerk }\end{array}$ \\
\hline 2. & $\begin{array}{l}\text { Admission up } \\
\text { to surgery }\end{array}$ & Admission & $\begin{array}{l}\text { - Calling at admission } \\
\text { registration desk } \\
\text { - Intake procedure }\end{array}$ & $\begin{array}{l}\text { Ambulatory depart- } \\
\text { ment } \\
\text { Clinical ward }\end{array}$ & $\begin{array}{l}\text { - Admission } \\
\text { desk clerk } \\
\text { - Nurse }\end{array}$ \\
\hline
\end{tabular}




\begin{tabular}{|c|c|c|c|c|c|}
\hline Phase: & Event: & Aspects of the event: & Location: & Involved: & \\
\hline & & $\begin{array}{l}\text { Preparations } \\
\text { for surgery }\end{array}$ & $\begin{array}{l}\text { - Stop eating, drinking } \\
\text { - Premedication } \\
\text { - Dress in operation gown } \\
\text { - Remove wrist watch, make } \\
\text { up, contact lenses, etc. }\end{array}$ & Clinical ward & - Nurse \\
\hline & & $\begin{array}{l}\text { Arrival at operating } \\
\text { ting theatre }\end{array}$ & $\begin{array}{l}\text { - Check medical documents } \\
\text { - Lay down on operating } \\
\text { table }\end{array}$ & Recovery room & $\begin{array}{l}\text { - Recovery room nurse } \\
\text { - Operating theatre nurse } \\
\text { - Anesthetist's assistant }\end{array}$ \\
\hline \multirow[t]{3}{*}{3.} & $\begin{array}{l}\text { Surgery up to } \\
\text { discharge }\end{array}$ & $\begin{array}{l}\text { Recovery from } \\
\text { anesthesia }\end{array}$ & & Recovery room & $\begin{array}{l}\text { - Recovery room nurse } \\
\text { - Anesthetist }\end{array}$ \\
\hline & & Recovery & $\begin{array}{l}\text { - Release pain } \\
\text { - Start drinking and eating } \\
\text { - Mobilisation } \\
\text { - Remove infusion } \\
\text { - Assistance with respiration } \\
\text { (possibly cholecystectomy } \\
\text { patients) } \\
\text { - Removal of unund drain (pos- } \\
\text { sibly cholecystectomy patients) }\end{array}$ & Clinical ward & $\begin{array}{l}\text { - Nurse } \\
\text { - Ward physician } \\
\text { - Physiotherapist (possibly } \\
\text { cholecystectomy patients) } \\
\text { - Sungeon (possibly) }\end{array}$ \\
\hline & & Discharge & - Information, explanation & Clinical ward & $\begin{array}{l}\text { - Ward physician } \\
\text { - Nurse } \\
\end{array}$ \\
\hline 4. & After discharge & $\begin{array}{l}\text { Visit ambulatory } \\
\text { department }\end{array}$ & $\begin{array}{l}\text { - Asking questions } \\
\text { - Removing clips }\end{array}$ & $\begin{array}{l}\text { Ambulatory depart- } \\
\text { ment }\end{array}$ & $\begin{array}{l}\text { - Surgeon } \\
\text { - Nurse of ambulatory } \\
\text { department }\end{array}$ \\
\hline
\end{tabular}


At least 17 different events were found to occur during the course of treatment and care (see Figure 4.4). For cholecystectorny, this number increased when echography and physiotherapy were required and when the patient had a wound drain. Patients also met many different health care providers during the course of their treatment and care. Patients undergoing herniorrhaphy met on an average 19 different physicians, nurses, laboratory workers and administrative employees. Patients undergoing cholecystectomy met on an average 22 different professionals. Further, these events took place at many locations. Both patients undergoing herniorrhaphy and patients undergoing cholecystectomy visited at least nine different places during their course of treatment, including the ambulatory department, the admission registration desk, the clinical ward, the operating theatre, the recovery room, and so on. In addition, all patients undergoing cholecystectomy visited the radiology department. These numbers of people and locations increased when additional medical information was required and when supplementary examinations were performed and extra physicians were consulted. On average, patients undergoing herniorrhaphy stayed in the hospital 3.7 days, while patients undergoing cholecystectomy stayed 8.1 days.

\section{Problems experienced by patients}

The structured interviews show that almost $50 \%$ of the patients reported fear of anesthesia, post-operative pain, and of side effects (see Table 4.5). Also, many patients wished to receive more information about anesthesia and post-operative physical conditions (see Table 4.6). During the open-ended interviews, most patients indicated that they were afraid of anesthesia. E.g. one patient mentioned: "I hope that I will wake up from the narcosis. I am more afraid of the narcosis than the operation itself, because after all, there is some risk involved". We conclude that many patients experienced fear of anesthesia and of side effects of the operation, and that they wished to receive more information about both.

Table 4.5: Percentage of patients having fear of aspects of surgery (resulss of interviews at day of admission $n=54$ ).

\begin{tabular}{|c|c|c|c|c|c|}
\hline & & $\begin{array}{c}\text { not at all } \\
\%\end{array}$ & $\begin{array}{l}\text { slightly } \\
\%\end{array}$ & $\begin{array}{c}\text { considerably } \\
\%\end{array}$ & $\begin{array}{l}\text { very much } \\
\%\end{array}$ \\
\hline 1. & Worried about illness & 52 & 37 & 7 & 4 \\
\hline 2. & Worried about operation & 69 & 20 & 7 & 4 \\
\hline 3. & Worried about narcosis & 59 & 22 & 11 & 7 \\
\hline 4. & Afraid of post-operative pain & 50 & 41 & 4 & 6 \\
\hline 5. & Afraid of surgical mistake & 52 & 41 & 6 & 2 \\
\hline 6. & $\begin{array}{l}\text { Afraid of post-ope- } \\
\text { rative side effects }\end{array}$ & 57 & 35 & 6 & 2 \\
\hline 7. & $\begin{array}{l}\text { Afraid of extended stay } \\
\text { in the hospital }\end{array}$ & 83 & 15 & - & 2 \\
\hline
\end{tabular}

Approximately $50 \%$ of the participants in the structured interviews wished to receive more information about their current physical condition, the cause of their illness, its 
consequences, and about how the operation is performed (see Table 4.6). On the first day of their stay in hospital, during the open-ended interviews several patients expressed uncertainty about the events that would take place after admission. Also, many patients were not aware of the things that were to happen in the first days after the operation and were unpleasantly surprised by drains, the need to mobilize quickly, and so forth. One patient complained: "... but I don't know what exactly happened. They didn't tell me, I had to ask it myself. The nurses told me that maybe the gallbladder would have to be removed, but nobody said to me that they would really take it away." Summarizing, we conclude that many patients wanted more information about medical details.

Table 4.6: Percentage of patients wishing to receive more information about several aspects of surgery (results of interviews at day of admission, $n=54$ ).

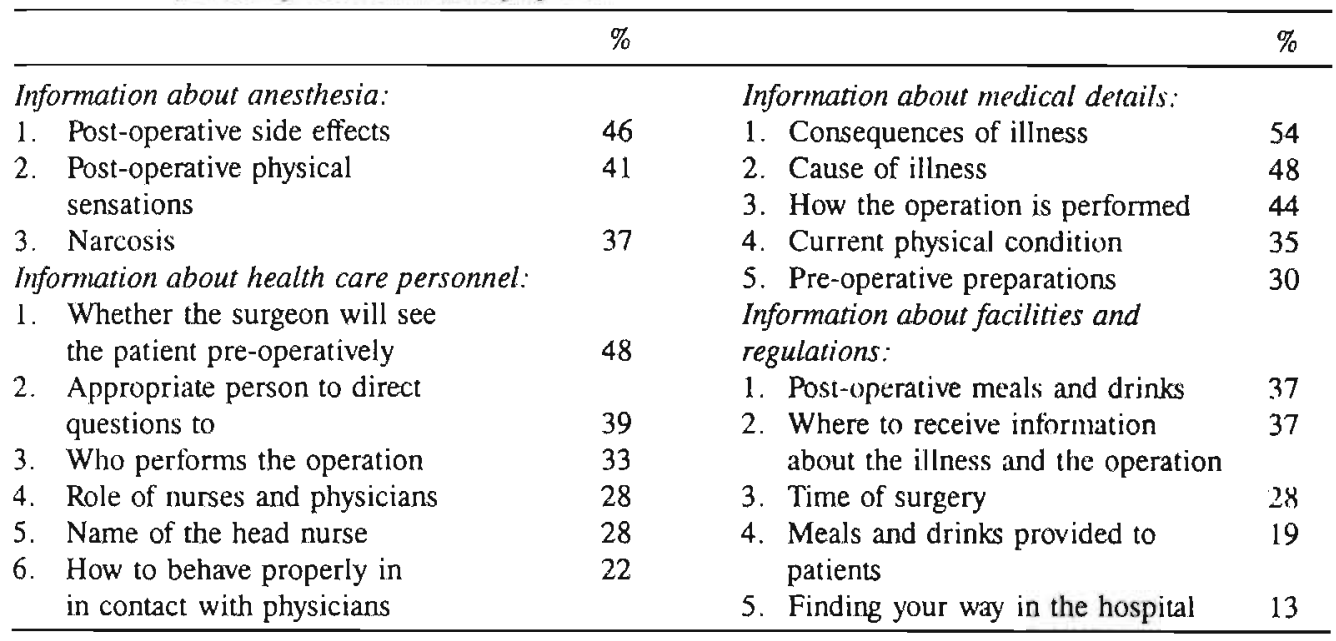

To many patients it was not clear which role various health care providers played in the process of their treatment and what their respective responsibilities were. For example, of the patients participating in the structured interviews, $48 \%$ desired to know whether the surgeon would visit them before the operation (see Table 4.6). This uncertainty more often concerned physicians, than nurses. Further, almost $40 \%$ of the patients wished to receive more information about the appropriate person whom to direct his or her questions to. During the open interviews, patients often indicated uncertainty about functions and responsibilities of the personnel they met. Some patients showed disappointment because of the superficial personal contact with "their" doctor. One patient said: "I don't know exactly who was the ward physician. Is he the person who always accompanies the head nurse and who also announces that you may go home?" During our observations of the visits by an anesthetist, one patient mistook the anesthetist for a priest. We conclude that many patients felt uncertain about the roles and functions of various health care providers. 
Table 4.7: Percentage of patients wishing to receive more information about several aspects of admission and surgery (results from interviews in the early post-operative period; $n=48^{l}$ ).

\begin{tabular}{|c|c|c|c|}
\hline & $\mathscr{q}$ & & $\%$ \\
\hline \multicolumn{2}{|l|}{ Information about persons: } & \multicolumn{2}{|l|}{ Information about facilities and } \\
\hline \multirow{2}{*}{$\begin{array}{l}\text { 1. Talk to physician before } \\
\text { discharge }\end{array}$} & \multirow[t]{2}{*}{44} & regulations: & \\
\hline & & 1. Where to receive information & 15 \\
\hline 2. Role of nurses and physicians & 31 & about illness and operation & \\
\hline 3. Who performed the operation & 21 & 2. Opportunities for recreation & 8 \\
\hline 4. How to deal with physicians & 13 & 3. Find your way in the hospital & 6 \\
\hline \multicolumn{2}{|l|}{ Information about medical details: } & \multicolumn{2}{|l|}{ Information about discharge and } \\
\hline \multirow{2}{*}{$\begin{array}{l}\text { 1. What has been done during } \\
\text { surgery }\end{array}$} & \multirow[t]{2}{*}{44} & recovery at home: & \\
\hline & & 1. How to improve physical & 50 \\
\hline \multirow{2}{*}{$\begin{array}{l}\text { 2. Consequences of surgery and } \\
\text { anesthesia }\end{array}$} & \multirow[t]{2}{*}{25} & condition & \\
\hline & & 2. Proper behavior after discharge & 40 \\
\hline 3. Current physical condition & 25 & 3. When will clips be removed & 40 \\
\hline \multirow[t]{3}{*}{ 4. Reason for fast mobilisation } & \multirow[t]{3}{*}{8} & 4. Best method to recover at home & 31 \\
\hline & & 5. Time of discharge & 21 \\
\hline & & 6. Dieting behavior ${ }^{2}$ & 15 \\
\hline
\end{tabular}

1 The number of patients is smaller than on the day of admission, because some were not interviewed for a scond time.

$2 \quad$ Asked to patients undergoing cholecystectomy only.

Of the paticnts participating in the structured interviews one week after discharge, approximately $50 \%$ had received information about discharge and about appropriate behavior after discharge from a nurse. Only 30\% received information about these subjects from the ward physician. More information on these subjects was desired by 30 $50 \%$ of the patients (see Table 4.7 ). The open-ended interviews confirm these results. Many patients said that they were not informed about proper behavior after discharge in order to facilitate recovery. One patient explained that she was taken by surprise: "On Friday morning the ward physician said to me: "You're doing fine; you can go home tomorrow". I was really amazed ..., because it was so soon. You know, the moment you are home, you find yourself back in the middle of running a family. And that is exhausting. Another thing is the diet. I had gone through the booklet and I was wondering how I would be able to prepare something decent for myself". We conclude that many patients wished to receive more information about expected discharge from hospital and about appropriate behavior after discharge to facilitate recovery.

Results of both the interviews with patients and with health care providers, as well as the results of the observations show that the problems experienced by patients, first can partially be related to organizational circumstances in the hospital that jeopardize proper patient education. Secondly, their problems seem to be caused by shortcomings in the methods by which health care providers offer information to patients.

\section{Organizational barriers to patient education}

In one of the hospitals it was customary for one and the same anesthetist to visit all patients whose operation was scheduled next day, to check their medical condition and to 
provide them with information. Also, he or she had the complete the anesthesia of the final operations that day and to attend to operations of urgent patients. This often caused interruptions of the visits, and sometimes patients were not visited at all. One anesthetist complained that this schedule sometimes caused him to visit patients as late as $10.30 \mathrm{p} . \mathrm{m}$. Therefore, we conclude that anesthetists' case load was too large to allow for proper surgical patient education.

As observed before, patients met many different health care providers during their hospital stay (see Figure 4.4). All these different faces with different functions and responsibilities sometimes confused patients, making it difficult for them to obtain the desired information from the most appropriate person. It is concluded that the large variety of health care providers patients met, hindered them in their attempts to obtain appropriate patient education.

The observations revealed various examples of inadequate interplay between health care providers with respect to information giving. For example, a nurse directed a patient to the surgeon to obtain specific information. However, the surgeon did not arrive on that particular day. Another patient was, besides herniorrhaphy, to undergo surgery for varicose veins. On admission, the nurse performing the intake procedure was not aware of this additional operation ${ }^{7}$. It can be concluded that a lack of coordination was found among health care providers. The methods of physicians and nurses to distribute knowledge about patients between one another were vulnerable to mistakes, resulting in lack of information or contradictory information.

Finally, the timing of visits by physicians was found to be difficult to predict. Their visit sometimes took patients by surprise, making it hard for them to prepare for the visit, to process the information that is given adequately, and to ask questions properly. Also, the visit sometimes took place at inconvenient locations, e.g. in a corridor or in the recreaton room.

\section{Inadequacies of the method of providing information}

The structured interviews show that many patients received no oral information on certain subjects at specific occasions (see Table 4.8). Comparison of patients' answers to questions concerning subjects about which they desired additional information and concerning subjects about which they had received oral information from staff members showed that this variation did not always correspond with variation in patients' needs and interests. Written materials were not always provided either. For example, on admission, $25 \%$ of the patients did not receive an information leaflet about the surgical staff or about the ward. Some patients stated during the open-ended interviews that they were not informed about medical details concerning the illness and the operation during their consultation with the surgeon at the ambulatory department. Also, according to patients, the content of the information offered by the nurse on admission varies widely. We conclude that the information was sometimes provided non-systematically and inconsistently.

Since the patient registration desk was not informed either about this additional reason for admission into the hospital, this patient was included in our open-ended interviews. 
Table 4.8: Percentage of patients that received oral information on admission from a nurse, ward physician and/or surgeon (results from preoperative interviews, $n=54$ ).

\begin{tabular}{lccc}
\hline & Nurse & Ward physician & Surgeon \\
\hline & $\%$ & $\%$ & $\%$ \\
Information about: & 54 & 56 & 67 \\
1. The illness and the operation & 85 & 44 & 31 \\
2. Preparations for the operation & 30 & 24 & 24 \\
3. Post-operative recovery & 56 & 2 & 2 \\
4. Ward regulations and facilities & & & \\
\hline
\end{tabular}

Many patients had difficulties in obtaining information from the physician. During the open-ended interviews, one patient said "The surgeon who was to perform the operation was to see me, but he did not show up. He only came the next morning, and was in a hurry. He introduced himself: 'I am doctor ... and in a few moments I am going to remove your gall bladder'. And that was all. He added 'Within one and a half hour we will collect you'. Those people are busy, I agree. But like this it is useless. He might as well not have come". Many things were not explained by physicians and frequently patients had to ask for information themselves. According to patients, contacts between physicians and patients often took place hastily and in an impersonal manner. The observations showed that patients often directed their questions to nurses, while obviously, these questions were meant for a physician. It is concluded from these findings that often, physicians are reluctant in offering information.

One third of the patients who participated in the structured interviews, said not to have met the anesthetist before the operation. If he or she did visit the patient, subjects considered important by the patient were not always discussed. Also, the observations showed that frequently patients were informed by the anesthetist hastily and sometimes superficially. It is concluded that regularly, patients received no information from the anesthetist, and when they did, the information was scarce and inconsistent.

Finally, it was observed that the provision of information at specific moments did not match with patients' needs for information at that time. On the one hand, on admission patients received a great deal of information all at once, which was difficult for them to process adequately. This was in particular the case because at that time they were still unfamiliar with the hospital environment and with the persons they met. On the other hand, at discharge they received less information than desired. In particular, from both the open-ended and the structured interviews it was clear that patients lacked information concerning appropriate behavior to facilitate recovery after discharge (See Table 4.7). From these findings it is concluded that the information provided to patients is distributed unevenly over time.

\subsection{Discussion}

In this study among patients undergoing herniorrhaphy or cholecystectomy in two Dutch hospitals, it was lound that during their hospital stay, patients experienced fear of 
anesthesia and side effects of anesthesia, and of post-operative pain. Also, they experienced lack of information about medical aspects of their disease, the operation and anesthesia, about the roles and responsibilities of the various health care providers they met during the course of surgery and recovery in hospital, and about discharge. The results suggest that the information which patients did receive, corresponded insufficiently with their need for information. This appeared to be caused in the first place by the circumstances under which patients are treated and cared for. The large number of health care providers involved in treatment and care of one and the same patient and their heavy work load affected patient education unfavorably. Second, the content of the information provided to patients at particular occasions, concerning particular subjects was found to vary within a health care provider and between different health care providers. This seemed not to be related to differences between patients' informational needs. In particular physicians appeared to be reluctant to respond to patients' inquiries. Also, information giving by various health care providers to one and the same patient was not well coordinated. Finally, patients received too much information on the day of admission, while they received little information at discharge.

Since relatively few patients were interviewed about their experiences during the final stages of the course of illness, surgery, and recovery, the information about events happening to patients at home and problems experienced after discharge from the hospital, may be incomplete. Thus, the treatment and information received from the general practitioner after discharge and, eventually from the surgeon during a post hospitalisation visit, did not receive proper attention in this study. However, since the main objective of the study was to examine information provision by staff members during admission, together with its shortcomings, in order to find opportunities to improve information provision, this is not considered as a relevant omission.

In hospital 1, data collection among patients was limited to open-ended interviews, while in hospital 2, besides open-ended interviews, structured interviews were carried out as well. Despite this variation between both hospitals in methodology of data collection among patients, we believe that essentially, the results of the study concerning problems experienced by patients are equally representative for both hospitals. First, because the findings of the structured interviews in hospital 2 were - more qualitatively - confirmed by those of the open-ended interviews in both hospitals. Second, because after discussion of the conclusions drawn from the results of the study, all relevant health care providers in both hospitals largely supported these conclusions (42).

Because, as explained in the introduction, cholecystectomy and herniorrhaphy may be considered as representative for most types of surgery of mild to intermediate seriousness, the results are believed to be applicable to most surgical patients in both hospitals that participated in the study. Also, since the results do not deviate remarkably from. those of previous studies of surgical patient education $(13-16 ; 18-20)$, they are likely to be representative for surgical patients in other hospitals. However, since many additional psychosocial problems relate to patients undergoing surgery for a life threatening illness (e.g. heart failure, cancer), we feel that the results cannot be generalized to this category of patients. 
The results of this study are believed to provide a sound basis for developing programs to improve surgical patient education, which can be carried out by health care providers. First, since the results are based on realistic and relevant information delivered by patients and health care providers, they may serve as an "eye opener" to health care providers. Second, they show a complete picture of the medical, nursing, and informational procedures taking place during hospitalisation for surgery, together with their shortcomings as experienced by patients. This picture is suited properly for validation by intersubjective agreement among relevant health care providers involved in treatment and care of herniorrhaphy and cholecystectomy patients. Finally, since the results indicate both opportunities and limitations for improving patient education, they provide starting points to be addressed by programs to improve patient education.

To improve surgical patient education, the results suggest first that the content of information delivered to patients should be improved. Topics to be considered are listed for example, by the U.S. Department of Veteran's Affairs (38) and by Devine (39). In particular, our results suggest the need to increase the amount of information provided regarding the role and functions of health care providers, medical aspects of the illness and preparations for and recovery from surgery and anesthesia, and about behavior facilitating recovery after discharge. Second, the method of information provision requires improvement. The consistency of information should be improved, in order to provide each patient with relevant and generally applicable information. Also, the information should be distributed more evenly across the course of treatment (more information before admission, i.e. at the ambulatory department, and at discharge, and less information on the day of admission). Inconsistencies and gaps in information provision should he avoided by unambiguous delineation of the responsibilities and tasks concerning information provision by different health care providers.

Based on the results of the current study, in both hospitals programs were developed to improve surgical patient education, in close cooperation with relevant staff members providing treatment and care for surgical patients. An extensive description of the process of development can be found in Breemhaar, Van den Borne \& Mullen (42).

\section{References}

1. Boeke, S. (1988),

Psychologische aspecten van het ondergaan van een operatie (diss.), Erasmus Universiteit, Rotterdam.

2. Johnston, M., Impending surgery, in: S. Fisher and J. Reason, (eds.) (1988), Handbook of life stress, cognition and health, Wiley \& Sons, New York.

3. Ray, C. (1982),

The surgical patient: psychological stress and coping resources, in: J.R. Eiser (ed.), Social psychological and Behavioral Medicine, Wiley, New York.

4. Salo, M. (1982),

Endocrine responses in anesthesia and surgery, in: J. Watkins and M. Salo (eds.), Trauma, stress and immunity in anesthesia and surgery, Butterworth, London. 
5. Mathews, A., Ridgeway, V. (1981),

Personality and surgical recovery: a review, British Journal of Clinical Psychology, 20, 243-260.

6. Wilson-Barnett, J. (1979),

Stress in hospitals, New York, Churchill, Livingstone.

7. Volicer, B.J., Isenburg, M.A., Burns, M.W. (1977),

Medical-surgical differences in hospital stress factors, Journal of Human Stress, june, 3-13.

8. Johnston, M., Vogele, C. (1993),

Benefits of psychological preparation for surgery: a meta-analysis, Annals of Behavioral Medicine, 15, 245-256.

9. Devine, E.C. (1992),

Effects of psychoeducational care for adult surgical patients: a meta-analysis of 191 studies, Patient Education and Counseling, 19, 129-142.

10. Kincey, J., Saltmore S. (1990),

Surgical treatments, in: M. Johnston and L. Wallace (eds), Stress and Medical Procedures, Oxford Medical Publications, Oxford.

11. Miller, S. (1989),

Information, coping and control in patients undergoing surgery and stressful medical procedures, in: A. Steptoe and A. Appels (eds.), Stress, Personal Control and Health, Wiley \& Sons, New York.

12. Taylor, S.E., Clark, L.F. (1986),

Does information improve adjustment to noxious medical procedures?, in: M.J.

Saks and L. Saxe, Advances in Applied Social Psychology, vol 3, Lawrence Erlbaum Associates, New Jersey.

13. Wallace, L.M. (1986),

Informed consent to elective surgery: the 'therapeutic' value?, Social Science and Medicine, 22, 29-33.

14. Visser, A. Ph. (1986),

Patient in het Ziekenhuis, Van Gorcum, Assen.

15. Webber, G.C. (1990),

Patient education, a review of the issues, Medical Care, 28, 1089-1103.

16. Engström, B. (1984),

The patients' need for information during hospital stay, International Journal of Nursing Studies, 21, 113-130.

17. Wallace, L.M. (1985),

Surgical patients' preferences for pre-operative information, Patient Education and Counseling, 7, 377-387.

18. Bubela, N., Galloway, S. (1990),

Factors influencing patients' informational needs at time of hospital discharge, Patient Education and Counseling, 16, 21-28.

19. Lauwers, H., Maris, N. (1990),

De totale heupoperatie en de voorlichting, Tijdschrift voor Ziekenverpleging, 2. 56-59. 
20. Libman, E., Creti, L., Fichten, C.S. (1987),

Determining what patients should know about transurethral prostatectomy, Patient Education and Counseling, 9, 145-153.

21. Wilson-Barnett, J., Osborne, J. (1983),

Studies evaluating patient teaching: implications for practice, International Journal of Nursing Studies, 20, p. 33-44.

22. Leigh, J.M., Walker, J., Janaganathan, J. (1977),

Effect of a preoperative anesthetic visit on anxiety, British Journal of Medicine, 2, 987-989.

23. Ruzicki, D.A. (1985),

Motivating patient care staff to teach: a plan for action, in: American Hospital Association Media Center, Surgical patient education does make a difference, Live Interactive Sattelite Video Teleconference.

24. Lindeman, C.A., Van Aernam, B. (1971),

Nursing intervention with the presurgical patient- the effects of structured and unstructured preoperative teaching, Nursing Research, 20, 319-332.

25. Krupat, E. (1986),

A delicate imbalance, Psychology Today, november, 22-26.

26. Borne, H.W. van den, Pruyn, J.F.A., Meij, K. de (1986),

Help given by fellow patients, in: Stoll, B.A. (ed.), Coping with Cancer Stress, Dordrecht, Martinus Nijhoff.

27. Wijmen, F. van (1988),

Juridische aspecten van patiëntenvoorlichting, in: V. Damoiseaux en A.Ph. Visser (red.), Patiëntenvoorlichting, Een interdisciplinaire benadering, Van Gorcum, Maastricht.

28. American Hospital Association (1982),

Policy and Statement on the Hospital's Responsibility for Patient Education Services, Chicago.

29. Joint Commission on the Accreditation of Hospitals and Health Care Organizations (1993), Accreditation Manual for Hospitals.

30. Devine, E.C., Cook, T.D. (1986),

Clinical and cost-saving effects of psychoeducational interventions with surgical patients: a meta-analysis, Research in Nursing and Health, 9, 89-105.

31. McCullough, C., Boggs, B.J., Varner, B.J. (1980), Implementation of educational programs for patients, Nursing Administration Quarterly, 4, 61-68.

32. Rogers, E. (1983),

Diffusion of innovations, third edition, New York, The Free Press.

33. Orlandi, M.A., Landers, C., Weston, R., Haley, N. (1990),

Diffusion of health promotion innovations, in: Glanz, Lewis, Rimer, (eds), Health behavior and health education theory, Jossey Bass.

34. SIG (1993),

Jaarboek Ziekenhuizen, Kliniek, Dagverpleging en Polikliniek, Utrecht. 
35. Mudde, E., Fahrenfort, M. (1990),

Wat vinden patiënten van de voorlichting?, Tijdschrift voor Ziekenverpleging, 43, 710-716.

36. Bokma, J., Dubbelboer, J. (1985), Patiëntenvoorlichting doorgelicht, Utrecht, Nationaal Ziekenhuis Instituut.

37. Breemhaar, B., Borne, H.W. van den, Mullen, P.D. (1996), An empirical study of the effectiveness of surgical patient education delivered by hospital staff members, in: B. Breemhaar, Development, implementation, and evaluation of surgical patient education, dissertation, Maastricht, University of Limburg.

38. Department of Veterans Affairs (1992),

New approaches to pre-operative patient health education, Satellite Conference, September 10.

39. Devine, E. (1985),

Recommended elements of surgical patient education based on current research, in: Surgical Patient Education does make a Difference, Live Interactive Satellite Teleconference, American Hospital Association.

40. O'Connor, F.W., Devine, E.C., Cook, T.D., Wenk, V.A. ('urtin, T.R. (1990), Enhancing surgical nurse's patient education: development and evaluation of an intervention, Patient Education and Counseling, 16, 7-20.

41. Zwaveling, A., De Boer, J. (1986),

Beter weten, beter genezen, Houten, The Netherlands, Unieboek.

42. Breemhaar, B., Borne, H.W. van den, Mullen, P.D. (1996),

A theory-based test of a method to install surgery patient education in every day hospital practice, in: B. Breemhaar, Development, implementation, and evaluation of surgical patient education, dissertation, Maastricht, University of Limburg. 


\title{
5 A theory-based test of a method to install preoperative patient education in everyday hospital practice
}

\author{
B. Breemhaar ${ }^{2}$, H.W. van den Borne', P.D. Mullen ${ }^{4}$
}

\subsection{Introduction}

Preoperative preparation of surgical patients is an area in which patient education has been studied most thoroughly. Based on a large number of studies that demonstrated that adequate preparation of patients for surgery can decrease negative emotions and enhance postoperative physical recovery (see for example: Devine, 1992), the US Agency for Health Care Policy and Research (1992) issued a guideline incorporating patient education as essential to post operative pain management. Nevertheless, in practice, preparation of patients for surgery by offering information and support shows many gaps (WilsonBarnett, 1994). It has been observed that, although nurses provide patients with information many times during hospitalization, this does usually not happen systematically, and nurses vary widely with regard to what they consider important and what they tell patients. Also, allocation of responsibility for particular tasks is not clear among members of different disciplines (Webber, 1990; Ruzicki, 1985). Shortcomings of surgical patient education are reflected in patients' reports (Wallace, 1986; Engström, 1986). Subjects mentioned by surgical patients about which they receive insufficient information include the reason for and consequences of surgery, specific medical details and instructions,

1 This study was supported by a grant from the Dutch Praeventiefonds, project number 26-20.

2 Drs. B. Breemhaar is researcher at IVA, Institute for Social Research of the University of Brabant, Tilburg, the Netherlands.

3 Dr. H.W. van den Borne is professor of Patient Education at the Dept. of Health Promotion of the University of Limburg, Maastricht, The Netherlands.

4 Dr. P.D. Mullen is Professor of Behavioral Science and Health Education and Deputy Director, Center for Health Promotion Research and Development, University of Texas, School of Public Health, Houston, Texas, USA. 
sexual consequences (Libman, Creti \& Fichten, 1987), functions of different health care providers, discharge from the hospital, and recovery at home (Bubela \& Galloway, 1990). Several barriers inhibit attempts to have hospital staff perform patient education adequately and on a regular basis. These barriers include time constraints, absence of support for nurses doing patient education and the widespread belief among professionals that they are already engaged in comprehensive patient education (Ruzicki, 1985; WilsonBarnett \& Osborne, 1983).

What causes the discrepancy between the results from investigations generally demonstrating benefits of adequate preparation for surgery and existing practices in hospitals? As indicated by Wilson-Barnett (1994), O'Connor, Devine, Cook, Wenk \& Curtin (1990), and Devine, O'Connor, Cook, Wenk \& Curtin (1988), one important reason may be that most patient education measures that were evaluated in controlled field experiments were performed by the investigator or an associate and not by regular health care providers employed by the hospital. Yet, patient education should be performed by staff members, because they have regular and extensive contact with patients while carrying out treatment and care tasks. Generally, patients wish to receive information first of all, from their "own" doctors and nurses (Van den Borne, Pruyn \& de Meij, 1986; Visser, 1986). Also, programmes of patient education are more likely to be continued after implementation, when they are developed in close cooperation with and carried out by health care providers themselves. In contrast, patient education developed and performed by an external agent is more likely to be terminated when the project is finished or when priorities shift.

How can researchers or patient education coordinators cooperate with hospital staff to develop and implement adequate measures of surgical patient education that can be performed by physicians, nurses and other relevant members of the hospital staff? In this chapter, we offer a description of the process of improving and implementing surgical patient education interventions in two Dutch hospitals. The interventions were based on a theory of organizational behavior concerning adoption and diffusion of innovations and on empirical results concerning effective preparation of patients for surgery. In the following sections, first we describe the theory and how this theory was translated into practice. Next, we will describe a test of the fidelity of the intervention's implementation, together with its results.

\subsection{Content of effective surgical patient education}

Many studies have investigated the effectiveness of methods to psychologically prepare and support patients for surgery and other invasive medical procedures. Generally, these methods are classified in three categories: informational approaches, behavioral approaches, and psychological support (Johnston \& Vögele, 1993; Devine, 1992; O'Connor et al., 1990).

Information offered to surgical patients can be divided into procedural and sensory information. Both types of information usually have been found to have beneficial effects on adaptation to the medical procedure studied, although the effects of sensory informa- 
tion seem superior to those of procedural information (Taylor \& Clark. 1986; Suls \& Wan, 1989). With behavioral approaches, patients have been instructed in behavioral techniques that facilitate physical examination or treatment and recovery after the procedure, e.g. coughing, breathing deeply, and relaxation. Cognitive approaches also have been put in this category, when they were aimed at restructuring patients' cognitions to promote adequate coping and reduce stress. Several studies have found positive effects of behavioral instructions (Schultheis, Peterson \& Selby, 1987; Kendall \& Watson, 1981), especially in combination with provision of information (Mathews \& Ridgeway, 1984). Finally, psychotherapeutic approaches have been employed, ranging from encouraging patients to express feelings about surgery to providing them with psychological support. Although the techniques that have been studied are diverse, they generally appear effective, particularly in reducing anxiety (Mathews \& Ridgeway, 1984; Anderson \& Masur, 1983). Based on a review of relevant studies, Devine (1992) concluded that these three approaches are all valuable elements of psychoeducational care for surgical patients.

\section{Patients' level of perceived control}

Several studies have demonstrated the importance of perceived control as a mediator of adaptation to stressful events (Breemhaar \& Van den Borne, 1991 (chapter 3); Syme, 1989; Averill, 1973). Perceived control can be defined as "...the subject's perception of a contingency between the performance of some behavior and the ability to avoid or escape a stressful, unpleasant event." (Gatchel, 1980, p. 1; see also: Wallston, Wallston, Smith \& Dobbins, 1987). Taylor (1991) argued that patient education and support can increase the level of perceived control among patients. Specifically, she asserted that providing patients with information and instructions that reduce uncertainty and anxiety or that facilitate behavioral responses to reduce pain and improve recovery after surgery, contributes to feelings of control. Johnston, Gilbert, Partridge \& Collins (1992) found that offering physiotherapy patients written information about behavioral opportunities to contribute to their recovery increased their sense of control. Similarly, Anderson (1987) found among patients undergoing cardiac surgery that providing them preoperatively with information and/or with behavioral instructions, increased perceived control, while increased levels of perceived control predicted a reduction in anxiety and fear.

Not all patients appear to benefit from measures designed to increase or maintain their level of perceived control, however. Such measures were demonstrated to be more useful among patients who generally expect a high level of control and in situations that offer opportunities for control. Among patients who generally expect a low level of control, these measures may have detrimental effects, e.g. increasing anxiety and physical complications and lengthening time of recovery (Miller, Combs \& Stoddard, 1989; Thompson, Cheek \& Graham, 1987).

To provide an explanation of the differential effects of increasing control, Miller et al. (1989) hypothesized that given control options, people attempt to limit the maximum danger of an undesirable event. In the absence of control, when efforts to minimize danger are fruitless, they are likely to stop their efforts and will employ more emotion focused ways of coping. Second, they hypothesized arousal to remain high in aversive situations when persons "monitor" the negative aspects of the event, while arousal 
decreases when they "blunt" these aspects. When an aversive event is controllable, monitoring is the main response and receipt of information is preferred, in order to attempt to minimize the danger of the event. When the event is not perceived as controllable, blunting is more likely to reduce arousal. In this case individuals reduce stress by engaging in a variety of coping techniques that place them in the presence of "psychological safety signals". However, people differ with respect to the extent that they stop monitoring and start blunting in situations that offer little control. Some continue to prefer information about the aversive event, since it places them in the presence of "external" safety signals. Thus, it is important to increase patients' perceived control, provided that this is tailored to their individual needs for control (Kincey \& Saltmore, 1990; Thompson, et al., 1987; Rogers \& Reich, 1986).

Adaptation of patient education to patients' information needs and hospital circumstances One approach to this issue might be to offer patients opportunities to exercise control over their care and treatment and let them decide to what extent they voluntarily employ these opportunities. For example, patients could be offered a videotaped instruction of the events in the hospital related to surgical treatment and care. With this information behavioral recommendations might be given that facilitate well-being and recovery (e.g. refraining from smoking pre-operatively, supporting the wound post-operatively to relieve pain), leaving patients free to decide whether they apply these instructions.

Also, the content of patient education should be tailored to individual patients' desires for information and the circumstances of a particular hospital. Although some needs and problems are common among surgical patients (Johnston, 1988; Ray, 1982), others differ by hospital and by type of surgery (Weinman \& Johnston, 1988). This may result from different teaching practices, different methods of treatment and care procedures or different characteristics of the patient population in a given hospital. Therefore, before designing interventions to improve surgical patient education in a particular hospital, patients' subjective experiences should be examined, together with the events occurring during their course of treatment and care in that hospital. This requires early involvement of staff members, who can provide infornation about events occurring during patients' course of treatment and recovery, ordering of the events, surroundings where they take place, persons performing the events, information given to patients, and patients' reactions. Their knowledge of and experience with everyday working routines at the wards in the hospital are indispensible to designing patient education interventions that fit in closely with everyday practice. Staff involvement also helps to create a firm foundation for implementing and maintaining the interventions, and enlarging opportunities for staff members to put them into practice. 


\subsection{Factors in successful adoption of innovations}

Patient education can be regarded as an innovation (O'Connor et al., 1990; Redman, 1981; McCullough, Boggs \& Varner, 1980). Several attributes of an innovation and of the process of developing and implementing the innovation can be distinguished that determine its rate of adoption. According to Rogers (1962), five attributes of innovations facilitate adoption. First, the innovation should be regarded as relatively advantageous to the potential users, in the sense of cost-effectiveness, time gained, social status, and so forth. Second, it should be compatible with the existing values and needs of the potential users. Third, the innovation should be easy to understand. Fourth, the innovation should be able to be tried out on a temporary basis. Finally, to increase communication, the results of trying out an innovation should be visible to others. Provided that the results are desired by the users, this will result in a higher rate of adoption of the innovation. In addition, Zaltman, Duncan \& Holbek (1973) mentioned three characteristics that facilitate adoption. An innovation is adopted more readily when it enhances social relationships between the users, when messages concerning the innovation are communicated easily between its users and when it is implemented by the time that its potential users are prepared to adopt it.

Rogers distinguished centralized and decentralized processes of adoption. The first is characterized by one way traffic from the change agent to the adopter, where the adopter is passive. In a decentralized adoption process "... participants create and share information with one another in order to reach a mutual understanding" (Rogers, 1983, p. 336). Decentralization is most appropriate when the users are sufficiently educated and when the innovation has limited technical complexity. Advantages of decentralization are a better fit between the innovation and the users' needs and problems and a sense of being able to control the process on the users' side. In this sense, Orlandi, Landers, Weston \& Haley (1990) have described a "linkage approach" to the process of innovation-development and diffusion to bridge the gap between the resource system from which the innovation originates and the user system for which the innovation is intended.

With these principles in mind concerning adoption of innovations, a strategy was chosen to organize the process of improvement and implementation of education for patients undergoing herniorrhaphy or cholecystectomy in both hospitals and to attain cooperation of hospital staff members.

\subsection{Developing and implementing improvements in patient education}

First, we sought support for the project among opinion leaders in both hospitals. The management and the surgical staff were approached to explain the project's objectives and method. During this discussion, both groups expressed recognition of inadequacies of the existing patient education. Especially among surgeons, this was an important condition for their support. Secondly, we approached the clinical and ambulatory nursing staff, anesthetists, and physiotherapists to explain the project and to obtain their cooperation. 
We explained that their experiences with working routines at surgical wards and their knowledge of treatment and care of surgical patients would serve as essential input in improving patient education. The fact that they would be allowed to monitor and control the process seemed to be an important prerequisite to their support of the project, since it guaranteed that the program that was to be developed would not be more complicated than desired. Also, taking existing practices as a starting point helped to ensure that the new program would be compatible with the values and needs of the potential users. To further increase compatibility, we discussed with all relevant disciplines how we planned to examine the route patients follow during their course of treatment in the hospital. All disciplines involved were asked for advice on the method of the examination, to increase the perceived validity of this method.

\section{Shortcomings of existing practices}

After support was obtained for the project, we undertook an examination in both hospitals of the routing that patients undergoing herniorrhaphy or cholecystectomy follow through the hospital during treatment, care, and recovery. This served to obtain a mutually shared picture by the investigators and the health care providers involved, of the practice of treatment and care of these patients and of problems with regard to patient education. As such, the examination had to provide information about shortcomings of patient education, thus providing a foundation for developing measures for improvement. Using observations and interviews with patients and health care providers, we examined which events take place and in which order, which health care providers patients meet during the events, how they treat patients, which information patients receive, and how patients feel and react during the events and how they react to the treatment by health care providers. All staff members were informed beforehand about the purpose of the examination and the activities that it would bring about, through announcements in their hospital's personnel bulletin.

The results showed that patients undergoing herniorrhaphy or cholecystectomy experience several emotional problems during their hospital stay, such as fear of anesthesia, lack of information about medical aspects of their disease and the operation, and lack of information about discharge (see Breemhaar, Van den Borne \& Mullen, 1996 (chapter 4) for a more extensive description). The information patients received corresponded insufficiently with their need for information. This was caused first by the organizational circumstances under which patients are treated and cared for. The large number of care providers and their heavy work loads affected patient education unfavorably. Secondly, the way physicians and nurses provided patients with information was shown to be inadequate. The content of the information was inconsistent, and in particular, physicians appeared to be reluctant to give information to patients. Also, patients were overloaded with information on the day of admission, while they received little information at discharge.

\section{Development of improvements}

To enhance cooperation and communication about the innovation between the initiator of the project and the adopters of the program and among the adopters themselves, a project group was installed after completion of the examination. Its members were, together with 
the project coordinator ${ }^{5}$, to decide what measures to improve patient education were to be developed and to contribute to their actual development. Also, they were expected to inform their colleagues about the proceedings of the process and to offer them opportunities for input, thus increasing the visibility of the development process. The group consisted of representatives of each relevant discipline contributing to treatment and care of patients undergoing surgery. Each member was nominated by his or her discipline colleagues. Before nomination all potential nominees were informed about the purpose of the group and the amount of time they were to invest in its activities.

During its first meeting, the project group discussed the results of the examination. Also, the group decided which shortcomings of patient education activities should receive attention. On the basis of shortcomings of surgical patient education found during the examination, during the second meeting specific improvements were proposed by the project coordinator. The members of the project group perceived some of them as unattainable, because of time, financial and/or organizational constraints. Most of these objections were raised by physicians in the group. In particular, in order to increase recognition among patients of the surgeon and the ward physician, the coordinator proposed to limit patient-doctor contacts to the ward physician. Although ward physicians are formally responsible for preparation of patients for surgery and for medical management during their recovery, surgeons were not prepared to leave the contacts with clinical patients completely to ward physicians. Also, some measures required skills which some or all of the members of the project group, in their opinion, did not possess and were not prepared to develop. For example, anesthetists were not prepared to participate in a training session to enhance their interpersonal communication skills. Finally, it was proposed to have ward physicians discuss with each patient before his or her discharge from the hospital, the medical regimen at home, behavioral recommendations, and how to handle possible physical complications. However, because of practical considerations this measure was not implemented.

Thus, not all improvements were attained despite their desirability in light of the acknowledged shortcomings in patient education. Most of the measures for which agreement was attained concerned information provision during the preoperative period, before or after admission (see next section). Also, most of these measures were designed to be carried out by nurses.

Next, the agreed upon measures were developed in 'task groups'. One task group was organized for each separate measure ${ }^{6}$, consisting of a representative of each relevant discipline. After completion a final meeting took place in which all measures were presented. Assignments were made for implementation of the measures, e.g. when to start, briefing and instructing colleagues, and distribution of patient education materials. It was made clear that the measures were initially to be implemented for a limited period of time only. Next, a decision was to be made about more permanent implementation,

The function of project coordinator was fullfilled by the first author (B.B.).

6 Separate groups worked on the development of written information, the slide-tape presentation, and agreements concerning provision of oral information on admission. 
after adjustment based on previous experiences. This served to increase the trialability of the measures, as perceived by the health care protessionals involved.

Unfortunately, in hospital 1 we did not succeed in establishing a project group. Here, the measures to improve surgical patient education were developed during separate meetings with representatives of the disciplines involved. As a result, many more meetings had to take place, extending the period of time covered by the development process. Also, since members from several disciplines contributed to a measure, additional care had to be taken by the project coordinator to orchestrate their activities. Failure to establish a project group in this hospital was caused by reluctance, especially among surgeons and anesthetists, to cooperate with members of other disciplines. They considered this to be time consuming, and they were not prepared to be involved in patient education tasks of other disciplines. It seems likely that this limited communication among health care providers about the new program and it may have hampered interpersonal relationships between them.

\section{Improvements in surgical patient education}

The program's content was based not only on the results of the examination in both hospitals of shortcomings of existing practices, but also on findings from previous evaluations of interventions to prepare patients for surgery and theoretical notions about the role of perceived control in preparation for surgery (Breemhaar \& van den Borne, 1991; chapter 3). The new program consisted of written, audiovisual, and oral information, provided pre operatively to patients, mainly by nurses. Figure 5.1 provides an overview of the existing patient education materials and of the improvements that were developed in both hospitals. Appendix 5.1 provides a more extended overview.

First, the information provided to patients was adapted more closely to patients' needs. This information was included in leaflets, a slide-tape presentation, and in oral communication. We included both procedural and sensory information, as well as instructions for patient behavior that would facilitate presurgical preparation and post operative recovery. Also, reassuring information was included about methods employed by health care providers to ensure patients' well-being. Written information was developed about surgery, anesthesia, health care providers involved, post operative bodily experiences, opportunities to relieve post operative pain, and about discharge. This information was included in leaflets (see appendix 5.2), which were provided to patients pre operatively by nurses, during patients' visit to the ambulatory department. Information about regulations and facilities at the hospital and at the ward was included in a folder that was available for patients to read at the ward ${ }^{7}$ (see appendix 5.3). A slide-tape presentation was produced showing and explaining procedures regarding admission and preparations and recovery from surgery (see appendix 5.4). By means of a "model patient" following the routing through the hospital during preparation for and recovery from herniorrhaphy or cholecystectomy, it showed the locations where medical examinations, preparations for surgery and surgery itself took place. Also, health care providers involved in these staff during the same period, but separately from project activities. 
activities were brought into the picture. It could be viewed pre operatively, some days prior to admission at the ambulatory department. Nurses were assigned to discuss particular topics with patients on admission to the hospital. To support nurses, a checklist was developed that displayed the topics (see appendix 5.5).

\begin{tabular}{|c|c|c|c|c|}
\hline & & & Existing patient education & New patient education \\
\hline \multirow[t]{2}{*}{1.} & $\begin{array}{l}\text { Written } \\
\text { information }\end{array}$ & Hospital 1 & $\begin{array}{l}\text { Leaflet about anesthesia } \\
\text { Leaflet about cholecystectomy } \\
\text { Leaflet about the hospital } \\
\text { Leaflet about the ward }\end{array}$ & $\begin{array}{l}\text { Improved leaflet about anesthesia } \\
\text { New leaflet about herniorrhaply } \\
\text { Improved leaflet about cholecystectomy } \\
\text { Folder at the ward with improved in- } \\
\text { formation about the hospital and the } \\
\text { ward }\end{array}$ \\
\hline & & Hospital 2 & $\begin{array}{l}\text { Leaflet about the hospital } \\
\text { Leaflet about 'who's who' } \\
\text { Leaflet about the ward }\end{array}$ & $\begin{array}{l}\text { New leaflet about anesthesia } \\
\text { New leaflet about herniorrhaphy } \\
\text { New leaflet about cholecyslecumy } \\
\text { Folder at the ward with improved in- } \\
\text { fornation about the wird and the } \\
\text { hospital }\end{array}$ \\
\hline 2. & $\begin{array}{l}\text { Audiovisual } \\
\text { information }\end{array}$ & $\begin{array}{l}\text { Hospital } \\
1 \& 2\end{array}$ & None & $\begin{array}{l}\text { Slide-tape presentation about } \\
\text { undergoing a herniorrhaply } \\
\text { Slide-tape presentation about } \\
\text { undergoing a cholecystectomy }\end{array}$ \\
\hline 3. & $\begin{array}{l}\text { Oral infor- } \\
\text { mation }\end{array}$ & $\begin{array}{l}\text { Hospital } \\
1 \& 2\end{array}$ & $\begin{array}{l}\text { Unstructured information by } \\
\text { nurse on admission } \\
\text { Unstructured information from } \\
\text { health care providers at } \\
\text { several times during } \\
\text { hospitalisation }\end{array}$ & $\begin{array}{l}\text { Systematic provision of information } \\
\text { by nurses on admission, supported } \\
\text { by a checklist displaying relevant } \\
\text { topics. } \\
\text { Unstructured information from } \\
\text { health care providers at several } \\
\text { times during hospitalisation } \\
\text { (unchanged) }\end{array}$ \\
\hline
\end{tabular}

Figure 5.1: Existing and new surgical patient education programs in both hospitals.

Second, the methods of information provision were improved, by mutual agreement with nurses and physicians regarding the timing of provision of written, oral and audiovisual information. This served to promote even distribution of information over time and to structure the subjects about which patients would receive information. Thus, the assignments also served to prevent unnecessary duplication of and gaps in the provision of information.

Third, it was attempted to enhance patients' level of perceived control or to prevent it from decreasing. Patients were provided information about behavioral opportunities to reduce discomfort and improve physical well-being. E.g. they were instructed to stop smoking a few days before surgery, to indicate postsurgical pain and nausea in order to receive appropriate medication, to reduce wound pain by supporting the wound, to cough and breathe deeply in order to improve pulmonary functioning and, if not contra-indicated, to move around post-operatively. Also, they were informed about the roles and responsibilities of particular health care providers, and encouraged to direct their ques- 
tions to the most appropriate staff member whenever they wished to. The suggestion was made that patients write down any questions, to remember asking them when this staff member arrived. To prevent undesirable consequences of increasing perceived control among patients predisposed with low needs for control, care was taken not to thrust information upon them. Therefore, patients were encouraged to read the written materials, to watch the slide-tape presentation, to ask questions, and to perform additional bodily movements only to the extent that they were willing to.

\section{Implementation of the improvements}

Nurses from both the clinical wards and the ambulatory department were expected to contribute significantly to successful implementation. To enhance comprehensibility, before implementation separate meetings were arranged for nurses in which we explained the purpose of the program, how they should bring the measures into practice and in which they were given the opportunity to ask questions. To increase visibility of the measures, a message was published in the hospital personnel bulletin informing staff members about the content of the improvements, time and location of implementation, and plan for evaluation.

In both hospitals limited opportunities were available to monitor hospital staff members during implementation. To promote continuation after initial implementation, one nurse was appointed from each ward and the ambulatory department of each hospital to monitor application of the program. He or she informed newcomers about the program and repeatedly supplied the project coordinator with information concerning application. Problems were discussed and if necessary, the measures were adjusted. For example, a few weeks after introduction of the program in hospital 2, it became clear that many patients who were scheduled for surgery did not visit the ambulatory department to watch the slide-tape presentation. Although every patient was informed by an ambulatory department nurse about the opportunity to watch, we decided, together with the nurse monitoring the application of the program at the department, to send each patient a letter which again informed him or her about the presentation. As a second example, in hospital 1 , contrary to assignments, surgeons did not provide patients with leaflets containing written information about surgery and anesthesia during their visit to the ambulatory department. Instead, they expected ambulatory department nurses to hand this information to patients. However, since not all of these nurses in this hospital had been involved in the development of the interventions, initially this information was not provided to patients at all. Additional attempts were undertaken to explain the aims and content of the efforts to improve surgical patient education and to motivate nurses of the ambulatory department to provide patients with the written materials.

\subsection{Test of utilization of the measures}

Data collected before and after implementation among patients served to assess the extent to which health care providers provided patients with information according to the new procedures. The amount of information received by patients and their evaluation of this 
information was examined by comparing data collected among surgical patients admitted before development and implementation of the new program (indicated as group 1 in the remainder of this text), with data collected among patients admitted after implementation of the new program (group 2). It was hypothesized that:

1. Patients in group 2 receive information from more preoperative sources than patients in group 1.

2. Patients in group 2 receive more written information about cholecystectomy and about anesthesia than patients in group 1.

3. Patients in group 2 evaluate this information more positively than patients in group 1 .

4. Patients in group 2 receive more oral information on admission from nurses than patients in group 1.

5. Patients in group 2 evaluate this information more positively than patients in group 1.

The hypotheses 2-5 are restricted to written information about cholecystectomy and about anesthesia and to oral information from nurses on admission because this information was provided to patients both before (group 1) and after (group 2) development and implementation of the program. With respect to written information about cholecystectomy and anesthesia, this was only the case in hospital 1 . With respect to these sources of information, the program primarily aimed to improve its content and the way it was distributed to patients. The remainder of the program was meant to provide additional information to patients (e.g. a leaflet about herniorraphy and a slide-tape presentation about herniorraphy or cholecystectomy) or to alter the moment and means of information (e.g. written information about the hospital and the ward in a folder at the ward instead of a leaflet provided to each patient). Since this additional information was provided (u) patients after development and implementation of the program only, no hypotheses were formulated concerning differences between both groups in receipt and evaluation of this information.

To examine whether execution of the program led to additional improvements in information provision, we also analysed oral information received from nurses on additional occasions apart from admission, and oral information received from additional health care providers. Further, we examined the amount of written information received about herniorrhaphy and about regulations and facilities at the hospital and at the ward, and finally, the extent to which patients in group 2 watched the slide-tape presentation.

\section{Participants}

Data were collected among patients scheduled for herniorrhaphy, laparoscopic or traditional cholecystectomy in both hospitals where the new program of surgical patient education was developed and implemented. Patients admitted during approximately four months before development and implementation of the new program in the particular hospital comprised group 1. Patients admitted during the first five months after implementation comprised group 2. Each of them was approached for participation by means of a letter, before or on admission to the hospital, provided they were 18 years or over, 
mastered the Dutch language, admitted into the hospital from their homes, no urgency was involved, and they had no a priori medical complications.

\section{Measures}

Data were collected by structured interviews with individual patients, conducted by trained interviewers. First, on the day of admission patients were asked whether or not they had received written information about surgery, anesthesia and whether they had noticed written information about the hospital and the surgical ward. If they had received or noticed the particular information, they were asked whether they had read it or not. If they had, their opinion was asked on a three point scale concerning sufficiency and comprehensibility of the materials. One score was calculated indicating the mean score on both questions. Second, also on the day of admission patients in group 2 were asked whether or not they had viewed the slide-tape presentation about cholecystectomy or herniorrhaphy.

Third, questions were asked concerning receipt of oral information from the surgeon, the ward physician and from the nurse. On the day of admission patients were asked whether they had received oral information from the surgeon, the ward physician, and a nurse on admission about 1) illness and surgery, 2) preparation for surgery, 3) recovery from surgery, and 4) regulations and facilities of the hospital and the ward. Postoperatively, patients were asked whether they were recently informed orally by each of these three staff members about 1) anesthesia and 2) success of surgery and their current physical condition. Also, they were asked whether or not they had received information from the anesthetist about anesthesia. One week after discharge, patients were asked whether or not they had received before or at discharge information concerning 1) conditions for and expected time of discharge and 2) behavioral recommendations to improve recovery. With respect to each of these sources of oral information, patients answering affirmatively were asked their opinion concerning sufficiency and comprehensibility of this information on a three point scale. Because the correlations of these two items averaged .73 , a single score was calculated.

Finally, an index score was calculated for each patient based on the number of leaflets and folders he or she had received, added to the number of subjects mentioned above about which oral information had been received on admission from nurses, and one more point when the patient watched the slide-tape presentation. Thus, this index indicates the total number of sources that were primarily addressed by the intervention, and from which he or she received information.

\section{Analyses}

$\mathrm{Chi}^{2}$ tests were performed to test differences between groups and between hospitals, with respect to the amount of written information received before or on the day of admission and the amount of oral information received from health care providers on admission, after surgery, and at discharge. To reduce the likelihood of type 1 errors, a Bonferroni procedure was employed (Van Knippenberg \& Siero, 1980). With respect to differences in written information received, the level of significance was reduced by dividing $\alpha=.05$ by the maximum number of sources from which patients received written information 
before or at admission ( $\mathrm{n}=5 ; \alpha=.01)$. With respect to oral information $\alpha$ was divided by the maximum number of subjects about which patients received oral information from a particular health care provider on admission $(n=4 ; \alpha=.0125)$, after surgery $(n=2$; $\alpha=.025)$, and before or at discharge $(n=2 ; \alpha=.025)$.

\subsection{Results}

\section{Response and attrition}

Of all patients approached for participation, 195 patients participated in the study (table 5.2). In total 249 patients were identified for participation. The selection criteria were not met by 16 patients. From the remaining 233 patients, 11 were not interested in participation, while seven patients considered the interviews too demanding, because of nervousness or old age. Although initially they agreed to participate, two patients withdrew their agreement before the first interview. Finally, for 18 patients the reason for refusal is unknown. Excluding patients who did not meet the selection criteria, the response percentage was 84 . In hospital 2 nonresponse was larger $(21.3 \%)$ compared to hospital $1\left(9.4 \% ; \mathrm{Chi}^{2}(1)=6.02, \mathrm{p}<.05\right.$; table 5.2). However, no differences were found in nonresponse between herniorrhaphy and cholecystectomy patients or between groups 1 and 2 .

Table 5.2: Number of patients approached for participation and those who actually participared by group, hospital, and type of surgery.

\begin{tabular}{|c|c|c|c|c|c|c|c|}
\hline & \multicolumn{3}{|c|}{ Hospital 1} & \multicolumn{3}{|c|}{ Hospital 2} & \multirow[t]{3}{*}{ Total } \\
\hline & \multirow[t]{2}{*}{ Hern.' } & \multicolumn{2}{|c|}{$\mathrm{Chol}^{2}$} & \multirow[t]{2}{*}{ Hern. ${ }^{\prime}$} & \multicolumn{2}{|c|}{ Chol. $^{2}$} & \\
\hline & & Trad. & Lap. & & Trad. & Lap. & \\
\hline \multicolumn{8}{|l|}{ Approached: } \\
\hline - Group 1 & 28 & $13^{3}$ & 2 & 42 & $14^{3}$ & 10 & 109 \\
\hline - $\quad$ Group 2 & 35 & $10^{3}$ & 20 & 43 & $6^{3}$ & 10 & 124 \\
\hline \multicolumn{8}{|l|}{ Responded: } \\
\hline - Group 1 & 28 & 11 & 2 & 33 & 11 & 10 & 95 \\
\hline - $\quad$ Group 2 & 31 & 5 & 20 & 32 & 2 & 10 & 100 \\
\hline
\end{tabular}

Hern. = Herniorrhaphy

Chol. = Cholecystectomy (traditional and laparoscopic)

Among patients scheduled for traditional cholecystectomy who were approached for participation, some may have undergone laparoscopic cholecystectony. Since some refused participation, it was not always known what type of surgery they underwent.

In total, 22 patients who participated in the preoperative interview did not complete the interview one week post discharge (table 5.3). Most patients dropped out of the study between the first and the second interview. Personal reasons to stop participation in the interviews occurred somewhat more often in group 1, while logistic reasons occurred somewhat more often in group 2. In group 1, attrition was larger (17\%) than in group 2 
$\left(7 \% ; \mathrm{Chi}^{2}(1)=4.43, \mathrm{p}<.05\right)$. No significant differences in attrition were found between hospitals and between types of surgery.

Table 5.3: Number of patients interviewed by group and time of interview.

\begin{tabular}{|c|c|c|c|c|c|}
\hline & \multirow[b]{2}{*}{ Group: } & \multicolumn{2}{|c|}{ Hospital 1} & \multicolumn{2}{|c|}{ Hospital 2} \\
\hline & & 1 & 2 & 1 & 2 \\
\hline Preoperative & & 41 & 56 & 54 & 43 \\
\hline Postoperative & & 35 & 55 & 48 & 40 \\
\hline One week post discharge & & 34 & 54 & 45 & 39 \\
\hline
\end{tabular}

Group differences in the total number of sources from which information was received The total number of sources from which patients received information was higher among patients in group $2(\mathrm{~m}=8.09$; s.d. $=1.77)$ than among patients in group $1(\mathrm{~m}=7.03$; s.d. $=2.12 ; \mathrm{t}(189)=3.76, \mathrm{p}<.01)$.

Group differences in receipt of written information about cholecystectomy and anesthesia, and in receipt of oral information on admission from nurses

The two groups did not differ significantly with respect to the proportion of patients who received leaflets about cholecystectomy and about anesthesia (table 5.4). These comparisons were limited to hospital 1 , since in hospital 2 these leaflets were not provided to patients in group 1.

In hospital 1 only, with respect to the subjects 'preparations for surgery' and 'regulations at the ward', patients in group 2 were informed orally by nurses significantly less often than in group 1 (table 5.5). 
Table 5.4: Proportion of patients in groups 1 and 2 who received written information, by hospital.

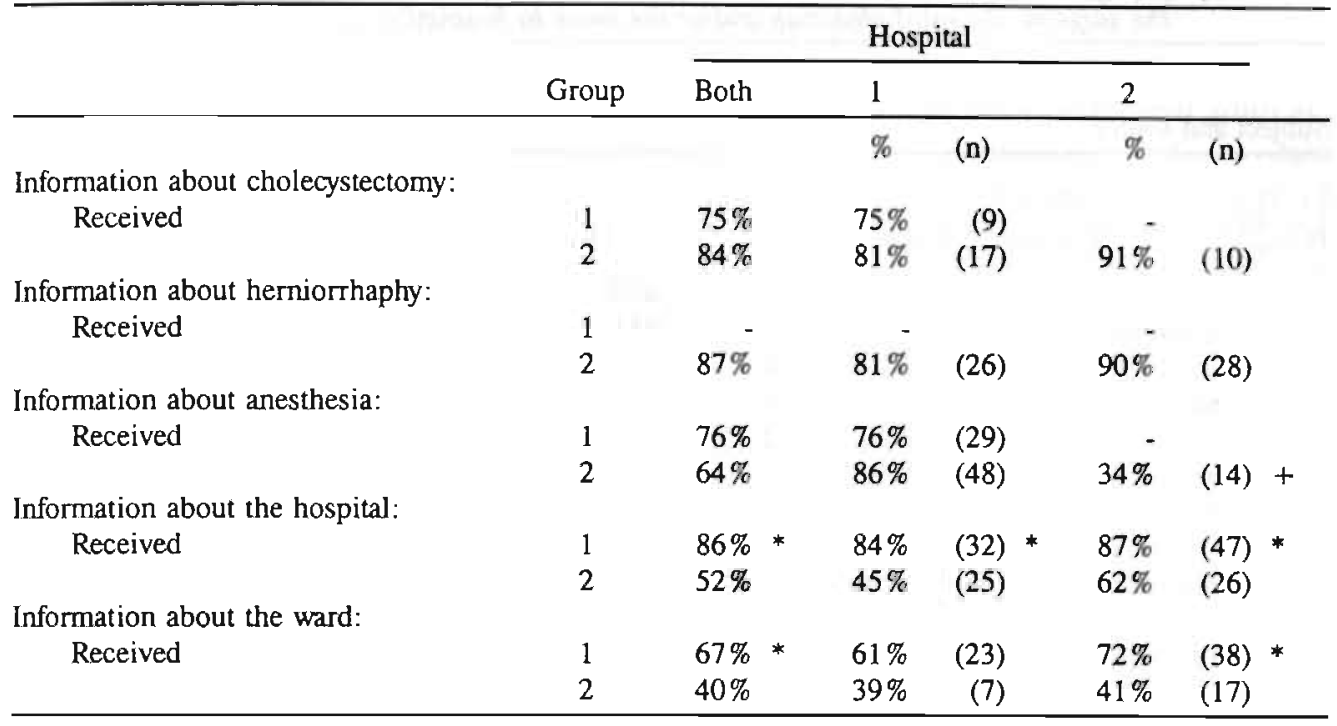

I $\alpha=.01$

* $\quad \mathrm{p}<0.01\left(\mathrm{Chi}^{2}\right.$-test of the difference between group 1 and 2$)$

$+\quad \mathrm{p}<0.01\left(\mathrm{Chi}^{2}\right.$-test of the difference between hospials)

Group differences in evaluation of written information about cholecystectomy and anesthesia, and evaluation of oral information on admission from nurses

The evaluation of the written information about cholecystectomy did not differ between groups. However, the leaflet about anesthesia was evaluated by patients in group 2 more positively $(\mathrm{m}=2.95$; s.d. $=.43)$ than in group $1(\mathrm{~m}=2.73$; s.d. $=.18$; Mann-Whitney$\mathrm{U}=494, \mathrm{p}<.01)$.

Patients' evaluation of the nurses' oral information on admission about the subjects 'preparations for surgery', 'illness and surgery' and 'regulations at the ward' did not differ between the groups. However, nurses' oral information on admission about 'recovery' was evaluated more positively by patients in group $2(\mathrm{~m}=3.00 ; \mathrm{s.d} .=0.00)$ than in group $1(\mathrm{~m}=2.84$; s.d. $=0.31$; Mann Whitney- $U=420 ; \mathrm{p}<.05)$. 
Table 5.5: Proportion of patients in groups 1 and 2 who received oral information on admission from the surgeon, the ward physician and/or the nurse by hospital'.

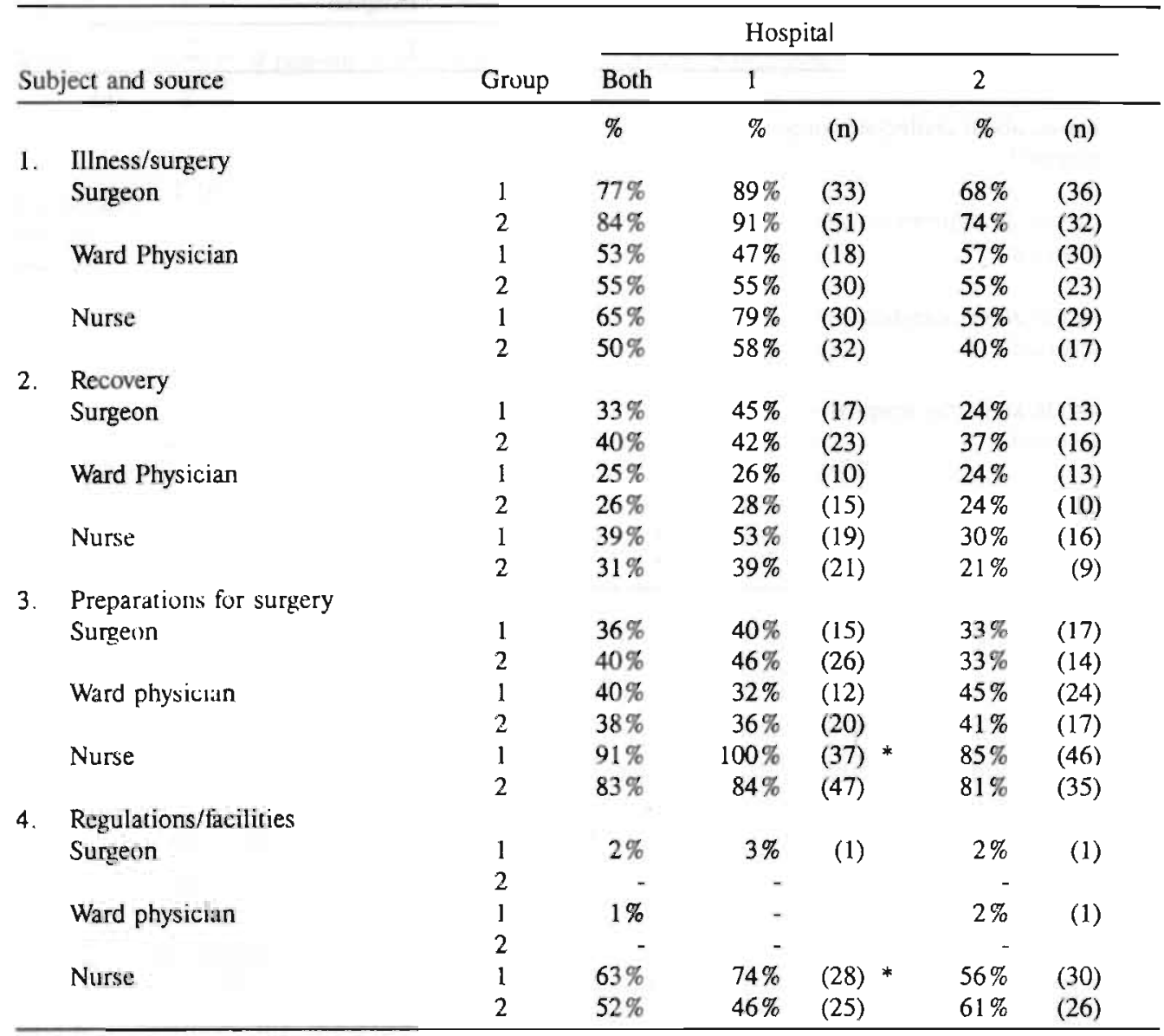

$\alpha=.0125$

$\mathrm{p}<.0125$ (Chi ${ }^{2}$ of the difference between group 1 and 2 )

Group differences in receipt of written and oral information from additional sources In both hospitals no leaflets were available with information about herniorrhaphy for patients in group 1. However, in group 2 a large majority of the patients was provided with this leaflet (table 5.4). Written information about the hospital and about the ward was received by significantly fewer patients in group 2 , compared to group 1 . With respect to written information about the ward, this difference was restricted to hospital 2 .

No differences were found for oral information on admission by surgeons and ward physicians (table 5.5). Postoperatively, the proportion of patients who received oral information from the surgeon, the ward physician, the nurse, and the anesthetist, did not differ significantly by group either. Finally, also at discharge no significant differences 
were obtained in either hospital between the proportion of patients in groups 1 and 2 receiving oral information from the surgeon, the ward physician or nurses.

Group differences in evaluation of written and oral information from additional sources No between group differences were observed in patients' evaluation of the written information received about the hospital and about the ward. Also, patients' evaluations of oral information received on admission by surgeons and ward physicians did not differ significantly by group. Neither were any differences observed between groups with respect to patients' evaluations of oral information received post operatively from the surgeon, the ward physician, the nurse, and the anesthetist. Finally, with respect to oral information received at discharge, patients in group 2 evaluated the information received from nurses about the subject 'recommendations for behavior at home' more positively $(\mathrm{m}=3.00$; s.d. $=0.00)$ than patients in group $1(\mathrm{~m}=2.80 ; \mathrm{s} . \mathrm{d} .=.38 ;$ Mann Whitney$\mathrm{U}=479 ; \mathrm{p}<.01)$.

\section{Audiovisual information}

Approximately $25 \%$ of the patients in group 2 watched the slide-tape presentation about herniorrhaphy or cholecystectomy.

\section{Differences between hospitals}

Comparison between hospital 1 and 2 of information received by patients and their evaluations, showed that generally patients in hospital 1 received more information than in hospital 2. In particular, patients in group 1 received preoperative information from more sources in hospital $1(\mathrm{~m}=8.79 ; \mathrm{s} . \mathrm{d} .=1.61)$, than in hospital $2(\mathrm{~m}=5.80$; s.d. $=1.46 ; t(90)=9.27 ; p<.01)$. Among patients in group 2 , no difference was obtained between hospitals.

In hospital 1 a significantly larger proportion of patients in group 2 received written information about anesthesia, compared to hospital 2 (table 5.4). No significant differences between the hospitals were found in evaluation of the written information.

After surgery in hospital 1, surgeons provided more oral information to patients in group 1 about 'anesthesia' $(50 \%)$ than in hospital $2(25 \%)\left(\mathrm{Chi}^{2}(1)=5.27 ; \mathrm{p}<.025\right)$. At discharge in hospital 1, surgeons provided significantly more information about 'discharge' (resp. group 1: 65\%; group 2: $51 \%$ ) than in hospital 2 (group 1: $30 \%$; group 2: $21 \%$; $\left.\mathrm{Chi}^{2}{ }_{\text {row }}(1)=9.59 ; \mathrm{p}<.025 ; \mathrm{Chi}^{2}{ }_{\text {grose } 2}(1)=8.44 ; \mathrm{p}<.025\right)$. At discharge in hospital 1 however, nurses provided fewer patients in group 2 with information about 'behavior at home' $(26 \%)$ than in hospital $2\left(50 \% ; \mathrm{Chi}^{2}(1)=5.33 ; \mathrm{p}<.025\right)$.

Concerning differences between hospitals in evaluation of oral information, it was found that patients in both groups evaluated oral information at discharge from ward physicians about 'recommended behavior at home' in hospital 2 more positively $(m=2.94$; $\mathrm{s.d}=.22)$ than in hospital $1(\mathrm{~m}=2.81$; s.d. $=.42)$; Mann-Whitney $U=601 ; \mathrm{p}<.025)$. In group 1 only, patients evaluated oral information from nurses about 'behavior at home' in hospital 2 more positively $(m=2.90 ; s . d .=.29)$ than in hospital $1(m=2.62)$; s.d. $=.46 ;$ Mann-WhitneyU $=107 ; \mathrm{p}<.025$ ). Finally, in group 2 only, patients rated information at discharge from ward physicians about 'discharge' in hospital 1 more 
positively $(\mathrm{m}=2.01$ ' s.d. $=.08)$ than in hospital $2(\mathrm{~m}=1.90$; s.d. $=.29$; Mann-Whitney $\mathrm{U}=407 ; \mathrm{p}<.025$ ).

\subsection{Discussion and conclusions}

In this article we described the process of development and implementation of a surgical patient education program in two hospitals. The process took place according to a 'linkage approach' (Orlandi et al., 1990), in which cooperation between the originators of the project and regular health care providers played a central role. Using a historical comparison group design, we evaluated the extent to which patients received patient education according to the program.

In agreement with hypothesis 1 , patients in group 2, who were admitted into the hospitals after implementation of the new program, received information from significantly more sources of information that were addressed by the program than patients who were admitted before implementation (group 1). Hypothesis 2 was not confirmed. Patients in group 2 did not receive significantly more written information about cholecystectomy and about anesthesia than those in group 1. Hypothesis 3 was partially confirmed. Written information about anesthesia was evaluated significantly more positive by patients in group 2 than by those in group 1. Patients' evaluation of the written information about cholecystectomy did not differ, however. Hypothesis 4 was not confirmed either. Patients in group 2 did not receive more oral information from nurses on admission than patients in group 1 . On the contrary, nurses informed patients in group 2 less often about the subjects 'preparation for surgery', and 'regulations and facilities of the ward', than patients in group 1. These differences were restricted to hospital 1. Finally, hypothesis 5 was partially confirmed. Patients in group 2 evaluated oral information received from nurses on admission about the subject 'recovery' significantly more positively than patients in group 1 .

These results suggest that the success of the program's implementation was limited. This conclusion is supported by the results of additional tests of group differences in information received. Fewer patients in group 2 than in group 1 received (or noticed) written information about the hospital and about the ward. Nurses' oral information at discharge about the subject 'recommendations for behavior at home' was evaluated more positively by patients in group 2 than in group 1 . The slide-tape presentation was watched by approximately one out of four patients in group 2 .

Although patients in group 2 were not found to receive more written information about cholecystectomy and about anesthesia, and also did not receive any more oral information from nurses on admission than patients in group 1, they received more information when all sources addressed by the new program were taken into account. This finding, which at first glance seems contradictory, may be explained by the fact that the total number of preoperative sources from which patients received information was increased by the new program. In hospital 1, a leaflet was introduced and provided to patients about herniorrhaphy, while in hospital 2 leaflets were introduced and provided about cholecystectomy, herniorrhaphy, and anesthesia. In addition, in both hospitals a slide-tape presentation was introduced for patients to view. Thus, considering all sources of preoperative information, 
we conclude that the program's implementation was successful. However, limiting the comparison to sources available both before and after implementation of the program, implementation was only modest.

To explain this last result, we offer three alternative explanations. First, to tailor the program to patients' needs for control, we intended to provide them with information only to the extent that they themselves desired information. Consequently, patients in group 2 may have desired little or no information and thus may not have undertaken action to be informed. Unfortunately, we measured receipt of information, not desire for information and cannot confirm this speculation.

Second, various barriers hindered providing information according to the plan. For example, as a result of limited space and personnel, in hospital 2 the slide-tape presentation was displayed only once each week. Therefore, most patients who wished to watch the presentation had to pay an additional visit to the hospital. Since this may have been inconvenient to many of them, this may explain the small proportion of patients who actually watched. This small proportion also explains the relatively small number of patients in group 2 in hospital 2, who received written information about anesthesia. Initially, information about anesthesia was provided to patients while watching the slidetape presentation. When it became clear that some did not arrive to watch the presentation, we decided to provide the leaflet about anesthesia during patients' visits to the surgeon at the ambulatory department. This occurred late in the implementation period, however.

Third, not all conditions that promote successful implementation of an innovation (Rogers, 1962; Zaltman et al. 1973) were met adequately. Promotion of surgical patient education appeared not to be fully compatible with some of the physicians' professional values and needs, since not all of them were prepared, nor did all of them feel the need to improve patient education. In hospital 1 , some physicians openly expressed reluctance to provide patients with adequate information and to undertake themselves action to improve surgical patient education. This was demonstrated by the surgeons' refusal to provide patients with written information about surgery themselves and, instead, to have nurses hand out the leaflets. Similarly, their refusal to participate in the project group may have been caused by lack of need experienced to improve patient education. A final indication that surgical patient education was not fully compatible with some of the physicians' professional values and needs, was the anesthetists' refusal to participate in a training session to improve their communication skills.

Another shortcoming from the perspective of diffusion may have been the long period of time that elapsed before the process of developing and implementing surgical patient education gained tangible results. This may have made the process insufficiently rewarding to some staff members. In particular, in hospital 1 as a result of external causes, much time elapsed before the results of the assessment were available. In addition, development of the intervention took a relatively long period of time, because of the failure to establish a project group. For physicians, the fact that they did not receive any additional monetary benefits for educating patients may have reduced the attractiveness of the intervention. Therefore, some of them claimed that they were not motivated to improve surgical patient education. 
On the other hand, the surgical patient education intervention may have been implemented too early for some potential users. In particular, this may have been the case for the ambulatory department nurses in hospital 1 , where surgeons decided to leave distribution of written patient education materials to nurses. Since they had not been involved in the development process, a hasty attempt was undertaken to prepare them for their contribution to the intervention. Therefore, they may not have been fully prepared to play their role.

Also, it seems likely in hospital 1 that the process of developing and implementing surgical patient education did not enhance social relationships between members of different disciplines. On the contrary, the surgeons' refusal to participate in the project group may have harmed the relationship between the surgeons and members of other disciplines.

Since most difficulties hampering adequate implementation of the program occurred in hospital 1, one would expect shortcomings in the program's implementation to be concentrated in this hospital. Comparison of the two hospitals concerning the extent to which patients received information does confirm this partially. First, in hospital 1 only, a smaller proportion of patients in group 2 received or read the folder about the ward than in group 1 . Second, also in hospital 1 only, nurses provided fewer patients in group 2 than in group 1 with oral information about 'preparations for surgery' and 'regulations at the ward'. Third, at discharge in hospital 1, nurses provided patients in group 2 less often with information about the subject 'behavior at home' than in hospital 2. However, despite the fact that in hospital 1 the leaflet about anesthesia was provided to patients in group 2 on an ad hoc basis by nurses of the ambulatory department, in this hospital it was received by a larger proportion of patients in group 2 than in hospital 2. Also, in hospital 1, after surgery, surgeons provided more oral information about 'anesthesia', and at discharge they provided more oral information about 'discharge' to patients than in hospital 2 . We may explain these three, somewhat unexpected findings by assuming that staff members in hospital 1 traditionally were more used to providing patients with information than in hospital 2.

Although the results of this study do not clearly demonstrate that implementation of the program was succesful, this does not necessarily mean that the program failed to reach its objectives, namely improvement of surgical patients' physical recovery and psychological well-being. We only measured the amount of information received by patients in group 1 and 2 . However, the quality of the information received by patients in group 2 was supposed to be higher than the quality of the information received by patients in group 1. Additional research is needed to compare the effects of the information on patients in both groups.

From this study we conclude that members of the regular hospital staff can be successful in providing information to surgical patients according to a predetermined program. This was demonstrated by an increase of infornation received by patients from sources addressed by the program after its implementation. However, also indications were obtained that the extent to which the new program was implemented, was limited.

Close cooperation with members of all relevant disciplines involved in treatment and care of surgical patients, seems a useful approach to develop and implement such a program, 
provided that the process is sufficiently rewarding to all staff members involved. Also, examination of existing routines of treatment, care and information provision to surgical patients, together with shortcomings in patient education provide an adequate starting point for the process of developing and implementing the program.

However, the study also demonstrated the importance of meeting conditions that enhance the likelihood that an innovation such as a program for surgical patient education will be adopted by its potential users. In particular, it showed that compatibility of the process of development of patient education with the needs and values of its potential users is an essential requirement, which was difficult to meet in this study. In the hospital where this condition was not met completely among the physicians, the process was considerably complicated and very time consuming. As a result, the program's implementation was less successful than in the other hospital. Finally, the study demonstrated the need to complete the process within a reasonable period of time to keep all participants sufficiently motivated, as well as the need to involve all care givers who are likely to contribute to surgical patient education, in the process from the start.

\section{References}

Agency for Health Care Policy and Research (1992),

Acute Pain Management in Adults: Operative Procedures, Rockville, Maryland,

U.S. Department of Health and Human Services.

Anderson, E.A. (1987),

Preoperative preparation for cardiac surgery facilitates recovery, reduces psychological distress and reduces the incidence of acute postoperative hypertension, Journal of Consulting and Clinical Psychology, 55, 513-520.

Anderson, K.O., Masur, F.T. (1983),

Psychological preparation for invasive medical and dental procedures, Journal of

Behavioral Medicine, 6, 1-40.

Averill, J.R. (1973),

Personal control over aversive stimuli and its relationship to stress, Psychological

Bulletin, 80, 286-303.

Breemhaar, B., Van den Borne, H.W. (1991),

Effects of education and support for surgical patients: The role of perceived control,

Patient Education and Counseling, 118, 199-210.

Breemhaar, B., Van den Borne, H.W., Mullen, P. (1996),

Inadequacies of surgical patient education, Patient Education and Counselling, 28, 31-44.

Bubela, N, Galloway, S. (1990),

Factors influencing patients' informational needs at time of hospital discharge, Patient Education and Counseling, 16, 21-28.

Devine, E.C. (1992),

Effects of psychoeducational care for adult surgical patients: A meta-analysis of 191 studies, Patient Education and Counseling, 19, 129-142. 
Devine, E.C., O'Connor, F.W., Cook, T.D., Wenk, V.A., Curtin, T.R. (1988),

Clinical and linancial effects of psychoeducational care provided by staff nurses to adult surgical patients in the post-DRG environment, American Journal of Public He'alth, 78, 1293-1297.

Fngstrï, B. (1984).

The patient's need for information during hospital stay, International Journal of Nursing Studies, 21, 113-130.

Gatchel, R.J. (1980),

Perceived control: A review and evaluation of therapeutic implications, in: A. Baum. J. Singer (eds.), Advances in Environmental Psychology, vol. 2, New Jersey, Lawrence Erlbaum.

Johnstun, M. (1988),

Impending surgery, in: S. Fisher and J. Reason, (eds.), Handbook of life stress, cognition and health, New York, John Wiley \& Sons.

Johnston, M., Vogele, C. (1993),

Benefits of psychological preparation for surgery: A meta-analysis, Annals of Behavioral Medicine, 15, 245-256.

Johnston, M., Gilbert, P., Partridge, C., Collins, J. (1992),

Changing perceived control in patients with physical disabilities: An intervention study with patients receiving rehabilitation, British Journal of Clinical Psychology, 31, 89-94.

Kendall, P.C., Watson, D. (1981),

Psychological preparation for stressful medical procedures, in: Medical Psychology,

Contributions to Behavioral Medicine, New York, Academic Press.

Kincey, J., Saltmore, S. (1990),

Surgical treatments, in: M. Johnston and L. Wallace (eds), Stress and Medical

Procedures, Oxford, Oxford Medical Publications.

Knippenberg, A. van, Siero, F. (1980),

Multivariate analyse, Deventer, The Netherlands, Van Loghum Slaterus.

Libman, E., Fichten, C.S., Creti, L. (1987),

Determining what patients should know about transurethial prostatectomy, Patient Education and Counseling, 9, 145-153.

Mathews, A., Ridgeway, V. (1984),

Psychological preparation for surgery, in: A. Steptoe, A. Mathews, (eds.), Health

Care and Human Behavior, New York, Academic Press.

McCullough, C., Boggs, B., Varner, C. (1980),

Implementation of educational programs for patients, Nursing Administration Quarterly, 4, 61-65.

Miller, S. M., Combs, C., Stoddard, E. (1989),

Information, coping and control in patients undergoing surgery and stressful medical procedures, in: A. Steptoe and A. Appels (eds.), Stress, Personal Control and Health, New York, John Wiley \& Sons. 
O'Connor, F.W., Devine, E.C., Cook, T.D., Wenk V.A., Curtin, T.R. (1990),

Enhancing surgical nurse's patient education: development and evaluation of an intervention, Patient Education and Counseling, 16, 7-20.

Orlandi, M.A., Landers, C., Weston, R., Haley, N. (1990),

Diffusion of health promotion innovations, in: Glanz, Lewis \& Rimer, eds., Health

Behavior and Health Education Theory, Jossey Bass.

Ray, C. (1982),

The surgical patient: psychological stress and coping resources, in: J.R. Eiser (ed.),

Social psychological and Behavioral Medicine, New York, John Wiley and Sons.

Redman, B.K. (1981),

Patient Education in Hospitals: Developmental Issues, Journal of Nursing Adminis-

tration, September, 28-30.

Rogers, E.M. (1983),

Diffusion of Innovations, third edition, London, The Free Press.

Rogers, E.M. (1962),

Diffusion of Innovations, London, The Free Press.

Rogers, M., Reich, P. (1986),

Psychological intervention with surgical patients: evaluation outcome, Advances in

Psychosomatic Medicine, 15, 23-50.

Ruzicki, D.A. (1985),

Motivating patient care staff to teach: A plan for action, in: American Hospital

Association Media Center, Surgical patient education does make a difference, Live

Interactive Satellite Video Teleconference.

Schultheis, K., Peterson, L., Selby, V. (1987),

Preparation for stressful medical procedures and person by treatment interactions,

Clinical Psychology Review, 7, 329-352.

Suls, J., Wan, C.K. (1989),

Effects of sensory and procedural information on coping with stressful medical procedures and pain: a meta-analysis, Journal of Consulting and Clinical Psychology, 57, 372-379.

Syme, S.L., (1989),

Control and health: a personal perspective, in: Steptoe, A., Appels, A. (eds.),

Stress, Personal Control and Health, New York, John Wiley and Sons.

Taylor, S.E. (1991),

Health Psychology, 2nd edition, New York, Random House.

Taylor, S.E., Clark, L.F. (1986),

Does information improve adjustment to noxious medical procedures?, in: M.J.

Saks and L. Saxe, Advances in Applied Social Psychology, vol 3, New Jersey,

Lawrence Erlbaum.

Thompson, S.C., Cheek, P.R., Graham, M.A. (1987),

The other side of perceived control: disadvantages and negative effects, in:

Spacapan, S., Oskamp, S. (eds.), The Social Psychology of Health, The Claremont Symposium of Applied Social Psychology, Beverly Hills, Ca., Sage. 
Van den Borne, H.W. van den, Pruyn, J.F.A., Meij, K. de (1986), Help given by fellow patients, in: Stoll, B.A. (ed.), Coping with Cancer Stress, Dordrecht, The Netherlands, Martinus Nijhoff.

Visser, A. Ph. (1986),

Patiënt in het Ziekenhuis, Assen, The Netherlands, Van Gorcum.

Wallace, L. (1986),

Informed Consent to elective surgery: the 'therapeutic' value?, Social Science and Medicine, 22, 29-33.

Wallston, K.W., Wallston, B.S., Smith, S., Dobbins, C.J. (1987),

Perceived control and health, Current Psychology Research Reviews, 6 (1), 5-25.

Webber, G.C. (1990),

Patient education: A review of the issues, Medical Care, 28, 1089-1103.

Weinman, J., Johnston, M. (1988),

Stressful medical procedures: an analysis of the effects of psychological interventions and the stressfullness of the procedures, in: Maes, S., Spielberger, C.D., Defares, P.B., Sarason, I.G., Topics in Health Psychology, London, John Wiley \& Sons.

Wilson-Barnett, J. (1994),

Preparing patients for invasive medical and surgical procedures 3: Policy implications for implementing specific psychological interventions, Behavioral Medicine, 20, 23-26.

Wilson Barnett, J., Osborne, J. (1983),

Studies evaluating patient teaching: implications for practice, International Journal of Nursing Studies, 1, 33-44.

Zaltman, G., Duncan, R., Holbek, J. (1973),

Innovations and Organizations, London, John Wiley \& Sons. 


\title{
6 Effectiveness of surgical patient education delivered by hospital staff members'
}

\author{
B. Breemhaar ${ }^{2}$, H.W. van den Borne ${ }^{3}$, P.D. Mullen ${ }^{4}$, G. Kok ${ }^{5}$
}

\subsection{Introduction}

Studies evaluating psychoeducational interventions demonstrated that in general these interventions can relieve surgical patients' stress and improve physical recovery from surgery (Horne, Vatmanides \& Careri, et al., 1994; Johnston \& Vogele, 1993; Lipsey \& Wilson, 1993; Devine, 1992; Suls \& Wan, 1989; Devine \& Cook, 1986; Hathaway, 1986; Mathews \& Ridgeway, 1984). Interventions comprise offering patients procedural and/or sensory information concerning surgery, behavioral instructions and cognitive restructuring (e.g. offering distraction) to facilitate well-being, and psychotherapeutic interventions (Devine, 1992; Kincey \& Saltmore, 1990; Schultheis, Peterson \& Šelby, 1987; Cochran, 1984). Á range of benefits has been measured, including post operative medicines and complications, length of stay, pain, resuming physical activities after surgery and psychological measures such as anxiety, preoperative fear, mood, and uncertainty, knowledge, and finally various hormonal levels as indicators of both physical recovery and psychological adaptation (Johnston \& Vogele, 1993; Salmon, 1992; Devine, 1992; Weinman \& Johnston, 1988; Rogers \& Reich, 1986).

Although many studies have demonstrated that psychoeducational interventions for surgical patients can be efficacious, the effectiveness or ecological validity of these

This study was made possible by a grant from the Dutch Praeventiefonds, projectnumber 26-20.

2 Drs. B. Breemhaar is researcher at IVA, Institute for Social Research of the University of Brabant, Tilburg, the Netherlands.

3 Prof dr. H.W van den Bome is professor of Patient Education at the Dept. of Health Education of the University of Limburg, Maasiricht, The Netherlands.

Dr. P.D. Mullen is professor of Behavioral Science and Health Education and Deputy Director, Center for Health Promotion Research and Development, University of Texas School of Public Health, Houston, Texas, USA.

5 Prof. dr. G.J. Kok is professor and chair, Dept. of Health Education of the University of Limburg, Maastricht, The Netherlands. 
studies may be questioned, because they typically used an 'external agent' (e.g. the researcher) who formed no part of the regular health care personnel (Wilson-Barnett, 1994; O'Connor, Devine, Cook, Wenk \& Curtin, 1990; Devine, O'Connor, Cook, Wenk \& Curtin, 1988). Thus, it remains unclear whether interventions that are carried out by regular staff members can bring about the same desired outcomes that were observed when external agents were used. Because of the confidence patients put in their health care providers (Van den Borne, Pruyn \& de Meij, 1986; Wallace, 1985), because of accreditation requirements (Department of Veteran's Affairs, 1992), and because of the need for continuity and cost reduction (Devine \& Cook, 1986), it is imperative that health care professionals themselves conduct patient education. Thus, this study will assess the effects of a surgical patient education intervention which was delivered to patients by regular health care providers during everyday practice of treatment and care in two hospitals.

This study also will investigate patients' level of perceived control as a variable which may explain the effectiveness of the intervention to reduce stress among surgical patients and to improve recovery from surgery (Salmon, 1992; Breemhaar \& Van den Borne, 1991 (chapter 3); Syme, 1989; Kok, 1988). Although various attempts have been undertaken to explain the benefits of educational interventions among surgical patients, no agreement exists concerning the exact causes (e.g. Contrada, Leventhal \& Anderson, 1994; Miller, Combs \& Stoddard, 1989). Wallston, Wallston, Smith \& Dobbins (1987) defined perceived control as "... the belief that one can determine one's own internal states and behavior, influence one's environment, and bring about desired outcomes" ( $p$. 5). As illustrated in figure 6.1, feelings of control are expected to keep stress within bounds and psychological and physical well-being at an acceptable level. Although the experience of hospitalization for surgery tends to decrease patients' perceived control (Taylor, 1991; 1979; Eisendraht, 1987), patient education and support are likely to stimulate perceived control (Breemhaar \& Van den Borne, 1991 (chapter 3); Taylor, 1991). Teaching patients skills to reduce pain offers them behavioral responses to decrease unpleasant aspects of medical treatment (Johnson \& Leventhal, 1974). Also, procedural and sensory information may improve patients' ability to predict more accurately what he/she is to undergo and to prepare for it better (Taylor \& Clark, 1986). Thus, as shown in figure 6.1 , perceived control may serve both as a mediating and as a moderating variable to the relationship between patient education and stress. Mediating, because the beneficial effects of patient education on stress are expected to depend on the extent patient education enhances perceived control. Moderating, because perceived control is expected to affect stress, irrespective of patient education. 
Threatening events associated with hospital admission and (recovery from) surgery (illness, physical incapabilities, loss of identity, pain, etc.)

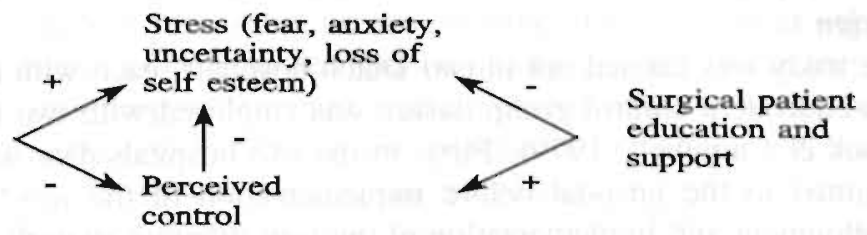

Figure 6.1: Theoretical model of the study.

A high level of perceived control does not seem to benefit every patient, however (Thompson, Cheek \& Graham, 1987). Patients predisposed with relatively strong feelings of control were found to benefit (Auerbach, 1989; Miller et al., 1989; Schultheis, et al., 1987; Mathews \& Ridgeway, 1984), while among patients predisposed with weak feelings of control, the effects are neutral or even detrimental. Consequently, to avoid harming patients' well-being and recovery, patient education interventions should take into account differences between patients to the extent that they desire control (Breemhaar \& Van den Borne, 1991 (chapter 3); Kincey \& Saltmore, 1990; Rogers \& Reich, 1986). The surgical patient education intervention examined in this study aimed to enhance or to preserve patients' level of control.

\subsection{Hypotheses}

With respect to the effectiveness of the intervention, we hypothesized that:

1. Surgical patients, admitted into the hospital after implementation of the new patient education program delivered by regular members of the surgical staff, will exhibit higher levels of psychological well-being and physical recovery, compared to patients admitted before implementation of the program.

2. Surgical patients admitted into the hospital after implementation of the new program will exhibit higher levels of perceived control, compared to patients admitted before implementation.

To examine perceived control as an explanatory variable for the effectiveness of the new program of patient education, we hypothesized that:

3. Patients with a high level of perceived control will demonstrate higher levels of psychological well-being and recovery from surgery, compared to patients with a low level of perceived control, whether or not they were exposed to the new program.

4. Improvements in psychological well-being and physical recovery from surgery among patients admitted into the hospital after implementation of the new program of surgical patient education, are mediated by increased levels of perceived control. 


\subsection{Method}

\section{Design}

The study was carried out in two Dutch hospitals, each with approximately 600 beds. A non-equivalent control group design was employed with two cohorts of surgical patients (Cook \& Campbell, 1979). First, in the two hospitals data were collected from patients admitted to the hospital before implementation of the new program (group 1). After development and implementation of the new program in each hospital, similar data were collected from patients who received information according to the new program (group 2). As figure 6.2 shows, collection of data and implementation of the new program of surgical patient education in both hospitals were not carried out simultaneously. In hospital 2 these activities took place approximately one year after those in hospital 1 .

$1990 \quad 1991 \quad 1992$

Month: $\quad \begin{array}{llllllllllllllllllllllllllll}4 & 5 & 6 & 7 & 8 & 9 & 10 & 11 & 12 & 1 & 2 & 3 & 4 & 5 & 6 & 7 & 8 & 9 & 10 & 11 & 12 & 1 & 2 & 3 & 4 & 5 & 6 & 7\end{array}$

Hospital 1: $\mathrm{O}_{1} \cdots\left(\right.$ group 1) $\quad \mathrm{XO}_{2} \quad \ldots-$ (group 2)

Hospital 2: $\quad \mathrm{O}_{1}$

$\mathrm{XO}_{2} \ldots$ (group 2)

$\mathrm{O}_{1}=$ Base line measurements among patients receiving existing information.

$\mathrm{X}=$ Implementation of the new program of surgical patient education

$\mathrm{O}_{2}=$ Measures among patients receiving information according to the new program. (In December ' 90 hospital 1 moved to a new location, and the program was delayed for two months.)

Figure 6.2: Design of the study.

\section{Participants}

The study was carried out among patients scheduled for herniorrhaphy or cholecystectomy, who met the following inclusion criteria: a) 18 years or over, b) command of the Dutch language, c) no urgency involved, d) admitted to the hospital out of the home, e) admitted one day pre-operatively, and f) admitted for hemiorrhaphy or cholecystectomy only.

\section{Surgery patient education program}

The content of the program was based on the results of an examination in both hospitals of patient flow, problems experienced by patients, and adequacy and quality of information provided to patients during the course of treatment and recovery (Breemhaar, Van den Borne \& Mullen, 1996 (chapter 4)). Further, findings from previous evaluations of interventions to prepare patients for surgery (chapter 2) were incorporated, together with theoretical notions about the role of perceived control in the beneficial effects of preparation for surgery (Breemhaar \& Van den Borne, 1991 (chapter 3)).

To enhance physicians' and nurses' involvement in giving patients information and support according to the program, this program was developed in close cooperation with hospital staff members, according to the linkage approach (Orlandi, Landers, Weston \& Haley, 199()). A project group was installed consisting of representatives of each relevant 
discipline contributing to treatment and care of patients undergoing surgery. Some measures that were initially proposed to be incorporated in the program were perceived as unattainable by some members of this group, because of time, financial and/or organizational constraints. For example, to increase recognition among patients of the surgeon and the ward physician, it was proposed to limit patient-doctor contacts to the ward physician. Although ward physicians were formally responsible for preparation of patients for surgery and for medical management during their recovery, surgeons were not prepared to leave the contacts with clinical patients completely to ward physicians. Also, it was proposed to have ward physicians discuss with each patient before his or her discharge from the hospital, the medical regimen at home, behavioral recommendations, and how to handle possible physical complications. However, because of practical considerations this measure was not implemented.

Consequently, not all improvements were attained which were desirable considering the shortcomings in patient education detected before. Most of the measures for improvement for which agreement was attained concerned information provision during the preoperative period, before or after admittance. Also, most of these measures were designed to be carried out by nurses. Below, a brief description of the program is provided (see chapter 5 for a more detailed description).

First, the content of the information provided to patients was adapted more closely to their needs, as they emerged from the examination. We included both procedural and sensory information, as well as instructions concerning patient behavior that is expected to facilitate presurgical preparation and post operative recovery. Reassuring information was included about methods employed by health care providers to ensure patients' wellbeing. Written information was developed about surgery, anesthesia, health care providers involved, post operative bodily experiences, opportunities to relieve post operative pain, and about discharge. This information was included in leaflets, which were provided to patients pre operatively by nurses, during their visit to the ambulatory department. A slide-tape presentation was produced showing procedures regarding admission and preparations for and recovery from surgery. This presentation used a "model patient" following the routing through the hospital during preparation for and recovery from herniorrhaphy or cholecystectomy, showing the location of medical examinations, preparations for surgery and the operating theatre. Also, health care providers involved in these activities were introduced. The slide-tape presentation could be viewed preoperatively at the ambulatory department on a voluntary basis, some days prior to admission. Finally, assignments were made to nurses concerning topics to be discussed with patients on admission into the hospital. To support nurses, a checklist was developed which displayed these topics. Simultaneous with this program development process, the nursing staff developed written information about regulations and facilities at the hospital and at the ward, and made this available in a folder for patients to read at the ward.

Second, the methods of information provision were changed by making agreements with nurses and physicians regarding the timing of provision of written, oral and audiovisual information. This was to promote an even distribution of information over time and to structure the subjects concerning which patients receive information. Thus, the agree- 
ments were also intended to prevent unnecessary duplication of and gaps in information provision.

Third, we attempted to enhance patients' level of perceived control, while respecting individual needs for control. We gave patients information about behavioral opportunities to reduce discomfort and to improve physical well-being. For example, in the leaflets and in the slide-tape presentation smokers were instructed to stop smoking a few days before surgery, all patients were instructed to indicate postsurgical pain and nausea in order to receive appropriate medication, to reduce wound pain by supporting the wound, to cough and breathe deeply in order to improve pulmonary functioning and, if not contra-indicated, to move around post operatively. Also, they were informed about the roles and responsibilities of particular health care providers, and encouraged to direct their questions to the most appropriate staff member whenever they wished to. To prevent undesirable consequences of increasing perceived control among patients predisposed with low needs for control, care was taken not to thrust information upon them. Therefore, they were encouraged to read the written materials, to watch the slide-tape presentation, to ask questions, and to perform additional bodily movements only to the extent that they were willing to.

\section{Measures}

Data were collected in four interviews with patients during their course of treatment and recovery. The interviews took place on the day of admission (time 1 ), two or three days after surgery (time 2), one week after hospital discharge (time 3), and one month after discharge (time 4). Table 6.3 displays the variables and the timing of measurement.

Independent variables: amount and judgement of information received At time 1 patients were asked whether they had received and read written information that was regularly provided to patients or was regularly available for patients to look up. If they had read this information, they were asked on a three-point scale to judge its comprehensibility and sufficiency. At time 1, in group 2 only, patients were asked whether or not they had watched the slide-tape presentation. 


\begin{tabular}{llll}
$\begin{array}{l}\text { Day of ad- } \\
\text { mission } \\
\text { (time 1) }\end{array}$ & $\begin{array}{l}2 \text { or } 3 \text { days } \\
\text { post-operative } \\
\text { (time } 2)\end{array}$ & $\begin{array}{l}\text { Post discharge: } \\
\text { one week } \\
\text { (time 3) }\end{array}$ & $\begin{array}{l}\text { one month } \\
\text { (time 4) }\end{array}$ \\
\hline
\end{tabular}

Receipt and evaluation of information":
a) Written information
b) Audio-visual information
c) Oral information

$x$

$x \quad \begin{aligned} & x \\ & x\end{aligned}$

Effect variables:

a) Resumption physical activities

b) No. phys. complaints after surgery

c) No. phys. complaints at measurement

d) Pain

e) Bothered by pain

f) Distressed by pain

g) Instrumental activities of daily living (IADL)

h) Job resumption

i) Resumption of domestic work

j) Resumption of leisure

k) Preoperative fear

l) Preoperative anxiety

m) Need for information about:

- hospital stay, surgery, opportunities to obtain information

- the illness

- surgery and hlth. care providers

n) Need for information about:

- surgery and its consequences

- the period after discharge

- discharge

n) Knowledge (2 different versions)

o) Subjective health

$\times(.93)$

$\times(.84)$

$x(.80)$

$x(.64)$

Mediating and moderating variables:

a) Quality of close relationship

b) Number of visits in hospital

c) Perceived control (3 different versions)

$\times(.80)$
$\times(.82)$
$\times(.66)$
$\times(.17)$

$x(r=.81)$

$\mathrm{x} \quad \mathrm{x}$

$\times(.72) \times(.80) \times(.77)$

$\times(.80)$

$(.66)$

$(.17)$ $x(.87)$

$\times(.55)$

$\mathrm{x}$

$x$

$x$

$x$

$x$

$x$
$x$

$x(.94)$

$x(.91)$

\section{$x$}

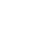

$x$

Information concerning length of stay and medications is not included in the table. This information was obtained from the medical files.

2 Between brackets is the measurement's reliability (Cronbach's $\alpha$, or KR-20 for scales with dichotomous items).

3 In some cases somewhat sooner or later, due to early or delayed recovery.

4 A summary score was calculated from these variables indicating the amount of information received before or on admission from sources that were addressed by the new program.

At time 1,2, and 3, it was asked whether they had been informed orally by surgeons, ward physicians and nurses about particular subjects on the day of admittance, shortly after surgery, and at discharge. With respect to each staff member who gave information about a particular subject, those reporting that they were informed, were asked to what extent (three-point scale) they considered this oral information comprehensive and suffi- 
cient. Finally, an index was calculated for the total amount of information received for each patient by counting the number of leaflets and folders he or she had received, added to the number of subjects mentioned above about which oral information had been received on admission from nurses, and one more point when the patient watched the slide-tape presentation.

\section{Dependent variables: Physical recovery}

Postoperative resumption of physical activities was assessed at time 2, using a Recovery Inventory consisting of eight items which form a Guttmann scale, of the time between surgery and the first time of performing activities. These activities ranged from movement in bed to passing water in a toilet (Wallace, personal communication; Wallace, 1984). At the same occasion we asked with respect to each of twelve physical complaints likely to occur post operatively (Wallace, 1984), whether patients had experienced any of these after surgery. Those answering affirmatively, were asked whether they still suffered from the particular complaint at the time of measurement. One score was calculated, based on the number of complaints experienced after surgery and another score was based on the number of physical complaints experienced at the time of measurement. With respect to the latter scores, no index of reliability was calculated, because subjects answered the question concerning a complaint at time of measurement only if they had experienced it previously following surgery. Thus, this variable had many missing values.

At time 2, patients rated the degree of post operative pain currently experienced at the incision on a scale from 0 to 10 (Johnson, Rice, Fuller, Endress, 1978; Flaherty \& likupatrick, 1978). Also, on a visual analogue scale they indicated how much they were physically bothered and felt distressed by the pain. Scale ends were labeled respectively "not bothered" and "not distressed" to "very much bothered" and "very much distressed". Two scores were calculated, corresponding to the number of millimeters between the lefthand scale end and the place where the patient marked the scale, varying from 0 to 10 . At time 3 instrumental activities of daily living (IADL) were measured by a 14-item scale (Spector, Katz, Murphy \& Fulton, 1987; Wallace, 1986; Katz \& Akpom, 1976; Katz, Ford, Moskowitz, Jackson \& Jaffe, 1963). A score was calculated indicating the number of activities which he or she could perform independertly without restrictions, divided by the number of activities which were applicable.

At time 4 patients indicated, if applicable, whether they had resumed their job and if so, whether this was to a similar degree as before the onset of illness and hospitalisation. A score was calculated ranging from 1 (not yet resumed) to 4 (fully resumed shortly after discharge). Patients who performed more than two hours domestic work weekly before the onset of illness and hospitalisation, were asked if they had resumed these activities. Finally, they indicated whether they resumed leisure activities. A score was calculated for both variables ranging from 1 (not yet resumed) to 3 (fully resumed).

From the medical record, data were recorded concerning the number of days in hospital (beginning on the first post-operative day up to and including the day of discharge), and the number of postsurgical analgesics and sleep medicines taken by patients, irrespective of dosage. 
Dependent variables: Psychological well-being

Various studies of the effectiveness of presurgical preparation employed pre'(1)('rutive fear as a covariate, because post operative recovery and psycholugical well-being were repeatedly found to be negatively related to preoperative fear (Auerbach, 1989). Also, the effectiveness of psychoeducational interventions was found to differ between putients with high and patients with low preoperative fear (chapter 2). In this study however, preoperative fear was treated as a dependent variable only, because most of the content of the new program of surgical patient education was provided hefore or during admission into the hospital and preoperative fear was measured at the end of the day of admission and was therefore likely to be influenced by the program.

Preoperative fear was measured by Johnson, Leventhal \& Dabbs' (1971) 'Scale of Worry' (Boeke, 1988; Utens, 1989), which measures on a four point scale patients' concern about their illness, surgery and anesthesia. To increase reliability of the measurement (from $\alpha=.77$ to .82 ) we added three items, fear of post operative pain, surgical mistakes, and adverse postsurgical physical symptoms (four point scale), concerns expressed by a relatively large percentage of patients during the needs assessment (Breemhaar, Van den Borne \& Mullen, 1996 (chapter 4)). Factor analysis with varimax rotation was performed on the item scores to examine the factor structure of the scale. All items were found to load on a single factor (53\% explained variance). The mean of the six item scores was calculated to represent preoperative fear.

Anxiety was measured three times, at time 1,2 , and 3, by the state version of the StateTrait Anxiety Inventory (Van de Ploeg, Defares \& Spielberger, 1980; Spielberger, Gorsuch \& Lushene, 1970). Missing values were replaced as follows: measurement 2 $(n=3)$ replaced by measurement 1 ; measurement 2 and $3(n=14)$ by measurement 1 ; measurement $3(n=9)$ by measurement 2 . For each of the three measurements of anxiety a score was calculated, consisting of the sum of the item scores.

Need for information was measured by assessing patients' desire for information about 1) medical affairs and events in the hospital, 2) names and responsibilities of relevant health care providers in the hospital and 3) regulations and facilities in the hospital and on the ward. Topics were selected based on previous studies of uncertainty among hospital patients (Van den Borne \& Pruyn, 1985; Visser, 1984; Stern, Maoz \& Leiser, 1982). Need for information was measured at time 1 and 2 on a four-point scale. Topics differed between measurements, according to what patients consider most important pre- and postsurgically. Presurgically, 18 , and postsurgically 16 items were employed.

Pre and post operative scores on need for information were separately subjected to principal component analysis with orthogonal rotation. Based on an item's Inading ( $\geq$ $.50)$, it was decided whether it belonged to a particular factor. Factor analysis of the scores at time 1 revealed three factors (see appendix 6.1). Factor I concerned the need for general information about hospital stay, surgery and opportunities to obtain additional information. Factor II concerned the need for specific information about the illness. One item (concerning the name of the head nurse) was removed from factor II to increase $\alpha$ by .10. Factor III concerned the need for specific information about surgery and the health care providers involved. Factor analysis of item scores at time 2 also resulted in three factors (see appendix 6.2). Factor I related to need for information about surgery. 
Factor II concerned the need for information about life after discharge from the hospital, and factor III concerned the need for information about discharge. Item scores belonging to the same factor were averaged to obtain a single indicator of the particular factor with respect to need for information.

Knowledge was measured by multiple choice questions about a) regulations and facilities in the hospital and at the ward, b) names and responsibilities of health care providers and c) medical subjects (Utens, 1989; Visser, 1984), at times 1 and 2 . To avoid testing effects, forms with equivalent content of 11 and 10 items respectively were employed. A score was calculated separately for knowledge pre and post operatively, by counting the numbers of correctly answered questions. The scores were found to have a correlation of $.81(\mathrm{p}<.01)$. However, the internal reliability of both scales was inappropriately low (table 6.3). Alternatively, separate scores were calculated pre and postoperatively for each of the three domains of knowledge. Again, the reliability of these scores was inappropriate (preoperative: $\alpha_{\text {regulations and facilities }}=.14, \alpha_{\text {names and responsibilities }}=.12, \alpha_{\text {medical sub- }}$ jects $=.17$, postoperative: $\alpha_{\text {regulations and ficilities }}=.43, \alpha_{\text {names and responsibilities }}=.23, \alpha_{\text {medical subjects }}=.03$ ), and therefore these measures of knowledge were omitted from further analyses.

Subjective health was measured at time 4 by three items. Patients were asked to judge their current health on a five-point scale, and to indicate on a four-point scale the extent to which they agreed with two statements: "I feel similar again like before the onset of illness and surgery" and "Everything goes similarly easy like before the onset of illness and surgery". The mean of the combined scores was calculated to represent subjective health.

\section{Mediating and moderating variables}

Previous studies indicated that surgical patients with strong social ties tend to recover faster compared to patients with weaker ties (Kulik \& Mahler, 1989). Therefore, social support was assessed as a moderating variable of the relationship between on the one hand patient education, and physical recovery and psychological well-being on the other. At time 1 patients indicated on a four-point scale their judgement of the quality of the relationship with their partner or someone else to whom they felt closely related. Also on a four-point scale, they indicated to what extent they felt alone while facing hospitalisation and surgery. Because both questions were correlated significantly $(r=.30 ; p<.001)$, the mean score was calculated as the first indicator of social support. The second indicator consisted of the mean number of visits patients received in the hospital each day from their partner or someone else to whom they felt closely related. During the first interview, they were asked how many times this person had visited them in the hospital since their admission. During the second and third interviews, they were asked how many times the person had visited them since the previous interview. The numbers were summed and divided by the number of days in hospital to represent the mean number of visits received. Cases with missing values $(n=12)$, were given their respective group's mean. Since the two indicators of social support were weakly correlated $(r=.12)$, they were used separately in further analyses.

We measured perceiv'ed control by asking the extent to which patients felt able to contribute to their own health, psychological well-being, social relationships and other generally 
valued domains of life. Patients indicated on a three-point scale whether they agreed with statements implicating perceived opportunities to influence their environment to obtain what they desired. Statements concerned situations relevant for patients admitted to a hospital for surgery or recovering from surgery (Taylor, 1991; Partridge \& Johnston, 1989; Eisendraht, 1987; Lucente \& Fleck, 1972; Tagliacozzo \& Mauksch, 1972). Further, items were constructed concerning emotional problems that previously (Breemhaar, Mullen \& van den Borne, 1996 (chapter 4)) were found to indicate loss of perceived control. For example, surgical patients were found to have difficulties identifying relevant health care providers and their responsibilities. Consequently, to assess perceived control, on admission one item stated "Now that I am admitted, I am visited by health care providers I'm unfamiliar with." Another stated "Now that I am admitted, I do not know whom to discuss problems with." Also, they were found to desire additional information concerning discharge and behavioral recommendations after discharge. Therefore, one item stated "After surgery I was uncertain about the day of discharge", and another stated "Since discharge I do not know what I can do to improve recovery." Perceived control was measured at times 1,2 , and 3 , using 14,18 , and 11 items respectively. Items differed for each measurement, according to which circumstances were found to be likely to threaten perceived control at that time of measurement (see appendix 6.3). For each measure the mean value of the item scores was computed. Among items of the scale used at time 3, two items were removed to increase $\alpha$ from .74 to .77 .

\section{Data collection and analysis}

Data were collected by structured face-to-face interviews at times 1,2 , and 3 , and, by telephone, at time 4. A letter signed by the project coordinator (BB) was sent to all patients who met the inclusion criteria, asking them to participate in the study. Interviews were conducted by trained interviewers, recruited from a pool of middle-aged experienced interviewers, mostly female. Each patient was interviewed across time by the same interviewer.

Hypotheses 1 and 2 were tested by performing in SPSSX (SPSS Inc., 1988) multivariate analyses of covariance of the differences between the two groups in mean scores on dependent variables indicating physical recovery and psychological well-being and the three variables indicating perceived control. During the period in which data were collected among patients in group 1, laparoscopy, a new technique to perform cholecystectomy, was introduced. Since patients undergoing laparoscopy are believed to recover faster than patients undergoing traditional cholecystectomy (Van Erp \& Bruyninckx, 1991), we controlled for type of surgery in the analysis. The number of visits received in hospital from persons patients felt closely related to, was included as a covariate.

Multivariate tests of the differences between the two groups were performed separately for variables indicating physical recovery and psychological well-being. These tests were limited to dependent variables measured at one and the same occasion, e.g. at time 1 or at time 2 . If the multivariate difference between groups was significant at the $p \leq .10$ level, the multivariate test was followed by univariate testing. This criterion was chosen to limit the risk of not detecting differences between both groups which may be relevant at the univariate level. To limit type I errors on the univariate level, univariate differ- 
ences were interpreted only when they were significant at the $p \leq .05$ level. Variables measured at times 3 and 4 were tested univariately only, first since the number of variables indicating physical recovery and psychological well-being at those times was restricted to one only. Second, because of relatively small n's at time 4. Multivariate analysis of variance with repeated measures was employed to test differences between groups in changes of anxiety during the course of treatment and recovery. This was restricted to anxiety, because this was the only variable that was measured invariantly over time.

Hypothesis 3 was tested by determining Pearson's correlation coefficients between patients' scores on perceived control at time 1, time 2, and time 3 on the one hand and on the other each of their scores on the variables of physical recovery and psychological well-being. For these analyses, patients in group 1 and 2 were pooled.

Finally, hypothesis 4 was tested by multivariate analyses of covariance of the differences between groups in mean scores on clusters of dependent variables indicating physical recovery or psychological well-being measured all at the same time. Included as covariates were, apart from number of visits, those measures of perceived control on which both groups were found to differ significantly. Again, this analysis was followed by univariate tests only when the multivariate test was significant at the $\mathrm{p} \leq .10$ level.

\subsection{Results}

\section{Initial response and attrition}

Of 249 patients approached for participation, 195 patients participated in the study (table 6.4). The selection criteria were not met by 16 patients. From the remaining 233 patients, 11 were not interested in participation, while seven patients considered the interviews too demanding, because of nervousness or old age. Although initially they agreed to participate, two patients withdrew their agreement before the first interview. Finally, for 18 patients the reason for refusal is unknown. Not considering patients who did not meet the selection criteria, the response rate was $84 \%$. Nonresponse was larger in hospital 2 $(21.3 \%)$, compared to hospital $1\left(9.4 \% ; \mathrm{Chi}^{2}(1)=6.02 ; \mathrm{p}<.05\right.$; table 6.4$)$. However, no differences were found in nonresponse between types of surgery and between group 1 and 2 . 
Table 6.4: Number of participants by group, hospital, and type of surgery.

\begin{tabular}{|c|c|c|c|c|c|c|c|}
\hline & \multicolumn{3}{|c|}{ Hospital 1} & \multicolumn{3}{|c|}{ Hospital 2} & \multirow[t]{3}{*}{ Total } \\
\hline & \multirow[t]{2}{*}{ Hern. ${ }^{\prime}$} & \multicolumn{2}{|l|}{ Chol. $^{2}$} & \multirow[t]{2}{*}{ Hern.' } & \multicolumn{2}{|c|}{ Chol. $^{2}$} & \\
\hline & & Trad. & Lap. & & Trad. & Lap. & \\
\hline \multicolumn{8}{|l|}{ Approached: } \\
\hline - Group 1 & 28 & $13^{3}$ & 2 & 42 & $14^{3}$ & 10 & 109 \\
\hline - $\quad$ Group 2 & 35 & $10^{3}$ & 20 & 43 & $6^{3}$ & 10 & 124 \\
\hline \multicolumn{8}{|l|}{ Responded: } \\
\hline - Group 1 & 28 & 11 & 2 & 33 & 11 & 10 & 95 \\
\hline - Group 2 & 31 & 5 & 20 & 32 & 2 & 10 & 100 \\
\hline
\end{tabular}

Hern. = Herniorrhaphy

Chol. = Cholecystectomy

Some patients scheduled for traditional cholecystectomy who were approached for participation and who refused, may have undergone laparoscopic cholecystectomy.

In total, 23 patients who participated in the interview at time 1 did not complete the interview at time 4 (table 6.5). One patient who did complete the last three interviews, did not participate in the first. Most patients dropped out of the study between the first and the second interview. In group 1, attrition was larger (17\%) than in group 2 (7\%; $\left.\mathrm{Chi}^{2}(1)=4.43 ; \mathrm{p}<.05\right)$. No significant differences in attrition were found between hospitals and between types of surgery.

Table 6.5: Number of patients interviewed by group and time of interview.

\begin{tabular}{|c|c|c|c|c|c|}
\hline & \multirow[b]{2}{*}{ Group: } & \multicolumn{2}{|c|}{ Hospital 1} & \multicolumn{2}{|c|}{ Hospital 2} \\
\hline & & 1 & 2 & 1 & 2 \\
\hline Time 1 (preoperative) & & 41 & 56 & 54 & 43 \\
\hline Time 2 (postoperative) & & 35 & 55 & 48 & 40 \\
\hline Time 3 (one week post discharge) & & 34 & 54 & 45 & 39 \\
\hline Time 4 (one month post discharge) & & 34 & 54 & 45 & 38 \\
\hline
\end{tabular}

Personal reasons to stop participation in the interviews occurred somewhat more often in group 1, while logistic reasons occurred somewhat more often in group 2 (table 6.6). 


\section{Privacy}

IIIness, nervousness, other weakness Group 1 Group 2

Interview makes no sense

Spouse unwilling to receive interviewer at home

Unexpected early discharge

Unexpected early admission

Surgery posiponed

Address unknown

Deceased

Reason unknown

$\begin{array}{ll}2 & 1 \\ 6 & 2 \\ 2 & - \\ 2 & - \\ - & 2 \\ - & 1 \\ 1 & - \\ 1 & 1 \\ 1 & 1\end{array}$

\section{Background characteristics}

Patients from both groups did not differ with respect to background characteristics (table 6.7). Since groin rupture occurs more often among men, while gall stones occur more often among women, and since a larger number of patients underwent herniorrhaphy than cholecystectomy, the number of male participants in both groups was larger than the number of females. The majority of the patients was unemployed at the time of the study. However, among the unemployed, $37 \%$ was retired. 


\begin{tabular}{|c|c|c|c|c|}
\hline$y^{2}$ & & & Group 1 & Group 2 \\
\hline & Sex & Male & $66 \%$ & $71 \%$ \\
\hline 1 & 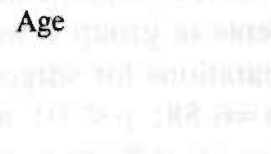 & $\begin{array}{l}18-29 \\
30-49 \\
50-69 \\
70 \text { and over }\end{array}$ & $\begin{array}{l}13 \% \\
36 \% \\
40 \% \\
11 \%\end{array}$ & $\begin{array}{r}6 \% \\
32 \% \\
32 \% \\
11 \%\end{array}$ \\
\hline 3. & Living arrangement & Living together & $76 \%$ & $87 \%$ \\
\hline 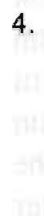 & Education & $\begin{array}{l}\text { Elementary school } \\
\text { Lower vocational or secondary } \\
\text { school or secondary vocational } \\
\text { school } \\
0 \text { levels/A levels or college } \\
\text { University }\end{array}$ & $\begin{array}{r}24 \% \\
54 \% \\
19 \% \\
3 \%\end{array}$ & $\begin{array}{r}28 \% \\
57 \% \\
\\
13 \% \\
2 \%\end{array}$ \\
\hline & Employed & Yes & $47 \%$ & $41 \%$ \\
\hline & $\begin{array}{l}\text { Monthly } \\
\text { income }\end{array}$ & $\begin{array}{l}\text { Df } 1000,- \text { or less } \\
\text { Df } 1000,- \text { to F2999,- } \\
\text { Df } 3000,- \text { to F4999,- }\end{array}$ & $\begin{array}{r}3 \% \\
73 \% \\
24 \%\end{array}$ & $\begin{array}{r}2 \% \\
72 \% \\
26 \%\end{array}$ \\
\hline & $\begin{array}{l}\text { Last admis- } \\
\text { sion to } \\
\text { hospital }\end{array}$ & $\begin{array}{l}<1 \text { year } \\
\geq 1 \text { year, < } 6 \text { year } \\
\geq 6 \text { years } \\
\text { Not applicable }\end{array}$ & $\begin{array}{l}12 \% \\
28 \% \\
40 \% \\
20 \%\end{array}$ & $\begin{array}{l}19 \% \\
31 \% \\
33 \% \\
17 \%\end{array}$ \\
\hline & $\begin{array}{l}\text { Last } \\
\text { surgery }\end{array}$ & $\begin{array}{l}<1 \text { year } \\
\geq 1 \text { year, < } 6 \text { years } \\
\geq 6 \text { years } \\
\text { Not applicable }\end{array}$ & $\begin{array}{r}8 \% \\
23 \% \\
40 \% \\
29 \% \\
\end{array}$ & $\begin{array}{l}10 \% \\
26 \% \\
36 \% \\
28 \%\end{array}$ \\
\hline
\end{tabular}

\section{Potential covariates}

Patients in group 2 received significantly more visits from their partner or from someone else they felt closely related to $(m=1.91)$, than patients in group $1(m=1.52$; $t(180)=2.71 ; p<.01)$. No between group difference was found in feelings of social support experienced. Further, patients receiving many visits, on average had a shorter length of stay $(r=.53)$ and resumed postoperative physical activities sooner $(r=.32)$ than patients receiving few visits. To control for effects of number of visits, it was used as a covariate.

\section{Fidelity of implementation}

With regard to written information, oral information from nurses on admission, and the slide-tape presentation, patients in group 2 received information from significantly more sources than patients in group $1(t(189)=3.76 ; p<.01)$.

Written information that was available for patients in both groups was not provided significantly more often to patients in group 2 than in group 1 . In fact, written information about the hospital and about the ward was noticed by significantly fewer patients in group 2 than in group 1 (resp. $\operatorname{Chi}^{2}(1)=25.13 ; p<.01$ and $\mathrm{Chi}^{2}(1)=10.74 ; \mathrm{p}<.01$ ). The only significant difference in patients' subjective evaluations of the written education 
materials was a more positive evaluation of the leaflet about anesthesia among patients in group 2 (Mann-Whitney-U $=494 ; p<.01$ ). The slide-tape presentation was watched by approximately $25 \%$ of the patients in group 2 .

Patients in group 2 did not receive oral information about any of the subjects significantly more often than patients in group 1. In fact, in hospital 1 only, patients in group 2 were significantly less often informed by nurses on admission about 'preparations for surgery' and 'reglementations at the ward' than in group 1 (resp. $\mathrm{Chi}^{2}(1)=6.58 ; \mathrm{p}<.01$ and $\mathrm{Chi}^{2}(1)=7.31 ; \mathrm{p}<.01$ ). However, examination of patients' evaluation of sufficiency and comprehensibility of the oral information shows that patients in group 2 on admission evaluated nurses' information about 'recovery' more positively than in group 1 (Mann Whitney- $U=420 ; p<.05$ ). Also, patients in group 2 evaluated the information from nurses at discharge about 'recommendations for behavior at home' more positively (Mann Whitney- $U=479 ; p<.01$ ). A more extended description of the results concerning the amount of information received and evaluation of this information is provided in chapter 5 .

We may conclude that considering the number of preoperative sources manipulated by the new program from which patients in group 1 and group 2 received information before or after admission into the hospital, implementation of the new program was succesful. However, considering the number of patients receiving information from sources which were available both before and after implementation of the new program, no increase was found from group 1 to group 2 . This indicates that implementation was not succesful. It should be remembered however, that the content of the information provided to patients was improved by the program. Therefore, not only the number of patients receiving information after implementation of the new program is indicative of its impact, also the quality of the information and its effect on patients is indicative of its impact.

\subsection{Effects of the new program}

\section{Physical recovery}

Multivariate analysis of covariance with number of visits during hospitalization as a covariate and length of stay, number of sleep medication and number of analgesics as dependent variables, showed a significant main effect of group. Univariate analysis showed that patients in group 2 stayed in the hospital less time than patients in group 1 (table 6.8). The multivariate interaction effect between group and type of surgery was significant as well. Subsequent univariate analysis showed that patients undergoing a traditional cholecystectomy in group 2 took more sleep medications postsurgery than patients in the first group, while this was reversed among patients who underwent a laparoscopic cholecystectomy. Further, except for resumption of leisure activities, no significant effects were obtained for any variables indicating physical recovery. Patients in group 2 resumed leisure activities sooner than patients in group 1. 


\section{Psychological well-being}

At time 1, multivariate analysis of the difference between group 1 and group 2 with number of visits as a covariate and anxiety, preoperative fear, and need for information as dependent variables showed a significant main effect of group (table 6.9). Univariately, at time 1 patients in group 1 had stronger needs for information about admission and the operation, compared to patients in group 2. No significant multivariate interaction effect was found at time 1 between group and type of surgery. At time 2, no significant multivariate main or interaction effects were found with respect to psychological wellbeing. Also, at time 3 and time 4, no significant univariate main or interaction effects were found with respect to anxiety and subjective health, respectively. 
Table 6.10: Mean scores for perception of control at time 1, 2, and by group and type of surgery.

\begin{tabular}{|c|c|c|c|c|}
\hline \multirow[t]{2}{*}{ Time (range of scores) } & \multirow[t]{2}{*}{ Group } & \multirow[t]{2}{*}{ Herniorrhaphy } & \multicolumn{2}{|c|}{ Cholecystectomy } \\
\hline & & & Traditional & Laparoscopic \\
\hline 1. (1-3): & $\begin{array}{l}1 \\
2\end{array}$ & $\begin{array}{l}1.49(\mathrm{n}=61) \\
\text { i. } .65(\mathrm{n}=63)\end{array}$ & $\begin{array}{l}1.47(\mathrm{n}=22) \\
1.54 \quad(\mathrm{n}=6)\end{array}$ & $\begin{array}{l}1.43(\mathrm{n}=10) \\
1.53(\mathrm{n}=30)\end{array}$ \\
\hline 2. $(1-3)$ : & $\begin{array}{l}1 \\
2\end{array}$ & $\begin{array}{l}1.53(n=55) \\
1.58(n=59)\end{array}$ & $\begin{array}{l}1.37(n=19) \\
1.37 \quad(n=7)\end{array}$ & $\begin{array}{l}1.45 \quad(n=8) \\
1.39(n=29)\end{array}$ \\
\hline 3. $(1-3):^{1}$ & $\begin{array}{l}1 \\
2\end{array}$ & $\begin{array}{l}1.45(\mathrm{n}=52) \\
1.29(\mathrm{n}=58)\end{array}$ & $\begin{array}{l}1.02(\mathrm{n}=18) \\
1.34 \quad(\mathrm{n}=7)\end{array}$ & $\begin{array}{l}1.26 \quad(n=8) \\
1.24(n=28)\end{array}$ \\
\hline
\end{tabular}

Univariate interaction effect $(F(2,164)=3.06 ; p=.05)$

At times 1 and 2, univariate analyses of covariance of the difference in perceived control between groups, with the total number of visits received during admission as covariate, did not find main effects of group. Also, no significant interaction effects were found between group and type of surgery. Neither were any significant main effects obtained for group at time 3 . However at time 3, patients who underwent traditional cholecystectomy in group 2 showed significantly stronger feelings of control compared to group 1 (table 6.10). Among patients undergoing herniorrhaphy this relationship was reversed; among patients undergoing laparoscopic cholecystectomy, no differences were detected at time 3.

Relationship of perceived control with physical recovery and psychological well-being As expected, except for the number of sleep medications taken, one or more of the three measures of perceived control were significantly and positively related to all variables indicating successful physical recovery (table 6.11). Also, one or more of the measures of perceived control were positively related to all variables indicating psychological wellbeing. In particular, except for postoperative pain, when the timing of measurements is taken into account, perceived control measured at the same time as any particular variable indicating physical recovery or psychological well-being, was significantly associated with this particular variable". The three variables concerning post-operative pain did not correlate significantly with perceived control measured two or three days after surgery.

E.g: need for information on admission about surgery and the number of postoperatixc physical complaints are associated significantly with perceived control at time 1 (preoperative) and time 2 (shonly postoperative) respectively. Also, resumption of work and anxiety one week after discharge are associated significantly with perceived control at time 3 (one week after discharge). 
Table 6.11: Relationship of perceived control at times 1, 2, and 3 with physical recovery and psychological well-being.

\begin{tabular}{|c|c|c|c|}
\hline Perceived control & time 1 & time 2 & time 3 \\
\hline \multicolumn{4}{|l|}{ Physical recovery: } \\
\hline Length of stay & -.11 & -.12 & $-.26^{*}$ \\
\hline Sleep medications & -.10 & -.08 & -.08 \\
\hline Pain medications & -.01 & $-.17=$ & $-.20^{\prime \prime}$ \\
\hline Time between surgery and first activities & -.02 & $-.33 \cdots$ & $-.24 \cdots$ \\
\hline Physical complaints & $-.21^{\cdots}$ & $-.36^{\cdots}$ & $-.40^{\cdots}$ \\
\hline Long term physical complaints & $-.21^{*}$ & $-.39^{\cdots}$ & $-.41^{\cdots}$ \\
\hline Wound pain & $-.22 *$ & -.09 & $-.19^{\circ}$ \\
\hline Worries about wound pain & -.10 & -.04 & $-.19^{*}$ \\
\hline Disturbance by wound pain & $-.15^{*}$ & -.10 & -.12 \\
\hline Number of ADL/HHA & .12 & $.33^{\cdots}$ & $.47^{-\cdots}$ \\
\hline Resuming work & .01 & .15 & $.27^{*}$ \\
\hline Resuming domestic work & .04 & .11 & $.35^{\cdots}$ \\
\hline Resuming leisure activ. & .07 & $20^{*}$ & $.21^{\cdots}$ \\
\hline \multicolumn{4}{|l|}{ Psychological well-being: } \\
\hline Preoperative fear & $-.37^{-=}$ & $-.29^{\cdots}$ & $-.26^{* *}$ \\
\hline Anxiety (preoperative) & $-.47 \cdots$ & $-.35 \cdots$ & $-.27^{*}$ \\
\hline \multicolumn{4}{|l|}{ Need for information about: } \\
\hline - admission and surgery & $-.26^{* *}$ & -.01 & $-.19^{*}$ \\
\hline - illness & $-.24 \cdots$ & $-.16^{\circ}$ & $-.15^{-}$ \\
\hline - surgery & $-.25^{* *}$ & -.06 & -.04 \\
\hline Anxiety (post operative) & $-.19^{*=}$ & $-.48 \cdots$ & $-.33^{*}$ \\
\hline \multicolumn{4}{|l|}{ Need for information about: } \\
\hline - surgery and consequences & $-.19^{*}$ & $-.27^{\cdots}$ & $-.22^{*}$ \\
\hline - time after discharge & $-.17^{*}$ & $-.29^{*}$ & $-.24^{\cdots}$ \\
\hline - discharge & $-.21^{--}$ & $-.35^{\cdots}$ & -.12 \\
\hline Arxiety (1 week after discharge) & $-.20^{\circ}-$ & $-.31 \cdots$ & $-.56^{-\cdot}$ \\
\hline Subjective health & .19 & $.26^{\circ}$ & $.46^{\circ}$ \\
\hline
\end{tabular}

- $p<0,05$

-. $\quad p<0,01$

Controlling for group differences in perceived control after discharge

According to hypothesis 4, improvements in psychological well-being and physical recovery from surgery among patients in group 2 are mediated by increased levels of perceived control. This hypothesis was tested by repeating analyses of covariance of the differences between group 1 and 2 in physical recovery and psychological well-being. Since among patients undergoing traditional cholecystectomy in group 2 we found higher levels of perceived control at time 3 compared to group 1, perceived control at time 3 was included as covariate, together with number of visits received. This allowed us to examine whether the differences obtained in length of stay, sleep medications, resumption of leisure activities, and need for information at admission about admission and surgery were mediated by the higher level of perceived control at time 3 found among traditional cholecystectomy patients in group 2, compared to those in group 1. 
The results (see table 6.12) showed a muitivariate interaction effect of group by type of surgery with respect to length of stay, number of analgesics and sleep medications. The univariate interaction effect between group and type of surgery with respect to sleep medications was still significant. The univariate main effect of group with respect to resumption of leisure activities was still significant as well. The univariate main effect of group on length of stay disappeared. No significant multivariate effects were found any longer with respect to psychological well-being on the day of admission.

Table 6.12: Mean scores of variables with respect to which previously multivariate and/or univeriate effects were obtained, after controlling for differences in perceived control one week after discharge between group 1 and 2.

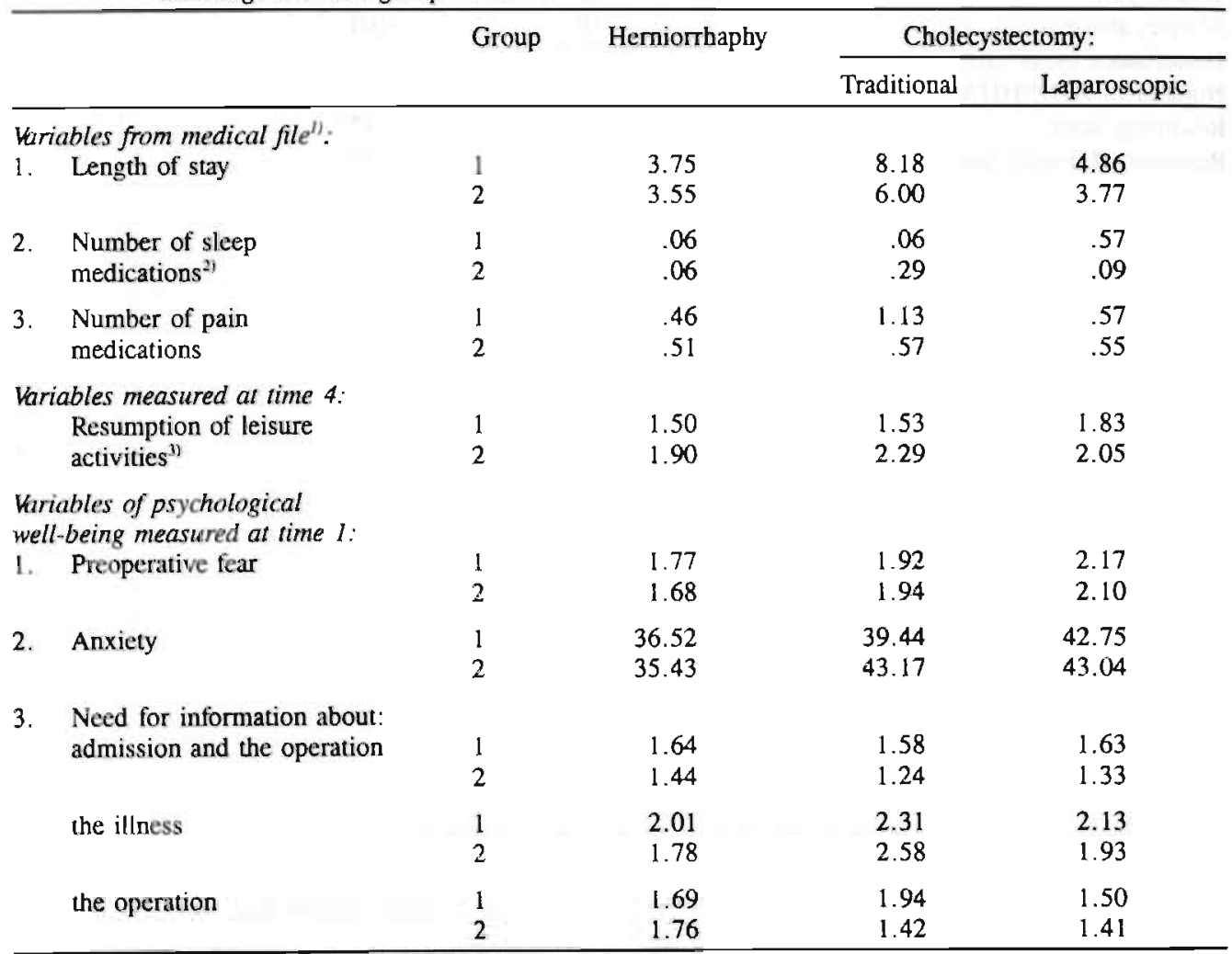

Multivariate interaction effect $(F(6,288)=3.60 ; p<.01)$.

Univariate interaction effect $(\mathrm{F}(2,145)=7.59 ; \mathrm{p}=.01)$.

Univariate main effect of group $(F(1,138)=5.27 ; p<.05)$.

\subsection{Discussion and conclusions}

Examination of the fidelity of implementation showed indications of only partial implementation of the new program. Patients admitted after implementation (group 2) received information from significantly more sources addressed by the program than patients 
admitted before implementation of the new program (group 1). This seems indicative of succesful implementation of the program. However, concerning written and oral information that was provided preoperatively to patients in both groups, patients in group 2 did not receive significantly more information than patients in group 1 . This seems to indicate that implementation was not succesful. These findings may be explained by the fact that the total number of preoperative sources from which patients received information was increased by the new program. In hospital 1, a leaflet was introduced and provided to patients about herniorrhaphy, while in hospital 2 leaflets were introduced and provided about cholecystectomy, herniorrhaphy, and anesthesia. In addition, in both hospitals a slide-tape presentation was introduced for patients to view. Thus, considering the amount of preoperative information received by patients before and after implementation of the new program, the succes of its implementation was only modest. However, since the quality of the information was improved by the new program, this does not exclude the possibility that the new program had beneficial effects on patients' physical recovery and psychological well-being.

Partial implementation of the program may have been caused by some unfavorable events and circumstances during its development and implementation. For example, one hospital moved to a new building two months after implementation of the program. Although its execution was interrupted for only two months, and essentially it could be continued as before, it is likely that adaptation to the new circumstances caused some disruption in program performance. Also in this hospital, contrary to initial agreements, surgeons decided not to provide patients with written information about surgery and anesthesia themselves. Instead, they expected nurses of the ambulatory department to hand this information to patients. Since these nurses had not been closely involved in developing the program, additional attempts had to be undertaken to explain its aims and content and to motivate them to provide patients with the written materials. Also, as was explained in chapter 5 , because of these and additional unfavorable circumstances, not all conditions that promote successful implementation of an innovation (Rogers, 1962; Zaltman et al. 1973) were met adequately.

Apart from partial implementation, the program's scope was limited since it did not offer a solution to all shortcomings of surgical patient education that were detected during the examination of existing practices of treatment, care and education of herniorrhaphy and cholecystectomy patients in both hospitals. Some improvements which were desirable, were not attained, like systematically providing patients with information at discharge, separating ward physicians' contacts with clinical patients from those of the surgeons, and distribution of information leaflets by surgeons. Therefore, the program's potential to improve patients' psychological well-being and physical recovery may have been below optimum.

Given the limited extent to which the program's implementation succeeded, which expectations were realistic concerning its effects on psychological well-being and on physical recovery? A decrease in uncertainty with respect to regulations and facilities at the ward and in the hospital was unlikely, because fewer patients in group 2 received written information about regulations and facilities at the ward and in the hospital than in group 1. Considering written information about surgery and anesthesia and oral informa- 
tion actually provided to patients, it is not clear which expectations were justified. On the one hand we found that patients in group 2 did not differ from patients in group 1 with respect to written information received about cholecystectomy and anesthesia, as far as this was available to both groups. Also, patients in group 2 did not receive more oral information from nurses on the day of admission than patients in group 1, nor did they receive more oral information from any other health care providers. On the other hand, concerning written information which was available only to patients in group 2, a considerable proportion did receive information about herniorrhaphy $(87 \%)$, cholecystectomy $(91 \%)$, and anesthesia (34\%; see chapter 5)). Further, in group 2 written information about anesthesia was evaluated significantly more positive than in group 1 . Also, oral information from nurses about some subjects was evaluated in group 2 significantly more positive than in group 1 . Finally, $25 \%$ of the patients in group 2 watched the slide-tape presentation about treatment and care of herniorrhaphy and cholecystectomy patients in hospital, whereas this was not available for patients in group 1.

Some evidence was obtained that the new program of surgical patient education, implemented by members of the regular hospital staff, improved cholecystectomy and herniorrhaphy patients' physical recovery and psychological well-being (hypothesis 1). Patients in group 2 were discharged sooner and resumed leisure activities sooner. Also, on the day of admission they felt less need for information about the admission and surgery. Finally, patients in group 2 undergoing traditional cholecystectomy took more sleep medications. Since patients were encouraged to ask for sleep medications whenever they desired postoperatively, this indicates that they were affected positively by the intervention.

However, no significant differences were found for the following variables indicating physical recovery: use of analgesics, postsurgical pain, resumption of physical activities, postsurgery physical complaints, IADL, and resumption of work. Also, no significant improvements were found for the following variables indicating psychological well-being: preoperative fear, pre operative uncertainty about the illness and the operation, post operative uncertainty, anxiety (three measures), and subjective health one month after discharge.

Among patients in group 1, more patients dropped out during the course of the study $(17 \%)$, compared to patients in group $2(7 \%)$. Also, in group 1 the reasons to stop participation were more often of a personal nature than in group 2 . For example, patients stopped participation because of privacy, nervousness, illness, or because their spouse was unwilling to receive the interviewer at home. In group 2 attrition was mainly due to logistic causes. Since refusal to continue participation for personal reasons may be positively related to worse physical and psychological functioning after surgery, this may partly explain the limited number of positive consequences found in group 2 .

Decreases in length of stay following surgical patient education were also found in previous studies (e.g. Wilson, 1981; King \& Tarsitano, 1981; Johnson, et al., 1978; Langer, Janis \& Wolfer, 1975). Recently however, length of stay in hospitals has decreased for medical, technological and financial reasons (Swinkels, 1990). In the present study patients who received patient education according to the new program were, on average, admitted 6-8 months later than patients who received existing patient education. 
Therefore, one might argue that the obtained decrease in length of stay was the result of a history effect.

To test for a possible history effect, length of stay was compared for a) all patients undergoing cholecystectomy and herniorrhaphy admitted to the two hospitals before implementation of the program $(n=260)$ and $b)$ all those admitted after implementation $(n=407)$. Data were provided by Stichting Informatie Gezondheidszorg (SIG), Utrecht, The Netherlands. Among these two groups of all patients, many were included who did not take part in the study and were not exposed to the new program of patient education (e.g., children, emergency patients, patients admitted to non-surgical wards, patients who did not speak Dutch, etc.). Therefore, a reduction in length of stay was, if caused by the new program of patient education, less likely to be detected among the total group of patients undergoing cholecystectomy or herniorrhaphy in both hospitals than among the participants in the study. Since the SIG-data did not allow identification of patients who participated in the study, they were included in both groups as well. Therefore, the comparison can be regarded as conservative. Among all patients, those admitted before implementation stayed on average 8.6 days in the hospital. Those admitted after implementation stayed on average 8.4 days. Thus, we feel confident to attribute the significant reduction in length of stay of 1.28 days found among patients participating in our study to the new program of patient education. Nevertheless, since length of stay tends to fluctuate strongly from month to month and between both hospitals, this conclusion should be treated with caution.

Patients who received patient education according to the new program were expected to experience stronger feelings of control (hypothesis 2 ). The only significant increase in perceived control, however, was found one week after discharge among patients who underwent traditional cholecystectomy. Among hermiorrhaphy patients, those in group 2 scored lower on this measure of perceived control than those in group 1. The latter finding is difficult to explain. One might assume that the program's information offered herniorrhaphy patients a more optimistic outlook to surgery and recovery than, afterwards when they had experienced it, was justified, for example because of a relatively high occurrence of postsurgical physical complications. However, no indications were found that the proportion of patients that showed complications differed between herniorrhaphy and cholecystectomy patients.

Among patients undergoing traditional cholecystectomy, the information appeared to shape realistic expectations and may have provided them with adequate behavioral instructions that proved to be useful. Since traditional cholecystectomy is generally recognized as an operation of moderate seriousness with a mildly complicated course of recovery (Zwaveling \& De Boer, 1986), instructions to ask for pain and sleep medications, relieve pain, dietary instructions and information about resumption of bodily functions, are likely to have matched their experiences more closely than among herniorrhaphy patients. Thus, as a result of this information their perception of their ability to contribute to their well-being during the course of treatment and recovery may have increased.

The absence of an increase in perceived control on the day of admission, may be explained as follows. Although on the day of admission they already had received most of the information that was part of the new program, as yet, patients had relatively few 
opportunities to validate the information in practice. Therefore, they had not yet experienced actually being able to contribute to their well-being during the course of treatment and recovery by asking questions and executing additional behavioral instructions. Thus, in addition to providing patients with information about opportunities to contribute to their own well-being, it may be important to put them explicitly in one or more circumstances that require -if they are willing to- asking questions or performing the recommended behaviors. Subsequently, it seems important to reinforce patients who do perform any of these behaviors.

The finding that no differences in perceived control were obtained postoperatively, may have resulted from the fact that each patient, regardless of information received, experiences to a particular extent pain and bodily discomfort after surgery, while patient behavior is predominantly controlled by situational factors (Johnson, et al., 1978). Consequently, information about postoperative sensations and opportunities to ask for pain and sleep medication and about patient behavior to reduce pain, may have been insufficient to increase patients' feelings of being able to improve their own physical recovery and well-being shortly after surgery. In situations that allow few opportunities to exert control, the most appropriate coping strategies would seem to be those directed towards regulation of emotions, like avoidance or restructuring of cognitions (Miller, et al., 1989). By design however, these modalities of patient support were relatively underrepresented in the program.

In accordance with hypothesis 3 , patients with a high level of perceived control scored higher on most variables indicating physical recovery and psychological well-being than patients low on perceived control. The only exceptions concerned the amount of postsurgical sleep medication taken, which was not associated with perceived control, regardless of its time of measurement, and the three variables concerning post-operative pain, which were not significantly correlated to perceived control measured shortly after surgery. Thus, as found in previous studies, enhancing surgical patients' feelings of control or preventing perceived control from decreasing, seems adequate to reduce their psychological stress and promote their physical recovery from surgery.

When perceived control one week after discharge was kept constant, the results showed that the difference between groups in length of stay and need for information about admission and surgery (day of admission) was no longer significant. This suggests that the relatively high level of perceived control after discharge among traditional cholecystectomy patients who received patient education according to the new program, is a relevant factor to explain the significant reduction in length of stay, and need for information. Their perception that they themselves were able to contribute to their recovery may have led them to perform preventive behaviors (e.g. adequate bodily movements) avoiding complications in wound healing, which resulted in earlier discharge. Shortly after surgery however, the two groups did not differ significantly in perceived control. Nevertheless, our explanation remains valid if it is supposed that the level of perceived control among traditional cholecystectomy patients in group 2 already started to rise during the period of recovery in hospital. Contrary to this explanation however, among herniorrhaphy patients perceived control after discharge was found to be significantly lower in group 2 than in group 1, while in group 2 their length of stay was not longer than in 
group 1 (table 6.8). This may be explained because herniorrhaphy patients are discharged sooner than traditional cholecystectomy patients. Therefore, among herniorrhaphy patients, an eventual onset of a reduction of perceived control is less likely to affect length of stay than is the onset of an increase in perceived control among traditional cholecystectomy patients.

The effectiveness of the program with respect to sleep medications and resumption of leisure activities was not mediated by perceived control. Independent of perceived control, the information in the new program directly promoted a higher intake of sleep medication and a more favorable recovery at home, leading to earlier resumption of leisure activities. This also explains why, despite a decrease in perceived control after discharge, herniorrhaphy patients in group 2 resumed their leisure activities sooner than those in group 1.

The finding that the difference between both groups on the day of admission in need for information about admission and surgery disappeared after keeping constant perceived control one week after discharge, was likely to be an artifact. Since the multivariate main effect of group on psychological well-being on admission had a high p value of .098 and because some cases $(n=22)$ had missing values on perceived control one week post discharge, this difference in need for information about admission and surgery was likely to disappear while controlling for perceived control.

This study offers no definite answer to the question to what extent perceived control mediates the benefits of patient education. Although the results suggest that perceived control is a relevant factor in recovery after surgery, additional variables were shown to play an important role as well. An explanation for the program's limited effect on perceived control may be the rather timid method employed to manipulate perceived control. Patients voluntarily decided whether or not they employed the procedural and sensory information, behavioral instructions, and suggestions to collect information themselves. Perhaps this was insufficiently committing, providing in particular patients predisposed with a desire for intermediate levels of perceived control, the opportunity to ignore these signals and remain passive. Further research is required to assess more adequately the impact of perceived control on patients' recovery and psychological wellbeing and to improve understanding of the exact mechanisms involved.

Although the effects of the program were limited, we conclude that surgical patient education provided by members of the regular hospital staff can be effective in enhancing some aspects of patients' recovery from surgery and psychological well-being. The effects were obtained without intensively monitoring staff members, and consequently, with few opportunities to provide them with feedback. Thus, like Wilson-Barnett (1994), we conclude that it is worthwhile to intensify developing and implementing programs of surgical patient education that can be carried out by members of the hospital staff. While doing this, close cooperation with staff members is essential and additional attempts are required to persuade physicians to get involved. To encourage staff members to provide education and support to surgical patients in a systematic and adequate manner, however, more evidence is needed that demonstrates clearly the effectiveness of these interventions when conducted by usual staff members. Alternatively, until we have better data, perhaps 
hospitals should appoint designated providers of surgery patient education who are appropriately motivated and more carefully trained.

\section{References}

Auerbach, S.M. (1989),

Stress management and coping research in the health care setting: an overview and methodological commentary, Journal of Consulting and Clinical Psychology, 57, 388-395.

Boeke, S. (1988),

Psychologische aspecten van het ondergaan van een operatie (diss.), Rotterdam, The Netherlands, Erasmus Universiteit.

Breemhaar, B., Van den Borne, H.W. (1991),

Effects of education and support for surgical patients: The role of perceived control,

Patient Education and Counseling, 118, 199-210.

Breemhaar, B., Van den Borne, H.W., Mullen, P. (1996),

Inadequacies of surgical patient education, Patient Education and Counselling Cochran, T.M. (1984),

Psychological preparation of patients for surgical procedures, Patient Education and Counseling, 5, 153-158.

Contrada, R.J., Leventhal, E.A., Anderson, J.R. (1994),

Psychological preparation for surgery: Marshalling individual and social resources to optimize self-regulation, in: Maes, S., Leventhal, H., Johnston, M., International Review of Health Psychology, New York, Jonn Wiley \& Sons.

Cook, T.D., Campbell, D.T. (1979),

Quasi Experimentation: Design and Analysis Issues for Field Settings, Boston.

Houghton Mifflin Company.

Department of Veteran's Affairs (1992),

New approaches to Preoperative Patient and Health Education, Satellite Conference, September 10, Department of Veteran's Affairs, Satellite Network.

Devine, E.C. (1992),

Effects of psychoeducational care for adult surgical patients: A meta-analysis of 191 studies, Patient Education and Counseling, 19, 129-142.

Devine, E.C., O’Connor, F.W., Cook, T.D., Wenk, V.A., Curtin, T.R. (1988),

Clinical and financial effects of psychoeducational care provided by staff nurses to adult surgical patients in the post-DRG environment, American Journal of Public Health, 78, 1293-1297.

Devine, E., Cook, T. (1986),

Clinical and cost saving effects of psychoeducational interventions with surgical pa-

tients: a meta-analysis, Res. Nurs. Hlth., 9, 89-105.

Eisendraht, S.J. (1987),

Issues of control in the general hospital setting, International Journal of Psychosomatics, 34, 3-5. 
Flaherty, G.G., Fitzpatrick, J.J. (1978),

Relaxation technique to increase comfort level of postoperative patients: a preliminary study, Nursing Research, 27, 352-355.

Fortin, F., Kirouac, S. (1976),

A randomised control trial of preoperative patient education, International Journal of Nursing Studies, 13, 11-24.

Hathaway, D. (1986),

Effect of preoperative instruction on postoperative outcomes: a meta-analysis. Nursing Research, 35, 269-275.

Horne, D.J. de L., Vatmanides, P., Careri, A. (1994),

Preparing patients for invasive medical and surgical procedures 1: Adding behavioral and cognitive interventions, Behavioral Medicine, 20, 5-13.

Johnson, J.E., Leventhal, H. (1974),

Effects of accurate expectations and behavioral instructions on reactions during a noxious medical examination, Journal of Personality and Social Psychology, 29, 710-718.

Johnson, J.E., Leventhal, H., Dabbs, J.M. (1971),

Contributions of emotional and instrumental response processes in adaptation to surgery, J. o. Personality and Social Psychology, 20, 55-64.

Johnson, J.E., Rice, V.E., Fuller, S.S., Endress, M.P. (1978),

Sensory information, instruction in a coping strategy and recovery from surgery,

Research in Nursing and Health, 1, 4-17.

Johnston, M., Vogele, C. (1993),

Benefits of psychological preparation for surgery: a meta-analysis, Annals of Behavioral Medicine, 15, 245-256.

Katz, S., Akpom, C.A. (1976),

A measure of primary sociobiological functions, International Journal of Health Services, 6,4933-507.

Katz, S., Ford, A.B., Moskowitz, R.W., Jackson, B.A., Jaffe, M. (1963),

The index of ADL, a standardized measure of biological and psychosocial function, Journal of the American Medical Association, 185, 914-919.

Kincey, J. and S. Saltmore (1990),

Surgical treatments, in: M. Johnston and L. Wallace (eds), Stress and Medical Procedures, Oxford, Oxford Medical Publications.

King I., Tarsitano, B. (1981),

The effect of structured and unstructured preoperative teaching: a replication, Nursing Research, 31, 324-329.

Kok, G.J. (1988),

Health motivation: health education from a social psychological point of view, in: Maes, S., C.D. Spielberger, P.B. Defares, I.G. Sarason (eds.), Topics in Health Psychology, John Wiley \& Sons, New York.

Kulik, J.A., Mahler, H.I.M. (1989),

Social support and recovery from surgery, Health Psychology, 88, 221-238. 
Langer, E.J., Janis, I.L. and Wolfer, J.A. (1975),

Reduction of psychological stress in surgical patients. J. o. Experimental Psychology, 155-165.

Lipsey, M.W., Wilson, D.B. (1993),

The efficacy of psychological, educational, and behavioral treatment: confirmation from meata-analysis, American Psychologist, 48, 1181-1209.

Lucente, E.F., Fleck, S. (1972),

A study of hospitalization anxiety in 408 medical and surgical patients, Psychosomatic Medicine, 34, 304-307.

Mathews, A., Ridgeway, V. (1984),

Psychological preparation for surgery, in: A. Steptoe, A. Mathews, (eds.), Health Care and Human Behavior, New York, Academic Press.

Miller, S. M., Combs, C., Stoddard, E. (1989),

Information, coping and control in patients undergoing surgery and stressful medical procedures, in: A. Steptoe and A. Appels (eds.), Stress, Personal Control and Health, New York, John Wiley \& Sons.

O'Connor, F.W., Devine, E.C., Cook, T.D., Wenk, V.A. and Curtin, T.R. (1990),

Enhancing surgical nurse's patient education: development and evaluation of an intervention, Patient Education and Counseling, 16, 7-20.

Orlandi, M.A., Landers, C., Weston, R., Haley, N. (1990),

Diffusion of health promotion innovations, in: Glanz, Lewis \& Rimer, eds., Health

Behavior and Health Education Theory, Jossey Bass.

Partridge, C., Johnston, M. (1989),

Perceived control of recovery from physical disability: Measurement and prediction,

British Journal of Clinical Psychology, 28, 53-59.

Rogers, M., Reich, P. (1986),

Psychological intervention with surgical patients: evaluation outcome, Advances in

Psychosomatic Medicine, 15, 23-50.

Salmon, P. (1992),

Psychological factors in surgical stress: implications for management, Clinical

Psychology Review, 12, 681-704.

Schultheis, K., Peterson, L., Selby, V. (1987),

Preparation for stressful medical procedures and person by treatment interactions,

Clinical Psychology Review, 7, 329-352.

Spector, W.D., Katz, S., Murphy, J.B., Fulton, J.P. (1987),

The hierarchical relationship between activities of daily living and instrumental activities of daily living, Journal of Chronic Disease, 40, 481-489.

Suls, J., Wan, C.K. (1989),

Effects of sensory and procedural information on coping with stressful medical procedures and pain: a meta-analysis, Journal of Consulting and Clinical Psycho$\log y, 57,372-379$.

Syme, S. L. (1989),

Control and health: a personal perspective, in: Steptoe, A., Appels, A., (eds.), Stress, Personal Control and Health, New York, John Wiley and Sons. 
Spss Inc. (1988),

SPSSX User's Guide, 3rd edition, SPSS Inc., Chicago, Illinois.

Spielberger, C. D., Gorsuch, R.L., Lushene, R.E. (1970),

Manual for the Stait-Trait Anxiety Inventory, Palo Alto, California, Consulting Psychologists Press.

Stern, B., Maoz, B., Leiser, D. (1982),

Preparing patients for surgery, Journal of Psychiatry related Science, 19, 279-288.

Swinkels, M.A.A. (1990),

Eerder thuis, beter af? Proefschrift, Rijksuniversiteit Leiden, The Netherlands.

Tagliacozzo, D.L., Mauksch, H.O. (1972),

The patient's view of the patient's role, in: E.G. Jaco (ed.), Patients, physicians and illness, Free Press, New York.

Taylor, S.E. (1991),

Health Psychology, 2nd edition, New York, Random House.

Taylor, S.E. (1979),

Hospital patient behavior: reactance, helplessness or control?, J.o. Social Issues, 35. 156-184.

Taylor, S.E., Clark, L.F. (1986),

Does information improve adjustment to noxious medical procedures?, in: M.J.

Saks and L. Saxe, Advances in Applied Social Psychology, vol 3, New Jersey, Lawrence Erlbaum.

Thompson, S. C., Cheek, P.R., Graham, M.A. (1987),

The other side of perceived control: disadvantages and negative effects, in: Spaca-

pan, S., Oskamp, S. (eds.), The Social Psychology of Health, The Claremont Symposium of Applied Social Psychology, Beverly Hills, Ca., Sage.

Utens, E.M.W.J. (1989),

Vorlichting aan hartchirurgische patiënten, Rotterdam, The Netherlands, Erasmus Universiteit.

Van de Ploeg, H.M., Defares, P.B., C.D., Spielberger (1980),

Handleiding bij de Zelf-Beoordelings Vragenlijst, Lisse, The Netherlands, Swets \& Zeitlinger.

Van den Borne, H.W., Pruyn, J.F.A. (1985),

Lotgenotencontact bij kankerpatiënten, Maastricht, The Netherlands, Van Gorcum.

Van den Borne, H. W. van den, Pruyn, J.F.A., Meij, K. de (1986),

Help given by fellow patients, in: Stoll, B.A. (ed.), Coping with Cancer Stress,

Dordrecht, The Netherlands, Martinus Nijhoff.

Van Erp, W.F.M., Bruijninckx, C.M.A. (1991),

De eerste ervaringen met laparoscopische cholecystectomie, Nederlands Tijdschrift voor Geneeskunde, 135, 272-276.

Visser, A.Ph. (1984),

Beleving van het verblijf in het algemene ziekenhuis, Assen, The Netherlands, Van Gorcum. 
Wallace, L.M. (1984),

Psychological preparation as a method to reduce the stress of surgery, Journal of Human Stress, summer, 62-77.

Wallace, L. (1985),

Informed consent to elective surgery: The therapeutic value? Social Science and Medicine, 22, 29-33.

Wallace, L. (1986),

Informed Consent to elective surgery: the 'therapeutic' value?, Social Science and Medicine, 22, 29-33.

Wallston, K.W., Wallston, B.S., Smith, S., Dobbins, C.J (1987),

Perceived control and health, Current Psychology Research Reviews, 6 (1), 5-25.

Weinman, J., Johnston, M. (1988),

Stressful medical procedures: an analysis of the effects of psychological interventions and the stressfulness of the procedures, in: Maes, S. Spielberger, C.D., Defares, P.B., Sarason, I.G., Topics in Health Psychology, London, John Wiley \& Sons.

Wilson, J.F. (1981),

Behavioral preparation for surgery: benefit or harm?, Journal of Behavioral Medicine, 4, 79-102.

Wilson-Barnett, J. (1994),

Preparing patients for invasive medical and surgical procedures 3: Policy implications for implementing specific psychological interventions, Behavioral Medicine, 20, 23-26.

Zwaveling, A., De Boer, J. (1986),

Beter weten, beter genezen, Houten, The Netherlands, Unieboek. 


\section{Development, implementation and evaluation of surgical patient education}

\section{Summary}

This dissertation describes the process of development and implementation of a program of education for patients undergoing hemiorraphy and cholecystectomy in two Dutch hospitals. It also describes an evaluation of the extent to which the program was implemented succesfully in two hospitals and of its effectiveness with respect to improving patients' physical recovery from surgery and psychological well-being.

Following an overview of the study in chapter 1 , chapter 2 briefly reviews previous evaluations of psychoeducational methods to prepare patients for surgery. These are grouped in three categories: cognitive-behavioral, informational, and psychotherapeutic approaches. Although in particular support for the effectiveness of cognitive-behavioral and informational approaches has been manifold, the results from previous studies do not allow straightforward conclusions as to which intervention is most effective with respect to particular outcomes. Whether combined interventions are more effective than single interventions is not entirely clear as well. To examine whether the effects of psychoeducational interventions differ between patients, studies were reviewed that investigated the effectiveness of presurgical preparation among patients undergoing abdominal surgery who differ in level of preoperative fear, way of coping and locus of control. Although the number of relevant studies obtained was limited and their results were not straightforward, we tentatively conclude that either patients with a high level of properative fear, patients who cope with the stress of hospitalization and surgery by "sensitizing" or "monitoring", and patients with an internal locus of control, tend to benefit to a relatively large extent from presurgical preparation. Interventions to prepare patients for surgery should take these individual differences into account.

Chapter three offers an explanation for the beneficial effects of interventions to prepare patients for surgery. Based on Lazarus' theory of adaptation to stressful events, it is argued that patients' level of perceived control determines the stress they experience in relation to illness, hospitalization and surgery, and the means they employ to cope with stress. A relatively high level of perceived control is related to decreased feclings of threat to well-being when facing an adverse event. Also, a high level of perceived control has been shown to be associated with problem solved coping strategies. Further, providing information and support has been demonstrated to increase patients' level of perceived 
control. However, interventions to enhance perceived control are not always beneficial. Patients' level of perceived control should match both their predisposed desire to exert control over the situations they are engaged in, and the opportunities that a situation at a particular time offers objectively to exert control. Therefore, efforts to enhance surgical patients' level of perceived control should carefully take into consideration their desire for control and the extent to which a particular situation allows them to exert control.

In chapter 4 , a study is described, performed in two hospitals to examine the course of treatment and care during hospitalization for herniorraphy and cholecystectomy. Interviews with patients and staff members and observations of various events in which patients met with health care providers served to obtain a representative picture of the events taking place, staff members whom patients meet, the circumstances under which this happens, information and support received by patients and their concerns. This served to obtain a mutually shared picture of the current situation with respect to patient education and support, and provided a basis for development of measures to decrease shortcomings in surgical patient education.

Most patients were found to experience fear for anesthesia and adverse physical postoperative reactions. Also, many patients felt uncertainty about their illness, treatment, care and staff members they met, and desired to receive additional information about these subjects. Further, information about discharge was considered insufficient by many patients. These shortcomings seemed partially to be related to organizational barriers in both hospitals that hindered adequate provision of information to patients. Further, in particular physicians provided patients with information in an inadequate manner. For example, information was given unexpectedly, hastily or too much at a time.

Chapter 5 describes the process of development and implementation of a new program of patient education for patients undergoing herniorraphy and cholecystectomy in both hospitals where the examination was carried out. Since the program was meant to be carried out by regular hospital staff members, it was developed in close cooperation with relevant health care providers, according to principles concerning successful adoption of innovations in organizations.

To meet these conditions, a project group was established in which representatives from relevant disciplines cooperated. The results of the examination, together with knowledge about effective means to prepare patients for surgery, and about the role of patients' perceived control, guided the proposal of measures to improve patient education. Not all improvements were considered feasible by members of the group which were desirable considering the shortcomings in patient education detected during the examination. Thus, the scope of the new program was limited. After consensus was obtained, these measures were worked out. In one hospital, we failed to establish a project group. Here, the program was developed during separate meetings with members from each discipline involved. After completion of development of the new program, all hospital staff members concerned were informed about its implementation.

The new program consisted of agreements among health care providers concerning distribution of written, audio visual and oral information to patients at different moments during the course of treatment and care. Most measures for which agreement was attained in the project group concerned information provision during the preoperative period and 
most of these measures were designed to be carried out by nurses. The new program included procedural and sensory information, information about functions and responsibilities of health care providers involved, and instructions concerning patient behavior to enhance physical recovery, and to relieve physical and psychological discomfort. To avoid excessive feelings of control among patients who prefer intermediate control, care was taken not to thrust information upon them.

Examination of the extent to which patients were provided with information according to the new program after its implementation, showed that implementation succeeded to a limited extent only. Overall, patients admitted after implementation received significantly more information from sources that were addressed by the new program than patients admitted before implementation. However, limiting comparisons to sources of information which were available both before and after implementation of the new program, patients admitted after implementation did not receive significantly more information from each source. This finding is explained first by assuming that, since patients voluntarily decided whether they read written information or asked questions, some patients may not have received information because they did not wish to. Second, various barriers hindered providing information according to the new program, like limited time and space for patients to watch the slide-tape presentation and, in particular physicians who were reluctant to provide patients with written information. Finally, not all conditions for successful implementation of the program were adequately met. It is concluded that although hospital staff members can be successful in improving information provision to surgical patients, sufficient attention is needed to adequately meet all conditions enhancing the likelihood that a new program of surgical patient education will be adopted by its potential users. This concerns the need for compatibility of the new program with their professional needs and values and the need to keep their motivation at an adequate level throughout the process of development and implementation.

However, our examination of the extent to which the new program was implemented, was limited to measuring the amount of infonnation received by patients. Apart from increasing the amount of relevant information provided to patients, the program also aimed to increase the quality of the information. Therefore the program was evaluated as well by assessing its impact on patients' physical recovery from surgery and their psychological well-being in both hospitals (chapter six). Scores on indicators of physical recovery and psychological well-being among 95 cholecystectomy and herniorraphy patients who were admitted before implementation of the new program, were compared with those of 100 patients admitted after implementation of the program. Also, the mediating effect of perceived control on the relationship between patient education and patient outcomes was examined. The results showed that patients admitted after implementation stayed in the hospital shorter and after discharge, resumed leisure activities sooner than patients admitted before implementation. On admission they expressed less need for information about admission and surgery. Patients undergoing traditional cholecystectomy admitted after implementation used more sleep medications than those admitted before implementation. One week after surgery an increase in perceived control was found among patients who underwent traditional cholecystectomy. Perceived control was positively related to most indicators of physical recovery and psychological well-being. 
Repeating analyses of the relationship between the new program of patient education and patients' recovery and well-being, including perceived control measured one week after discharge as a covariate, suggested that perceived control was a relevant factor responsible for patients' decrease in length of stay. However, the differences between both groups in sleep medications taken and resumption of leisure activities was maintained.

The limited effectiveness of the new program to improve surgical patients' recovery and well-being is explained by the limited scope of the new program, and by the limited success of the program's implementation. An explanation for the program's limited effect on perceived control may be the rather timid method to manipulate this variable. We conclude that surgical patient education provided by hospital staff members can be effective in improving some aspects of surgical patients' physical and psychological wellbeing. Therefore, it seems worthwile to intensify developing and implementing programs of surgical patient education that can be carried out by members of hospital staff. To enhance them to provide patient education in a systematic and adequate manner, however, more evidence is needed that demonstrates clearly the effectiveness of these interventions when conducted by usual staff. Until we have better data, perhaps hospitals should appoint designated providers of surgery patient education who are appropriately motivated and more carefully trained. 


\section{Ontwikkeling, implementatie en evaluatie van voorlichting voor operatiepatiënten}

\section{Samenvatting}

Dit proefschrift beschrijft het proces van het ontwikkelen en implementeren van een voorlichtingsprogramma voor patiënten die een liesbreuk of een galblaasoperatie ondergaan in twee Nederlandse ziekenhuizen. Tevens wordt een onderzoek beschreven watarin is geëvalueerd in hoeverre het programma naar wens is uitgevoerd in twee ziekenhuizen en wat het effect van het programma is op het fysieke herstel van patiënten van hun operatie en op hun psychisch welbevinden.

Volgend op een overzicht in hoofdstuk 1 van de studie als geheel, wordt in hoofdstuk 2 een overzicht gegeven van eerder verricht onderzoek naar de effecten van psycho-educatieve methoden om patiënten voor te bereiden op een operatie. Deze methoden kunnen worden verdeeld in drie categorieën, te weten cognitief-gedragsmatige methoden, influrmatie georiënteerde methoden en psychotherapeutische methoden. Hoewel met name steun is gevonden voor cognitief-gedragsmatige en informatie georiënteerde methoden. staan de resultaten geen duidelijke conclusies toe omtrent een antwourd op de vrady welke interventiemethode het meest effectief is met betrekking tot specificke effectvariabelen. Tevens blijft onduidelijk of combinaties van verschillende interventies meer effect sorteren dan enkelvoudige interventies.

Teneinde na te gaan of verschillende voorbereidingsmethoden verschillende effecten hebben voor verschillende categorieën van patiënten, zijn eerdere onderzoekingen verkend waarin de effecten van verschillende interventies zijn onderzocht onder patiënten die een buikoperatie ondergingen en onderling verschilden in preoperatieve vrees, gehanteerde verwerkingsstrategie en beheersingsoriëntatie. Hoewel het aantal relevante studies beperkt was en hun resultaten niet geheel eenduidig waren, komen we voorzichtig tot de volgende conclusie. Patiënten met een hoog niveau van preoperatieve vrees, patiënten die de stress die (het herstel van) een operatie met zich mee brengt verwerken door hier alert mee om te gaan en de gebeurtenissen bewust tot zich laten doordringen, en tenslotte patiënten met een interne beheersingsoriëntatie hebben relatief veel baat bij psychoeducatieve methoden van voorbereiding op een operatie. Bij het toepassen van dergelijke interventies dient rekening te worden gehouden met deze individuele verschillen tussen patiënten.

Hoofdstuk 3 beschrijft een verklaringsmodel voor de gunstige effecten van methoden om patiënten voor te bereiden voor een operatie. Op basis van de theorie van Lazarus 
omtrent aanpassing aan stiessvolle gebeurtenissen wordt verondersteld dat de mate waarin patiënten controle waarnemen bepalend is voor de stress die zij ervaren bij ziekte, ziekenhuisopname en een operatie en voor de wijze waarop zij deze stress verwerken. In aversieve situaties gaat een relatief hoog niveau van waargenomen controle samen met relatief geringe gevoelens dat het welbevinden wordt bedreigd. Tevens gaat een hoog niveau van waargenomen controle gepaard met probleemgerichte vormen van verwerking. Tenslotte is gebleken dat het niveau van waargenomen controle van patiënten stijgt door hen te ondersteunen en door hen informatie te geven. Echter, het vergroten van het niveau van waargenomen controle van patiënten blijkt niet altijd positief te zijn. Het niveau van de door patiënten waargenomen controle dient in overeenstemming te zijn met enerzijds de mate van controle die zij wensen uit te (kunnen) oefenen op de situatie waarin zij zich bevinden (persoonskenmerk) en anderzijds met de mogelijkheden die die situatie op een gegeven moment toestaat om daadwerkelijk controle uit te oefenen. Daarom dienen pogingen om de waargenomen controle van patiënten te vergroten zorgvuldig rekening te houden met het door patiënten gewenste niveau van controle en de mogelijkheid die een situatie biedt om controle uit te oefenen.

In hoofdstuk 4 wordt een studie beschreven die in twee ziekenhuizen is uitgevoerd om de gang van zaken te verkennen bij de verzorging en de behandeling van patiënten die een liesbreuk- of een galblaasoperatie ondergaan. Door middel van interviews met patiënten en met leden van het (para)medisch personeel en observaties van contacten tussen patiënten en zorgverleners is een representatief beeld gekregen van de gebeurtenissen die patiënten meemaken, de (para)medici die zij ontmoeten, de omstandigheden waarin deze plaatsvinden, de informatie en steun die zij ontvangen en hun subjectieve ervaringen. Hiermee werd een gezamenlijk door patiënten, zorgverleners en de onderzoeker gedeeld beeld verkregen van de bestaande situatie met betrekking tot de voorlichting aan en de ondersteuning van patiënten. Deze fungeerde als basis voor maatregelen om tekortkomingen in de voorlichting van patiënten te verminderen.

Uit dit beeld komt naar voren dat het merendeel van de onderzochte patiënten vooral bang is voor anaesthesie en voor vervelende postoperatieve lichamelijke reacties. Tevens toonden veel patiënten onzekerheid over hun aandoening en de behandeling en de zorg die hen stond te wachten en wensten zij hierover meer informatie te ontvangen. De informatie die zij over het ontslag uit het ziekenhuis ontvingen vonden velen ontoereikend. Deze tekortkomingen bleken gedeeltelijk samen te hangen met organisatorische omstandigheden in beide ziekenhuizen, die een adequate informatievoorziening door hulpverleners aan patiënten in de weg stonden. Voor een ander deel bleken deze tekorten samen te hangen met een inadequate wijze waarop -met name door artsen- de informatie aan patiënten werd verstrekt. Veel informatie werd bijvoorbeeld op een onverwacht moment en te gehaast verstrekt en vaak werd teveel informatie in één keer gegeven.

In hoofdstuk 5 volgt een beschrijving van het proces waarin de verbeteringen van de voorlichting aan liesbreuk- en galblaasoperatiepatiënten zijn ontwikkeld en geïmplementeerd in beide ziekenhuizen waar de boven beschreven verkenning is uitgevoerd. Aangezien het in de hedoeling lag dat de maatregelen ter verbetering van de voorlichting door leden van de ziekenhuisstaf zelf uit werden gevoerd, is dit proces in nauwe samenwerking met hen uitgevoerd. Hierbij is te werk gegaan volgens principes van succesvolle adoptie 
van innovaties in organisaties. Om aan de condities die deze principes voorschrijven tegemoet te komen is een projectgroep geïnstalleerd waarin vertegenwoordigers van alle relevante disciplines zitting hadden, die zijn betrokken bij de behandeling en verzorging van liesbreuk- en galblaasoperatiepatiënten. De resultaten van de eerder uitgevoerde verkenning, samen met kennis van effectief gebleken methoden om patiënten voor te bereiden op een operatie en de rol van waargenomen controle, vormden de leidraad voor het opstellen van voorstellen voor verbetering van de voorlichting van patiënten.

Niet alle voorgestelde maatregelen welke, gezien de gesignaleerde tekortkomingen van de voorlichting als wenselijk werden beschouwd, werden door de leden van de projectgroep uitvoerbaar geacht. De reikwijdte van het programma van verbeteringen werd daardoor beperkt. Na overeenstemming over de treffen maatregelen zijn deze in samenwerking met leden van de projectgroep uitgewerkt. In één ziekenhuis is het niet gelukt om een projectgroep te installeren. In dit ziekenhuis is het programma van verbeteringen ontwikkeld tijdens afzonderlijke bijeenkomsten met leden van de verschillende betrokken disciplines. Na voltooiing van de ontwikkeling van het programma zijn alle leden van de betrokken (para)medische disciplines geïnformeerd over de voorgenomen implementatie van het programma.

Het verbeterde programma bestond uit afspraken tussen hulpverleners over het verstrekken van schriftelijke, audiovisuele en mondelinge informatie aan patiënten, op verschillende momenten tijdens de behandeling en verzorging in het ziekenhuis. De meeste maatregelen waarover overeenstemming werd bereikt betroffen het verstrekken van informatie tijdens de preoperatieve periode, en de meeste hiervan waren bedoeld om te worden uitgevoerd door verpleegkundigen. Het verbeterde programma bevatte procedurele en sensorische informatie, informatie over de functies en verantwoordelijkheden van de betrokken zorgverleners en instructies voor gedrag dat kan bijdragen aan een voorspoedig verloop van het postoperatieve herstel en aan het bevorderen van het fysiek en psychisch welbevinden. Om te vermijden dat patiënten die de voorkeur geven aan een gemiddeld niveau van waargenomen controle door blootstelling aan het programma een ongewenst hoog niveau van controle zouden ervaren, werd er zorg voor gedragen dat zij hun blootstelling aan de informatie desgewenst konden beperken.

Bestudering van de mate waarin patiënten na implementatie van het verbeterde programma informatie ontvingen volgens de gemaakte afspraken, wijst uit dat de implementatie slechts gedeeltelijk is geslaagd. Over het geheel genomen ontvingen patiënten die werden opgenomen na implementatie van het programma significant méér informatie van de voorlichtingsbronnen waarover in het kader van het programma afspraken waren gemaakt, dan patiënten die daarvoor waren opgenomen. Als de vergelijking echter wordt beperkt tot voorlichtingsbronnen die zowel voor als na invoering van het verbeterde programma beschikbaar waren en die in het kader van het programma inhoudelijk werden verbeterd en gestandaardiseerd, bleken patiënten opgenomen na implementatie niet meer informatie te ontvangen van ieder van deze bronnen. Deze resultaten zijn ten eerste verklaard doordat, als onderdeel van het verbeterde programma, patiënten op vrijwillige basis konden besluiten of zij de hen aangeboden informatie bekeken en lazen of niet en of zij vragen stelden aan zorgverleners of niet. Patiënten die weinig behoefte hadden aan informatie, hebben daardoor mogelijk ook weinig informatie ontvangen. Ten tweede 
waren er verschillende praktische hindernissen die informatieverstrekking volgens het nieuwe programma in de weg stonden, zoals beperkte mogelijkheden voor het aan patiënten vertonen van een klankbeeldpresentatie en, m.n. onder specialisten, terughoudendheid om patiënten van schriftelijke informatie te voorzien. Tenslotte waren niet alle condities voor succesvolle implementatie van het programma volledig vervuld. Geconcludeerd is dat hoewel leden van de ziekenhuisstaf in staat zijn gebleken om hun informatie aan vertrekking operatiepatiënten te verbeteren, ruimschoots aandacht dient te worden besteed aan het voldoen aan de voorwaarden die de kans vergroten dat een verbeterd programma van patiëntenvoorlichting wordt geadopteerd door de beoogde gebruikers. Dit betreft met name aandacht voor het verzorgen van compatibiliteit tussen het nieuwe programma en de professionele behoeften en waarden van de gebruikers en het op peil houden van hun motivatie voor het nieuwe programma gedurende het gehele proces van ontwikkeling en implementatie.

In hoofdstuk 6 wordt een evaluatie beschreven van het effect van het verbeterde progamma op het postoperatieve herstel en het psychologisch welbevinden van operatiepatiënten in beide ziekenhuizen. De scores van 95 galblaas- en liesbreukoperatiepatiënten die vóór invoering van het nieuwe programma werden opgenomen op indicatoren van het lichamelijke herstel en het psychisch welbevinden zijn vergeleken met die van 100 patiënten die daarna werden opgenomen. Daarnaast is het mediërende effect onderzocht van waargenomen controle op de relatie tussen patiëntenvoorlichting en de effectvariabelen. De resultaten toonden dat patiënten die na invoering van het nieuwe programma waren opgenomen een kortere opnameduur hadden, na ontslag hun vrije tijd activiteiten eerder hervatten en dat de traditionele galblaasoperatiepatiënten onder hen meer slaapmiddelen gebruikten dan traditionele galblaaspatiënten die vóór invoering van het programma waren opgenomen. Voorts bleken patiënten die na invoering van het programma waren opgenomen op de opnamedag minder behoefte te hebben aan informatie over de opname en de operatie dan patiënten die daarvóór waren opgenomen. Patiënten die een traditionele galblaasoperatie hadden ondergaan na invoering van het nieuwe voorlichtingsprogramma, bleken een week na ontslag sterkere gevoelens van waargenomen controle te ervaren dan patiënten die een traditionele galblaasoperatie hadden ondergaan vóór invoering van het programma. Waargenomen controle bleek positief gerelateerd aan de meeste variabelen van fysiek herstel en psychologisch welbevinden. Herhaald uitvoeren van de analyse van het verband tussen het nieuwe voorlichtingsprogramma enerzijds en het fysiek herstel en het psychologisch welbevinden van patiënten anderzijds, met de scores op waargenomen controle één week na ontslag uit het ziekenhuis als covariaat, wijst uit dat waargenomen controle mogelijk van belang is voor de kortere opnameduur van patiënten die na invoering van het nieuwe programma waren opgenomen. De verschillen tussen beide groepen in de hoeveelheid gebruikte slaapmiddelen en de tijd die na ontslag verstreek alvorens men zijn/haar vrije tijds activiteiten hervatte, bleven echter bestaan. Dit suggereert dat het voorlichtingsprogramma ook ongeacht hun niveau van waargenomen controle na ontslag, cen positieve invloed op de patiënten uitoefende.

De beperkte mate waarin het nieuwe programma er in is geslaagd om het fysieke herstel en het psychologisch welbevinden van de patiënten in gunstige zin te beïnvloeden, is verklaard door de beperkte reikwijdte van het programma en het beperkte succes van de 
implementatie van het programma. Een veklaring van de beperkte invloed die het programma had op waargenomem controle van patiënten, kan zijn gelegen in de tamelijk terughoudende methode die is gehanteerd om waargenomen controle te manipuleren. Geconcludeerd is dat het verstrekken van voorlichting aan operatiepatiënten door ziekenhuismedewerkers een succesvolle methode is om sommige aspecten van het fysieke herstel van patiënten en hun psychisch welzijn te verbeteren. We achten het daarom de moeite waard om inspan-ningen te intensiveren ten behoeve van het ontwikkelen en implementeren van voorlichtingsprogramma's voor operatiepatiënten die door leden van de ziekenhuisstaf zelf kunnen worden uitgevoerd. Om hen te motiveren om patiëntenvoorlichting op systematische en ook verder op adequate wijze te verzorgen, zijn meer aanwijzingen gewenst waaruit de effectiviteit van dergelijke maatregelen blijkt, indien uitgevoerd door medewerkers van ziekenhuizen. Tot aan het moment waarop dergelijke aanwijzingen in ruimere mate beschikbaar zijn valt te overwegen om voorlichting aan operatiepatiënten te laten verzorgen door speciaal daartoe door ziekenhuizen aangewezen professionals die daarvoor voldoende gemotiveerd zijn en beschikken over de benodigde vaardigheden en opleiding. 
Appendices 
Appendix 2.1

STUDIES INCLUDED IN THE REVIEW, WHICH EXAMINED THE INTERACTION BETWEEN PRESURGICAL

PREPARATION AND PATIENTS' PREOPERATIVE FEAR, COPING OR LOCUS OF CONTROL 
Appendix 2.1: Studies included in the review, that examined the interaction between presurgical preparation and patients' preoperative fear, coping or locus of control.

\begin{tabular}{|c|c|c|c|c|c|}
\hline Study & $\begin{array}{l}\text { Subjects (type of } \\
\text { surgery) }\end{array}$ & Interventions & Ty pe of delivery & Outcome variables & $\begin{array}{l}\text { Intermediating } \\
\text { variables studied }\end{array}$ \\
\hline *1. Cohen (1975) & $\begin{array}{l}\text { Cholecystectomy } \\
\text { Hemiorrhaphy }\end{array}$ & $\begin{array}{l}\text { a. Behavioral instructions } \\
\text { (TUCOBEL) } \\
\text { b. Restructuring cognitions } \\
\text { c. Assurance }\end{array}$ & $?$ & $\begin{array}{l}\text { a. Anxiety } \\
\text { b. Length of stay } \\
\text { c. Pain medications } \\
\text { d. Complications }\end{array}$ & Coping \\
\hline *2. Andrew (1970) & Herniorrhaphy & a. Procedural information & Audio tape & $\begin{array}{l}\text { a. Length of stay } \\
\text { b. Total medications }\end{array}$ & Coping \\
\hline $\begin{array}{l}\text { *3. Picket \& Clum } \\
\text { (1982) }\end{array}$ & Cholecystectomy & $\begin{array}{l}\text { a. Behavioral instructions } \\
\text { (relaxation information and } \\
\text { training) } \\
\text { b. Restructuring cognitions }\end{array}$ & $?$ & $\begin{array}{l}\text { a. Pain } \\
\text { b. Pain medications } \\
\text { c. Anxiety }\end{array}$ & Locus of control \\
\hline *4. Wilson (1981) & Cholecystectomy & $\begin{array}{l}\text { a. Procedural and sensory } \\
\text { information } \\
\text { b. Behavioral instructions } \\
\text { (relaxation information and } \\
\text { training) } \\
\text { c. Combination of a. and b. }\end{array}$ & $\begin{array}{l}\text { Audio tape } \\
\text { Audio tape \& } \\
\text { individual } \\
\text { exercises }\end{array}$ & $\begin{array}{l}\text { a. Length of stay } \\
\text { b. Pain medications }\end{array}$ & $\begin{array}{l}\text { a. Coping } \\
\text { b. Preoperative fe- } \\
\text { ar }\end{array}$ \\
\hline $\begin{array}{ll}\text { *5. } & \text { Hartsfield \& } \\
\text { Clopton (1985) }\end{array}$ & Cholecystectomy & $\begin{array}{l}\text { a. Reassurance } \\
\text { b. Behavioral instructions } \\
\text { (self-care) } \\
\text { c. Neutral information (placebo } \\
\text { control group) }\end{array}$ & $\begin{array}{l}\text { Audio tape } \\
\text { Audio tape } \\
\text { Audio tape }\end{array}$ & Preoperative anxiety & Locus of control \\
\hline $\begin{array}{l}\text { *6. Johnson, } \\
\text { Rice et al. } \\
\text { (1978) }\end{array}$ & Cholecystectomy & $\begin{array}{l}\text { a. Procedural information } \\
\text { b. Sensory information } \\
\text { c. Behavioral instructions } \\
\text { (TUCOBEL') } \\
\text { d. Combination of a. and } c \text {. } \\
\text { e. Combination of } b \text {. and } c \text {. }\end{array}$ & $\begin{array}{l}\text { Audio tape } \\
\text { Audio tape } \\
\text { Audio tape } \\
\text { plus individual } \\
\text { help }\end{array}$ & $\begin{array}{l}\text { a. Pain } \\
\text { b. Pain medications } \\
\text { c. Mobility } \\
\text { d. Mood } \\
\text { e. Length of stay } \\
\text { f. Recovery after discharge }\end{array}$ & Preoperative fear \\
\hline
\end{tabular}




\begin{tabular}{|c|c|c|c|c|c|}
\hline Study & Subjects & Interventions & Type of delivery & Outcome variables & Intermediating \\
\hline $\begin{array}{l}\text { 7. Klos, Cumming, } \\
\text { et al. (1980) }\end{array}$ & Cholecystectomy & $\begin{array}{l}\text { a. Combination of procedural } \\
\text { information and behavioral } \\
\text { instructions (TUCOBEL) }\end{array}$ & $\begin{array}{l}\text { a. Leaflet } \\
\text { b. Individual by } \\
\text { nurse } \\
\text { c. a. and b. }\end{array}$ & $\begin{array}{l}\text { a. Length of stu: } \\
\text { b. Pain medicatiuns } \\
\text { c. Activity } \\
\text { d. Mobility } \\
\text { e. Mood }\end{array}$ & Preoperative fear \\
\hline $\begin{array}{l}\text { 8. Dumas \& John- } \\
\text { son }(1972)\end{array}$ & $\begin{array}{l}\text { Gynaecological } \\
\text { surgery }\end{array}$ & $\begin{array}{l}\text { a. Restructuring of cognitions } \\
\text { combined with procedural and } \\
\text { sensory information }\end{array}$ & $\begin{array}{l}\text { Oral, before or } \\
\text { after admission or } \\
\text { both }\end{array}$ & $\begin{array}{l}\text { a. Postoperative vomiting } \\
\text { b. Medication } \\
\text { c. Pass water } \\
\text { d. Blood pressure } \\
\text { e. Infections } \\
\text { f. Mobility } \\
\text { g. Length of stay }\end{array}$ & $\begin{array}{l}\text { Preoperative anxi- } \\
\text { ety }\end{array}$ \\
\hline $\begin{array}{l}\text { 9. Williams et al. } \\
\text { (1975) }\end{array}$ & Therapeutic abortion & $\begin{array}{l}\text { a. Procedural information and } \\
\text { reassurance }\end{array}$ & $\begin{array}{l}\text { Oral by anesthesi- } \\
\text { ologist on day of } \\
\text { admission }\end{array}$ & a. Anxiety & Preoperative fear \\
\hline 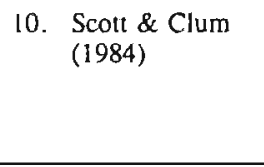 & $\begin{array}{l}\text { Cholecystectomy, } \\
\text { hysterectomy }\end{array}$ & $\begin{array}{l}\text { a. Relaxation instructions } \\
\text { b. Procedural and sensory infor- } \\
\text { mation } \\
\text { c. Combination of both }\end{array}$ & $\begin{array}{l}\text { 1. Oral and writ- } \\
\text { ten, pre and } \\
\text { post surgery } \\
\text { 2. Oral, pre and } \\
\text { post surgery }\end{array}$ & $\begin{array}{l}\text { a. Pain (McGill) } \\
\text { b. Anxiety (STAI) } \\
\text { c. Coping (sensitizing vs. } \\
\text { avoidance) } \\
\text { d. Post surgical analgesics }\end{array}$ & Coping \\
\hline 11. DeLong (1970) & General surgery & Procedural information & Audiotape & $\begin{array}{l}\text { a. Anxiety (STAI) } \\
\text { b. Recovery }\end{array}$ & Coping \\
\hline
\end{tabular}

1 TUCOBEL $=$ TUm, COugh, Breathe deeply and Exercise Legs. 
Appendix 5.1

SURGICAL PATIENT EDUCATION BEFORE AND AFTER IMPLEMENTATION OF THE NEW PROGRAM IN BOTH HOSPITALS 


\begin{tabular}{lll}
\hline & & $\begin{array}{l}\text { Content of existing patient } \\
\text { education }\end{array}$ \\
\hline $\begin{array}{ll}\text { Written } \\
\text { infor- } \\
\text { mation }\end{array}$ & $\begin{array}{l}\text { Hospital } \\
\text { 1. }\end{array}$ & $\begin{array}{l}\text { Leaflet about anesthesia: } \\
\text { - Responsibility of anesthesiologist. } \\
\text { - Pre operative preparations for } \\
\text { anesthesia at the ward and at the }\end{array}$ \\
& & operating theatre. \\
& - Events during anesthesia and surgery. \\
& - Constant monitoring- \\
& - Stay at recovery room. \\
& - Return to surgical ward and start of \\
& recovery.
\end{tabular}

\section{Content of new patient}

education

Leaflet about anesthesia, handed out by nurse at ambulatory ward.

- Responsibility of anesthesiologist.

- Types of anesthesia.

- Pre operative visit by anesthesiologist.

- Recommendation to ask qutestions.

- Preparations for mesthesia at the ward and the operating theatre.

- Events during aesthesia and surgery.

- Reassurance: constant monitoring.

- Stay at recovery room.

- Post operative physical sensations.

- Asking pain/anti nausea medication.

- Return to surgical ward and start of recovery

\section{Leaflet about cholecystectomy:}

- Functioning of gall and gall bladder.

- What are cholelithiasis, cholecystitis, and jaundice, including syptoms?

- Presurgical preparations on the day of admission and on the day of surgery.

-What is done during surgery?

- Pain at the wound after surgery.

- Advice to breath deeply and cough after surgery.

- Reason for insertion of wound drains, vena drip, and gastric tube.

- Resuming eating. drinking, and mobilisation during levivery.

- Discharge, recommendations for behavior at home, and dietary restrictions.
Leaflet about cholecystectomy and leaflet about herniorrhaphy handed out by nurse at ambulatory ward:

- Functioning of gall and gall bladder.

- What is a groin rupture or cholelithiasis?

- What is done during surgery?

- Staff members by whom patients will be visited, and whom they can ask questions.

- Presurgical preparations during day of admission, and during the day of surgery.

- Timing of surgery.

- Physical sensations after surgery.

- Medical treatment and care during recovery after surgery.

- Asking pain/anti nausea medication.

- Patiens' opportunities w enhance recovery (physical movenuents, deep breathing and coughing, mobilisati. on).

- Resuming eating, drinking during recovery.

Discharge and recommendations for behavior at home.

- Contact surgical department in case of questions or complications. 
Content of existing patient education

Leaflet about the hospital:

- General preparations for admission.

- Admission into the hospital.

- Diagnostic and therapeutic procedures, and care.

- Patients' legal rights and opportunities to complain.

- Pastoral and psychological services.

- Patient education center.

- Facilities and rules at the nursing wards.

- Hospital facilities (e.g. radio, tv, phone, shops, library).

- Discharge procedure and facilities. after discharge

Leaflet about the surgical ward:

- Names and functions of surgeons. and ward physicians.

- Daily schedule of care routines.

- Ward rules.

- Ward facilities.

Hospital 2

\section{Leaflet about the hospital:}

- Introduction of staff members.

- Admission into the hospital.

- During admission: diagnostic and therapeutic procedures, nursing wards.

- Psychological and pastoral services.

- Daily schedule during admission.

- Hospital facilities (e.g. library, creation activities, radio, phone, shops).

- Visiting hours.

- Discharge procedure and facilities after discharge.

- Satisfaction questionnaire and complaints.

- Plan of the hospical.
Content of new patient education

Folder at the surgical ward with information about the hospital and about the ward:

- Names, functions, and tasks of nurses, surgeons, ward physicians.

- Recommendation to ask questions.

- Daily schedule of care routines.

- Ward rules.

- Ward facilities.

- Hospital facilities.

- Patient education center.

- Creative and library facilities.

- Pastoral and psychological services.

- Discharge procedure and facilities after discharge

- Patients' legal rights and opportunities to complain.
Leaflet about the hospital handed out at the patient registration desk: Unchanged

Leaflet about anesthesia handed out by nurse at the ambulatory ward:

Similar to hospital 1

Leaflet about cholecystectomy and leaflet about herniorrhaphy handed out by nurse at the ambulatory ward: Similar to hospital 1

Folder at the surgical ward with information about the ward and about the hospital:

- Plan of the surgical ward.

- Intruduction of stiff members (nurses, surgenns, ward physicians) and recommendation to ask questions. 
Content of existing patient education

\section{Hospital Leaflet about 'Who's who':}

2

Introduction of surgeons.

Introduction of ward physicians.

- Introduction of nurses.

- Introduction of fysiotherapists.

Leaflet about the surgical ward:

- Events on day of surgery.

- Ward regulations.

- Introduction to ward by volunteer.

- Assistance by nurse and recommendation to ask questions.

- Plan of ward.
2. Audio- Hospital None

visual

infor-

mation
Content of new patient. education

Folder at the surgical ward with information about the ward and about the hospital (continued):

- Working schedule of surgeons.

- Daily ward schedule and ward regulations.

- Ward facilities (e.g. menu, tv, radio, phone).

- Hospital facilities (e.g. mail, restaurant, shops, translation, services, library).

- Discharge procedure and facilities after discharge.

Recreational services.

- Psychological and paswral services.

- Patient service desk.

- Patients' legal rights.

Slides-tape presentation about undergoing a cholecystectomy and slides-tape presentation about undergoing a herniorrhaphy, shown at the ambulatory department by a nurse or an employee of the patient education desk:

- Introduction to the subject.

- Admission procedure.

- Introduction of surgeons, anesthetists, ward physicians, physiothepist, and dietician, together with their responsibilities.

- Pre operative preparations (e.g. visits by ward physician and anesthetist, shaving, sleep medication, ride to eperating theatre), including staff members by whom they are performed.

Pre operative events at the operating theatre, including induction of anes. thesia, accompanied by reassuring information.

- Stay at the recovery roum, and events undertaken by nurses and anesthesists to guard patients' post opentive condition.

- Post surgical physical sensations and recommendation -if necessary- to ask nurse for pain and nausea medication.

- Rerurn to surgical ward. 
Content of existing patient education

Hospital

$1 \& 2$

3.

$\begin{array}{ll}\text { Oral } & \text { Hospital } \\ \text { infor- } & 1 \& 2 \\ \text { mation } & \end{array}$

Unstructured information by nurse on admission.

Unstructured information from various health care providers several moments during hospitalisation.
Content of new patient education

Slide-tape presentation about undergoing a herniorrhaphy and about undergoing a cholecystectomy (continued):

- Activities to enhance recovery, including staff members by whum they are performed.

- Recommendation of patient activities that promote recovery (e.g. deep breaching, mobilisation).

- Discharge, together with recommendation to ask questions to the nurse or ward physician.

- Display (in letters) of patient behavior to improve well-being and recovery

Structured provision of information by nurses on admission, supported by checklist displaying relevant topics:

- Check of previous information received, written and orally.

- Hand out leaflet about ward.

- Explanation of events on day of admission (physical examination, visit of anesthesiologist, pre operative medication, rafrain from eating and drinking, etc.).

- Explanation of events on day of surgery (pre operative medication, emptying bladder, dress in surgical gown gown, ride to operating theatre, etc)

- Explanation of post operative events (recovery room, information to and visits of relatives, wound and pain medication, mohilisation, physicians' visit, length of stay, visits by surgeon and ward physician, etc.).

Unstructured information from various health care providers at several moments during hospitalisation (unchanged) 
Appendix 5.2

LEAFLETS CONTAINING INFORMATION ABOU'T

ANESTHESIA AND SURGERY (HOSPITAL 1, IN DUTCH) 


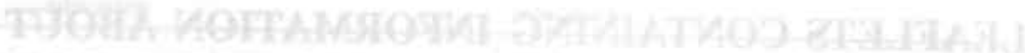

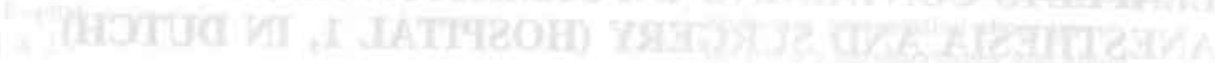


Heeft u na het lezen nog vragen, dan kunt u tijdens de opname in he: ziekenhuis deze vragen stellen aan. de anesthesist of de verpleegkundigen op de afdeling.
Binnenkort ondergaat $u$ een operatie of onderzoek waarbij verdoving (anesthesie) nodig is. De arts die deze verdoving verzorgt, is de anesthesist In deze brochure staan de belangrijkste zaken die bij anesthesie van belang zijn op een rijtie. $U$ vindt hierin antwoord op vragen als:

- Wat is anesthesie en wat doet een anesthesist?

- Hoe verloopt de voorbereiding?

- Hoe verloopt de anesthesie?

- Waar word ik wakker?

- Van welke nawerkingen kan ik last krijgen?

\section{Wat is anesthesie en wat doet een anesthesist?}

Anesthesie bietekent letterlijk gevoelloosheid. De arts die de verantwoording heeft over de anesthesie is de anesthesist. Een anesthesist doet meer dan alleen de verdoving toedienen: hij waakt voortdurend over uw lichamelijke toestand tijdens de operatie en bestrijdt pijn en eventuele andere ongemakken die zich na de operatie kunnen voordoen. Kortom: de anesthesist helpt u de operatie en de periode erna goed door te komen.

verschillende soorten
Er zijn verschillende soorten anesthesie. De meest bekende vorm is de algehele anesthesie. Hierbij wordt het hele lichaam verdoofd en bent $u$ tijdelijk buiten bewustzijn (onder narcose).

Bij een plaatselijke of regionale anesthesie maakt de anesthesist alleen een bepaald gedeelte van het lichaam gevoelloos. Tijdens dergelijke operaties blift u dus in principe wakker.

Welke anesthesie u krijgt, hangt af van met name leeftijd, lichamelijke conditie en de soort operatie. Wanneer u zelf bepaalde wensen heeft, kunt $u$ deze vertellen aan de anesthesist. Hij houdt hiermee dan rekening bij zijn beslissing over de scort anesthesie.

\section{Hoe verloopt de voorbereiding?}

\section{Bezoek van de anesthesist}

Op de dag voor de operatie komt de anesthesist langs om te bespreken welke vorm van anesthesie voor $u$ geschikt is. Heeft u vragen of wensen 
vragen over de operatie

'nuchter' zijn

een goede

nachtrust

een kunstgebit. contactlenzen en andere zaken

pré-medicatie

voorpust

operatieteam over de verdoving, dan kunt u deze aan hem voorleggen.

Het komt nog vaak voor dat patiënten aan de anesthesist vragen stellen over de operatie. De anesthesist is echter de specialist op het gebied van uw veiligheid tijdens de operatie. Hij is op de hoogte van alle lichamelijke functies die hierbij van belang zijn. Vragen over de operatie zelf kunt u beter aan de zaalarts of chirurg stellen.

Door spoedoperaties of operaties die langer duren dan verwacht. kan nooit precies worden aangegeven hoe laat de anesthesist komt. Meestal is dit aan het eind van de middag of 's avonds.

Vanaf twaalf uur 's avonds mag u niet meer roken, eten of drinken. Een lege maag voorkomt overgeven tijdens of direct na de operatie. Is de operatie 's middags. dan krijgi u vaak 's ochtends nog een licht ontbijt.

Een goede nachtrust is belangrijk. De vreemde omgeving en de ongewone situatie houden u misschien onnodig uit de slaap. Daarom schrijt de anesthesist een slaaptablet voor die $u$ van de verpleegkundige krijgt. $U$ kunt dit innemen wanneer $u$ daar de behoette toe voelt.

Tijdens de operatie kan een anesthesist onder andere aan de natuurlijke kleur van uw huid zien hoe het met u gesteld is. Eventuele nagellak en make-up moet $u$ daarom verwijderen, net als een horloge en sieraden. Ook een kunstgebit of contactlenzen moet $u$ uitdoen.

Kort voor de operatie krijgt u een zogenaamde pré-medicatie. Dit zijn medicijnen die het lichaam alvast voorbereiden op de narcose. Van de verpleegkundige krijgt $u$ daarvoor een injectie in uw been of een tablet. Dit maakt $u$ kalm en slaperig en u kunt er een droge mond van krijgen.

\section{Hoe verloopt de anesthesie?}

\section{Op de operatiekamer}

Als u aan de beurt bent rijden verpleegkundigen u naar de voorpost van de operatiekamer. Hier blijven patiënten totdat ze naar de operatiekamer kunnen. Medewerkers van de voorpost gaan na of de gegevens kloppen: en of alle voorbereidingen raar wens zijn verlopen.

Op de operatiekamer werken de medewerkers van het operatieteam. Dit team bestaat uit de chirurg. de anesthesist en de verpleegkundigen die 
hen assisteren. Allen dragen speciale operatiekleding en een muts, en hebben een mondkapje voor.

algehele

anesthesie

plaatselipke anesthesie

geen seconde alleen
Als u op de operatietafel ligt, plaatst de assistent van de anesthesist enkele electrodes op uw borst. Deze electrodes registreren het hartritme tijdens de operatie. Ook wordt nog even de bloeddruk gemeten. Vervolgens brengt de anesthesist altijd een infuusnaald in uw onderarm aan. Bij een algehele anesthesie brengt hij door deze infuusnaald een slaapmiddel in. Hierdoor valt $u$ in slaap: in feite is dit dus de laatste handeling voor de operatie die $u$ bewust meemaakt.

Bij een plaatselijke anesthesie gaat de anesthesist anders te werk. Een anesthesie die veel voorkomt is de prik in de rug. Bij operaties onder het niveau van de navel wordt deze soms toegepast. De anesthesist brengt het verdovingsmiddel in via een injectie laag in de rug. Hiervan voelt u niet meer dan de prik van de infuusnaaid.

Het voert te ver om alle technieken van de plaatselijke anesthesie te bespreken. In alle gevallen krijgt u na de infuusprik nog een tweede prik met het verdovingsmiddel.

Bij een plaatselijke anesthesie blijt $u$ in principe wakker. Als u liever niets van de operatie wilt zien of horen, kan de anesthesist $u$ een licht slaapmiddel toedienen.

\section{Tijdens de anesthesie}

Tijdens de algehele anesthesie ademt $u$ door een buisje dat in uw luchtpijp is aangebracht. Aan het einde van de operatie wordt deze weer verwijderd. De anesthesie-verpleegkundige controleert uw lichamelijke toestand; u wordt geen seconde alleen gelaten. Ademhaling, hartslag. temperatuur, bloeddruk, vochtverlies: dit alles word door moderne apparatuur geregistreerd. Dit geldt ook bij plaatselijke anesthesie. Als het nodig is wordt door het infuus vocht, pijnstillende, spierverslappende of slaapverwekkende middelen toegediend.

$\mathrm{Na}$ afloop van de operatie laat de anesthesist $u$ wakker worden.

\section{Waar word ik wakker?}

\section{De uitslaapkamer}

Na de operatie gaat u naar de uitslaapkamer (de recovery). Hier liggen meer patiënten die geopereerd zịn. Op deze kamer werken 
gespecialiseerde verpleegkundigen die in samenwerking met de anesthesist steeds controleren hoe het met u gaat. Zodra u weer voldoende wakker bent en uw aigemene conditie stabiel en veilig is, brengen verpleegkundigen u naar de afdeling.

\section{Intensive care}

Soms is er gedurende langere tijd intensieve verzorging en bewaking nodig. Dit hangt af van de aard van de operatie en uw algemene conditie. In dat geval gaat u naar de intensive care. Met behulp van moderne apparatuur houden gespecialiseerde verpleegkundigen u nauwlettend in het oog.

\section{Van welke nawerkingen kan ik last krijgen?}

pijn

trisselijhineid

dorst

keelpijn of heesheid

moeite met bewegen
Van de verpleegkundige krijgt u een pijnstillend middel dat door de anesthesist is voorgeschreven. Het kan echter voorkomen dat dit niet voldoende is en dat de hoeveelheid moet worden aangepast. Zeg daarom gerust aan de verpleegkundige wanneer u pijn heeft.

Sommige patienten zijn na de operatie misselijk. Of dit zo is hangt af van de scort operatie, de anesthesie-middelen en uw algemene conditie. Gaat de misselijkheid niet over, vraag dan aan de verpleegkundige om een middel.

Veel patiènten hebben na de ingreep dorst. Vaak mag u vlak na de operatie nog niets drinken. Tegen de dorst maakt de verpleegkundige dan uw lippen vochtig. Drink niet meteen grote hoeveelheden zodra u weer wat mag drinken: dit voorkomt misselijkheid.

Doordat u tijdens de algehele anesthesie door een buisje heeft geademd, reageent de keel soms geirriteerd. Hierdoor kunt u na de operatie last hebben van keeipijn of heesheid. Deze irritaties gaan na enkele dagen weer over.

Als u plaatselijk bent verdoofd met een prik in de rug, kunt $u$ de eerste vier tot zes uur na de operatie de onderste helft van het lichaam niet bewegen. Ook het plassen gaat kort na de operatie wat moeilijker dan normaal. Om de urine vanzelf uit de blaas te laten vloeien, krijgt u hiervoor soms een blaas-catheter. Als de verdoving is uitgewerkt gaat het plassen weer beter. 


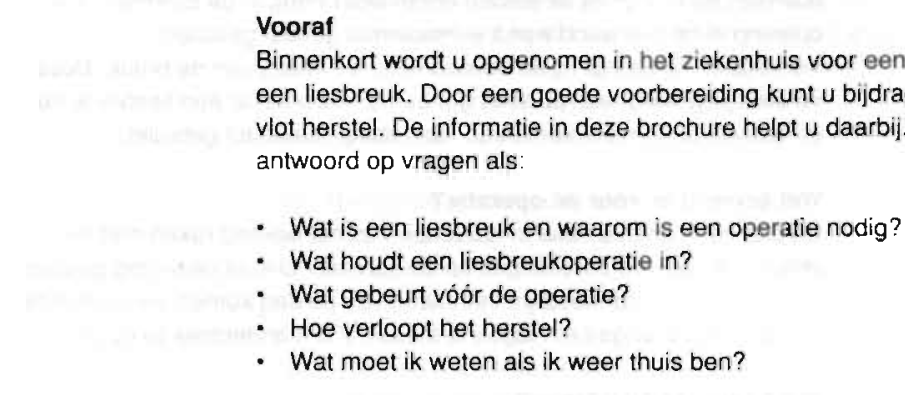

vragen

Heeft u na het lezen nog vragen, dan kunt u die altijd stellen aan de verpleegkundige of aan de arts nadat $u$ in het ziekenhuis bient opgenomen. Voor dringende vragen waarop u voór opname een antwoord wilt, kunt u contact opnemen met de polikliniek Chirurgie, telefoonnummer 040-588550 of met het Patientenservice-bureau, telefoon 040-589472.

\section{Wat is een liesbreuk en waarom is een operatie nodig?}

Een liesbreuk is een uitstulping van het buikvlies door een zwakke plek of opening (breuk) van de buikwand in de liesstreek. In deze uitstulping kan een gedeelte van de buikinhoud, zoais vocht of een deel van de darm, terechtkomen. De breuk zwelt hierdoor op, vooral bij een staande houding of bij hoesten of persen.

Een liesbreuk kan aangeboren zijn of ontstaan op latere leeftijd. Bijna iedereen heeft bij de geboorte een uitstulping van het buikvlies in de lies. Normaal gesproken groeit deze dicht. Gebeunt dit niet, dan spreken we van een aangeboren liesbreuk.

Ook op latere leeftijd kan een liesbreuk voorkomen. Deze kan ontstaan als er vaak een grote druk op de buikwand is, bijvoorbeeld bij iemand die vaak op een verkeerde manier tilt, veel hoest of hard perst bij de ontlasting of bij het plassen.

Een liesbreuk verdwint nooit uit zichzelf. Het heeft zelis de neiging om groter te worden. Ook bestaat er bij iedere tireuk de kans dat de darm bekneld raakt. In dat geval is een spoedoperatie noodzakelijk. Dit wordt voorkomen met een 'gewone' liesbreukoperatie. 
Wat houdt een liesbreukoperatie in?

Bij een liesbreukoperatie verwijdert de chirurg de uitstulping van het buikvlies en brengt hij de inhoud ervan weer terug in de buikholte. De opening in de buikwand wordt vernauwd of geheel gesloten.

versteviging

Vervoigens verstevigt hij de buikwand op de plaats van de breuk. Deze versteviging wordt een plastiek genoemd. Als u vaker een liesbreuk heeft gehad, wordt hiervoor soms een klein stukje kunststof gebruikt.

\section{Wat gebeurt er voor de operatie?}

De dag van opname staat in het teken van het bekend rah:n met de afdeling en de voorbereidingen op de operatie. U kunt deze dag gewoon uw eigen kleren aanhouden. In de loop van de dag komen verschillende personen bij u langs om vragen te stellen of om onderzoek te doen.

Wie komen er bij u langs?

verpleegkundige Op de afdeling heeft u bij opname eerst een gesprek met een verpleegkundige. Hij of zij licht $u$ in over zaken als de dagindeling, de regels op de aldeling en de voorbereiding op de operatie.

zaalarts In de loop van de dag komt de zaalarts langs om u te onderzoeken en enkele vragen te stellen. De zaalarts is een specialist in opleiding en heeft de dagelijkse zorg over de patiënten van de aideling. Met vragen over uw aandoening of de operatie kunt $u$ het beste bij de zaalarts terecht.

chirurg Dergelijke vragen kunt $u$ ook stellen aan de chirurg die $u$ voor de operatie komt bezoeken.

anesthesist Aan het eind van de middag of 's avonds vertelt de anesthesist hoe de verdoving verloopt. Vragen of wensen over de verdoving kunt $u$ met hem bespreken. U kunt zich voorbereiden op dit gesprek door de speciale anesthesiefoider te lezen. Heeft u deze op de polikliniek niet gekregen, vraag dan een exemplaar aan de verpleegkundige.

\section{Hoe verloopt de voorbereiding op de operatie?}

's middags 's Middags krijgt u van de verpleegkundige een zogenaamde klyx toegediend. Hierbij brengt de verpleegkundige via de anus een vloeistof in de darm die het uiteinde van de darmen leegspoelt. Dit is nodig om ontlasting tijdens de operatie te voorkomen en ervoor te zorgen dat de stoelgang ha de operatie weer makkelijk verloopt. voorkomen. Deze injectie krijgt u ook na de operatie twee keer per dag totdat u weer goed loopt en beweegt. 
's nachts

's ochtends

Vanaf 24.00 uur mag u voor de operatie niets meer eteri of drinken. Een lege maag voorkomt overgeven en verslikken tijdens de operatie.

Denkt u moeilijk in slaap te komen, vraag dan aan de verpleegkundige een slaapmiddel, als hij of zij u niet al éen heeft gegeven.

Haren en bacteriën kunnen de operatiewond besmetten. Om dit te voorkomen scheert een verpleegkundige 's ochtends de huid van de buik op de plaats van de operatie. Vervolgens wast $u$ zich met desinfecterende zeep.

Een kunstgebit en contactlenzen moet u uitdoen. Ook een horloge, sieraden, nagellak en make-up moet u verwijderen. Tijdens de operatie kan een anesthesist onder andere aan de natuurlijke kleur van uw huid aflezen hoe het met $u$ gesteld is.

Korte tijd voordat u naar de operatiekamer gaat, wordt u gevraagd een operatiehemd aan te doen. Vervolgens geeft de verpleegkundige $u$ een tablet of een injectie in uw been met een kalmerend middel. Dit dient als voorbereiding op de verdoving. Hievan krijgt u een slaperig gevoel en een droge mond.

\section{Tijdstip van de operatie}

De arts of verpleegkundige kan nooit met zekerheid zeggen wanneer u aan de beurt bent. Operaties duren soms langer dan verwacht en spoedoperaties kunnen tussendoor komen. Hierdoor wordt u soms later geholpen dan eerst de bedoeling was.

\section{Hoe verloopt het herstel na de operatie?}

De operatie is afgelopen en er is nu tijd nodig om te herstellen.

Wat merkt u van de operatie en op welke manier kunt $u$ zelf meewerken aan het herstel?

\section{Wat merkt u van de operatle?}

Sommige patiënten hebben na de operatie een infuus in de arm. Dit zorgt ervoor dat er voldoende vocht binnentiomt. De ochtend na de coperatie verwijdert de verpleegkundige het infuus.

De operatie heeft soms tot gevolg dat u direct erna wat misselijk bent. Gaat dit niet over, vraag dan de verpleegkundige om een middel.

De eerste dagen na de operatie zal de wond gevoelig zijn.

Een normaal gevolg van de operatie is dat alle bewegingen pijnlijk zijn, evenals diep ademhalen en hoesten. Hier kunt u de verpleegkundige een pijnstiller voor vragen. 
Soms krijgt de huid onder het litteken na een of twee dagen een roodblauwe kleur. Dit komt door een bloeduitstorting in het weefsel. Deze bloeduitstorting zakt langzamerhand naar de penis en de balzak of naar de grote schaamlip die hierdoor ook een donkere kleur kunnen krijgen. U kunt dit vergelijken met een blauwe plek; het kan verder geen kwaad en geleidelijk zal het verdwijnen.

Op de dag na de operatie wordt de pleister van de wond verwijderd. De zaalarts bekijkt wanneer de hechtingen eruit kunnen. Om infectie tegen te gaan behandelt de verpleegkundige de wond dagelijks met jodium.

eten en drinken

bewegen

regelmatig diep ademhalen

\section{Hoe kunt u zelf meewerken aan het herstel?}

Direct na de operatie mag $u$ alweer iets drinken. Op de eerste dag na de operatie krijgt u vloeibaar voedsel zoals pap. De volgende dag kunt u weer gewoon eten en drinken.

Het is belangrijk dat $u$ al snel na de operatie weer in beweging komt. Dit is goed voor de bloedcirculatie en de spijsvertering. Zelfs bewegingen in bed zoals omdraaien en rechtop gaan zitten zijn goed voor het herstel. Wilt u gaan zitten, dan is het van belang de wond te ontzien. Draai daarom eerst op de zij en duw daarna met de armen het bovenlichaam omhoog.

De eerste dag komt u ook al even uit bed. De verpleegkundige helpt $u$ om even op een stoel te zitten en enkele passen door de kamer te lopen. Zodra u weer voldoende beweegt, zijn de injecties tegen trombose niet meer nodig.

Voor uw longen is het goed dat $u$ de eerste dagen regelmatig, bijvoorbeeld eens per kwartier, diep ademhaalt. Merkt $u$ dat er slijm in de longen zit, dan is het van belang dit goed op te hoesten. Door hierbij met uw hand de wond te ondersteunen en de knieën te buigen, vermindert de pijn.

\section{Wanneer kunt u naar huis?}

Meestal duurt de opname ongeveer zes dagen. De zaalarts bekijkt of $u$ koorts-vrij bent, de ontlasting normaal verloopt, de wond is genezen en u weer goed kunt lopen. De dag voor uw vertrek geeft hij of zij adviezen voor het verdere herstel thuis.

Wilt u nadere informatie, verzoek de zaalarts dan om een gesprek. $U$ kunt dit gesprek voorbereiden, bijvoorbeeld door bepaalde vragen op te schrijven. Een bekende van u kan bij dit gesprek aanwezig zijn. 
Wat moet $u$ weten als $u$ weer thuis bent?

- Met alle bewegingen en activiteiten die pijnilijk zijjn, moet u de eerste tijd na het ontslag voorzichtig aan doen. U kunt echter gewoon lopen en fietsen. Tillen mag ook, maar zodra u hierbij moet persen is de grens bereikt.

- Wanneer u weer kunt werken hangt af van het soort werk: met bureauwerk kunt $u$ binnen eén of twee weken weer beginnen. Bij zwaar lichamelijk werk zult u enkele weken langer geduld moeten hebben.

- De wond heeft geen speciale verzorging nodig. U kunt zich gewoon wassen of douchen.

- Voor een controlebezoek op de polikliniek regelt de zaalarts voor u een afspraak. Meestal is deze twee weken na het ontslag.

- Voor eventuele vragen of problemen kunt u de polikliniek chirurgie bellen (tel. 040-588550). 
Deze folder is nieuw.

Bent u varı mening dat bepaalde informatie ontbreekt of onduidelijk is, dan horen wij dat graag. $U$ kunt uw reactie hieronder opschrijven en doorgeven aan het Patiēntenservice-bureau.

Deze folder is tot stand gekomen in een samenwerking tussen het IVA Tilburg en het Sint Joseph Ziekenhuis Veldhoven. Overname van deze folder, geheel of gedeeltelijk, kan alleen na schrittelijke toestemming van het Patiëntenservice-bureau, Sint Joseph Ziekenhuis Veldhoven. 


\section{siz}

nog vragen?

patiëntenservice bureau

waarom een operatie? chirurgie

de galblaasoperatie

\section{Vooraf}

Binnenkort wordt u opgenomen in het ziekenhuis voor een operatie aan de galblaas of galwegen. Door een goede voorbereiding kunt u bijdragen aan een vlot herstel. De informatie in deze brochure helpt u en uw familieleden daarbij. U krijgt hierin antwoord op vragen als:

- Wat is gal en wat zijn galstenen?

- Wat houdt een galoperatie in?

- Wat gebeurt voor de operatie?

- Hoe verloopt het herstel?

- Wat moet ik weten als ik weer thuis ben?

Heeft u na het lezen nog vragen, dan kunt u die altijd stellen aan de verpleegkundige of aan de arts nadat $u$ in het ziekenhuis bent opgenomen. Voor dringende vragen waarop u vóór opname een antwoord wit, kunt u contact opnemen met de polikliniek Chirurgie, telefoonnummer 040-588550 of met het Patièntenservice-bureau, tel. nummer 040-589472.

\section{Wat is gal en wat zijn galstenen?}

In de lever wordt dag en nacht een dikke gelige vloeistof aangernaakt die gal wordt genoemd. Deze gal hebben we nodig voor de vertering van vette stoffen in het voedsel. Gal die hierbij niet meteen nodig is, worcit opgeslagen in de galblaas. Zodía er voedsel in de darmen komit, perst de galblaas de gal via de atvoerbuis in de dunne darm. Een deel van de gal komt in de ontlasting terecht en geeft deze de bruine kleur. Uw klachten worden veroorzaakt door galstenen. Dit zijn kalkachtige harde brokjes die in de galblaas of in de grote galwegen kunnen ontstaan. Grofweg zijn er drie verschijnselen die een operatie noodzakelijk maken:

1. Een steen kan klem komen te zitten in de afvoerbuis van de galblaas. De gal stroomt nu rechtstreeks naar de clarmen. De galblaas trekt zich krachtig samen om het steentje uit de afvoerbuis te persen. Dit veroorzaakt pijnaanvallen (kolieken) rechts boven in de buik en in de rug. Deze pijnaanvallen houden op wanneer het steentje docrschiet naar de grote galbuis of wanneer de galblaas te uitgeput is om verder te persen. 
2. Een steen kan zo vastgeklemd zitten in de afvoerbuis dat er geen gal meer in en uit de galblaas kan. De galblaas kan niet meer werken en raakt dan vaak ontstoken. Dit geeft aanhoudende buikpijn en hoge koorts.

3. Een steen kan ook klem komen te zitten in de grote galbuis. De gal kan nu niet meer in de darm lopen en komt in het bloed terecht. Dit veroorzaakt een gelige huidskleur (geelzucht) en een donkergele of donkerbruine kleur van de urine. Doordat de gal niet meer in de darm terechtkomt krijgt de ontlasting een bleke kleur.

schernatisch

overzicht van lever. gablaas en dunnedarm in het lichaam

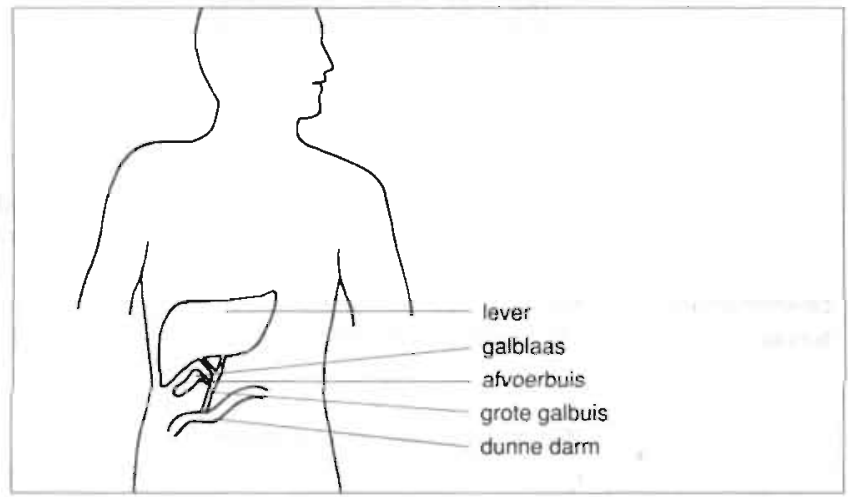

Wat houdt een galblaasoperatie in?

Bij een galblaasoperatie haalt de chirurg de galblaas weg. Hiervoor maakt hit een snede midden in de bovenbuik of rechts onder de ribben.

De galstenen in de grote galbuis worden eveneens verwijderd. Om te controleren of alle stenen zijn weggehaald, wordt er tijdens de operatie soms een röntgenioto gemaakt.

De galblaas wordt weggehaald omdat de kans groot is dat er zich stenen zullen blijven vormen. Het is goed mogelijk om zonder galblaas te leven. De gal zal in het vervolg direct van de lever naar de darmen stromen. De eerste tijd na de operatie zal de gal uw ontlasting donkerder kleuren. Na enkele weker heeft de galproductie zich aan de nieuwe omstandigheden aangepast, en krijgt uw ontlasting weer de normale kleur. 


\begin{abstract}
Wat gebeurt er voor de operatie?
De dag van opname staat in het teken van het bekend raken met de afdeling en de voorbereidingen op de operatie. In de loop van de dag komen verschillende personen bij $u$ langs om vragen te stellen of om onderzoek te doen.

\section{Wie komen er bij u langs?}

verpleegkundige

zaalarts

chirurg

fysiotherapeut

anesthesist

's middags

's nachts

Op de afdeling heeft $u$ bij opname eerst een gesprek met een verpleegkundige. Hij of zij licht $u$ in over zaken als de dagindeling, de regels op de afdeling en de voorbereiding op de operatie. Vragen over de verzorging of over de afdeling kunt $u$ altijd aan deze verpleegkundige stellen.

In de loop van de dag komt de zaalarts langs om u te onderzoeken en enkele vragen te stellen. De zaalarts is een specialist in opleiding en heeft de dagelijkse zorg over de patiënten van de afdeling. Met vragen over uw aandoening of operatie kunt $u$ het beste bij de zaalarts terecht. Deze vragen kunt $u$ ook stellen aan de chirurg die u voor de operatie komt bezoeken.

De fysiotherapeut komt 's middags en leert $u$ alvast oefeningen zodat $u$ straks na de operatie goed kunt ademhalen en hoesten. Dit is nodig om de longen na de operatie zo snel mogelijk weer goed te laten werken.

Aan het eind van de middag of 's avonds komt de anesthesist en licht $u$ in over de verdoving. Vragen of wensen over de verdoving, kunt $u$ aan hem stellen. U kunt zich op dit gesprek voorbereiden door de speciale anesthesiefolder te lezen. Heeft u deze op de polikliniek niet gekregen, vraag dan een exemplaar aan de verpleegkundige.

\section{Hoe verloopt de voorbereiding op de operatie?}

's Middags krijgt u van de verpleegkundige een injectie om trombose te voorkomen. Na de operatie krijgt u deze injectie twee of drie keer per dag totdat u weer loopt.

Ook krijgt u 's middags een zogenaamde klyx toegediend. De verpleegkundige brengt via de anus een vloeistof in de darm die het uiteinde van de darm leegspoelt. Dit veroorzaakt geen pijn. Een klyx is nodig om ontlasting tijdens de operatie te voorkomen en ervoor te zorgen dat de stoelgang na de operatie weer makkelijk verloopt.

Vanaf 24.00 uur 's nachts mag u voor de operatie niets meer eten of drinken. Een lege maag voorkomt overgeven en verslikken tijdens de operatie.

Denkt u moeilijk in slaap te komen, vraag dan aan de verpleegkundige
\end{abstract}


een slaapmiddel, als hij of zij u niet al een heeft gegeven.

Haren en bacteriën kunnen de operatiewond besmetten. Om dit te voorkomen, scheert een verpleegkundige 's ochtends de huid van de buik op de plaats van de operatie. Vervolgens wast $u$ zich met desinfecterende zeep.

Een kunstgebit en contactlenzen moet u uitdoen. Ook een horloge, sieraden, nagellak en make-up moet u verwijderen. Tijdens de operatie kan een anesthesist onder andere aan de natuurlijke kleur van uw huid aflezen hoe het met $u$ gesteld is.

Korte tijd voordat u naar de operatiekamer gaat. wordt u gevraagd een operatiehemd aan te doen. Vervolgens geeft de verpleegkundige $u$ een tablet of een injectie in uw been met een kalmerend middel. Dit dient als voorbereiding op de verdoving. Hiervan krijgt u een slaperig gevoel en een droge mond.

\section{Tijdstip van de operatie}

De ans of verpleegkundige kan nooit met zekerheid zeggen wanneer $u$ aan de beurt bent. Operaties duren soms langer dan verwacht en spoedoperaties kunnen tussendoor komen. Hierdoor wordt u soms later geholpen dan eerst de bedoeling was.

\section{Hoe verloopt het herstel na de operatie?}

nawerkingen

De operatie is afgelopen en er is nu tijd nodig om te herstellen. Wat merkt $u$ van de operatie en op welke manier kunt $u$ zelf meewerken aan het herstel?

\section{Wat merkt u van de operatie?}

De eerste dagen na de operatie is de wond nog gevoelig. Een normaal gevolg van de operatie is dat alle bewegingen pijnlijk zijn, evenals diep ademhalen en hoesten. Hier kunt $u$ de verpleegkundige een pijnstiller voor vragen.

De operatie heeft soms tot gevolg dat u direct erna wat misselijk en dorstig bent. Tegen de misselijkheid kan de verpleegkundige $u$ iets geven.

Drinken mag vlak na de operatie nog niet; om de dorst te verminderen, makkt de verpleegkundige uw lippen vochtig.

infuus

\section{Welke hulpmiddelen zijn aangebracht?}

De eerste dagen na de operatie heeft $u$ een infuus in de arm. Dit zorgt ervoor dat $u$ voldoende vocht krijgt. Zodra $u$ zeif weer voldoende drinkt, verwijdert een verpleegkundige het infuus. 
maagsonde

wonddrain

hechtingen

verwijderd

bewegen
Dit is een slangetje dat via de neus naar uw maag loopt. Hierdoor blijt uw maag kort na de operatie leeg. Meestal verwijdert de verpleegkundige deze sonde al op de eerste dag na de operatie.

Het slangetje dat in de wond is gelegdi, is nodig om het bloed en wondvocht af te voeren. Komt er bijna geen vocht meer uit de drain, dan haalt de verpleegkundige deze weg. Dit is na twee of drie dagen al het geval.

Soms heeft de specialist tijdens de operatie de galbuis geopend. Dan heeft u nog een tweede slangetje in de wond. Deze drain voert de overtollige gal at. Een week na de operatie worden er enkele röritgenfoto's gemaakt. Hierop ziet de specialist of de gal goed naar de darm loopt en of er geen stenen zijn achtergebleven. Wanneer alles in orde is, haalt de verpleegkundige de drain tien dagen na de operatie weg.

\section{Wondbehandeling}

Op de dag na de operatie haalt de zaalarts de pleister van de wond. Om infectie tegen te gaan, behandelt de verpleegkundige de wond dagelijks met jodium. De hechtingen worden meestal tien dagen na de operatie verwijderd.

\section{Eten en drinken}

Eten en drinken mag u vak na de operatie nog niet. Op de eerste dag na de operatie luistert de zaalarts naar uw buik om te horen of de darmen alweer beginnen te werken. Gaat dit goed, dan mag u voor het eerst weer wat drinken. De eerste dag krijgt u alleen wat te drinken, daarna wordt het eten en drinken verder opgebouwd volgens een bepaald schema.

\section{Hoe kunt u zelf meewerken aan het herstel?}

Het is belangrijk dat $u$ al snel na de operatie weer in beweging komt. Dit is goed voor de bloedcirculatie en de spijsvertering. Zelfs bewegingen in bed zoals omdraaien en rechtop gaan zitten zijn goed voor het herstil.

Wilt u gaan zitten, dan is het van belang de wond te ontzien. Draai daarom eerst op de zij en duw daama met de armen het bovenlichaam omhoog.

De eerste dag na de operatie helpt de verpleegkundige $u$ orn even uit bed te komen en op een stoel te zitten. Op de tweede dag loopt u met de verpleegkundige enkele passen door de kamer.

Zodra u weer voldoende beweegt, zijn de injecties tegen trombose niet meer nodig. U kunt dan ook weer douchen. 
Meestal hebben patiënten geen last van de wondjes. Wel voelt de rechter bovenbuik wat pijnlijk aan en sommige patiënten hebben een pijnlijk gevoel in de rechter schouder.

's Avonds op de dag van de kijkoperatie verwijdert een verpleegkundige de maagsonde. Op de dag na de operatie worden de infuus en de drain weggehaald. Op deze dag krijgen patienten alleen vloeibaar voedsel. Op de tweede dag na de operatie mag weer normaal worden gegeten.

\section{Het ontslag}

Als alles normaal verloopt mogen patiënten op de tweede of de derde dag na de kijkoperatie al naar huis. Na het ontslag gelden er geen beperkingen voor het verrichten van lichamelijke activiteiten, hoewel het raadzaam is om de eerste week na het ontslag voorzichtig aan te doen en tijdig rust te nemen. Ook is het beter om de eerste tijd voorzichtig te zijn met vet eten.

Heeft u na het lezen van deze informatie nog vragen over de kijkoperatie, dan kunt u deze altijd stellen aan uw arts. 
Appendix 5.3

FOLDER CONTAINING INFORMATION ABOUT REGULATIONS AND FACILITIES IN THE HOSPITAL AND AT THE WARD (HOSPITAL 1, IN DUTCH) 


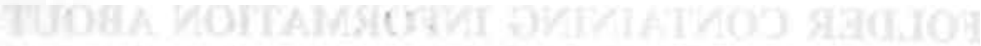

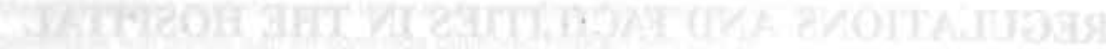

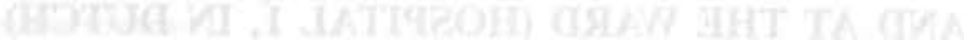




\section{Welkom op onze afdeling}

Allereerst heten wij u van harte welkom op onze afdeling.

Afdeling $1 \mathrm{C}$ is een verpieeg.

afdeling algemene

chirurgie/traumatologie.

Uw komst bij ons kan

verschillende redenen heboen

observatie, onderzoek of

behandeling. Hoe dan ook:

voor kortere of voor langere tijd bent $u$ onze gast. Op deze pagina's geven we daarom informatie over de afdeling. Hopelijk raakt u hierdoor wat meer bekend met de dagelijkse gang van zaken.

$\mathrm{U}$ vindt antwoord op de volgende vragen:

- Wie komt u tegen op de afdeling?

- Hoe ziet de dagindeling eruit?

- Welke regeis zijn er?

Heeft u na het lezen van deze pagina s vragen. dan kunt u deze altijd stellen aan de medewerkers van de afdeling.

\section{Wie komt U tegen op de afdeling?}

\section{De verpleegkundigen}

Met de verpleegkundigen zult $u$ het meest contact hebben. Zij zorgen voor de dagelijkse verpleging en verzorging. Het verpleegkundig team bestaat uit verpleegkundigen en leerling-verpleegkundigen: De dagelijkse leiding van de atdeling berust bij het verpleegkundig afdelingshoofd. Op atdeling $1 \mathrm{C}$ is dit de heer $\mathrm{J}$. Vlemmix.

Verder werken op de afdeling een aldelingssecretaresse, een voedingsassistente en een meclewerkster van de huishoudelịke dienst.

\section{De specialisten}

De specialisten die verant-

woordelịk zịn voor de

medische gang van zaken zijn:

dr C. Bruyninckx

J. Charbon

dr F: Croiset van Uchelen

M. Luiting

dr H. Kluck

dr Th. van Straaten

De specialisten werken nauw mer elkaar samen en zịn ais leam verantwoordelikk voor uw medische behandeling. Zij streven emaat dat $u$ zoveel mogelijk door uw eigen specialist wordt behandeld. Door omstandigheden kan het echter eens voorkomen dat de ene specialist de ander moet vervangen. Dit heeft geen gevolgen voor uw behandeling de specialisten wisselen regelmatig gegevens uit en zi!n hierdoor goed op de hoogte. van elkaars patiènten

\section{De zaalarts}

De zaalarts is een arts die wordt opgeleid tot specialis! Tijdens de opleiding regelt de zaalarts de medische zorg voor de patiënten op de afdeling. U zult hem/haar regeimatig tegenkomeri: de zaalarts loop" dagelijks visite.

Vragen over uw aandoening of operatie kunt u aan de zaalarts

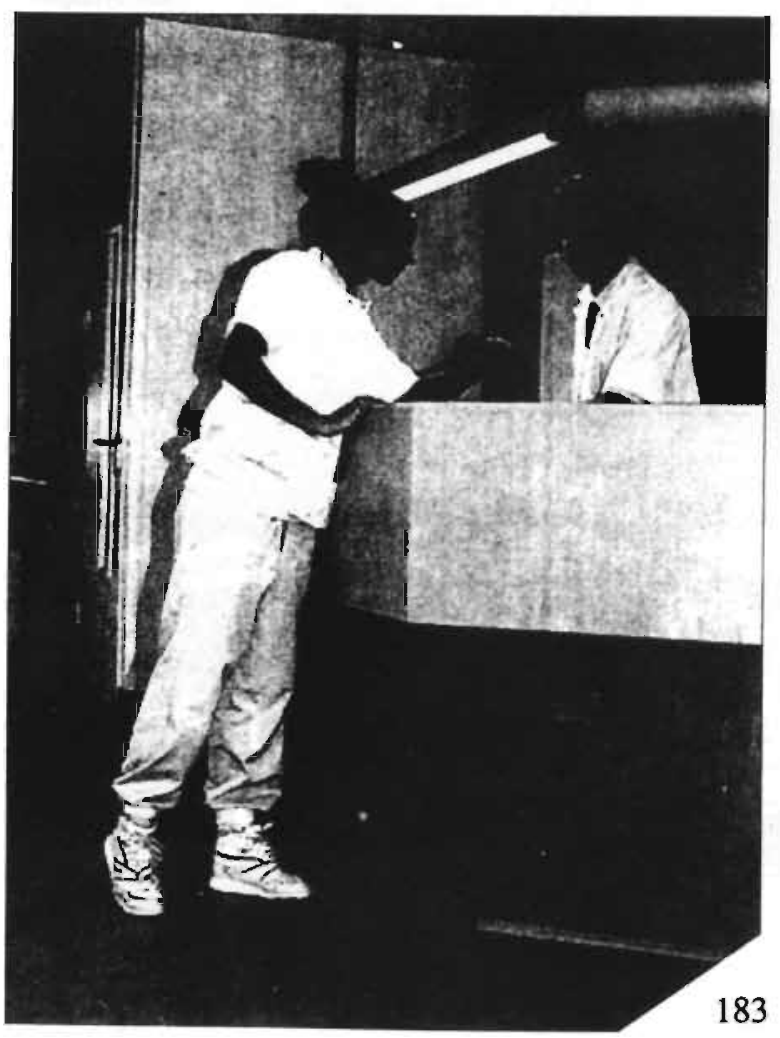




\section{De 'grote visite'}

ledere dinsdagmiddag is de 'grote visite'. Deze bestaat uir twee delen. Eerst komen de specialisten, de zaalarts en het verpleegkundig afdelingshoofd bij elkaar om uw gegevens te bespreken. Vervolgens bezoeken ze u op de afdeling. Ze informeren dan hoe het met u gaat en geven informatie over de verdere behandeling.

Heeft u vragen, dan kunt u deze altijd stellen aan uw specialist of aan de zaalarts die na afloop nog even op uw kamer komt.

\section{Hoe ziet de dagindeling er uit?}

Dit is niet meer dan een globale beschrijving van de dag.

\section{'s ochtends}

07.00 uur

wekken en eventueel temperatuuropname

08.00 vur

ontbijt en medicijnen

$U$ kunt zich voor of na het ontbijt wassen.

Heeft u hierbij hulp nodig, dan kunt u dit aan de

verpleegkundige vragen.

09.30 vir

kotfie, thee of fris

's middags
12.00 uur
warme maaltijd en medicijnen
12.30 uur
eventueel temperatuuropname
$12.45-13.45$ uur
rust
$13.45-14.30$ uur
bezoek
14.30 uur
kotfie, thee of fris
15.00 uur
medicinnen en eventuele
verzorging
17.00 uur
broodmaaltijd en medicijnen

's avonds

$18.45 \cdot 19.30$ uur

bezoek

19.30 uur

kottie, thee of fris

22.00 uut

medicijnen

23.00 vur

nachtrust

Wij schrijven u niet voor

wanneer u moet gaan slapen

Zorgt u er wel voor dat het

rustig is op de afdeling.

\section{Welke regels gelden op de afdeling?}

Om de verzorging zo goed mogelijk te laten verlopen, gelden op onze afdeling een aantal regels.

\section{Later ontbijten}

Voor een onderzoek, behande ling of bloedprik moet u soms nuchter blijven. De verpleegkundige vertelt $u$ dit. $U$ ontbijt dus pas wanneer $u$ het onderzoek achter de rug heeft. Laat even weten wanneer $u$ weer terug op de afdeling bent: we maken dan meteen een ontbijt klaar.

\section{Op de afdeling blijven}

's Ochtends tussen $8.00-8.30$ uur kan het zijn dat u een bloedprik krijgt. Wilt u zorgen dat $u$ deze tijd op de afdeling bent? Uiteraard geldt dit niet wanneer $u$ voor onderzoek of behandeling elders in het ziekenhuis moet zijn.

\section{Niet in bed?}

Wanneer $u$ niet in bed hoeft te blijven kunt $u$ uw tijd doorbrengen in het dagverblijf. Geeft u even door aan de secretaresse of verpleegkundige wanneer $u$ de afdeling verlaat; we weten u dan te vinden als wij u nodig hebben. bijvoorbeeld wanneer de zaalarts op visite komt.

\section{Rust}

Om elkaar zo min mogelijk te storen tijdens het rustuur. vragen wij $u$ om dan op de kamer te blijven. Heeft u geen behoefte aan rust dan kunt u ook naar het dagverblijf gaan.

\section{Roken}

Roken is alleen toegestaan in het daarvoor aangewezen dagverblijf.

\section{Bezoek \\ De bezoektijden zijn: \\ 's middags $13.45-14.30$ uur 's avonds 18.45 - 19.30 uur Is het voor uw bezoek niet mogelijk om op deze tijden te komen, geef dit dan even door aan de verpleegkundige. Op afspraak is het mogelijk een of twee bezoekers te ontvangen tussen 17.00 uur en 17.45 uur in plaats van het normale middagbezoek. \\ $\cup$ mag maximaal twee personen per bezoek ontvangen.}

Als u samen met uw familie meer informatie wil over uw aandoening of behandeling. dan kunt u na het bezoekuur terecht bij het hoofd van de afdeling of zijn vervang(st)er. Wanneer uw familieleden de zaalarts of specialist willen spreken. kunnen ze een afspraak maken bij de atdelings-secretaresse.

\section{Vragen? \\ Wensen?}

Heeh u tijdens uw verblijt op onze afdeling vragen of wensen, stel ze! Op deze manier kunnen we het verblijf in het Sint Joseph Ziekenhuis voor $u$ zo aangenaam mogeiijk maken. 


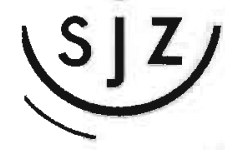

In het Sint Joseph Ziekenhuis bieden wij u de mogelijkheid om uw eigen menu samen te stellen.

Elke morgen krijgt u uw persoonlijke menukaart uitgereikt. Hierop kunt u aangeven wat $u$ de volgende dag graag witt eten. Alle op de menukaart aangeboden gerechten zijn aangepast aan het dieet dat u eventueel volgt. $U$ kiest de gerechten die $u$ het lekkerst vindt.

Op de voorkant van de menukaart staat precies beschreven hoe u de kaart kunt invullen. Heeft u hierbij toch nog vragen, aarzel dan niet om deze te stellen aan de afdelingsassistente of verpleegkundige die de kaart bij u komt ophalen.

\section{Dranken}

Drie maal daags vrager de verpleegkundigen wat $u$ wit drinken. Hieronder treft $u$ een overzicht aan van de diverse dranken die wij u kunnen bieden.

kotfie

thee

bouillon

natrium-arme bouillon

\section{Zuivelproducten}

nalfvolle melk

magere melk

karnemelk

magere chocolademelk

magere yoghurt

ycghurt

vanillevia

chocoladevla
Indien u een dieet volgt. kunt u ook kiezen uil

natrium-arme halfvolle melk natrium-arme magere melk. natrium-arme karnemelk natrium-arme yoghurt

\section{Frisdranken}

seven-up

sinas

spa rood

limonadesiroop

appelsap (ongezoet)

jus d'orange (ongezoet)

Indien u een dieet volgt, kunt u ook kiezen uit:

E-10 sinas

tomatensap

natrum-arme tomatensap

suikervrije limonadesiroop

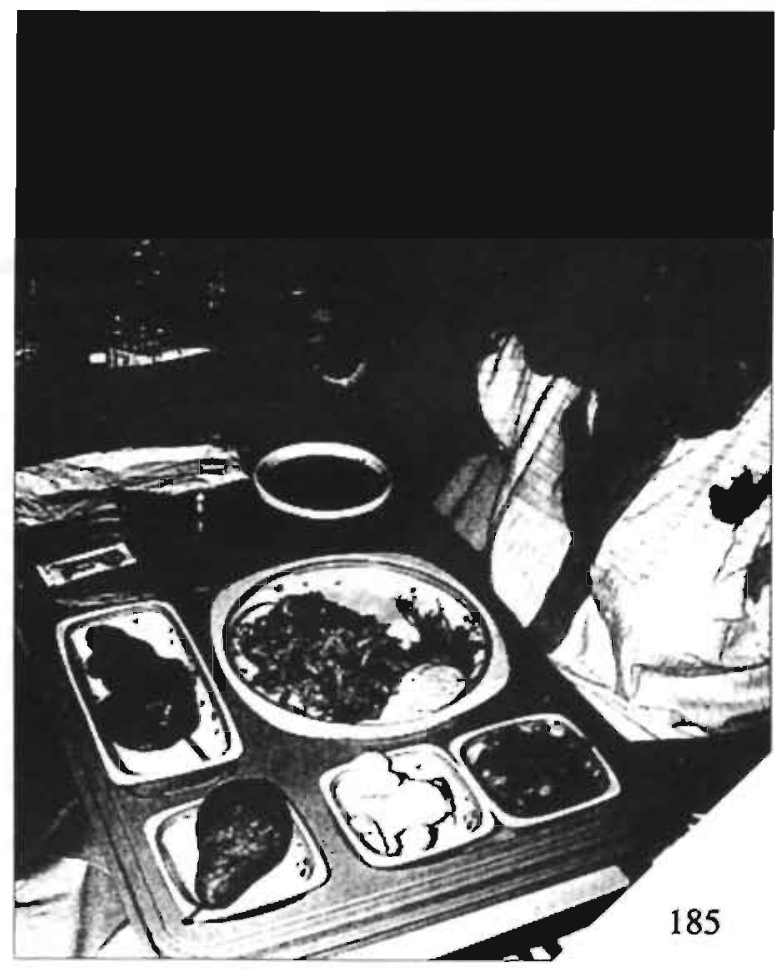




\section{Radio}

Bij elk bed is een radio-

aansluiting waarop

verschillende programma's te

beluisteren zin. Met behulp van

een hoofdtelefoon ontvangt u

het geluid

De Einclhovense Regionale

Verplegingsomroep verzorgt

dagelijks van 07.00 uur's

ochtends lot 19.00 uur 's

avonds muziekprogramma's.

De programma's zijn:

$07.00-08.00$ uur

Een goede morgen met de ERVO

Een non-stop programma met rustige. voornamelijk

instrumentale muziek.

$08.00-09.00$ uur

Graag gedraaid

Een gevaneerd programma met

Nederlandastairge en

butenlandse muziek.

$09.00-10.00$ uur

Muziek Boutique

Muziek tussen 1960 en 1980.

zowel afkomstig uit ons eigen

land als ut het buttenland.

$10.00 \cdot 11.00$ uur

Koffie met een koekje

Een gezellig programma met

rustige luistermuziek.

wat korte praatjes. een stukje cabaret en een gedicht of boekfragment als "koekje".

\section{$11.00-12.00$ uur}

Van eigen bodem

Een opgewekt Nederiandstalig

programma voor jong en

oud. Mel onder meer een 78 .

toerenplaat uit de jaren

veertig en vijfig.

\section{$12.00-13.00$ uur}

Muziek A.U.B

Een non-stop programma met lichte muziek. waarvan de meeste instrumentaal is.
$13.00-14.00$ uur

Cabaretaria

Een programma met

conferences en luistermuziek.

$14.00-15.00$ vur

Vitamine $M$

In dit herizame programma

contunu muziex. waarin

ledereen iels van zịn of haar

gading kan vinden.

$15.00-16.00$ uur

Tussen Piep en Stok

Een muzikale happening voor de iets oudere luisteraar. met een knipoog naar de jaren van weleer en een greep uit ERVO's kraakplatenkabinet.

\section{$16.00-19.00$ uur}

Musiquette

Twee uur populair klassieke

muziek. met daarin een

complete operette en aandacht

voor een solist(e)

$18.00-19.00$ uur

Tussen diner en TV

Een programma met lichte popmuziek, aangevuld mei spreuken en gezegden.

\section{Alleen op zaterdag}

$10.00-10.30$ uur

Verzoekplatenprogramma speciaal voor kinderen in het Sint Joseph Ziekenhuis.

$10.30-13.00$ uur

Verzoekplatenprogramma

speciaal voor het Sint

Joseph Ziekenhuis met daarin

een kwis en huisintormatie.

Het telefoonnummer van de

studio is (58)9533

$19.00-22.00$ uur

Sport en Informatie

In dit sport- en informatie. programma van de ERVO rechtstreekse verslagen van de thuiswedstrijden van EVV en PSV, reportages, viaaggesprekken, berichten en muziek

\section{Alleen op zondag}

$16.00-18.00$ uur

Muziek voor u

Een klassiek verzoekplatenprogramma waarin ook uw verzoekje welkom is. $U$ kunt daarvoor vanaf 15.00 uur de studio bellen: 452451 of 335220 . 
$\sin$

Televisie

In elke patientenkamer staat minstens éen kleurentelevisie.

Via een hoofdtelefoon ontvangt $u$ het geluid van de televisie.

Op de televisie kunt $u$ de volgende zenders ontvangen:

Informatiekanaal van het Sint Joseph Ziekenhuis

Nederland 1

Nederland 2

Nederland 3

BRT 1

Duitsland 1

Duitsland 2

Super Channel

RTL 4

Kabelkrant Veldhoven

De Eindhovense Regionale Verplegingsomroep zendt de thuiswedstrijden van EVV en PSV uit op de televisie. Dit gebeurt echter niet rechtstreeks, maar in de loop van de week. Ook de kerkdiensten worden door de ERVO uitgezonden. Informeent u bij de verpleegkundige wanneer de vitzendtijden zijn.

\section{uw kamer}

\section{Telefoon}

U kunt een telefoontoestel aan bed krijgen. De telefoonhuur bedraagt f 2,50 per dag. Wanneer twee patiënten dezelide telefoon gebruken, wordt âan beiden de telefoonhuur in rekening gebracht. Indien u telefoon wenst, kunt u dit laten weten aan de verpleegkundige. Deze regelt de aansluiting voor $u$.

$U$ kunt zelf rechtstreeks bellen met aansluitingen in de regio die beginnen met de kengetallen 040 en 049... Deze gesprekken zijn gratis. Gesprekken buiten de regio kunt u aanvragen via de tele. looncentrale (telefoonnummer 9). De kosten hiervan worden in rekening gebracht, als deze hoger zijn dan $f 5$.

\section{Post}

"s Morgens wordt de post bezorgd op alle verpleegafdelingen. Uitgaande post kunt u meegeven aan de afdelingssecretaresse.

Post kiigt u het snelst als de adressering juist is. $U$ werkt hieraan mee door aan familie kennissen en andere relaties uw volledige ziekenhuisadres te geven:
Uw naam
afdeling met uw
kamernummer
Sint Joseph Ziekenhuis
Posibus 7777
$5500 \mathrm{MB}$ Veldhoven.

U kunt het abonnement van uw krant over laten schrijuen naar uw kamer in het ziekenhuis. 


\section{Bibliotheek}

In het Sint Joseph Ziekenhuis is een "rijdende" biblıotheek waar $u$ boeken en tijdschrijtten kunt lenen. De dames van jeze bibliotheek komen ıedere week. een keer bij $u$ langs. Leent $u$ de boeken niet uit aan medepaliènten of aan uw bezoek. Wanneer $u$ hef ziekenhuis verlaat kunt u de geleende boeken teruggeven aan de verpleegkundige op uw afdeling

\section{Winkel}

Tegenover de hoofdingang vindt $u$ een winkel waar $u$ onder andere tijdschriften, kranten. toiletartikelen, cadeaus en ansichtkaarten kunt kopen. De winkel is dagelijks geopend van 13.00 uur tot 20.00 uur. Voor patıenten die niet van de afdeling af mogen of in bed moeten blijuen, is er een rijdende winkel. $U$ kunt hier onder andere briefpapier. postzegels, kranten en tolietartikelen kopen. De dames van de rijdende winkel komen doorgaans twee maal per week bij $\mathrm{u}$ langs

\section{Koffieshop}

In de kottieshop tegenover de ingang van de poliklinieken kunt $u$ op werkdagen terecht van 08.00 uur tot 20.00 uur. Hier kunt u katfie. Iris of een luxe broodje of snack krijgen. In de weekeinden is de kotfie. shop geopend gedurende de bezoektijden.

\section{Kaapsalon en pedicure}

Op de begane grond. in de centrale gang. trett u een kapsaion aan.

Als $u$ in bed moet blijven heipt de kapper u op verzoek op uw kamer.

$\checkmark$ kunt vragen of de afdelings. secretaresse of

verpleegkundige een atspraak voor $\cup$ wil regelen.

Als $u$ uw voeten wilt laten verzorgen door een pedicure. $k$ 'nt $u$ een afspraak maken via de atdelingssecretaresse of verpleegkundige van uw afdeling

Voor de duidelijkheid: kapper en pedicure worden niet door het ziekenhuis betaaid. $U$ moet contant met hen atrekenen.

\section{Patiëntenservicebureau} Het Sint Joseph Ziekenhuis heeft een patientenservicebureau voor patiènten en hun direct betrokkenen. De medewerkers van dit bureau kunnen helpen met zakelijke informatie over ziekten en aandoeningen en de behandeling daarvan patientenverenigingen. de gang van

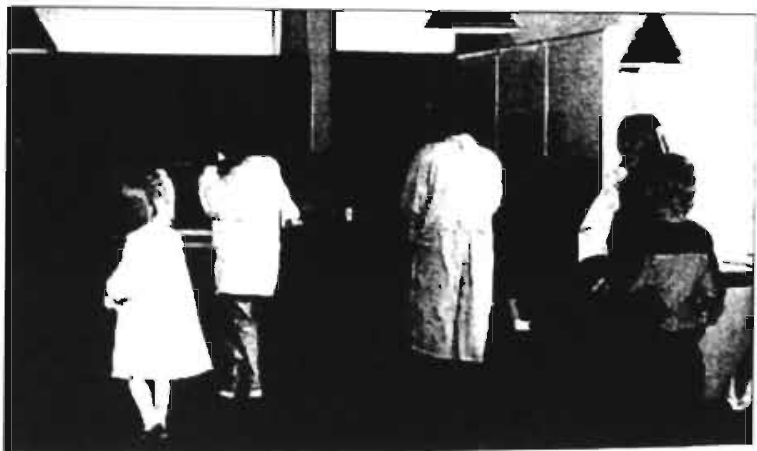

\begin{abstract}
zaken in het ziekenhuis. informatie over andere hulpver. leningsinstellingen etcetera. In het bureau vindt $u$ allerlei folders, artikelen en boeken met medische informatie en videofilms over verschillende aandoeningen.

Informatie over de aanwezige literatuur en films is op uw verpleegaídeling verkrijgbaar. Vraag ernaar bij de verpleegkundige.
\end{abstract}

Als u belangstelling heeft voor een videofilm, bespreek dit dan met uw behandelend specialist. Hel patientenservicebureau is geopend op werkdagen van $09.00-17.00$ uur. Het is te vinden bij de ingang van de poliklinieken, telefoonnummer: (58) 9472 .

\section{Postkantoor}

Het Sint Joseph Ziekenhuis beschikt over een eigen post. agentschap. U kunt hier terecht voor uw postbankzaken, het versturen van brieven en pakketten, postzegels, etcetera. $U$ vindt het postagentschap in de centrale gangi bij de hoofdingang.

\section{Vrijwilligers}

$\cup$ zult regelmatig te maken kriigen me! de vrijwiligers in hel Sint Joseph Ziekenhuis. Z! nemen verschillende taken op zich. Zo dragen zij zorg voor het vervoer van patienten in bedden en verzorgen zij de bloemen die op uw kamer staan. 
Tijdens uw verblijf in het ziekenhuis kunt u een beroep doen op de afdeling activiteitenbegeleiding. In deze periode heeft u misschien behoefte aan andere ontspanningsvormen dan in usw dagelijks leven. De activiteitenbegeieidsters Margriet Kager-Allard en Pascale Zijlmans zullen u hiertij graag adviseren en ondersteunen. Geeft u even door aan de verpleegkundige wanneer u belangstelling heeft voor onderstaande activiteiten. Als u niet meer in bed hoeft te blijven, kunt u de atdeling activiteitenbegeleiding lopend of per rolstoel bezoeken. $U$ vindt deze op de derde etage van de gang direct naast de verpleegatdelingen. Ook met uw eigen hobby/handwerk bent u welkom.

U kunt de afdelingl dagelijks telefonisch bereiken op nummer (58)9577 tussen $14.00-14.30$ uur.

\section{Mogelijke activiteiten}

Handenarbeid, o.a.:

graveren

kaarsen versieren

glas verven

calligrafie

houtbranden

tekenen

figuurzagen

schilderen

boetseren

pitriet

gipsgieten

zandgieten

marmeren

pitten en zadenmozaïek

krimpie dinkie

Handwerken. o.a.:

poppen en beesten maken

appliceren

textielverf

zijde beschilderen

\section{Uitleen van:}

Cassettebanden van gesproken krant en/of boeken over de meest viteenlopende onderwerpen. De sassettes kunt u beluisteren met de bijgeleverde apparatuur.

\author{
Spelen, o. a: \\ tafelvoetbalspel \\ risik \\ sjoelbak \\ monopolie \\ mastermind \\ ganzenbord \\ stratego \\ yahtzee \\ mens erger je niet \\ kaarten \\ scrabble \\ kwartetspelen \\ vier op een rij \\ zeeslagje \\ schaken \\ rummikub \\ dammen
}

Diaseries (eventueel met geluidsband)

- met handviewer

- met projector en scherm op aanvraag voor minimaal 6 personen

Aangepaste hulpmiddelen: $0 . a$.: kaantenstandaard

leesstandaard

haakblok 
Appendix 5.4

SCRIPT FOR THE SLIDE-TAPE PRESENTATION ABOUT HERNIORRHAPHY (HOSPITAL 2, IN DUTCH) 
'OPERATIE AAN EEN LIESBREUK, WAT NU?'

Een voorlichtingsprogramma over liesbreukoperaties

in het St. Elisabeth Ziekenhuis, Tilburg

script

11 september 1991

Ben Smit 


\section{INTRO}

\section{beeld:}

Algemene sfeerbeelden (buiten) St. Elisabeth Ziekenhuis.

Mensen lopen in en uit. De naam van het ziekenhuis

\section{commentaar (vrouwen stem):}

Bijna alle mensen zien tegen een operatie op, vooral de narcose. Dat heeft te maken met gevoelens van onmacht, angst voor de pijn, angst voor het onbekende. Een manier om die angst en bezorgdheid weg te nemen is u te laten zien wat er allemaal gebeurt rond een liesbreukoperatie.

Bekijkt u dit programma rustig. Na afloop kunt u vragen stellen aan de medewerkster van het ziekenhuis, die bij het bekijken van het programma aanwezig is. De belangrijkste gegevens in dit programma, vindt u ook in de voorlichtingsfolder over de operatie.

\section{TITEL}

geluid:

Muziek.

\section{'OPERATIE AAN EEN LIESBREUK, WAT NU?'}

\section{OPNAMEDAG}

\section{beeld:}

Hoofdingang, de Heer van Gijsel (patiënt), een man van ongeveer 40 jaar. komt met zijn vrouw en weekendtas het ziekenhuis binnen. Via de portier gaan ze naar de afdeling opname. Beelden vervolgen in de afdeling opname.

\section{getuid:}

Muziek. Set-noise (dit zijn geluiden van bijvoorbeeld stemmen, apparatuur, lift, etc.) versterkt het beeld.

\section{commentaar:}

Omdat de chirurg, in overleg met $u$, geadviseerd heeft om $u$ te laten opereren aan een liesbreuk krijgt u van ons een oproep om naar het ziekenhuis te komen. Wanneer u die oproep krijgt is mocilijk te zeggen. Soms is er een lange wachtlijst of zijn er spoedeisende operaties. Toch proberen wij u zo snel mogelijk te informeren.

Is de opnamedag bekend, dan verwachten wij u op de afgesproken tijd bij de afdeling opname. Hier worden uw gegevens nog eens gekontroleerd. 
....en u zit in het ziekenfonds?.....Goed, dan zal ik u naar de afdeling brengen. (dialoog in overleg met opnameburo)

beeld:

Patiënt en zijn vrouw lopen samen met medewerkster, op de rug gezien, naar de afdeling.

\section{MET WIE KRIJGT U ALLEMAAL TE MAKEN?}

beeld:

Groepsfoto met verpleegkundigen, koks, artsen, secretaresse, chirurg, anesthesist, fysiotherapeuten, diëtiste, enz. in hun specifieke kleding (chirurg met mond- en haarkap, kok met muts, enz.)

\section{commentaar:}

Vanaf het eerste moment dat $\mathrm{u}$ in ons ziekenhuis verblijft, staat er een team van vakbekwame mensen voor u klaar. Sommigen ziet u dagelijks zoals de artsen en verpleegkundigen. Anderen werken meer op de achtergrond.

Om u toch wegwijs te maken stellen wij die teamleden aan u voor, waar u veel mee te maken krijgt.

\section{WIE DOET WAT?}

beeld:

Vanuit de groepsfoto komt steeds die groep of personen naar voren waarover we gaan praten. Dit herhaalt zich bij verpleegkundigen, a ddelingsarts, anesthesist, chirurg, เnz. Na elke animatie-intro gaan we verder met beelden om het commentaar te verduidelijken.

\section{geluid:}

Muziek en commentaar.

beeld:

Chirurg aan het werk.

commentaar:

Allereerst de chirurgen. Aan het SEZ zijn zes algemene chirurgen verbonden. De chirurg opereert en is er verantwoordelijk voor, dat uw medische behandeling goed verloopt. De chirurgen werken nauw samen en voeren dagelijks overleg over alle patiënten, dus ook over $\mathrm{u}$.

beeld:

Anesthesist aan het werk. 
Verder kennen we de anesthesist. Hij is de specialist die de verdoving verzorgt en maakt over uw gezondheid kort voor, tijdens en de eerste tijd na de operatie. De anesthesist komt de dag voor de operatie langs om kennis met u te maken en om de verdoving te bespreken.

heeld:

Afulelingsarts.

\section{commentaar:}

Aan de afdeling waar u wordt opgenomen, is een afdelingsarts verbonden. Hij of zij vormt, samen met de chirurg en anesthesist, een hecht team en is op de hoogte van alle gegevens over uw gezondheid. De afdelingsarts komt elke dag bij u langs en daarom kunt $\mathrm{u}$ alle problemen of vragen in verband met uw aandoening, operatie of herstel met hem of haar bespreken. Ook uw familieleden kunnen het beste met de afdelingsarts contact opnemen bij eventuele vragen of problemen.

\section{beeld:}

Verpleegkundige.

\section{commentaar:}

En tot slot, de verpleegkundigen. De teamleiders van de verpleegkundigen voeren dagelijks overleg met de afdelingsarts en bespreken dit met hun team. De verpleegkundigen zijn dus op de hoogte van uw specifieke situatie. Met vragen over de verzorging of de voorbereiding op de operatie kunt u bij de verpleegkundigen terecht. En als u iets niet begrijpt of $u$ wilt meer informatie, weten zij de juiste weg.

\section{DE VOORBEREIDING OP DE OPERATIE}

\section{beeld:}

In beeld volgen we de Heer van Gijsel in de verschillende situaties en lokaties. Belangrijk is vooral de interaktie tussen hulpverleners en patiënt.

Vervelende handelingen zoals bijvoorbeeld het geven van een injectie, komen niet nadrukkelijk (close-up) in beeld.

\section{geluid:}

Muziek en set-noise. Dialogen tussen hulpverleners en patiënt verduidelijken de situaties. Het geheel moet een rust uitstralen en uit alles blijkt dat we met een vakbekwaam team te maken hebben.

\section{commentaar:}

U kent nu een aantal leden van het team waar u de komende dagen mee te maken krijgt. Laten we eens kijken hoe het een en ander gaat verlopen. 
beeld:

Patiënt met vrouw en verpleegkundige in spreekkamer en koffie.

$\mathrm{Na}$ aankomst op de afdeling stelt een verpleegkundige u enkele vragen, nodig voor de behandeling en verzorging en vertelt een aantal dingen over de voorbereidingen op de operatie en het herstel daarna.

dialoog:

Heeft $u$...... (dialoog in overleg met verpleegkundige).

beeld:

Op de afdeling.

Verder maakt hij of zij u wegwijs op de afdeling waar bijvoorbeeld het toilet is, hoe laat het eten geserveerd wordt en op welke kamer u komt te liggen.

dialoog:

En als u zich wilt douchen dan moet u hier zijn...... (dialoog in overleg met verpleegkundigen)

beeld:

In bed.

commentaar:

In de loop van de dag komt een verpleegkundige om de huid te scheren rondom de plaits waar $u$ straks geopereerd wordt. Dit is noodzakelijk om besmetting van de wond te voorkomen.

beeld:

In bed met gesloten gordijnen.

commentaar:

Ook de afdelingsarts komt langs om met u kennis te maken. De afdelingsarts stelt een paar vragen en verricht, als dat nodig is, nog een lichamelijk onderzoek. Al deze informatie wordt doorgegeven aan het team van chirurgen en anesthesisten.

dialoog:

Wat bedoelt u met...........? (dialoog in overleg met afdelingsarts) 
En als u nog vragen heeft, of u begrijpt iets niet, vraagt het gerust aan de afdelingsarts. $\mathrm{Hij}$ of zij is degene die u medisch begeleidt en dus alle informatie kan geven. Ook aan uw familie.

\section{beeld:}

Patiënt in gesprek met de anesthesist.

\section{commentaar:}

En dan de verdoving. Daarover doen veel bakerpraatjes de ronde. Dat je in je slaap gaat praten of dat je wakker wordt tijdens de operatie. Laat u zich niets wijs maken. Verpleegkundigen onder leiding van de anesthesist waken tijdens de operatie constant over uw gezondheid. Kosten nog moeite worden gespaard. En dat u zenuwachtig bent is best begrijpelijk. En mocht u toch vragen hebben, tijdens zijn bezoek zal de anesthesist zeker het een en ander verduidelijken.

dialoog:

In overleg met anesthesist.

beeld:

In bed.

commentaar:

Vanaf 12 uur 's nachts mag u niets meer drinken of eten. De maag moet leeg zijn zodat $\mathrm{u}$ tijdens de operatie niet kunt overgeven. En bent u een roker, probeer het voor enkele dagen op te geven. Na de operatie zult u er zeker voordeel van hebben.

\section{commentaar:}

Voor het slapen gaan krijgt $\mathrm{u}$ een slaaptablet. Dit kan u wat helpen tegen de spanning.

dialoog:

Hier heeft u een ... (dialoog in overleg met verpleegkundige)

\section{DE DAG VAN DE OPERATIE}

\section{beeld:}

Op de kamer.

\section{commentuar:}

De dag dat $\mathrm{u}$ geopereerd wordt, krijgt $\mathrm{u}$ een operatiehemd aan...... .....ook is het noodzakelijk dat u uw contactlenzen en kunstgebit uitdoet. En voor de dames geldt geen nagellak of make up. Voor de anesthesist is het nl. belangrijk dat hij uw natuurlijke huidskleur ziet tijdens de operatie. 
commentaar:

$\mathrm{Nu}$ kan het gebeuren dat de operatie op het laatste moment wordt uitgesteld. Een heel vervelende situatie.

beeld:

Ambulance bij de ingang.

De reden kan zijn dat er bijvoorbeeld een ernstig verkeersslachtoffer is binnen gebracht of dat een operatie is uitgelopen. Vanzelfsprekend proberen wij dit ongemak tot een minimum te beperken.

beeld:

In bed.

commentaar:

Gaat alles volgens planning, dan krijgt $u$ als voorbereiding op de operatie, een prik in het been en een tabletje. Dit geeft een soezerig effect en soms een droge mond. Dit is normaal en is geen reden om u ongerust te maken.

beeld:

Transport op de gang/in de lift met een set-noise.

En in uw eigen bed wordt u naar de operatiekamer gebracht.

\section{DE OPERATIEKAMER}

beeld:

Aankomst van de patiënt in de voorbereidingskamer. Voorkomen moet worden dat de beelden van deze ruimte alsmede de OK een te 'mechanische' sfeer uitstralen. Vakmensen, specialisten, mensen dus, hebben hier alles onder kontrole. De apparatuur die we zien zijn slechts hulpmiddelen. Een aantal opnamen worden weer vanuit het standpunt van de patiënt gemaakt.

\section{geluid:}

Muziek en set-noise. Dialogen tussen hulpverleners en patiënt verduidelijken het verhaal. Alleen bij binnenkomst in de OK wordt de set-noise nadrukkelijker (galm van pratende mensen, piepende apparaten, etc.)

beeld:

Voorbereiding (er liggen meer patiënten). 
In de voorbereidingskamer wordt u opgevangen door een verpleegkundige. Zij/hij controleert wederom uw gegevens.

dialoog:

Hallo, ik ben..... hoe voelt u zich?.. (dialoog in overleg met OK-personeel).

commentaar:

En als alles in orde is, dan gaat u naar de operatiekamer.

beeld:

Operatiekamer.

De operatiekamer maakt op veel mensen een kale en steriele indruk. Door elkaar pratende mensen en ingewikkelde apparaten.

\section{geluid:}

De voorbereiding van een operatie wordt in scene gezet om de geluiden te registreren. Alleen de eerste 5 minuten zijn belangrijk.

commentaar:

We hebben deze ruimte zo ingericht om u snel en goed te kunnen behandelen.

beeld:

Patiënt krijgt infuus.

commentaar:

In de operatiekamer komt $u$ op een speciaal bed te liggen. Hier krijgt u ook een infuus. daarmee kan de anesthesist de verdoving en medicijnen toedienen.

beeld:

Totaal van operatiekamer in bedrijf in scene met patiënt.

commentaar:

Bij een liesbreukoperatie kunt u kiezen uit twee soorten verdoving: een algehele verdoving, waarbij u dus van de hele behandeling niets merkt. En een plaatselijke verdoving, $\mathrm{u}$ kunt dan de behandeling zelf volgen. Welke verdoving voor $\mathrm{u}$ het beste is kunt $\mathrm{u}$ met de anesthesist bespreken.

beeld:

De twee verschillende verdovigen (totaal en plaatselijk) worden ook in beelden vastgelegd. Totale verdoving: de patiënt slaapt. Plaatselijke verdoving: de patiënt kijkt belangstellend op de monitor (vooral niet angstig!) 
commentaar:

Voor welke verdoving u ook kiest, van de operatie zelf voelt u absoluut niets. Bovendien wordt u tijdens de operatie nooit alleen gelaten, al die tijd letten wij nauwkeurig om $\mathbf{u}$.

\section{NA DE OPERATEE}

beeld:

Operatiekamer.

We zien een gezicht (ogen open en ogen dicht versie).

commentaar:

Pas als de operatie helemaal klaar is en niet eerder, beëindigen wij de verdoving.

Dan volgen we de patiënt naar de uitslaapkamer (hier niet flitsen! en denk aan de andere patiënten in beeld). Mannen en vrouwen liggen door elkaar.

geluid:

Set noise, muziek en dialogen versterken de beelden.

uitslaapkamer

commentaar:

$\mathrm{Na}$ de operatie heeft u een infuus aan uw lichaam zitten. Vrij kort na de operatie wordt deze weer verwijderd.

commentaar:

Alle bewegingen zullen pijnlijk zijn, evenals hoesten en diep ademen. U hoeft zich daar geen zorgen over te maken. Het is een normaal gevolg van de operatie. En als wilt, vraag dan aan de verpleegkundige om een pijnstillend middel. Ook is het mogelijk dat u zich wat misselijk voelt, ook daar kan de verpleegkundige iets voor geven.

dialoog:

Heeft u misschien..... (dialoog in overleg met $\mathrm{OK}$ )

\section{TERUG NAAR DE AFDELING}

beeld:

Patiënt gaat terug naar de afdeling. We volgen daar de gebeurtenissen.

geluid:

Muziek en set-noise. Dialogen patiënt en hulpverleners versterken het beeld.

beeld:

Gang/lift. 
En als alles in orde is, dan gaat $u$ weer terug nalar de afdeling.

commentaar:

Op de dag na de operatie komt de afdelingsarts kijken of alles in orde is. En heeft u nog vragen?......

dialoog:

(dialoog in overleg met afdelingsarts).

verpleegkundige legt uit hoe het kussen tegen de buik gedrukt moet worden

\section{commentaar:}

Belangrijk is dat u na de operatie goed zicht, zo komt het slijm in uw longen los. Als u de behoefte voelt om te hoesten, moet u het slijm goed ophoesten. Dit voorkomt eventuele complicaties.

dialoog:

Probeert $u$ het nog maar eens.... (dialoog in overleg met verpleegkundige over diep zuchten, hoesten en lachen)

beeld:

Verpleegkundige helpt bij het uit bed stappen.

commentaar:

Ook is het belangrijk dat u snel na de operatie weer in beweging komt. Dit bevordert de bloedcirculatie en herstelt uw conditie. Om de operatiewond zo min mogelijk te belasten, moet u op de juiste wijze overeind komen en uit bed stappen. De verpleegkundige helpt u daarbij. Dalarna mag u het zelf proberen.

Beelden tonen de zelfwerkzaamheden van de Heer van Gijsel: de eerste wankele stappen, dan gaat het al beter en tenslotte loopt hij op de gang, alleen.

\section{NAAR HUIS}

beeld:

We zien aan alles dat zijn verblijf in het ziekenhuis op een einde loopt. Ruimt zijn spullen op, maakt hier en daar een praatje en zijn gezicht verraadt dat het allemaal best meeviel. We volgen voor het laatst (samen met zijn vrouw) een aantal handelingen.

geluid:

Muziek en set-noise. Dialoog tussen patiënt, zijn vrouw en hulpverleners verhelderen het een en ander. 
beeld:

Afdelingsarts/patiënt zit op bed.

dialoog:

Meneer van Gijsel, het ziet er allemaal prima uit... u mag morgen weer naar huis.... (dialoog met afdelingsarts)

commentaar:

Als u voldoende bent hersteld, meestal is dat een dag of drie na de operatie, mag u weer naar huis. De afdelingsarts beslist wanneer u naar huis mag.

Bereid u zich goed op het ontslag voor. Stel uw vragen over hoe het straks thuis moet tijdig aan de afdelingsarts of verpleegkundige. En als $u$ bang bent iets te vergeten schrijf uw vragen op een briefje.

beeld:

Patiënt, aangekleed met verpleegkundige die het ontslagprotocol invult (waar?)

dialoog:

Over opvang thuis, werken en controlebezoek (dialoog in overleg met verpleegkundige)

\section{KORTE SAMENVATTING}

beeld:

Patiënt loopt samen met zijn vrouw en verpleegkundige naar de uitgang. Daarover titels met maximaal 4 items.

geluid:

Muziek.

commentaar:

We zullen in het kort de belangrijkste dingen nog even met $u$ doornemen.

- Als eerste: vraag gerust als iets niet duidelijk is of als u meer wilt weten. Vonr medische zaken aan de afdelingsarts of specialist en voor algemene zaken de ver. pleegkundigen.

- Als u slecht slaapt, u voelt zich misselijk of u heeft pijn na de operatie vraag gerust om een middeltje hier tegen.

- Het is belangrijk dat u goed zucht en hoest, en dat u voorzichtig uit bed stapt. Hier moet $u$ ook op letten in de eerste periode als $u$ weer thuis bent.

- Alle gegevens kunt u nog eens rustig nalezen in onze voorlichtingsfolders. 


\title{
13. AFTITELING
}

beeld:

Patiënt verlaat met zijn vrouw het ziekenhuis. Kijkt nog een keer achterom en lacht. Daarover de aftiteling.

geluid:

Muziek.

\author{
realisatie \\ SYNAR, AUDIO VISUELE PRODUCTEN \\ in opdracht van: \\ IVA, INSTITUUT VOOR SOCIAAL- \\ WETENSCHAPPELIJK ONDERZOEK, TILBURG
}

met dank aan:

PERSONEEL VAN HET ST. ELISABETH ZIEKENHUIS IN TILBURG

FAMILIE VAN GIJSEL

\author{
m.m.v. \\ copyright: \\ IVA, Tilburg \\ SYNAR, EINDHOVEN
}

(c) 1991 
Appendix 5.5

CHECKLIST OF SUBJECTS TO DISCUSS WITH PATIENTS BY NURSES ON ADMISSION (HOSPITAL 1, IN DUTCH) 
FORYULIER VOOR DE MONDELINGE VOORLICHTING (bij patiéntenstatus voegen)

\title{
VOORLICHTING OP OPNAMEDAG
}

\author{
Naan patiënt : \\ Datum
}

\section{Algeneen}

O Ingelicht door behandelend arts? (operatiefolder + narcosefolder ontvangen?)

o Is narcoseformulier ingevuld?

o Anamneseformulier invullen

o Afdelingsboekje uitreiken

" Rondleiding op afdeling

Pre-operatief, dag van opnane

o Onderzoek + statussen door zaalarts

- Bezoek anaesthesist

o Laxeren

0 's Avonds douchen met hibiscrub

- Slaapredicatie

o Nuchter vanaf 24.00 uur

- Tromboseprofylaxe

o Dieet

* Paraaf plaatsen indien onderwerp besproken is met patient 
Pre-operatief, dag van ingreep

0 's Morgens douchen met hibiscrub

O Uitplassen

- Prepareren

0 Pre-medicatie

o Sieraden, prothese, make-up e.d.

o Operatiehemd, identificatie-armband

o Infuusstandaard

o Voorpost

O O.K.

\section{Post-operatief}

o Recovery (controles, infuus)

- Informatie familie

o Bezoek familie

0 Afdeling (controles)

o Pijnstilling

o Wond (omvang, plaats, etc.)

0 Eten en drinken

0 Infuus"

0 Drains, magsslang, catheter

o Onderzoeken

0 Fysiotherapie

o Mobilisatie

- Tromboseprofylaxe

0 Bijwerkingen (pijn, misselijkheid etc.)

o Artsenvisite

- Opnameduur

o Ontslag (verwijzing gesprek(ken) t.z.t.)

Kan afwijkend zijn van standaard voorlichting. 
Appendix 6.1

FACTOR-ANALYSIS OF NEED FOR INFORMATION (PRESURGICAL) 


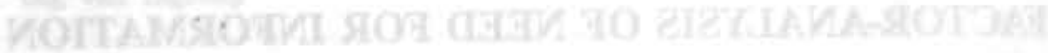

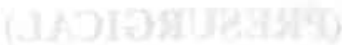


Factor-analysis with varimax rotation of the scores of all items with respect to need of information on the day of admission resulted in four factors with an eigen value of 1 or higher. Four items ("When it is allowed to resume eating, drinking and walking after surgery", "Which physical sensations I will experience after surgery", "When the surgeon will come to visit me" and "What is being done during surgery") loaded lower than .50 on any factor. Repeating the analysis without these four items produced a solution with three factors. However, two items ("How to find your way in the hospital" and "Whom you can approach most conveniently with questions and troubles") had a factor loading lower than .50 on any of the three factors. The analysis was repeated without these two items, resulting in three factors with an eigen value greater than 1 and which were readily interpretable.

The first factor concerned seven items indicating the desire to receive general information about admission into the hospital, about surgery, and about opportunities to collect additional information. The second factor concerned three items indicating the desire to obtain information about the illness. The third factor concerned two items about the desire to receive particular information about surgery, i.c. when the operation will take place and by whom it will be performed.

\section{Factor:}

II

III

To which extent would you desire to receive information about:

a. Preparations for surgery .79

b. Anesthesia

c. How to treat and talk to the physician

d. Where to obtain information about illness and surgery

e. Current physical condition

f. Side effects of surgery and anesthesia

g. What I will receive to eat and drink in the hospital

f. Name of the Head nurse .64

$k$. Cause of the illness

1. Consequences of the illness

h. Time of surgery

o. By whom the operation will be performed 


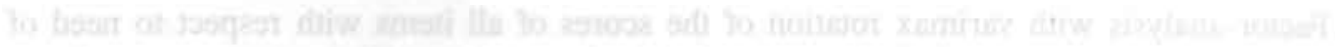

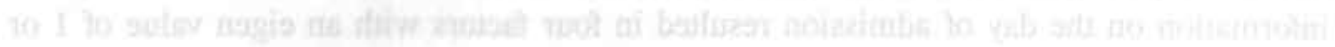

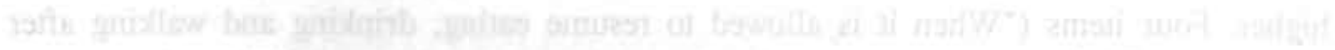

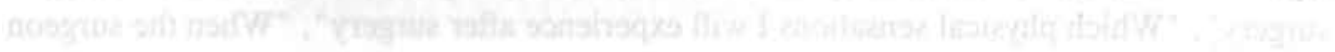

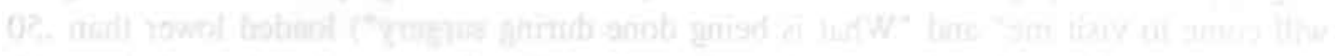

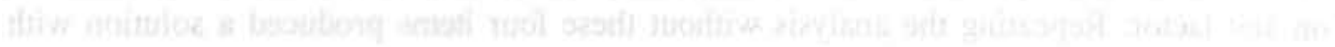

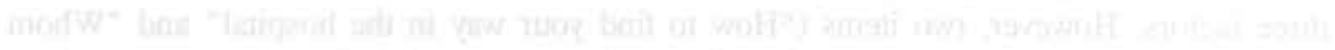

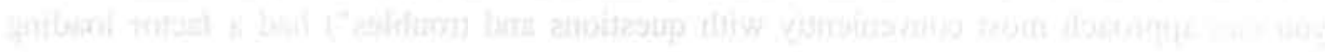

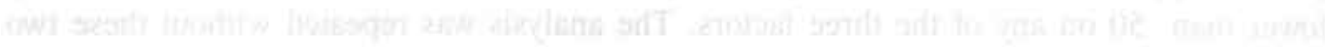

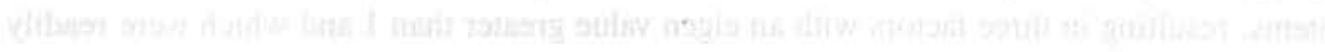

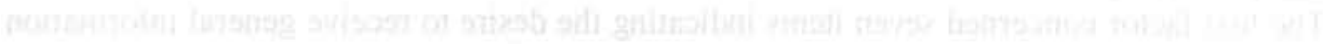

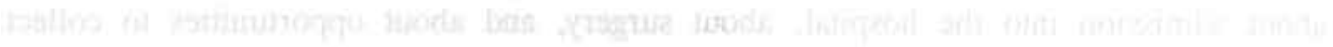

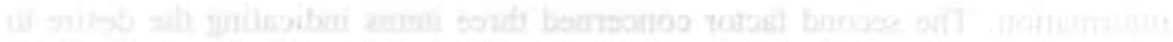

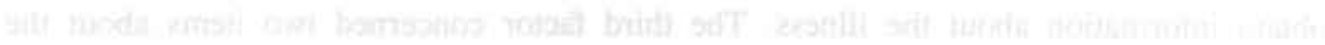


Appendix 6.2

FACTOR-ANALYSIS OF NEED FOR INFORMATION (POSTSURGICAL) 
214 
The scores on four items ("Role and functions of physicians and nurses", "How to find your way in the hospital", "Leisure opportunities in the hospital" and "Reason for rapid post surgical mobilization") were strongly skewed and therefore omitted from the analysis. Factor-analysis with varimax rotation on all remaining items concerning post surgical need for information resulted in three factors, each with an eigen value greater than 1 . All items loaded high, with the exception of "How to treat and talk to the physician". Repating the analysis without this single item resulted in three factors which were readily interpretable.

The first factor related to five items indicating the desire for information about subjects related directly to surgery, like the consequences of surgery, current physical condition, who performed surgery, etc. The second factor related to three items indicating the desire for information about functioning after discharge from the hospital. The third factor related to three items indicating the desire for information about discharge from hospital itself. For example, patients wanted to know the timing of discharge and whether they would be in the position to talk to the surgeon at the time of discharge.

\begin{tabular}{|c|c|c|c|}
\hline & Factor: & II & III \\
\hline \multicolumn{4}{|l|}{ To which extent would you desire to receive information about: } \\
\hline a. Current physical condition & .70 & & \\
\hline b. Consequences of surgery and anesthesia & .74 & & \\
\hline c. What was being done during surgery & .71 & & \\
\hline d. Who performed surgery & .68 & & \\
\hline e. Whom to talk with in case of questions or problems & .63 & & \\
\hline f. How to regain physical condition & & .79 & \\
\hline g. Recommendation adequate behavior after discharge & & .71 & \\
\hline h. How to manage adequately at home & & .83 & \\
\hline i. Date and time of discharge & & & .57 \\
\hline j. When clips will be removed & & & .86 \\
\hline k. Talk with physician before discharge & & & .50 \\
\hline Explained variance: & $43 \%$ & $12 \%$ & $10 \%$ \\
\hline Eigen value: & 4.7 & 1.3 & 1.0 \\
\hline
\end{tabular}




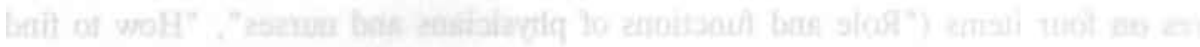

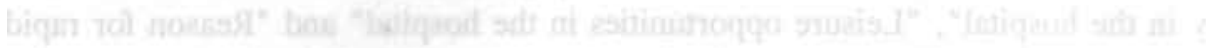

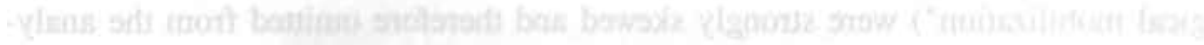

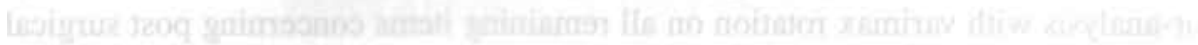

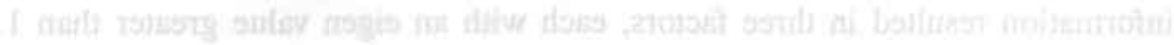

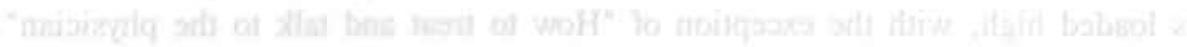

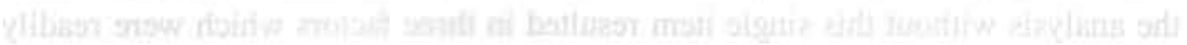

sldiat

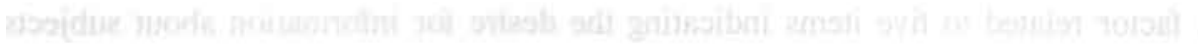

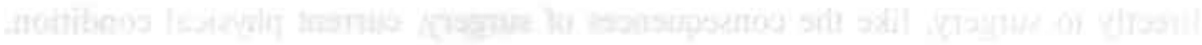

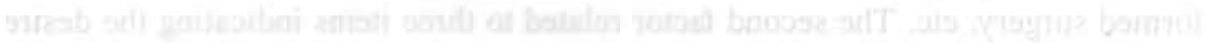

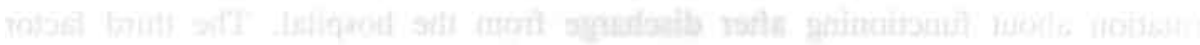

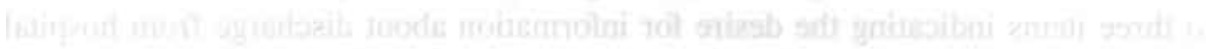

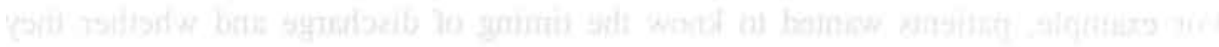

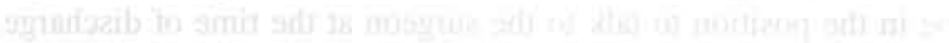

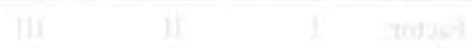

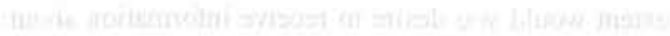

(1)

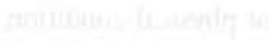

bis

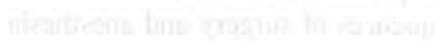

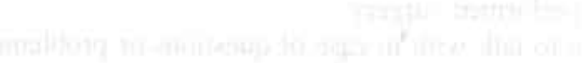

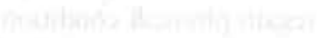

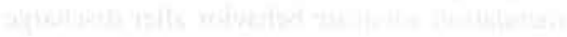

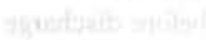


Appendix 6.3

MEASUREMENT OF PERCEIVED CONTROL 
"Now that I am admitted ..."

1. ... I can not have contact with the ones I love."

2. ... Am I visited by health care providers I'm unfamiliar with."

3. ... Am I required to do things without knowing why."

4. ... I cannot decide myself when to eat or drink."

5 . ... I feel treated like a number."

6. ... I find it hard to obtain information."

7. ... I feel insecure about coming events."

8. ... I do not control my emotions."

9. ... I can not relax in the way I wish to."

10. ... I do not know whom to discuss problems with."

11.... I feel that insufficient time is taken for my casc."

12. ... I can not select which social contacts I will have."

13. ... I can not predict what I will eat."

14. ... I can not predict when I will eat."

B. Measurement of perceived control 2 or 3 days post operative:

"After surgery ...

1. ... I could not relax like I wish to."

2. ... I was hindered to go where I wished to."

3. ... I could do nothing to decrease pain."

4. ... I could do nothing to speed recovery."

5. ... I felt that insufficient time was taken for me."

6. ... I could not aid with my treatment and care."

7. ... I could not predict coming events."

8. ... I could not talk everything over with my physician.".

9. ... I felt that they spoke about me instead of with me."

10. ... I did not know whom to talk to about my problems."

11.... I did not feel free to go where I wished to."

12. ... I felt my self dependant on others."

13. ... I did not feel free to ask for help when needed"."

14. ... I did not always obtain the help I needed'."

15. ... I felt not always taken seriously'."

16. ... I felt hindered in contacts with others ${ }^{1} . "$

17. ... I felt hindered by limitations in privacy."

18. ... I was uncertain about the day of discharge."

Skewed distribution of scores

C. Measurement of perceived control 1 week after discharge:

"Since discharge ...

1. ... I can not eat and drink what I like to."

2. ... I don't feel like my old self."

3. ... I am afraid to move freely."

4. ... I do not know what I can do to improve recovery."

5. ... I dot not know what I should leave out to improve recovery."

6. ... l feel dependant on others."

7. ... I receive more visitors than is good tor me $\mathrm{l}^{\mathrm{*}}$

8. ... My house companions spare me more than necessary."

9. ... I can not perform my leisure activities."

10. ... I an tied to my home."

11... I am tired more quickly than usually. 


\section{Curriculum vitae}

Bert Breemhaar werd op 12 augustus 1957 geboren te Hoogezand-Sappemeer. Van 1970 tot en met 1975 volgde hij Hoger Algemeen Vormend Onderwijs aan de Scholengemeenschap te Lelystad. Gedurende $1975 \mathrm{t} / \mathrm{m} 1978$ was hij werkzaam als radiologisch laborant bij het Academisch Ziekenhuis te Groningen, waar hij in 1977 het diploma radiodiagnostisch laborant van de Nederlandse Vereniging van Radiologisch Laboranten behaalde. Van 1977 t/m 1979 volgde hij Voorbereidend Wetenschappelijk Onderwijs aan het Noordelijk Avond College te Groningen. Aan de Rijksuniversiteit Groningen begon hij in 1979 aan zijn studie Psychologie. In 1986 behaalde hij aan deze universiteit zijn doctoraalbul met als afstudeerrichting Sociale Psychologie. Van 1986 tot 1989 was hij werkzaam bij de Faculteit Gezondheidswetenschappen van de Rijksuniversiteit Limburg te Maastricht, eerst gedurende enige tijd als onderzoeksassistent, daarna als toegevoegd onderzoeker. M.i.v. 1989 tot op heden is hij werkzaam bij de sectie Gezondheid \& Welzijn van het IVA, Instituut voor Sociaal Wetenschappelijk Beleidsonderzoek en Advies te Tilburg. Het onderzoek warop dit proefschrift is gebaseerd werd verricht in de periode waarin hij werkzaam was bij het IVA. 
